\title{
2. Kritische Edition der sahidischen Version des Johannesevangeliums
}

Hans Förster, Kerstin Sänger-Böhm, Matthias H. O. Schulz 



\section{Einführung zur Textausgabe}

Die kritische Edition des sahidischen Johannesevangeliums ist, wie nahezu jede kritische Edition eines in einer Vielzahl von Quellen handschriftlich überlieferten Textes, weder Abbild einer Einzelhandschrift noch Wiedergabe des Erscheinungsbildes einzelner Manuskripte, sondern bietet einen der Mehrzahl der Quellen entsprechenden Text und verweist auf Unterschiede in Apparaten. ${ }^{54}$

Gegenstand der folgenden Ausführungen sind die den Editionstext strukturierenden Elemente wie Worttrennungen und Interpunktion sowie das Vorgehen bei Apparateintragungen. Da bis auf pbo, ly 1 und ly 2 nur sahidische Handschriften behandelt werden und alle Manuskripte durch SMR-Nummern identifizierbar sind, unterbleibt die Angabe des Kürzels "sa« vor Handschriftennummern und in anderen Kontexten außer bei Verweisen auf Nummern in Biblia Coptica.

\section{Orthographie und Worttrennung}

Es ist in sahidisch-koptischer Tradition bisher weder eine einheitliche Orthographie noch ein allgemeines System für Wortabtrennungen bekannt, wie sie für moderne Sprachen charakteristisch sind. Die Orthographie ist für das Sahidische zwar überwiegend einheitlich, doch nicht innerhalb einzelner Handschriften oder sogar gesamtägyptisch standardisiert. ${ }^{55}$ Manche Schreibungen, etwa in 1 und 3 mмaүad= (statt maүad=) oder in 4 xekadc (statt xekac), mögen auf eine frühe Entstehung verweisen, da sie in jüngeren Handschriften nicht oder nur selten vorliegen. ${ }^{56}$ Andere orthographische Unterschiede wie Maein statt maın (mit

54 Die kritische Edition ersetzt nicht das Studium der Quellen, denn jeder Textzeuge ist in Funktion und Ausfertigung einzigartig und kulturhistorisch nur im Kontext seiner Entstehung und Bestimmung interpretierbar, wie auch der enthaltene Text in seiner spezifischen Form unlösbar mit dem Sitz im Leben seines Trägers verbunden ist. Jede Handschrift besitzt besondere Eigenschaften wie Material, Format, Ausführung der Schrift mit Setzung von Initialen und Verzierungen bzw. textkritischen Symbolen oder Nummerierungen. Zugefügte Elemente werden als Paratexte vom Text unterschieden; diese Bestandteile werden in Folgekapiteln beschrieben.

55 Doch erlauben erhaltene Schultexte den Schluss, dass die Ausbildung in den einzelnen Schreibschulen auf eine standardisierte Schreibung von Silben und Wörtern ausgerichtet war, siehe etwa die Syllabare in Hasitzka 1990: 55-63 Nr. 73-82 mit Tf. 27-29 und die Wortübungen bzw. -listen in Hasitzka 1990: 63-67 Nr. 83-91 mit Tf. 30-33, 151-200 Nr. 226-266 mit Tf. 75 und 79-92. Für ein frühes bohairisches Beispiel eines Schülerheftes mit Silbenübungen, Namenslisten und biblischen Textauszügen siehe Husselmann 1947 und Hasitzka 1990: 133-140 Nr. 207.

56 Aber siehe in 19 ммаудат in 16,32 und ммаүaаy in 17,20. 
oder ohne Tremata) und andere Fälle, in denen eı statt $ı$ und umgekehrt geschrieben ist, erlauben keine Rückschlüsse, da sie in früh wie spät datierten Manuskripten erscheinen. Auch das Vorhandensein eines $€$ in Fällen, in denen andere Handschriften einen Supralinearstrich setzen, bietet keinen Anhaltspunkt für eine Datierung, da auch innerhalb von Handschriften keine Einheitlichkeit vorliegt. Als Haupttext wurde die Orthographie der Mehrheit der Manuskripte zugrunde gelegt; nur in begründbaren und am Schluss angeführten Fällen wurden Entscheidungen gegen die Mehrheit der Handschriften getroffen. Zumeist betreffen sie Angleichungen an Schreibungen, die eher einer Standardorthographie zu entsprechen scheinen, oder bei Lehnwörtern an griechische Orthographie.

Obgleich einige Arbeiten der systematischen Vereinheitlichung der Wortabtrennungen gewidmet sind, existieren bisher keine verbindlichen Regelungen, wie Wortabtrennungen $\mathrm{zu}$ organisieren seien. ${ }^{57}$ Für die Editionen wurde ein pragmatischer Ansatz gewählt. Das Hauptaugenmerk lag darauf, lesefreundliche und auch verzeichnungsfähige Texte zu bieten. Das Vorgehen wird bei den Erläuterungen zu Eintragungen des textkritischen Apparates beschrieben.

\section{Interpunktion}

Die Interpunktion der Edition wurde normalisiert. Im Zeithorizont des Forschungsprojekts war eine vollständigen Dokumentation der in den Handschriften verwendeten syntaktischen Zeichen nicht möglich. Es treten Hochpunkt, Mittelpunkt und Punkt auf der Linie sowie Apostroph auf. Im günstigsten Fall dienen sie der Strukturierung syntaktischer bzw. inhaltlicher, seltener morphologischer Einheiten, doch gelegentlich erscheint ihre Setzung auf sprachlicher Ebene willkürlich. Lediglich der seltene Doppelpunkt (noch seltener drei Punkte oder kreuzförmige Punktgruppen) wird relativ regelmäßig verwendet, um das Ende längerer Abschnitte zu kennzeichnen, die oft mit den KephalaionEinteilungen nach griechischem oder koptischem Modus zusammengehen. ${ }^{58}$ Als generelle Bemerkung kann gelten, dass die Anzahl an Interpunktionszeichen zunimmt, je jünger eine Handschrift ist, was mit der Häufung von Initialen und textkritischen Zeichen wie Diplen und Paragraphoi korreliert.

57 Die frühesten Arbeiten zu Wortabtrennungen bei koptischen Texten stammen von E. Amélineau, siehe Amélineau 1913 und Amélineau 1914-1915. Hier werden Wortabtrennungen angelehnt an die von W. Till formulierten Regeln vorgenommen, vergleiche Till 1934: 66-69; Till 1941: 50-52; Till 1960: 155-170, doch wird zum Teil auch davon abgewichen, was nachfolgend mit Beispielen erläutert wird.

58 Vergleiche etwa 1 und 286. Beide Handschriften setzen an Abschnittsenden fast regelmäßig Doppelpunkte. 
Im Mehrheitstext der kritischen Edition sind Hochpunkte sparsam zur Strukturierung syntaktischer Einheiten eingefügt worden. Da 5 als Kollationsbasis diente, sind Interpunktionszeichen vielfach deckungsgleich mit denen dieser Handschrift. Satzzeichen beeinflussen maßgeblich die Interpretation, wie der Text jeder Einzelhandschrift ursprünglich verstanden und gebraucht wurde, doch vermag eine sinnvolle Darstellung aller belegten Interpunktionsvarianten in einem Apparat diesen Umstand nicht zu beleuchten, sondern ihn durch die Informationsmenge nur zu verschleiern. Für die kritische Edition wurde daher nach dem Vorbild der Ausgabe des griechischen Textes in NA 28 auf eine vollständige Verzeichnung verzichtet. Es wurde allein in den Fällen eine abweichende Interpunktion abgebildet, wo sie den Schluss erlaubt, dass Manuskripte Phrasen und Satzteile/Sätze anderen Versen angliedern als in moderner Versgliederung. Es wird empfohlen, die heutige Einteilung nach Versen und die Setzung von Interpunktion als nicht textinhärente Orientierungshilfen zu begreifen.

\section{Setzung von Diakritika im Haupttext}

Die Setzung von Diakritika wie Supralinearstrichen oder Tremata im Haupttext wurde nach der handschriftlichen Bezeugung standardisiert. ${ }^{59}$ Auf eine Setzung von Diakritika in den Apparaten wurde verzichtet, da sie nur einzelhandschriftlich möglich wäre. Diakritika sind in Handschriften nicht willkürlich gesetzt, doch ist eine systematische Setzung selbst in vollständigen, gut lesbaren Manuskripten wie 1, 4, 5, 9 oder 19 nicht gegeben. Als Systematisierung sind Tremata nur bei wortanlautendem ı sowie bei Aufeinandertreffen von ı mit einem anderen Vokal gesetzt worden.

\section{Verzeichnung von Varianten}

Der zweigeteilte Apparat trägt dem Umstand Rechnung, dass viele Abweichungen einzelner Manuskripte vom Mehrheitstext nicht lexikalischer oder grammatischer Natur sind, sondern in abweichender Orthographie bestehen. ${ }^{60}$ Ziel war es, Angaben auf das Notwendige zu beschränken und überflüssigen Text zu vermeiden. Deswegen werden alle Bestandteile (von Zusammenschreibungen) durch Spiegel-/ Geviertstrichen ausgespart, die nicht direkt von einer Variantenlesart betroffen sind.

59 Insbesondere bei den Nasalen $\mathrm{m}$ und $\mathrm{w}$ sowie dem Sonor $\mathrm{p}$ ist die Setzung von Supralinearstrichen in den Handschriften sehr regelmäßig, bei anderen Konsonanten hingegen nicht.

60 Fehlerhafte Schreibungen, die grammatikalisch und lexikalisch korrekten, wenngleich sonderbaren Text ergeben, wurden zumeist im textkritischen Apparat verzeichnet, doch muss ihr Wert durch Nutzerin oder Nutzer im Einzelfall selbst bestimmt werden. 
Grundlage aller Eintragungen sind grammatikalisch vollständige Einheiten. Alle Apparateinträge verzeichnen nur diejenigen Bestandteile, die tatsächlich abweichen; alle mit dem Haupttext buchstabenidentischen Elemente werden durch Spiegelstriche ersetzt. Alle im Apparat ohne vorangehenden Spiegelstrich verzeichneten Angaben gehen dem zugehörigen Text voran oder ersetzen ihn bis zu dem grammatikalischen Element, das mit dem Haupttext identisch ist. Alle im Apparat einem vorangehenden Spiegelstrich folgenden Angaben ersetzen oder ergänzen den Haupttext ab dem zuletzt grammatikalisch identischen Element. Zumeist liegen einfache Abweichungen von Phrasenbeginn und -ende, Ersetzungen durch abweichende Artikel oder Erweiterungen bzw. Verringerungen um Präposition vor.

\section{IV.1. Substantive mit Artikel bzw. mit Präposition + Artikel (Objektanschluss)}

Substantive, auch Personen- und Ortsnamen, werden mit Artikel, Demonstrativoder Possessivartikel, doch nicht mit anderen grammatischen Elementen verbunden; nur Präpositionen aus Einzelbuchstaben zum Objektanschluss sind hiervon ausgenommen. Bei Einträgen sind Nomen gewöhnlich nur bei orthographischen Varianten vertreten; Abweichungen bei gleichlautendem Artikel bzw. Präposition + Artikel sind selten. Varianten bei Artikel oder Präposition + Artikel werden ohne Nomen verzeichnet. Entstünden durch Auslassungen Unklarheiten, wird der Gesamttext wiederholt:
2,22
${ }^{\Gamma 3}$ етеграфн
${ }^{\mathrm{r}} \mathrm{NTE}-12$
-грапн 3 (orthographische Variante)
4,46 r:etкand
r: Г:1 ekana 1, 103 / r:2 NT- 5

Betrifft eine Variante die Hinzufügung einer Präposition, die Artikel und Nomen nicht berührt, wird sie im Apparat mit Spiegelstrich angeführt:
3,19
${ }^{11}$ поүоёім
${ }^{\Gamma 1} \mathrm{e}-10,19,105,141,181$

Beim Fehlen einer Präposition wird der Artikel allein angeführt, wenn die Angabe eindeutig ist, sodass bei nicht mit der Präposition buchstabenidentischem Artikel die Einfachnennung ausreicht:
2,23
${ }^{\Gamma}$ GMMMdëin
${ }^{\Gamma} \mathrm{M}-19,116$

Sind Präposition und Artikel buchstabenidentisch (Präposition $\mathrm{N}^{-}+$Pluralartikel $\mathrm{N}^{-}$) spiegelt sich dies im Apparateintrag ebenso wider ( $\mathrm{N}^{-}$versus $\mathrm{NN}^{-}$) wie Lautassimilationen von Präposition oder Artikel an den Anfangskonsonanten des Nomens, seltener des Indefinitpronomens:
2,22 $\quad{ }^{3}$ етеграфн
${ }^{\mathrm{r}} \mathrm{NTE}-12$

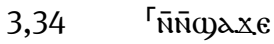
$\mathrm{r}_{\mathrm{N}}-3$
1,13 Гїроме
г: Г:1 NP- $1 /{ }^{\text {г:2 }} \mathrm{NN}-15^{\mathrm{L}}, 19$
3,2 ${ }^{\Gamma 2} \overline{\mathrm{N}} \lambda d \alpha \gamma$
${ }^{\mathrm{r}} \mathrm{NN}-15^{\mathrm{L}}$
$\lambda$ - 1 (orthographische Variante) 
Als Objekte werden determinierte Nomina nicht mit Verben bzw. adverbialen Prädikaten verbunden; undeterminierte Nomina werden als Objekte gewöhnlich angebunden, da vielfach lexikalisierte Verbindungen vorliegen:

12,43 аүмере пеоо

9,5 Тत्र пкосмос

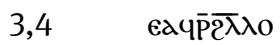

8,59 aүü̈0ne

18,20 дї свш

Possessivpräfixe (пג, тג, Na), die Zugehörigkeit zu Person oder Sache anzeigen, werden getrennt geschrieben und nur mit einem Substantiv verbunden, wenn es sich um einen lexikalisierten Begriff handelt:

18,23 па пеөоо

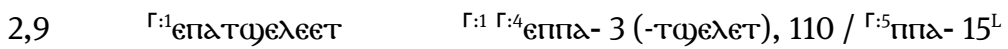

Substantivierte Relativsätze und mehrteilige Nominalgefüge, die äquivalent zu einem gewöhnlichen Nomen in einem Satzgefüge verwendet werden, werden wie Sätze behandelt und entsprechend nach Bestandteilen getrennt:

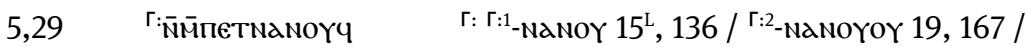
Г:3 N2ENחETNANOYOY 9

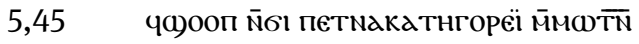

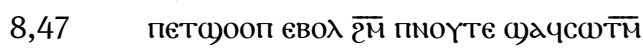

\section{IV.2. Konjugationsbasen, ihre Konversionen, Relativsätze und Negationen}

Konjugationsbasen und ihre Konversionen werden als Einheiten behandelt und nur mit Suffixpronomina + Prädikat verbunden, nicht mit (determinierten) Nomen oder nominalen Satzgefügen. Nur die Konjugationsbasen für Präteritum (Ne-) und Perfekt I (a-) werden regelmäßig mit Substantiven bzw. substantivischen Gefügen verbunden:

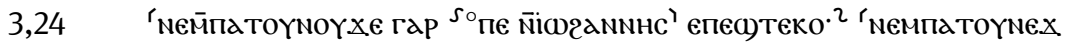 Іоганnнс гар пє 1 / ${ }^{\circ} 9,19,116,141,167$ /

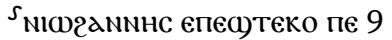

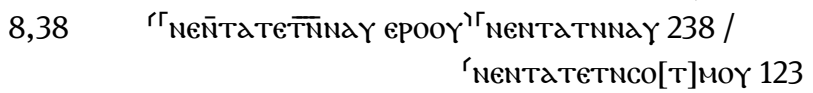

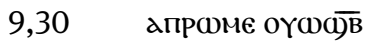
9,14 мепсавватом ${ }^{\circ} \Delta \epsilon \pi \epsilon \quad{ }^{\circ} 110$
4,8 ${ }^{\Gamma 1}$ NeaYBoK $\quad{ }^{\Gamma 1} \mathrm{a} \gamma-112,193$

oү $\overline{\mathrm{N}} / \overline{\mathrm{MN}}$ (es ist/gibt bzw. es ist/gibt nicht) werden nur mit Pronomina und undeterminierten Indefinitpronomina ( $\lambda$ daץ, oүa, oүon) oder undeterminierten Nomina zusammen, doch verbunden mit der Präposition $\overline{\mathrm{N}} \mathrm{T \epsilon}-/ \overline{\mathrm{N}} \mathrm{Td}=(\overline{\mathrm{N}} \mathrm{T} \epsilon)$ stets separat geschrieben. Vorangehende determinierende Konjugationsbasen und 
Relativpräfixe werden mit Ausnahme des Präteritums (nє-) und des Umstandssatzes (e-) immer gesondert geschrieben, so auch bei Zahlangaben. Bei (substantivierten) Relativsätzen wird Getrenntschreibung bevorzugt, doch können Zusammenschreibungen (auch im Apparat) aufgrund von Kontraktion notwendig werden:
4,6 NEYN̄ Оүпнгн

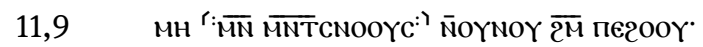

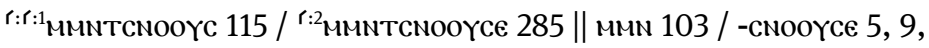 127, 197, 285 / NoYoүnoy 19 (orthographische Varianten)
3,29 пєтєүั̄тач
13,8 $\overline{M N} \overline{T K}$ MєPOC MENTK 141
6,9 EүN̄toY N̄oёiк
4,18 петеоүज̄теєY петеүNтеєч 1 (orthographische Variante)

Die Negation TM wird als Bestandteil der Konjugationsbasis behandelt:
3,3 еүTMXпеога єүтем- 15 181 (orthographische Variante)
4,48 EтєTN $\overline{T M N a Y}$ ететнтем- 10 (orthographische Variante)

Das Relativpronomen (єтє), auch substantiviert (пєтє, мєтє), wird verbunden geschrieben, außer vor determinierten Nomina mit oder ohne Präposition, vor Konjunktionen, Kopulae und Zeitadverbien (темоҮ) oder Demonstrativpronomina:
4,18 петеоүӣтеєч петеүмтеєч 1 (orthographische Variante)
9,24 петенєчо ${ }^{\Gamma 1} \overline{\mathrm{N}} \overline{\mathrm{B}} \lambda \mathrm{C}$

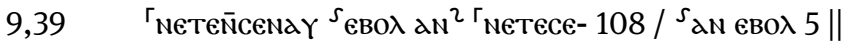
nєTnce- 19, 127 (orthographische Variante)

3,29 етє паї пє

14,27 етє тю̈і тє тwє 1 (orthographische Variante)

8,41 ете пноүте пе

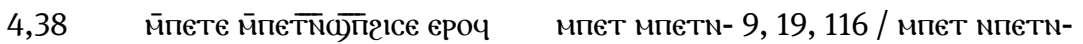
4, 141 / - )еп- 19, 141, 181 (orthographische Varianten)

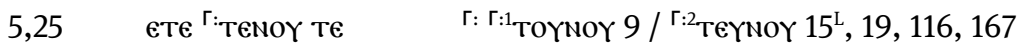

Ist das $\mathrm{N}^{-}$der Klammernegation $\mathrm{N}^{-}-\mathrm{a}$ vorhanden, wird es immer an das folgende Satzglied angebunden:

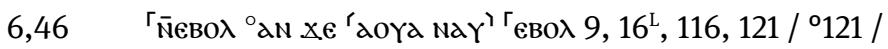
'ачnaY 4, 5, 8, 112

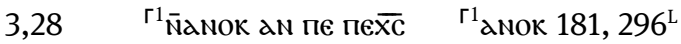

\section{IV.3. Pronomina und pronominale Äquivalente}

Selbständige Personalpronomen, auch in druckloser Form, werden separat geschrieben und nur mit dem N- der Negation verbunden. Proklitische Pronomi- 
na und Suffixpronomia, auch -тнт̄м und -тнү $\overline{\mathbf{T N}}$, werden mit Konjugationsbasis, Prädikat oder Präposition verbunden:

\begin{tabular}{|c|c|c|}
\hline 3,28 & 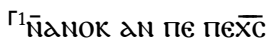 & ${ }^{\Gamma 1}$ dNOK $181,296^{\mathrm{L}}$ \\
\hline 9,5 & †रМ пкосмос & \\
\hline 8,26 & етвєтнү $\overline{T N}$ & \\
\hline 9,1 & єаүхпоч єчо $\overline{\mathrm{N}} \overline{\mathrm{B} \lambda} \lambda \epsilon$ & \\
\hline
\end{tabular}

\section{IV.4. Verben}

Verben im status absolutus, nominalis und Qualitativ werden nur mit Konjugationsbasis + pronominalem Subjekt verbunden, sonst abgetrennt. Nur bei undeterminiertem Substantiv oder Indefinitpronomen ( $\lambda$ da〉, oүa, oүon) als Objekt werden im status nominalis Zusammenschreibungen vorgenommen:

3,3 еүт̈.

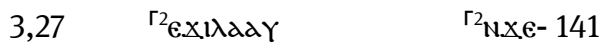

Verben im status pronominalis werden mit Konjugationsbasis und pronominalem Subjekt und gegebenenfalls pronominalem Objekt verbunden; ebenso wird das participium coniunctum mit Bezugswort und Artikel zusammengeschrieben:

18,1 र̄терєчхоо

10,12 пхаївекє

Imperative und mit apl= gebildete Imperative werden getrennt geschrieben; nur Pronomina sind gegebenenfalls als Objekt angeschlossen:

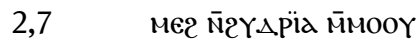

18,23 apI $\overline{M N} T P E$

8,38 apicor

Mit $\overline{\mathrm{p}}$ - (status nominalis von ëipe) gebildete Verbgefüge werden verbunden:

8,57 мппаткртаїо мпатк-106/ мпатек-9, 10, 16 L 127, 285 / мпдтекер- 19, 125 / -тдеıо 13, 136 (orthographische Varianten)

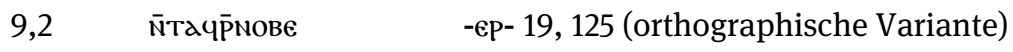

Infinitive in einfachen und komplexen Konstruktionen werden mit anzeigenden Bildungspräfixen bzw. Präpositionen ( $\epsilon-,,(\varepsilon) т \mathrm{e} \epsilon-/(\epsilon)$ трє $\approx, \mathrm{N}-/ \mathrm{M}-)$ verbunden. Nur selten werden in Handschriften komplexe Konstruktionen durch einen einfachen Infinitivanschluss ersetzt, der allein im Apparat angeführt wird:

$$
\begin{aligned}
& 3,4 \quad{ }^{\Gamma^{2}} \text { етречвок } \quad{ }^{{ }^{2}} \mathrm{e}-10,13,14^{\mathrm{L}}, 15^{\mathrm{L}}, 106,115,116,117,136, \\
& 174,306^{\mathrm{L}}
\end{aligned}
$$

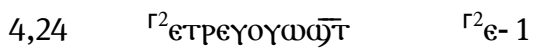

Das Hilfsverbum a)- ('in der Lage sein`, ıkönnen`) wird mit dem folgenden Verb verbunden. Bei mehrteiligen Prädikaten wird das Hilfsverb dem ersten Element 
angefügt und vom Rest getrennt, um Unklarheiten $\mathrm{zu}$ vermeiden. Bei oү $\overline{\mathrm{N}} / \overline{\mathrm{MN}}$ (es ist/gibt bzw. es ist/gibt nicht) bedingt $\omega$ )- Getrenntschreibung:
9,4 ā̄e

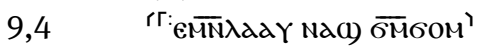
Г: г:1 MN- 4 / Г:2 20TE MMN- 106, 136 /

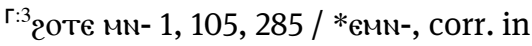 готе мN- 123 / ' 'емN Ф)бом 174

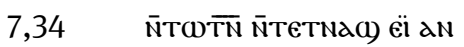 nтетnndec) 9, 19, 115, 116, 123 (-o) / l 112 (orthographische Varianten)
$\left.3,2 \quad \overline{M N}^{\Gamma 1} \mathrm{Q}\right) \mathrm{GOM}$ ${ }^{\ulcorner 1}$ бом 4, 15 $, 19,106,116,167,181$, $306^{\mathrm{L}}$

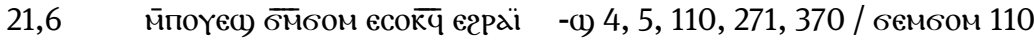 (orthographische Variante)

\section{IV.5. Präpositionen und Präpositionalgefüge}

Präpositionen werden als grammatikalisch vollständige Einheiten separat geschrieben. Einzig Präpositionen im status nominalis aus Einzelbuchstaben (€und $\left.\mathrm{N}^{-}\right)$werden mit dem folgenden Wort verbunden:

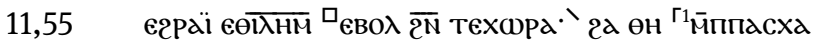

$$
\begin{aligned}
& { }_{12} \text { / Г1 мпасха 16 } 1 \text { || еөзероүсданм 1, 4, } 12 \text { / } \\
& \text { єө厄ॄХHM } 19 \text { (orthographische Varianten) }
\end{aligned}
$$

Ersetzt eine Einzelbuchstabenpräposition eine separate Präposition, werden Artikel oder Bezugswort angeführt, um den Eintrag eindeutig zu halten:
12,21
':
r: r:1 ${ }^{\mathrm{NT}} \mathrm{T}-1,14^{\mathrm{L}}, 127,285,301^{\mathrm{L}} /{ }^{\mathrm{r}: 2} \mathrm{eT}-440^{\mathrm{L}}$

Zusammengesetzte Präpositionen bzw. Präpositionalgefüge werden nach Be-

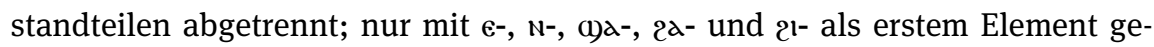

\begin{tabular}{|c|c|}
\hline 19,41 & $\overline{\mathrm{N}} 20$ YN $\overline{\mathrm{N}} 2 \mathrm{HTq}$ \\
\hline 13,37 & еграї гарок \\
\hline 1,7 & єво入 २Ітоотч \\
\hline 2,10 & горагрӓ̈ \\
\hline
\end{tabular}
bildete Gefüge werden zusammengeschrieben: 「c)d e2par 9, 15 , 116 || c)aY2pal (sic!) 136 (or- thographische Variante)

\section{IV.6. Kopulae und Konjunktionen}

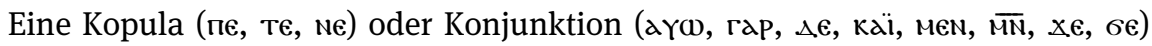
wird nie mit anderen Wörtern verbunden. Tritt eine Kopula oder Konjunktion zwischen Elemente, die eigentlich zusammengeschrieben werden, werden sie voneinander getrennt:
6,22
aYNaY XE $\overline{M N}$ Ge Xö $\bar{M} M a Y$
MMN 1, 103, 121, 301 ${ }^{\mathrm{L}}$
(orthographische Variante) 


\section{IV.7. Zahlangaben}

Zahlangaben werden separat geschrieben, außer mit Artikel und/oder den Präpositionen $\epsilon^{-}$und $\mathrm{N}^{-}$oder der (temporalen) Konjunktion $\overline{M N} \bar{N} c d$. Zahlangaben

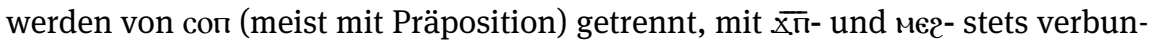
den geschrieben, ebenso mit $\kappa \epsilon$ (andere/-r/-s). Kommen mє2- und con (enttont сєп) vor, werden sie verbunden, doch von der Zahlangabe getrennt:

\begin{tabular}{|c|c|c|}
\hline 6,70 & $\bar{M} \Pi \overline{M N T}$ сNOOYC & \\
\hline 11,39 & ${ }^{\ulcorner 2}$ пччтооҮ гар пє & ${ }^{\ulcorner 2} \Pi \epsilon-19,110$ \\
\hline 13,38 & $\overline{\mathrm{N}}$ )оMNT $\overline{\text { Nс} с о п ~}$ & \\
\hline 20,26 & $\overline{M N} \bar{N} C \lambda()$ MOYN $\Delta \epsilon \overline{\text { N}} 200 Y$ & $\begin{array}{l}\text { MNN' } c^{\prime} d-15^{L} \text { (orthographische Vari- } \\
\text { ante bzw. Fehler) }\end{array}$ \\
\hline 2,1 & 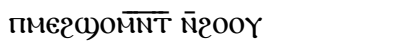 & \\
\hline $1,39(1)$ & 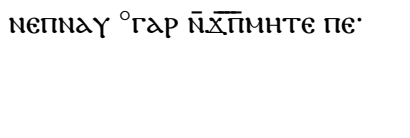 & 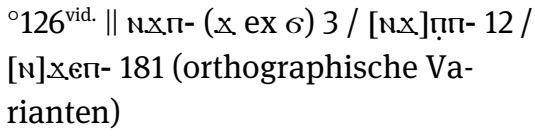 \\
\hline 21,2 & кесNаҮ $е в о \lambda \overline{2^{N}}$ мєчмдөнтнс & -мдөүтнс 182 \\
\hline 9,24 & 'м̄пмегсеп смаү' & 'м[ח]MегсnaY 218 \\
\hline
\end{tabular}

In Verbindung mit Verben werden Zahlen separat geschrieben. Ausgenommen sind nur Verbindungen mit $\overline{\mathrm{p}}$ - (status nominalis von ë̈р):

\begin{tabular}{|c|c|c|}
\hline 4,18 & $r_{d} x_{l}$ tor & ${ }^{r_{\alpha p} x_{1}} 9,112,115,124,167,190,291^{\mathrm{L}}$ \\
\hline 8,57 & 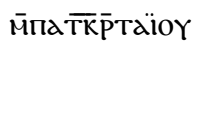 & $\begin{array}{l}\text { ємпатк- } 106 \text { / мпатек- 9, 10, 16 }, 127,285 \text { / } \\
\text { мпатекер- 19, } 125 \text { / -таєіоҮ 13, } 136 \text { (ortho- } \\
\text { graphische Varianten) }\end{array}$ \\
\hline
\end{tabular}

\section{IV.8. Weitere Angaben}

Bei Apparateinträgen, die mehrere Textelemente betreffen, werden nicht variierte Elemente durch Spiegelstriche ausgespart. Teils bedeutet das, dass nur der Mittelteil des Haupttextes tatsächlich verzeichnet wird:

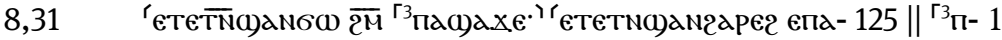

Bei Korrekturen wird unterschieden, ob es sich um nachträgliche Einfügungen ursprünglich ausgelassenen Textes, gegebenenfalls mit Abweichungen, oder um durch Tilgung modifizierten Text handelt:

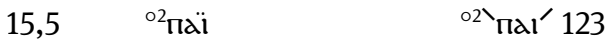

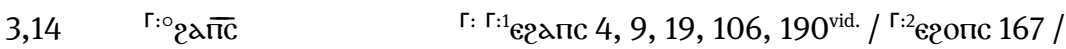

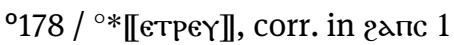

Bei ursprünglich ausgelassenem und nachgetragenem Text, ersetzt eine Ellipse (...) Wörter, die buchstabenidentisch dem Haupttext entsprechen: 
1,51

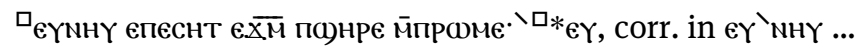

$$
\begin{aligned}
& \text { мпроме' } 126
\end{aligned}
$$

Wäre ein Eintrag durch Auslassung von Teilen missverständlich, wird der Gesamttext wiederholt, ebenso wenn eine Kürzung bei Textausfall einen falschen Eindruck vermitteln könnte:

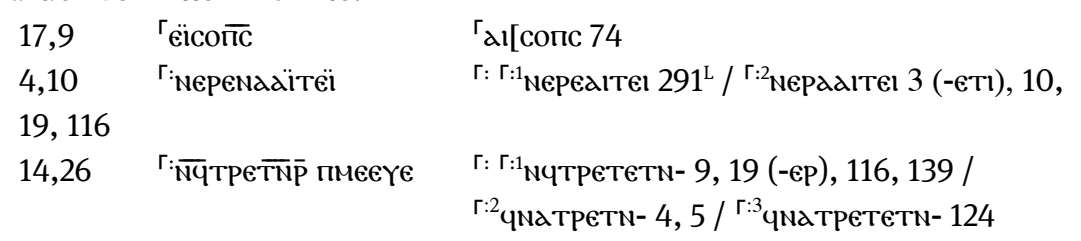

In Verbindungen von futurischem $\mathrm{Na}$ mit dem status pronominalis von ëipe ( $\left.\mathrm{da}_{2}=\right)$ wird oft ein a ausgelassen. Meist sind dies orthographische Varianten, doch werden sie gelegentlich im textkritischen Apparat verzeichnet, da Pronomina oder Konjugationsbasen mit einbezogen sind:

\begin{tabular}{|c|c|c|}
\hline 9,24 & ' '̈пмегсеп сNаY' & 'м[ח]ме2сnау 218 \\
\hline 4,10 & $\Gamma:$ Nependä̈тё̈ & Г: Г:1 Nepealtel 291 / Г:2 NepaalTel 3 (-еTl), 10, \\
\hline 4,12 & $\Gamma_{\text {:NAddK }}$ & $\begin{array}{l}19,116 \\
\text { Г: Г:1 } \epsilon-291^{L} / \Gamma: 2 \operatorname{endaK~} 1 /^{\Gamma: 3} \kappa-10,116 / \Gamma: 4 \\
\operatorname{KNadK~} 112\end{array}$ \\
\hline
\end{tabular}

Fehlen bei im Apparat verzeichneten Handschriften Elemente des Haupttextes bei sonst identischem Text, fehlt auch ein Spiegelstrich:
5,44
r:Tetnad)
r: Г:1 1 etetnd- 5, 121 / r:2 TeTna 3

Nur wenn Verzeichnungen in den Apparaten einfacher dargestellt werden können, werden Zusammenschreibungen getrennt:
5,44
ETETN $X_{1}{ }^{\circ 1}$ EOOY
${ }^{\circ 1} 19,167$
19,39
eYNa $\left.\bar{P}{ }^{\Gamma 1} a \omega\right) \in \bar{N} \lambda I T P a$

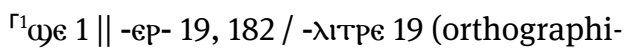 sche Varianten)

\section{Verzeichnung von Varianten im orthographischen Apparat}

Um Eintragungen zwischen textkritischem und orthographischem Apparat klar zu scheiden, werden orthographische Varianten nicht durch textkritische Symbole verzeichnet. Im Mehrheitstext zugehörige Wörter oder Phrasen werden im orthographischen Apparat vor einer schließenden geraden Klammer wiederholt; bei mehr als zwei betroffenen, im Haupttext getrennt geschriebenen Elementen werden Angaben per Ellipse (...) auf die rahmenden Bestandteile beschränkt. Wie beim textkritischen Apparat werden alle nicht variierten Textelemente durch Spiegelstriche ersetzt. Durch die Wiederholung des Haupttextes sind Angaben eindeutig und bedürfen keiner weiteren Erläuterung. 


\section{Unterschiedliche Versionen einzelner Verse}

In manchen Fällen scheinen kombinierte textkritische Varianten in einem Vers auf eine Zweiteilung der handschriftlichen Überlieferung hinzudeuten, die auf unterschiedliche griechische Vorlagen zurückgehen mag. ${ }^{61} \mathrm{Um}$ dies abzubilden, werden im Haupttext beide Versversionen mit entsprechendem Verweis angeführt, was 1,39; 3,30; 9,38 und 15,3 betrifft. $^{62}$

\section{Entscheidungen gegen die Mehrzahl der Handschriften}

In einigen Fällen wurden Entscheidungen gegen die Mehrheit der sahidischen Handschriften getroffen. Diese seien aufgelistet und begründet:

1,27 Am Versbeginn wurde пєтмнү (von 5 Hss. bezeugt) anstatt von ечмнү (von 7 Hss. bezeugt) als Haupttext gewählt, da die Variante näher am griechischen Text ist.

1,28 Für den Haupttext wurde die Schreibung внөдвара gewählt, da sie im Griechischen vergleichsweise gut bezeugt ist, wohingegen die meisten anderen Schreibungen in sahidischen Hss. entweder nicht oder schwach bezeugt sind oder Singulärlesarten bzw. itazistische Verschreibungen darstellen.

2,1 Kand wurde trotz schlechterer Beleglage in den Haupttext genommen, da diese Wortform aus Sicht der griechischen Orthographie korrekt ist und das Wort über das Griechische ins Sahidische gekommen ist.

4,10 In den Haupttext wurde im konjugierten Verbalgefüge NependalTı die mit । statt eı vokalisierte Form dırı aufgenommen, obgleich sie schwach belegt ist. Gleichwohl scheint dies gerechtfertigt, da die Konjugationsbasis мерєма-, die im Verhältnis die meisten Handschriften in dieser Orthographie bieten, in fünf Handschriften sicher bezeugt ist $\left(1,4,5,115,301^{\mathrm{L}}\right)$, von denen drei $(1,4,5)$ dirt haben.

5,14 Gegen die Mehrzahl der Handschriften wurde die Form прпп in den Haupttext genommen, da sie an anderen Stellen des Johannesevangeliums die häufiger bezeugte Schreibung darstellt.

5,34 Gegen eine minimal höhere Zahl von Handschriften wurde die Form NNeıxı in den Haupttext genommen, da sie orthographisch klarer die Negativkonstruktion repräsentiert.

5,41 Gegen die Mehrzahl der Handschriften wurde die Form nweıx in den Haupttext genommen.

5,45 Gegen die Mehrheit der handschriftlichen Bezeugung wurde -катнгоре in Annäherung an griechische Standardorthographie in den Haupttext genommen.

61 Siehe die Ausführungen der Einleitung (S. 11 mit Anm. 33).

62 Mögliche weitere, doch weniger klare Beispiele sind 1,26; 4,14; 4,48; 6,32; 7,47; 9,19; 9,25; 9,32; 10,38; 16,3; 18,36; 20,10; 20,19 und 20,28. 
7,14 Gegen die Mehrzahl der Handschriften wurde die Form eпр̄ne in den Haupttext genommen, nicht епєрпе.

7,32 Der griechischen Standardorthographie folgend wurde beide Male die Form фapıcdıc in den Haupttext genommen, obgleich фapıccaloc besser bezeugt ist.

7,47 Der griechischen Standardorthographie folgend wurde die Form фapıcaloc in den Haupttext genommen, obgleich фapıccaloc besser bezeugt ist.

7,48 Der griechischen Standardorthographie folgend wurde die Form фapıcaloc in den Haupttext genommen, obgleich фapıccaloc besser bezeugt ist.

8,13 Der griechischen Standardorthographie folgend wurde die Form sapıcaloc in den Haupttext genommen, obgleich фapıccaloc besser bezeugt ist.

8,19 Gegen die Mehrzahl der Handschriften wurde beim ersten Auftreten im Vers die Form oү $\triangle \epsilon$ in den Haupttext genommen, da sie an anderen Stellen des Johannesevangeliums die häufiger bezeugte Schreibung darstellt.

8,20 Gegen die Mehrzahl der Handschriften wurde die Form пр̄пє in den Haupttext genommen, da sie an anderen Stellen des Johannesevangeliums die häufiger bezeugte Schreibung darstellt.

9,10 Legt man die Mehrzahl der Handschriften zugrunde, dürfte $6 \epsilon$ nur als Einfügung im Apparat erwähnt sein, doch lassen sich die Handschriften in zwei Gruppen einteilen, je nach Stellung von $6 \in$ nach пєхаY (8 von 17 Handschriften) oder zwischen Nac) und N2€ (ebenfalls 8 von 17 Handschriften). Nur 1 hat $6 \in$ gedoppelt; bei 106 ist die Dopplung an der zweiten Stelle getilgt. Lediglich 109 und 174 lassen $\varsigma €$ gänzlich aus.

10,10 Gegen die Mehrzahl der Handschriften wurde der griechischen Standardorthographie folgend еімнті in den Haupttext genommen, nicht еммнтеı.

10,16 Gegen die Mehrheit der Handschriften wurde die Form ̄єкєєссоо in den Haupttext genommen, da sie eher eine Standardorthographie des Sahidischen repräsentiert als die mit $\mathrm{e}$ anlautende Form.

10,23 Gegen die Mehrzahl der Handschriften wurde die Form пр̄пє in den Haupttext genommen, nicht перпе.

11,37 Gegen die Mehrheitsbezeugung wurde die Form N̄тачоүळм in den Haupttext genommen, da sie gegenüber der durch anlautendes e gekennzeichneten Form eher dem orthographischen Standard des Sahidischen entspricht.

11,56 Gegen die Mehrzahl der Handschriften wurde die Form пр̄пє in den Haupttext genommen, nicht перпє.

11,57 Der griechischen Standardorthographie folgend, wurde die Form фapıcaloc in den Haupttext genommen, obgleich фapıccaloc besser bezeugt ist.

12,3 Gegen die Mehrzahl der Handschriften wurde N̄Nap $\triangle$ oc in den Haupttext genommen, da die Formen nap $\triangle$ oc und Naptoc erkennen lassen, dass entweder grammatisch unkorrekt eine Präposition fehlt oder der Pflanzenname nap^oc (Indische Narde, grie-

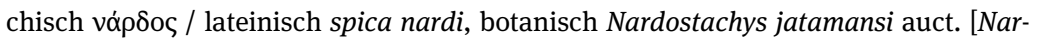
dostachys grandiflora DC.]) nicht mehr als solcher verstanden wurde. 
12,39 Gegen die Mehrzahl der Handschriften wurde мпоү() in den Haupttext genommen, da dies eher einem orthographischen Standard im Sahidischen entspricht als мпоүе().

13,33/34 Die Mehrzahl der Handschriften fügt темо am Ende von 13,33 (5 von 12 Handschriften) oder am Beginn von 13,34 (7 von 12 Hss.) ein, was wohl als versübergreifende Variante zu sehen ist. Drei Handschriften lassen das Wort aus. Um eine möglichst einfach verständliche Verzeichnung zu erzielen, wurde темо am Beginn von 13,34 in den Haupttext genommen, obwohl rein quantitativ ein geringfügig höherer Anteil an Handschriften (7 zu 8 Handschriften) das Wort hier nicht hat.

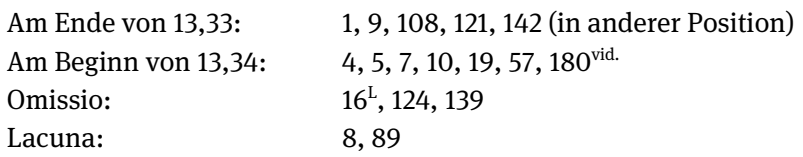

14,9 Gegen die Mehrzahl der Handschriften wurde $\bar{m}$ псоүळNт in den Haupttext genommen, da dies eher einem orthographischen Standard im Sahidischen entspricht als мппексоүшнт.

16,27 пеют (1.) wurde statt пют in den Haupttext genommen, da im selben sowie in angrenzenden Versen sonst die Mehrzahl der Handschriften die Form пеıют hat, was eine Standardisierung rechtfertigt.

18,3 Gegen die Mehrzahl der Handschriften wurde der griechischen Standardorthographie folgend die Form cпєıрd in den Haupttext genommen, doch vergleiche $\sigma \pi \iota \rho \alpha\left[v\right.$ in $\mathfrak{P}^{66}$

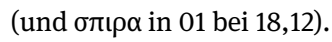

18,39 Obgleich die Mehrheit der Handschriften nєoүсоone hat, wurde die Schreibung меүсооме in den Haupttext genommen, da die kontrahierte Form eher dem Standard der sahidischen Orthographie entspricht.

19,11 Gegen die Mehrzahl der Handschriften wurde der griechischen Standardorthographie folgend еммнтı in den Haupttext genommen, nicht емннтеı.

19,15 Gegen die Mehrzahl der Handschriften wurde der griechischen Standardorthographie folgend еммнтІ in den Haupttext genommen, nicht еммнтеı.

21,2 Kana wurde trotz schlechterer Beleglage in den Haupttext genommen, da diese Wortform aus Sicht der griechischen Orthographie korrekt ist und das Wort über das Griechische ins Sahidische gekommen ist. 


\section{Textkritische Zeichen}

Als textkritische Zeichen werden zumeist diejenigen zugrunde gelegt, die auch die Ausgabe des griechischen Neuen Testamentes in NA 28 verwendet. Andere textkritische Zeichen folgen dem Leidener Klammersystem. Da gegenüber NA 28 für das sahidische Johannesevangelium nicht alle Zeichen benötigt wurden und ihre Bedeutung teilweise vereinfacht wurde, seien sie vorab erklärt:

- Das folgende Wort wird in den angegebenen Handschriften ausgelassen.

口 、 Die von diesen Zeichen umschlossenen Wörter, Satzteile oder Sätze werden in den angegebenen Handschriften ausgelassen. ${ }^{\square}$ bezeichnet den Beginn, ’ das Ende des ausgelassenen Abschnitts.

r Das folgende Wort wird in den angegebenen Handschriften durch ein oder mehrere andere ersetzt.

r > Die von diesen Zeichen umschlossenen Wörter werden in den angegebenen Handschriften durch anderen Text ersetzt, was teils auch Umstellungen mit einbezieht.

$s ?$ Die im Text von diesen Zeichen umschlossenen Wörter werden in den angegebenen Handschriften umgestellt.

T An der durch dieses Zeichen markierten Stelle werden von den angegebenen Handschriften ein oder mehrere Wörter eingefügt.

: $\quad$ Hochgestellte Doppelpunkte umschließen Text, dessen Zugehörigkeit zu einem Vers in den angeführten Handschriften durch Interpunktion unterschieden wird (cf. 1,3/ 1,4). Es wird vermerkt, welche Handschriften den Text welchem Vers zurechnen.

vid. Der Text einer mit ${ }^{\text {vid. }}$ (ut videtur) bezeichneten Handschrift ist nicht mit letzter Sicherheit lesbar, doch der angeführte Text beruht auf einer hohen, gewöhnlich an Buchstabenresten darstellbaren Wahrscheinlichkeit.

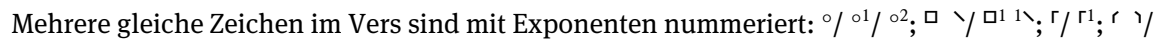
$\mathrm{r}^{1}{ }^{1} ;{ }^{\top} /{ }^{T 1} ; s^{2} / s^{112}$. Exponenten dienen an Beginn- und Endmarkierungen auch zur Unter-

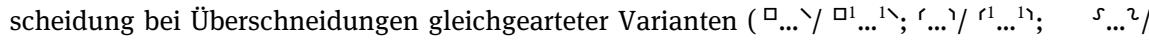
$\left.{ }^{s 1} . .{ }^{12}\right)$; die Beginnmarkierung wird im Apparat wiederholt. Ein Doppelpunkt nach einem textkritischen Zeichen $\left(r: / r: T^{T} / s^{s}\right)$ verweist auf verschiedene Varianten im selben Textabschnitt; die einzelnen Varianten werden durch Exponenten versweise durchgezählt.

\section{Verwendete Zeichen des Leidener Klammersystems}

[ ] Der umklammerte Abschnitt ist in der Handschrift nicht lesbar oder nicht erhalten.

( ) Der umklammerte Text ist in der Handschrift abgekürzt und hier komplettiert.

$\langle\quad$ Der umklammerte Text ist in der Handschrift nicht vorhanden und wurde emendiert.

\{ \} Der umklammerte Text der Handschrift wurde von den Herausgebern als fehlerhaft oder überflüssig getilgt.

II II Der umklammerte Text der Handschrift wurde vom Schreiber oder Korrektor getilgt.

1, Der umschlossene Text wurde in der Handschrift ursprünglich ausgelassen und als Korrektur eingefügt oder bei getilgtem Text als Korrektur eingefügt (oft interlinear).

Bei nicht erhaltenem oder unleserlich getilgtem Text erfolgt die Angabe wahrscheinlich verlorener Buchstaben durch Punkte oder Zahlangabe (z. B. [ . ... oder [ \pm 4$]$ ] 4 Buchstaben). 


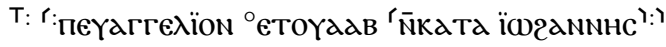

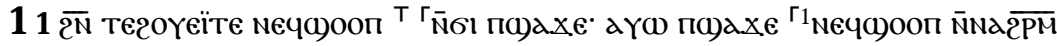

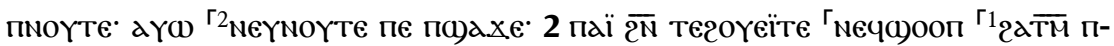

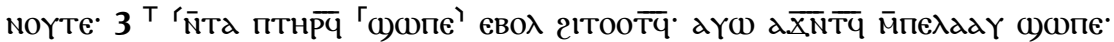

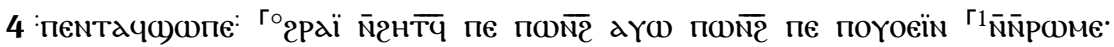

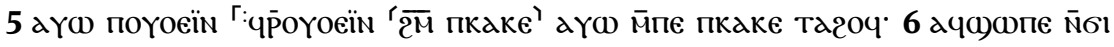
оүрсоме 'еаүт̄

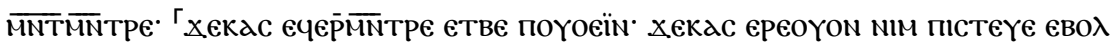

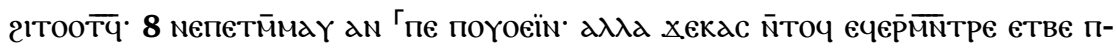

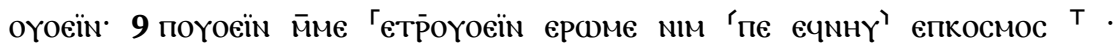

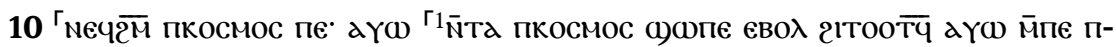

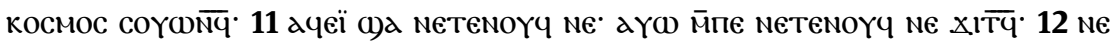

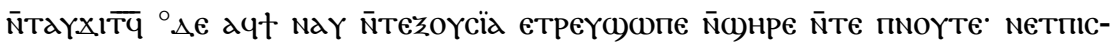

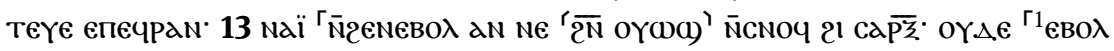

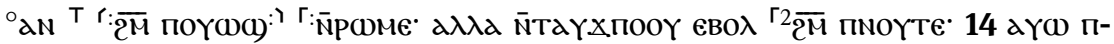

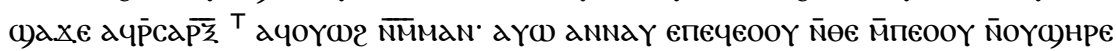

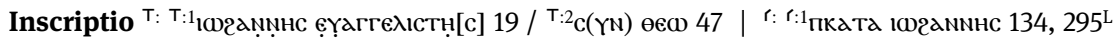

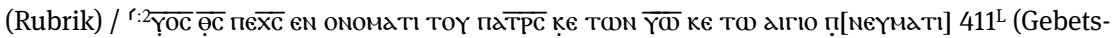

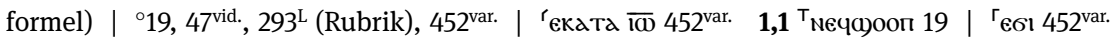

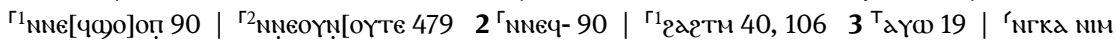

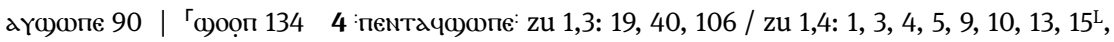

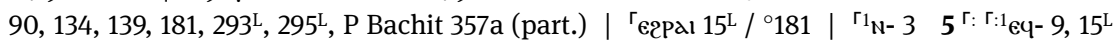

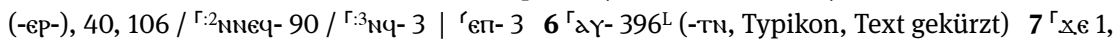

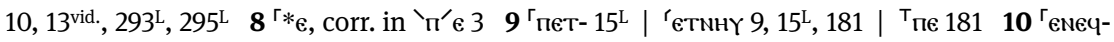

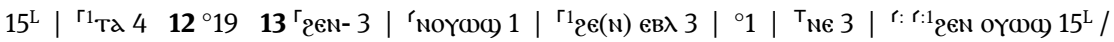

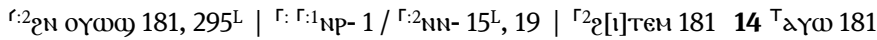

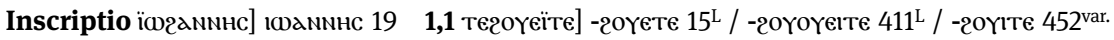

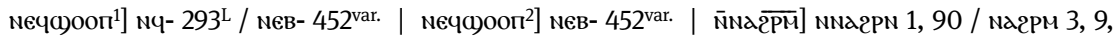

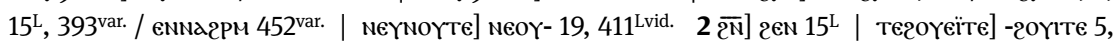

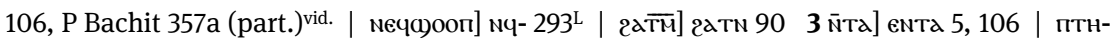

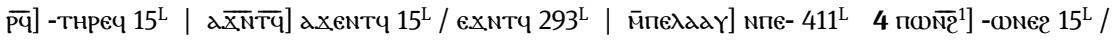
- -

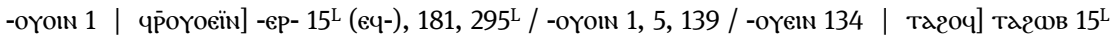

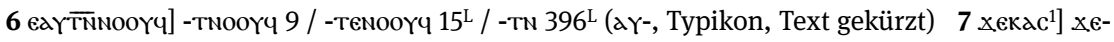

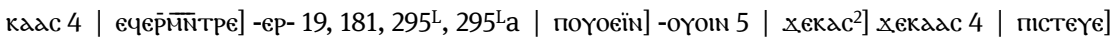

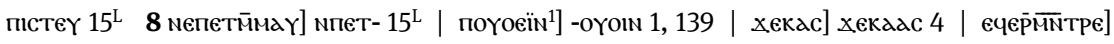

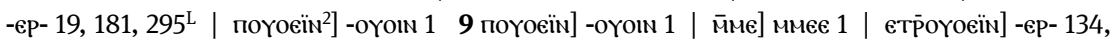

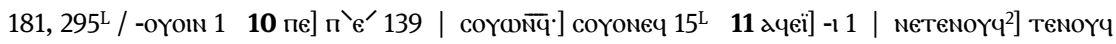

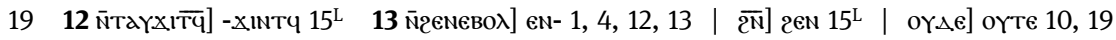

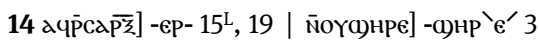




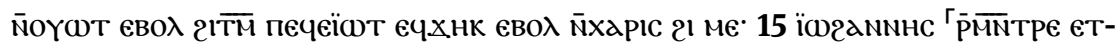

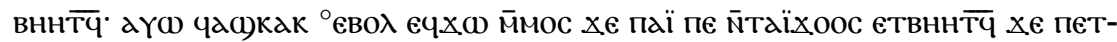

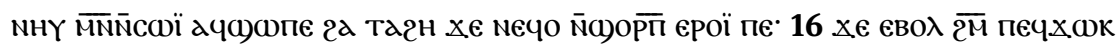

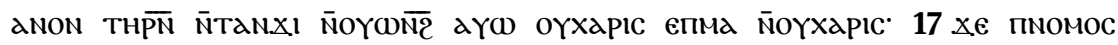

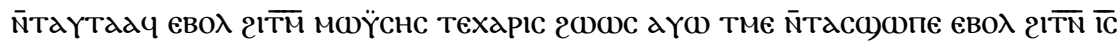

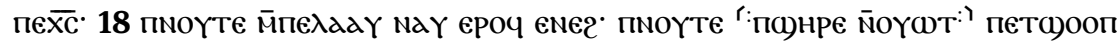

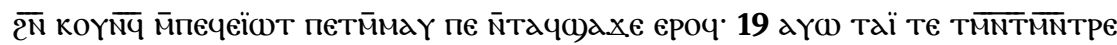

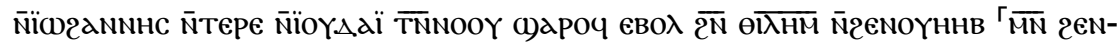

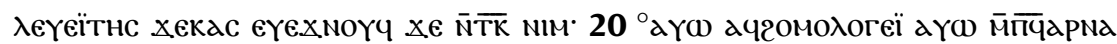

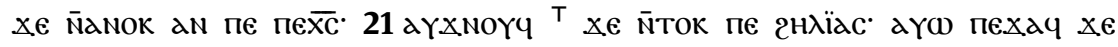

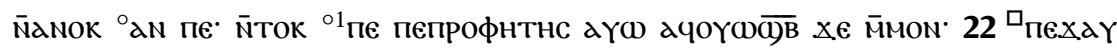

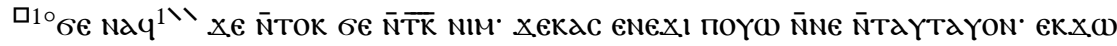

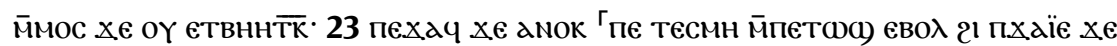

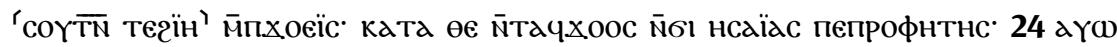

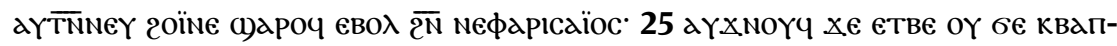

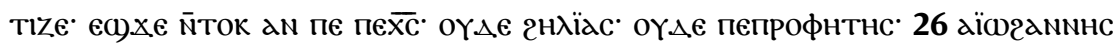

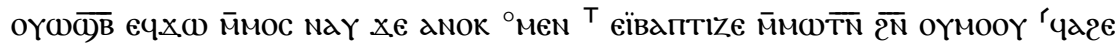

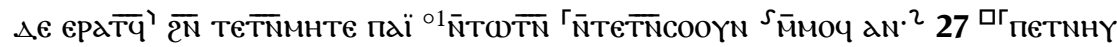

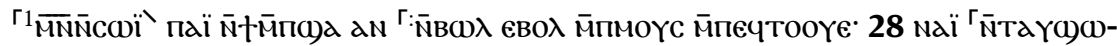

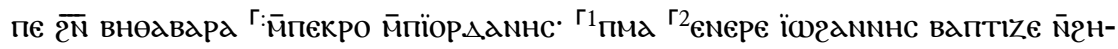

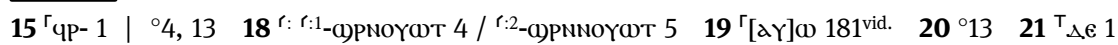

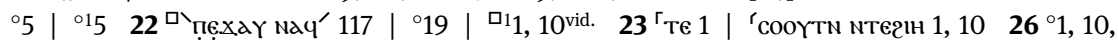

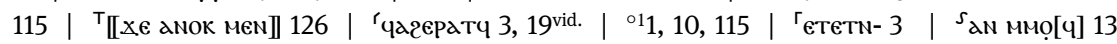

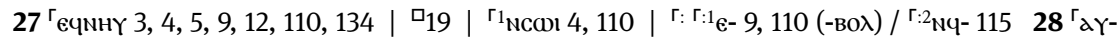

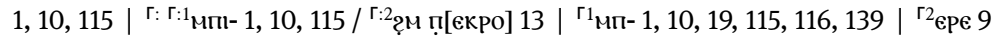

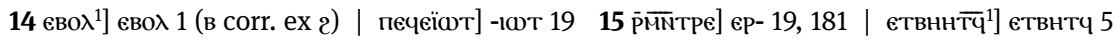

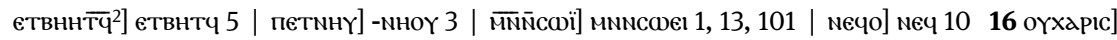

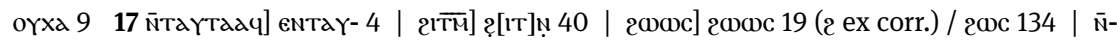

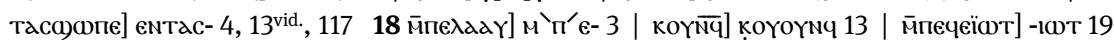

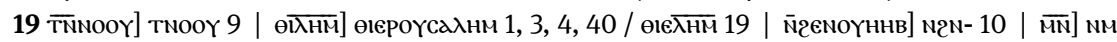

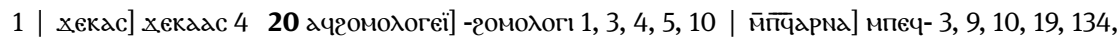

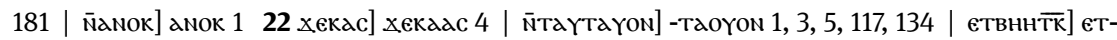

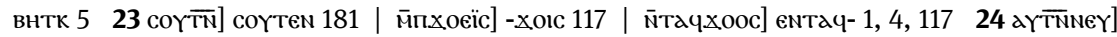

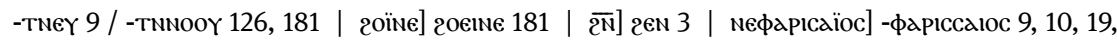

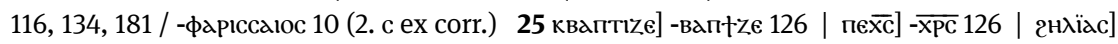

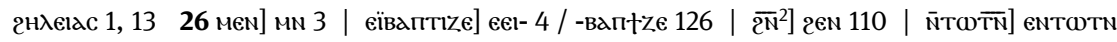

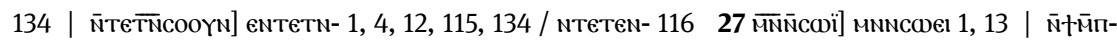

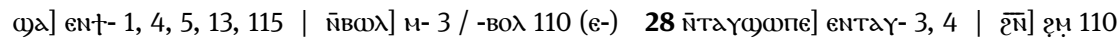
внөдвара] веөнвара 4, 13, 110 / внөнвара 5, 9, 116 / внөарава 1/ ваєөнвара 3 | мппіорАданс] мпє- 9 | ваптіzе] ва̣п†те 110 


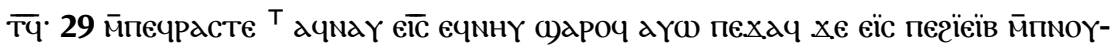

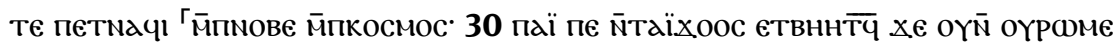

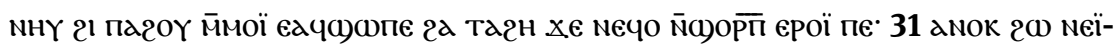

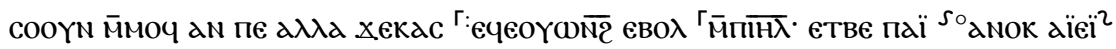

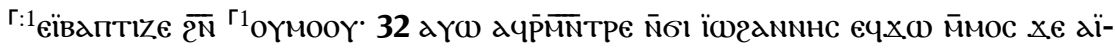

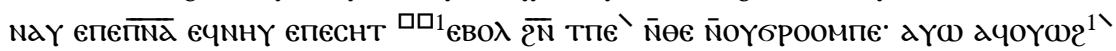

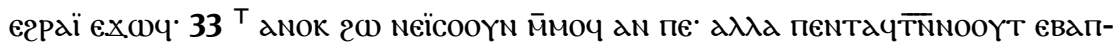

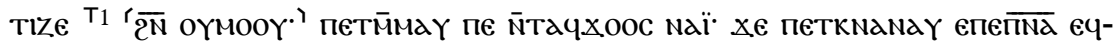

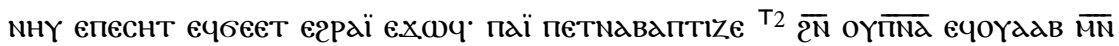

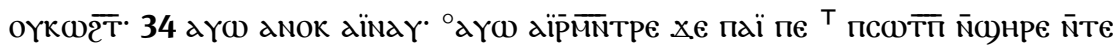

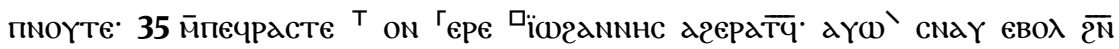

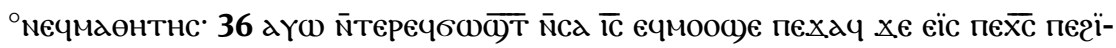

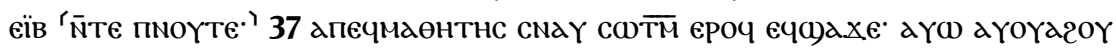

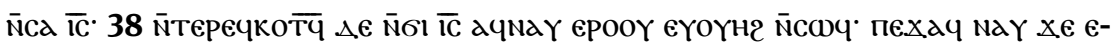
тетN

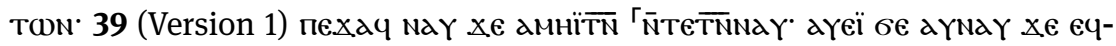

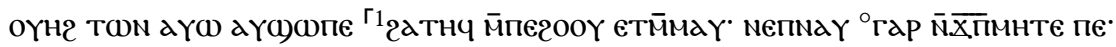

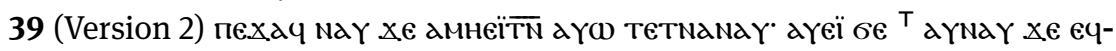

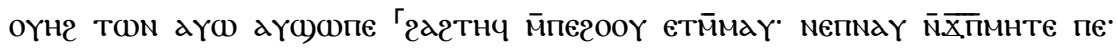

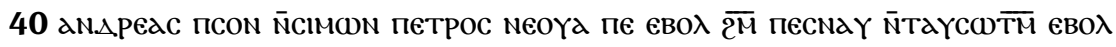

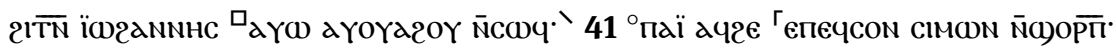

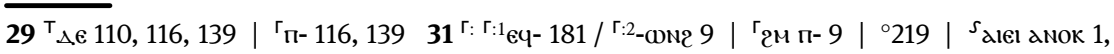

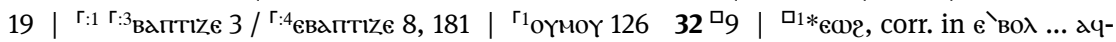

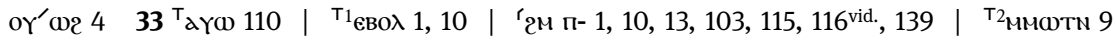

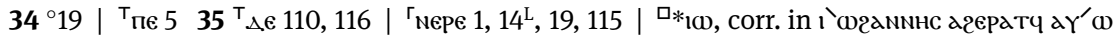

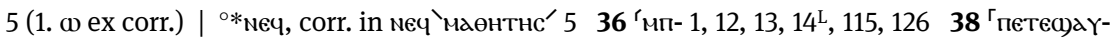

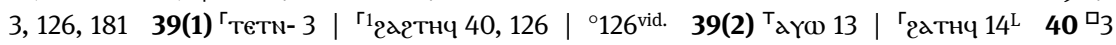
$41{ }^{\circ}$ 'חal' 3 | 'печ- 19
}

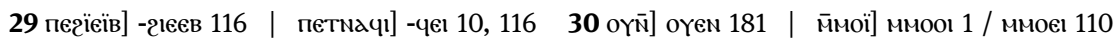

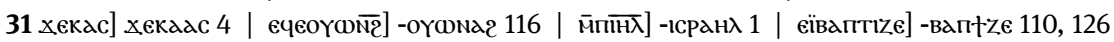

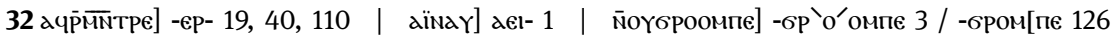

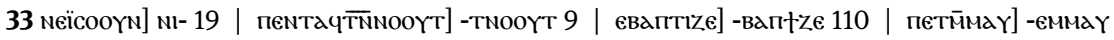
181 / - 'м' ммау 3 | петкманаү] петек- 19, 110, 116 | ечnнү] ечеч- 126 | епеснт] епснт 10

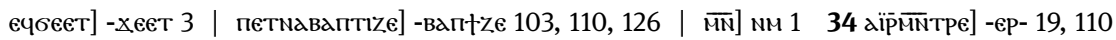

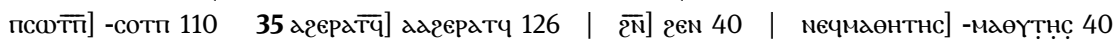
37 аүоүагоү] аүагоү 11038 етет̄ -оүадмег 1 / -оүагмч 139 | псаг] -сад 110 (с ех corr.) | екоүнг] -оүннг 126 39(1) амнїте]

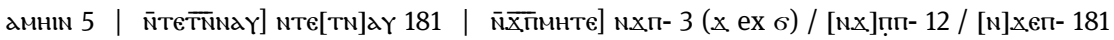

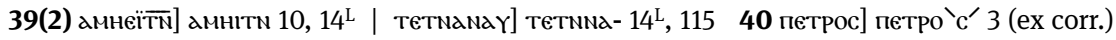

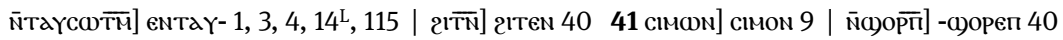




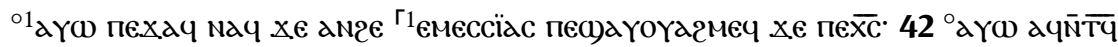

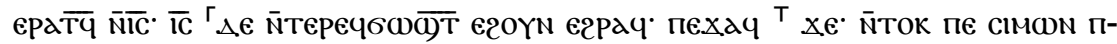

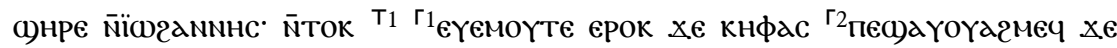

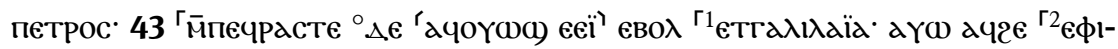

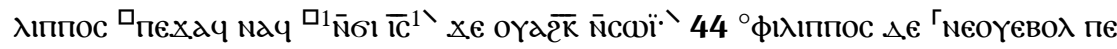

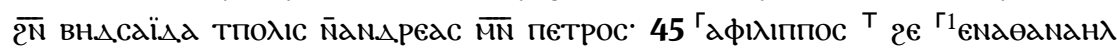

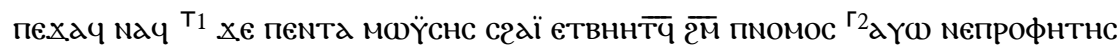
ангє єроч· $\overline{\mathrm{ic}}$ понеє

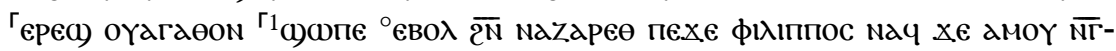

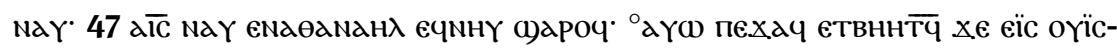

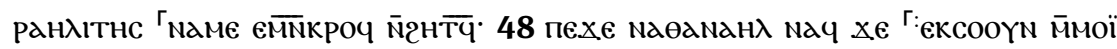

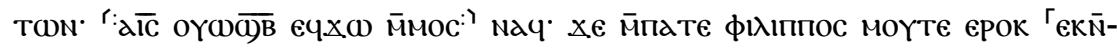

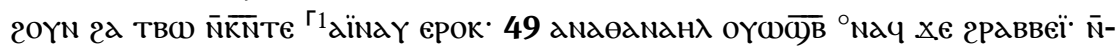

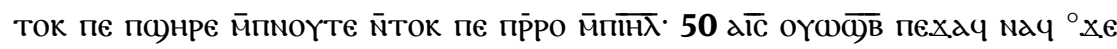

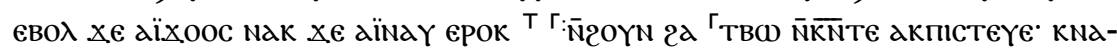

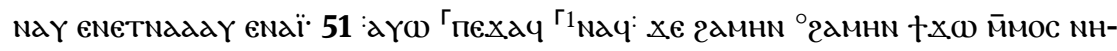

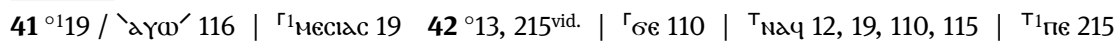

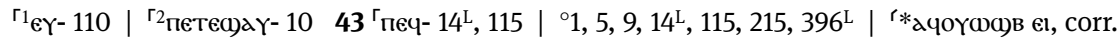

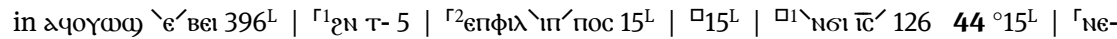

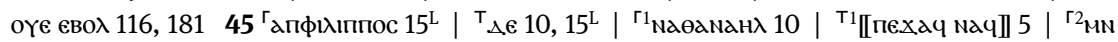

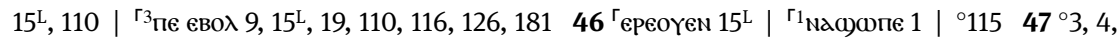

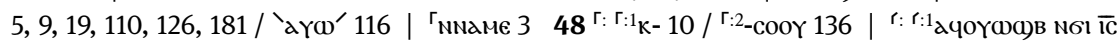

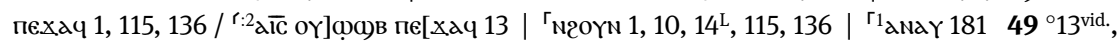

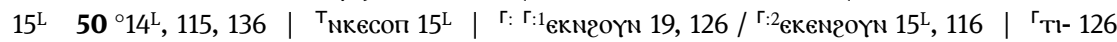
51 :аүс пехач мач: zu 1,50: 9 / zu 1,51: 1, 3, 4, 5, 10, 12, 13, 14 , 15L, 19, 40, 110, 115, 116, 126,

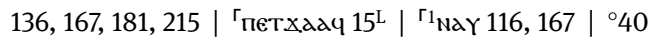

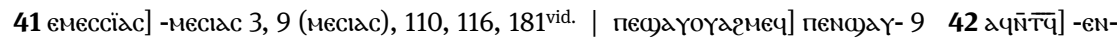

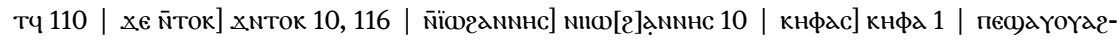

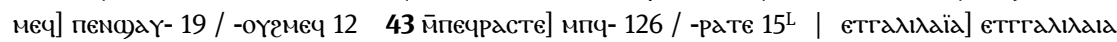

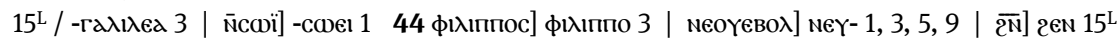

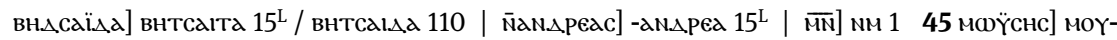

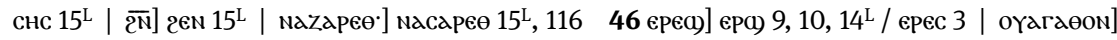

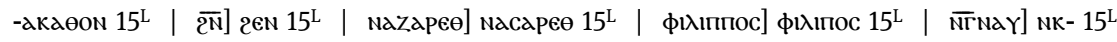

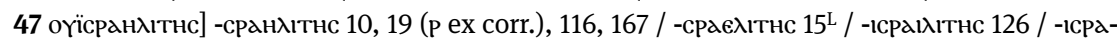

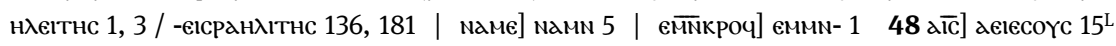

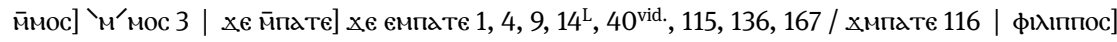

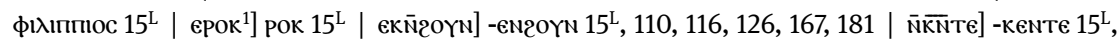

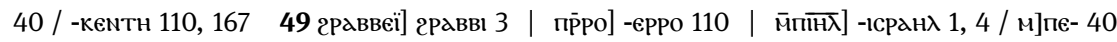

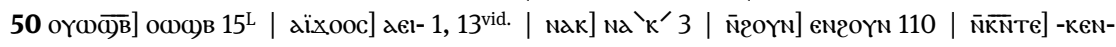

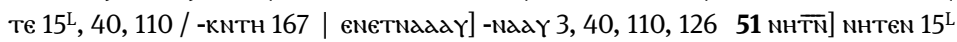




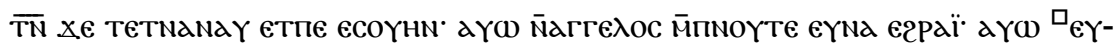

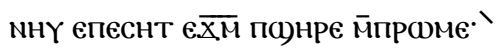

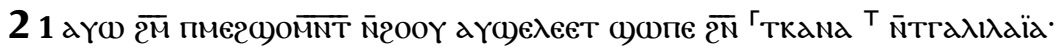

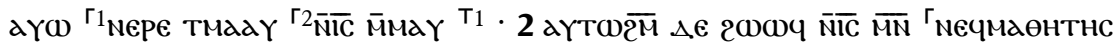
єто)

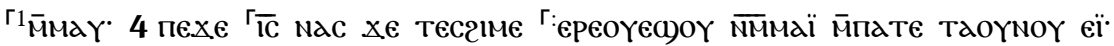

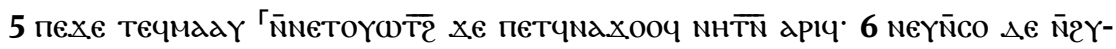

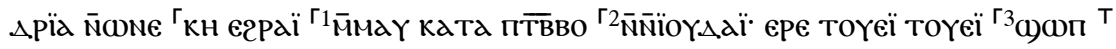

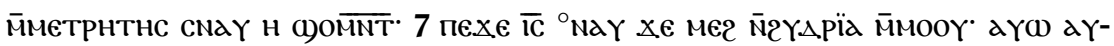

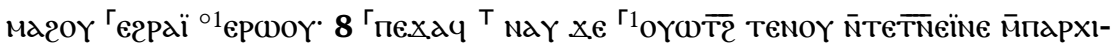

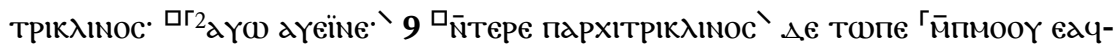

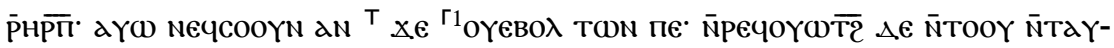

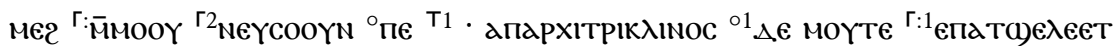

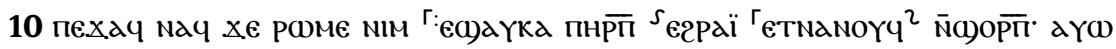

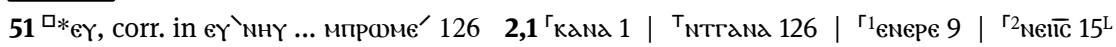

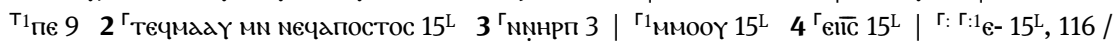

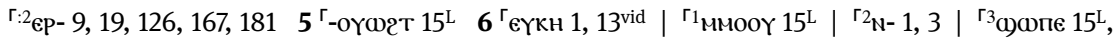

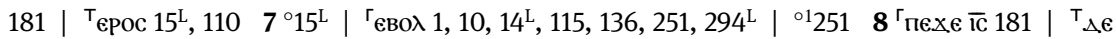

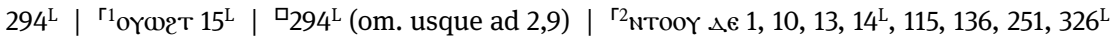

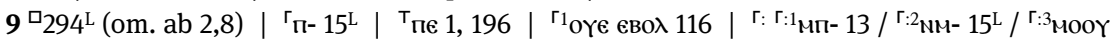

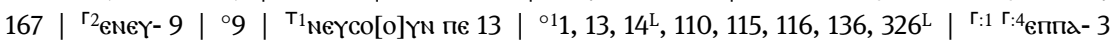

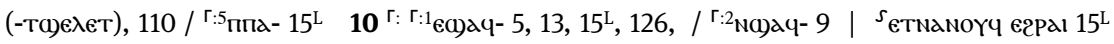

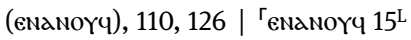

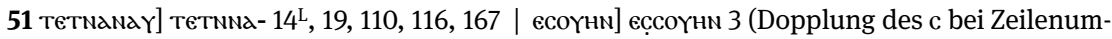

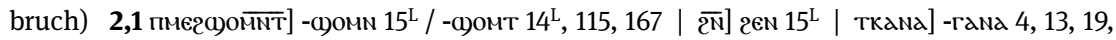

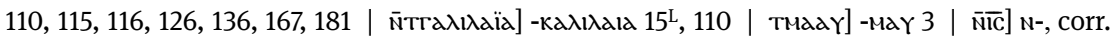

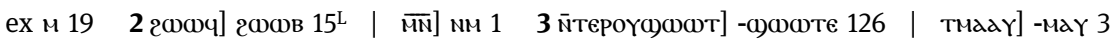

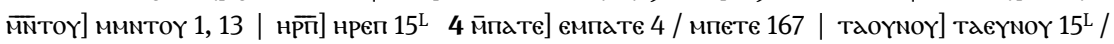

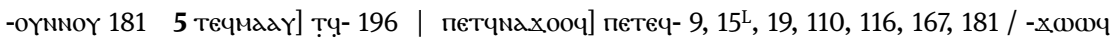

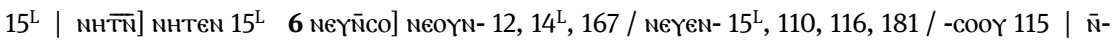

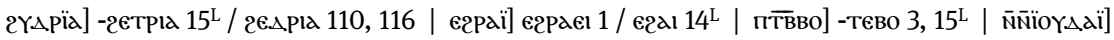
nNe- $15^{\mathrm{L}}$ | тоүеї] тоү 3 | ммметрнтнс] -метрітнс 5 / -ммтрнтнс 15 / -мнтрнтнс 19, 116, 167 |

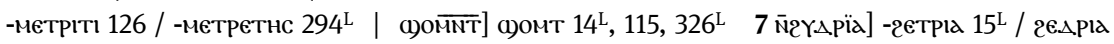

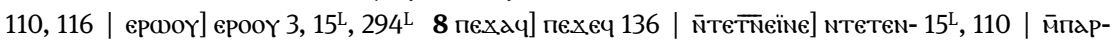
хІтрік

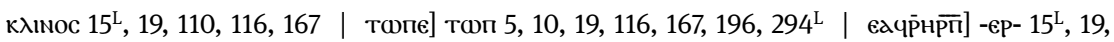

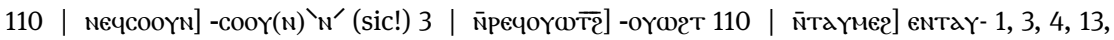

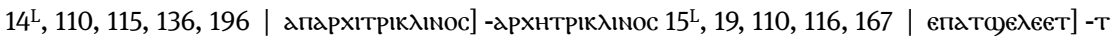

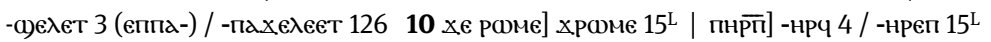




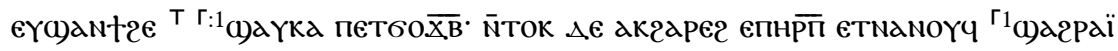

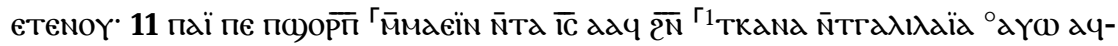

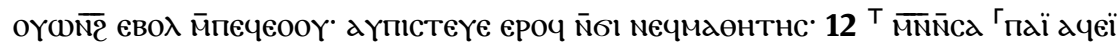

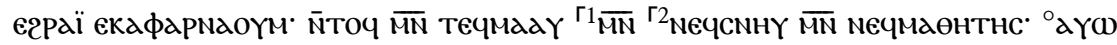

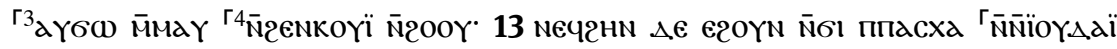

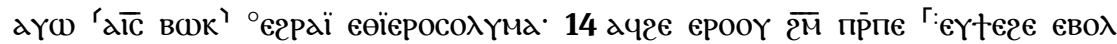

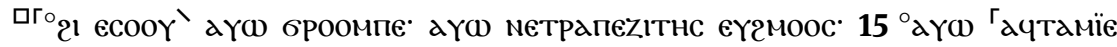

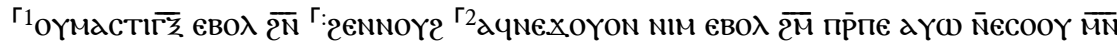

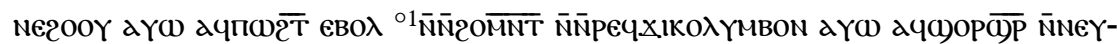

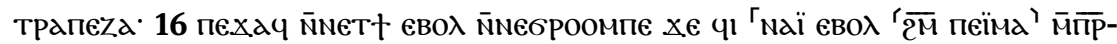

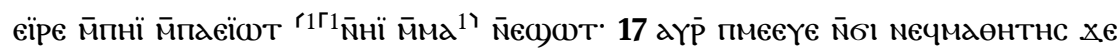

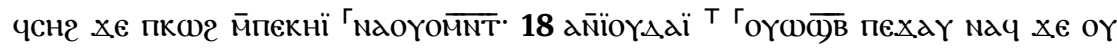

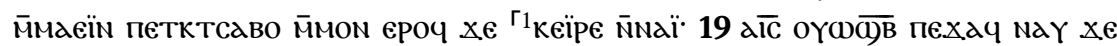

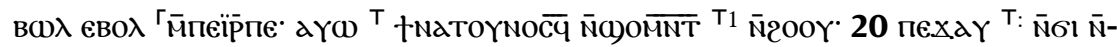

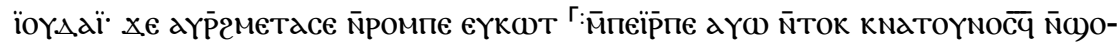

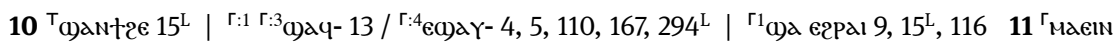

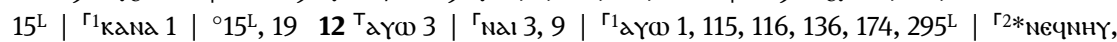

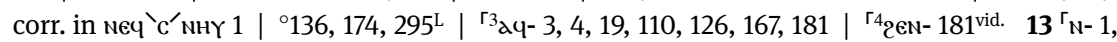

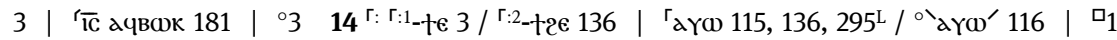

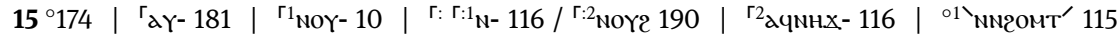

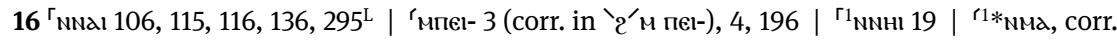

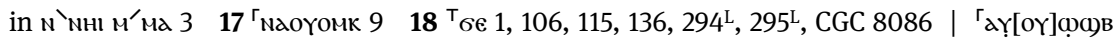

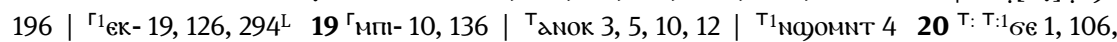

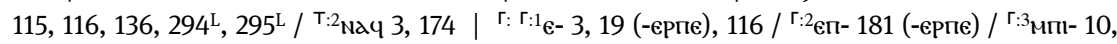
115,167

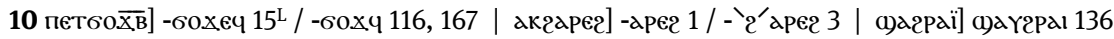

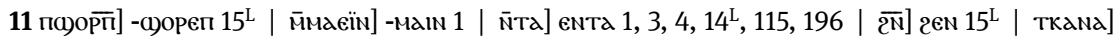

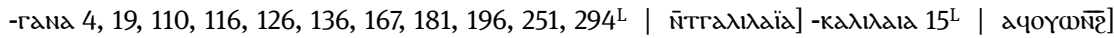

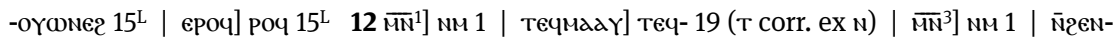
коүi] м2N- 3, 10, 110, 167 / -коүєе 113 еөїєросодүма] -өєероүсолүма 5, 110, 116 / -өієлнм 126,

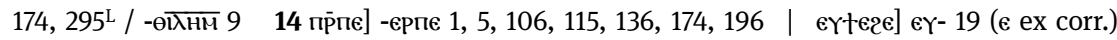
броомп] бромпе 126, 174 | метрапеzітнс] -трапесітнс 5, 116 / -трапєzеітнс 115, 13615 дчта-

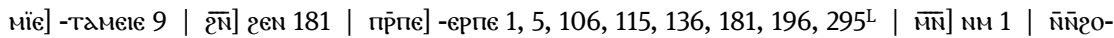

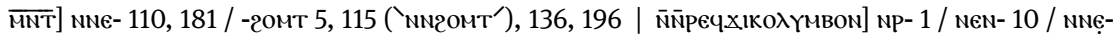

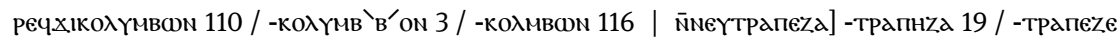

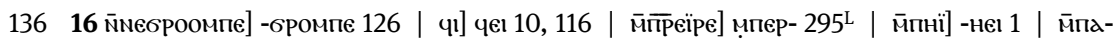

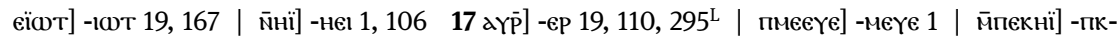
126 / -неь 1 | мдоүомпт] -оүомт 5, 10, 19, 106, 116, 126, 136, 174, 2955', CGC 808618 петктса-

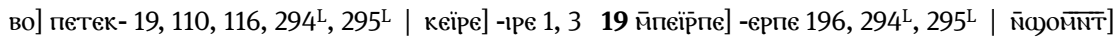

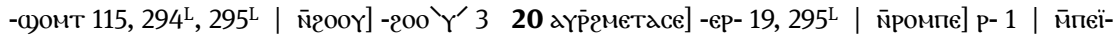

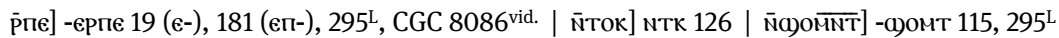




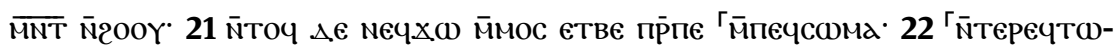

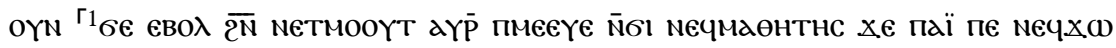

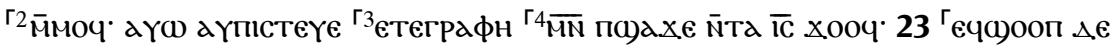

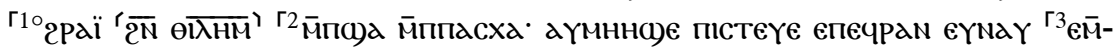

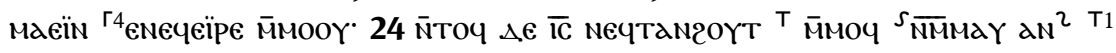

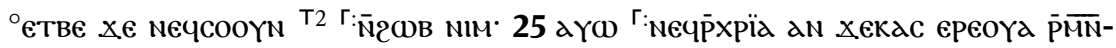

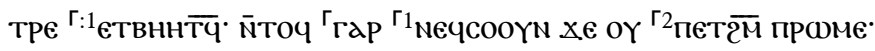

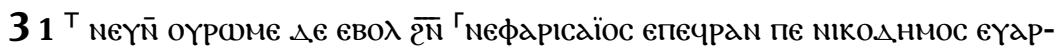

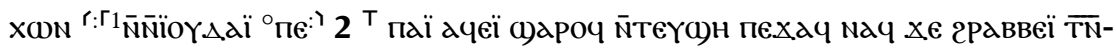

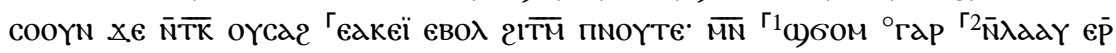

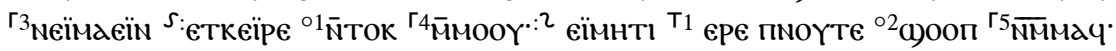

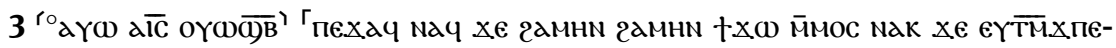
oүa N̄кесоп $\overline{M N}{ }^{\ulcorner 1}$ ф)

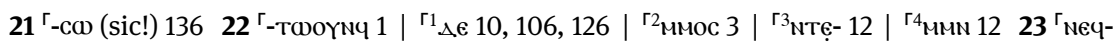

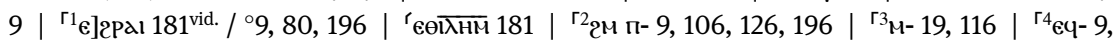

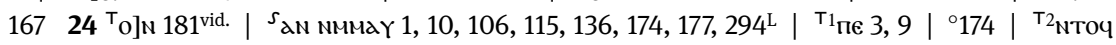

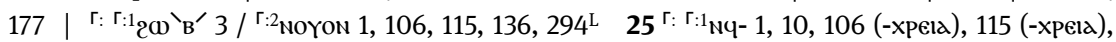

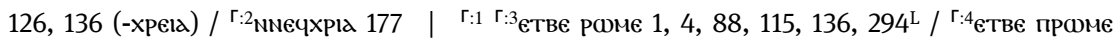

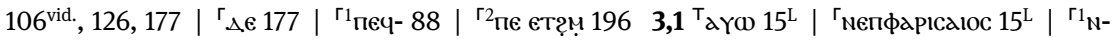

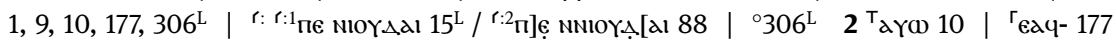

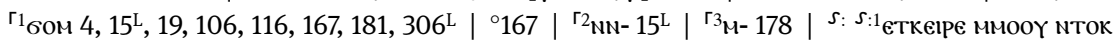

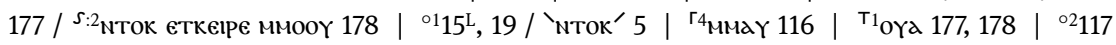

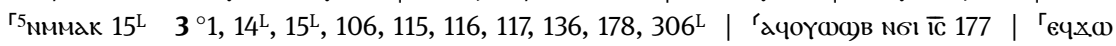
ммос $174 \mid{ }^{\Gamma 1}$ бом $1,4,9,15^{\mathrm{L}}, 106,116,167,177,178,181,306^{\mathrm{L}} 4^{\circ} 15^{\mathrm{L}}$

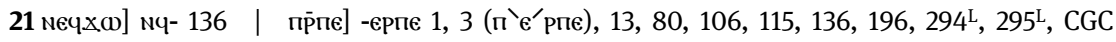
8086 vid. 22 аүр̄] -ер 19, 295L | пмеєүє] -меүє 1 / -мемеєүе 136 | мечмдөнтнс] -мдөнс 9 / -мдөү-

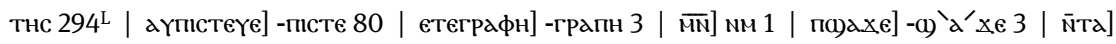

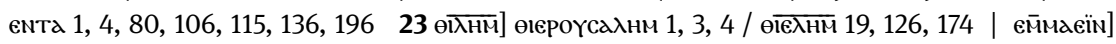

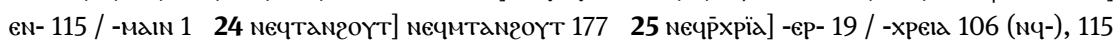

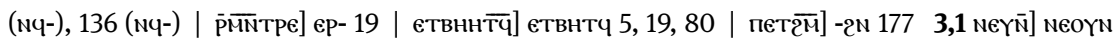

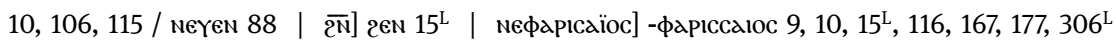

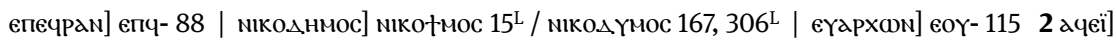

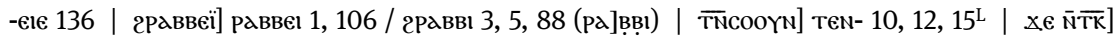

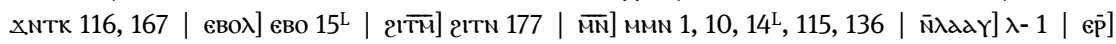

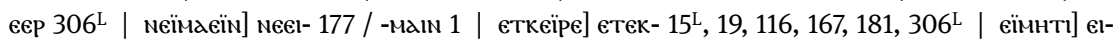

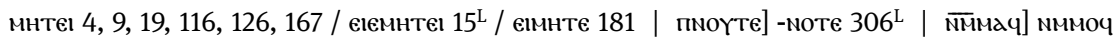

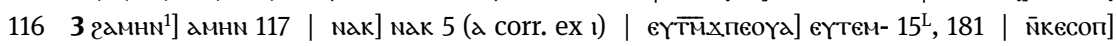

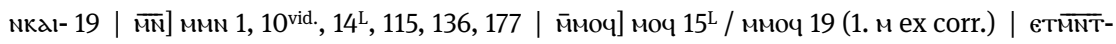

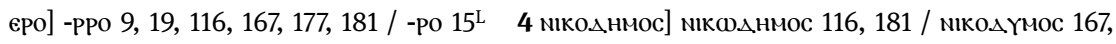
$306^{\mathrm{L}}$ 


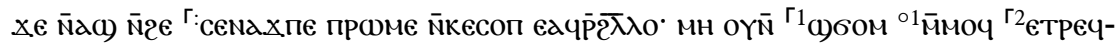

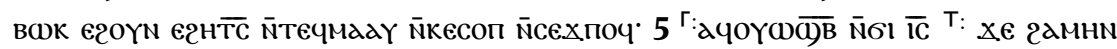

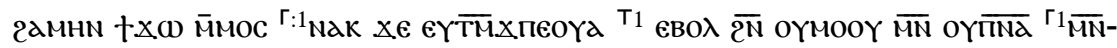

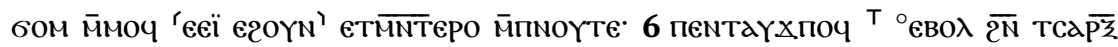

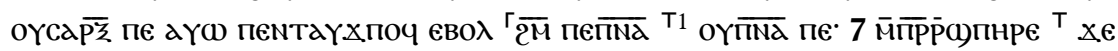

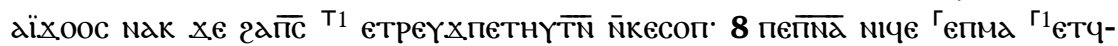

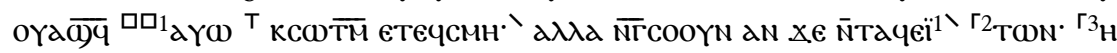

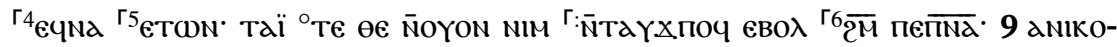

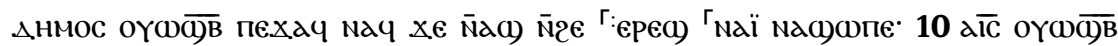

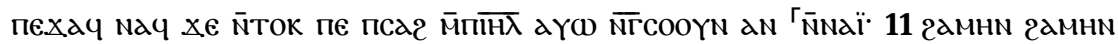

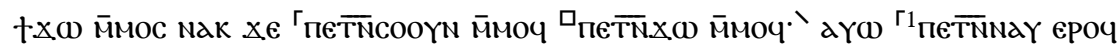

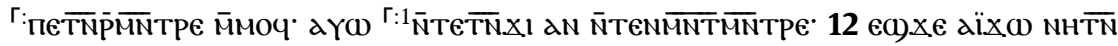

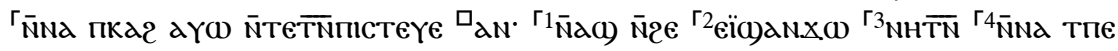

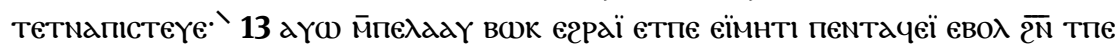

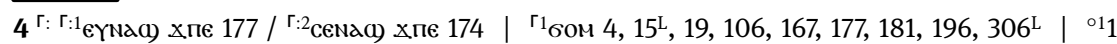

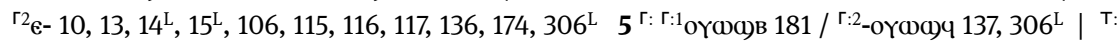

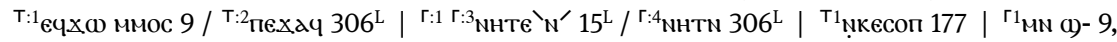

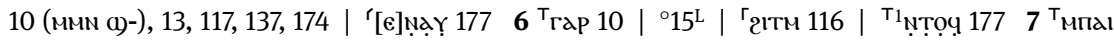

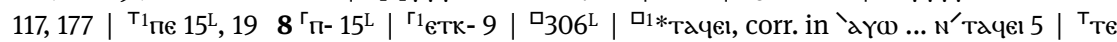

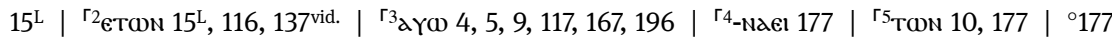

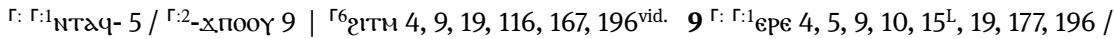

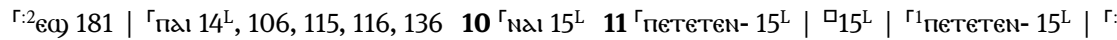

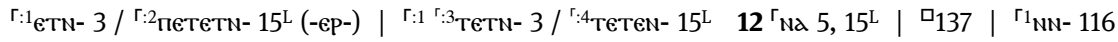
${ }^{\mathrm{r} 2}$ eind- $15^{\mathrm{L}}, 19 \mid{ }^{\Gamma 3}$ epotw $1,106,115,136 \mid{ }^{\Gamma 4} \mathrm{Na} 5$

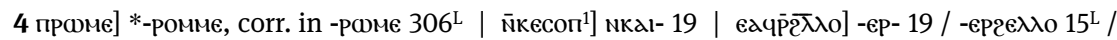

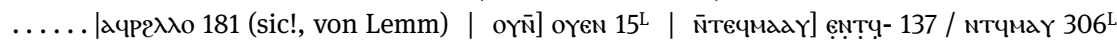

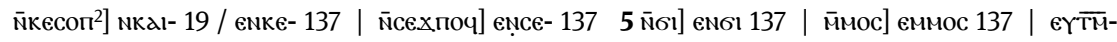

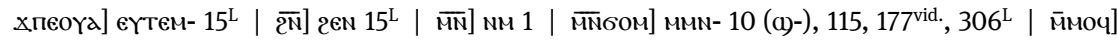

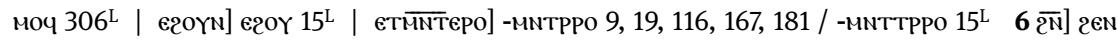

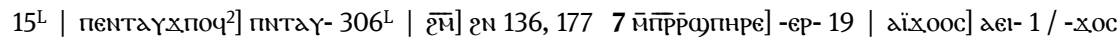

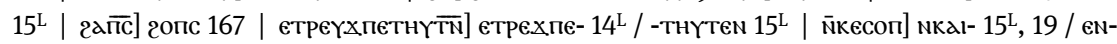

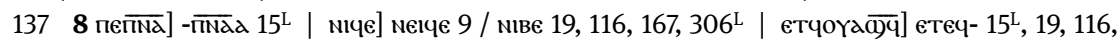

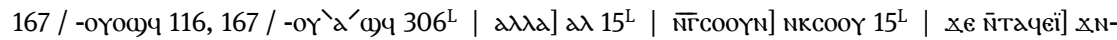

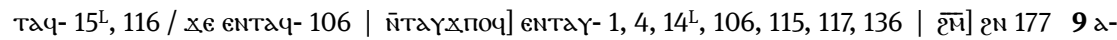

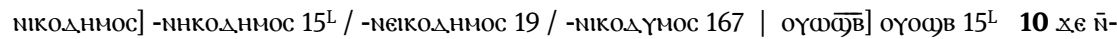

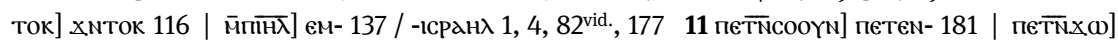

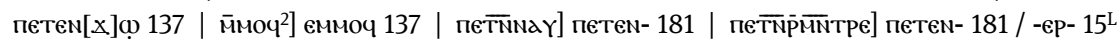

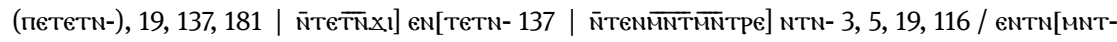

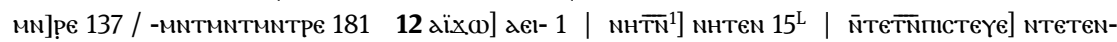

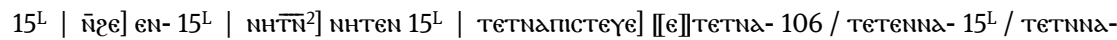

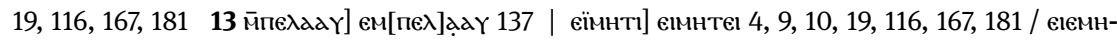

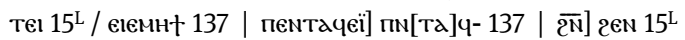




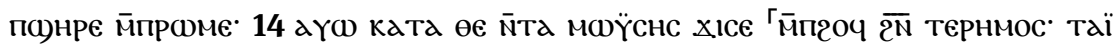

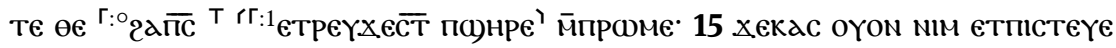

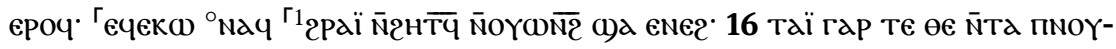
те мерє пкосмос госте печо)нре '

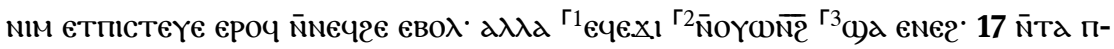

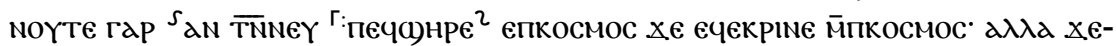

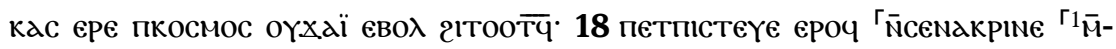

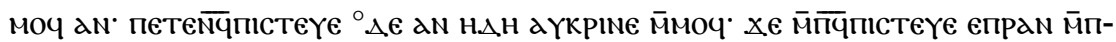

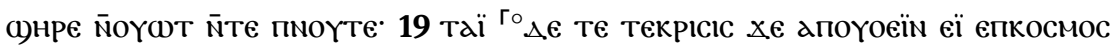

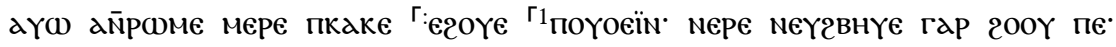

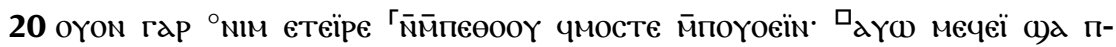

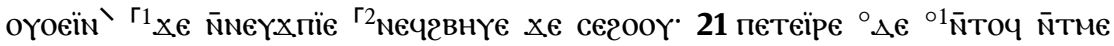

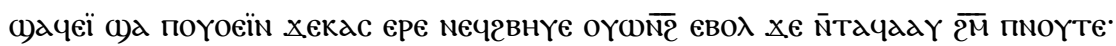

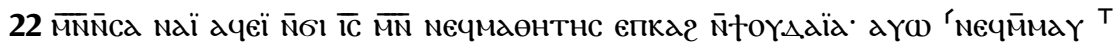

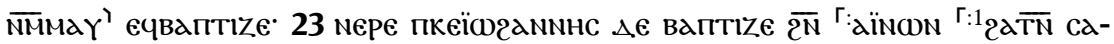

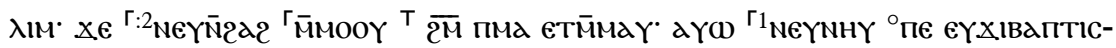

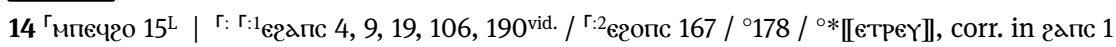

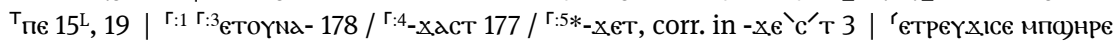

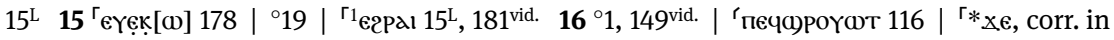

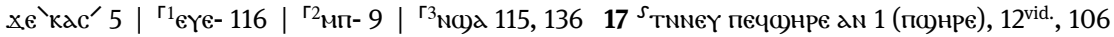

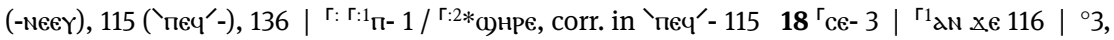

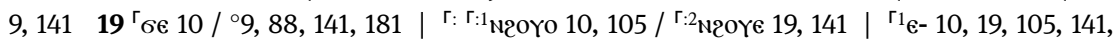

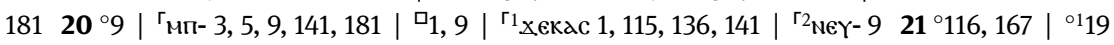

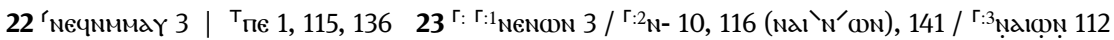

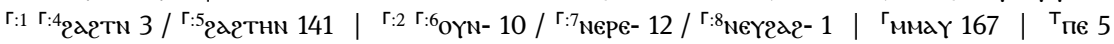

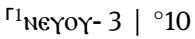

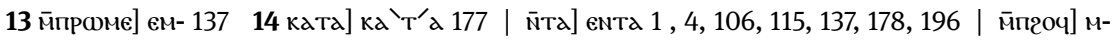

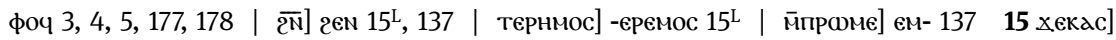

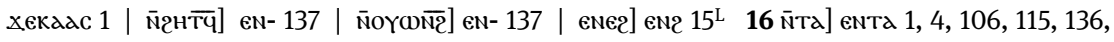

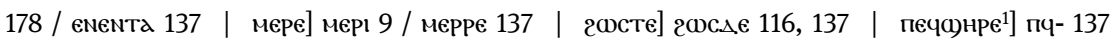

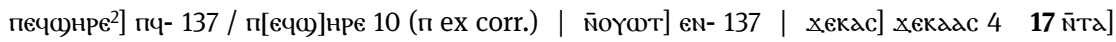

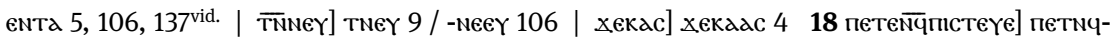
116, 167 /пет(м)мч- 141 / -пістеү 19 | хе мйппстеүє] хмпеч- 10 / хе мпеч- 9, 19, 116, 141, 167, 18119 дпоүоеїл] -оүоім 1 / -оүеім 141 | епкосмос] епкос 3 (мос оm. bei Seitenwechsel) ам̄роме] але- 181 | мере] мері 9 / 'ме' -гвноүе 4, 105, 11520 eтеїе] -ıре 1, 3 |

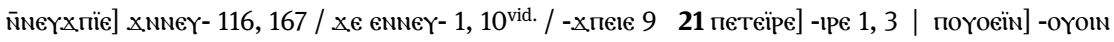

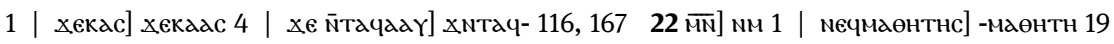

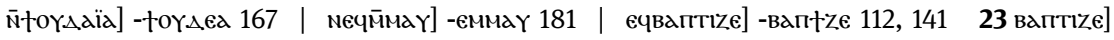

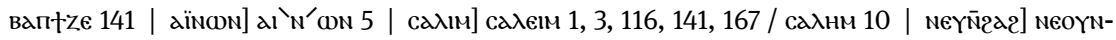
3, 112, 136, 167, 181 | меүNнү] NeоY- 3 


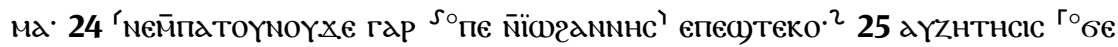

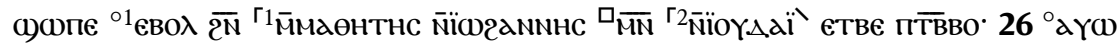

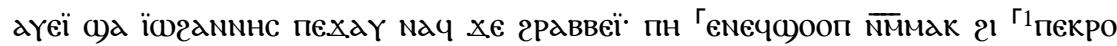

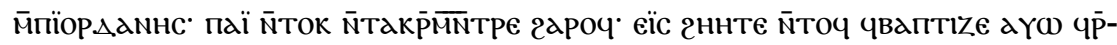

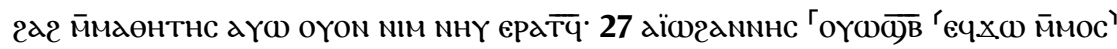

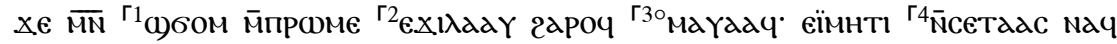

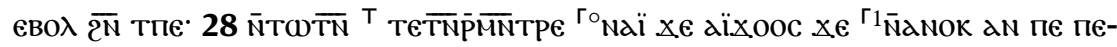

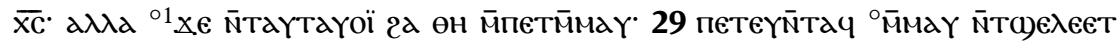

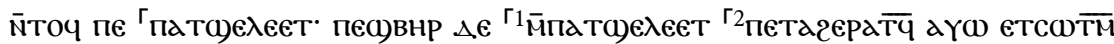

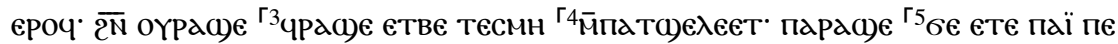

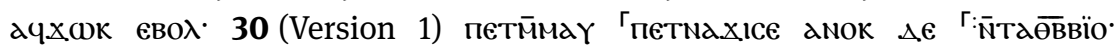

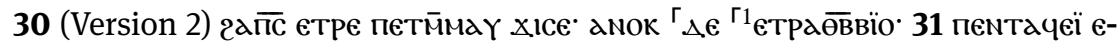

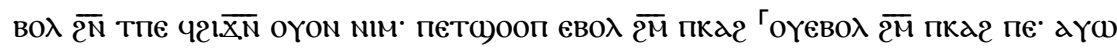

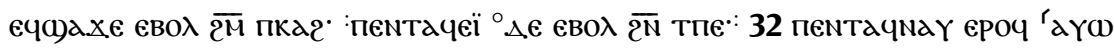

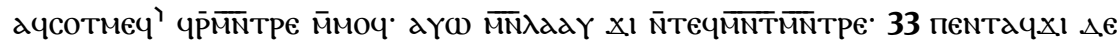

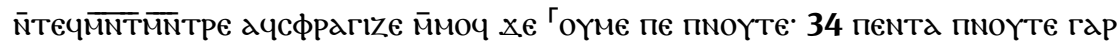

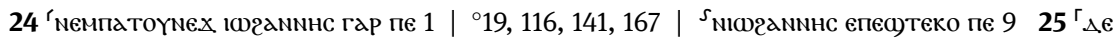

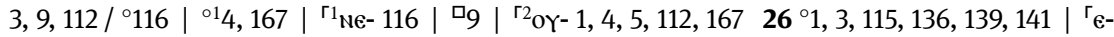

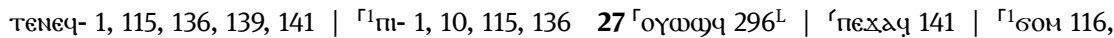

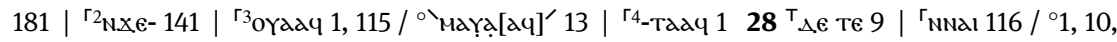

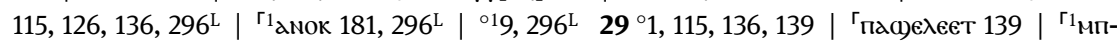

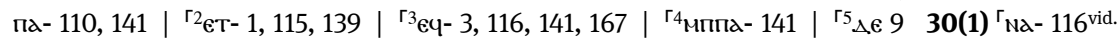

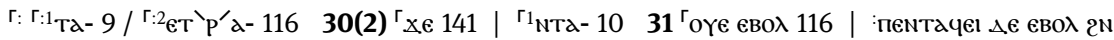
тпе zu 3,31: 3, 4, 5, 9, 13, 19, 110, 112, 115, 116, 136, 139, 141, 167, 181, 187 / zu 3,32: 1, 10 | ' $3^{\text {vid. }}$

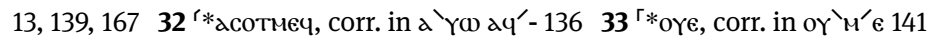

24 мем̄патоүноүхе] ммпатоү- 3, 112, 116, 167 / емемпатоү- 141 / -noүх 116, 16725 аүZнтнсіс]

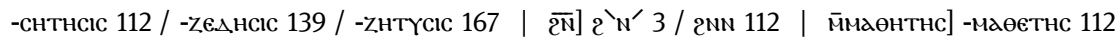

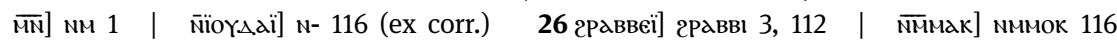

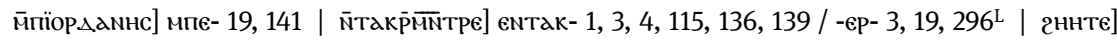

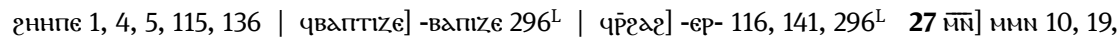

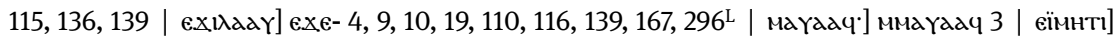

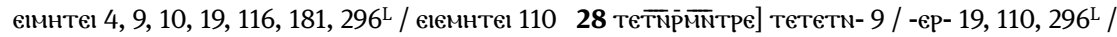

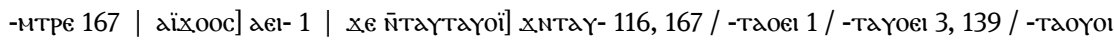

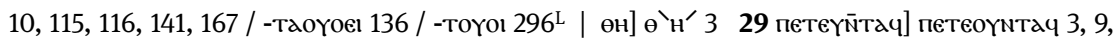

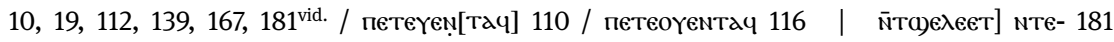

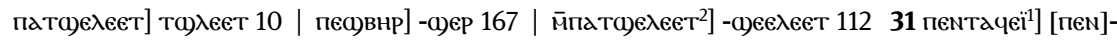

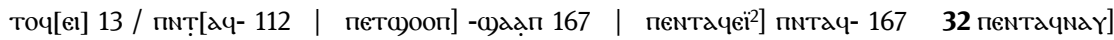

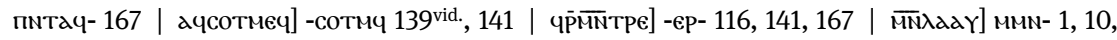
19, 115, 136, 14133 пентачхі] пnтач- 167 | ачсфрагіzе] -сфрагаzе 136 | оүме] -меє 3, 13 


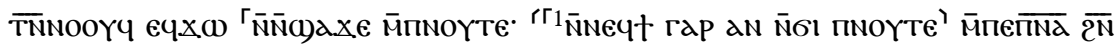

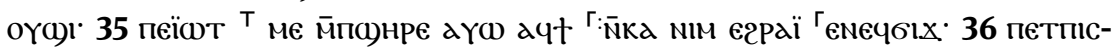

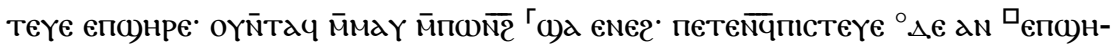

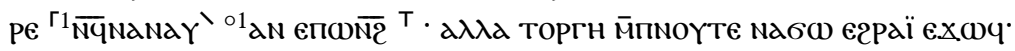

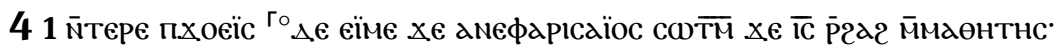

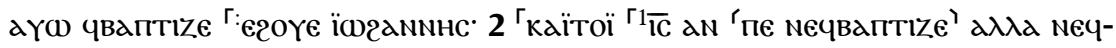

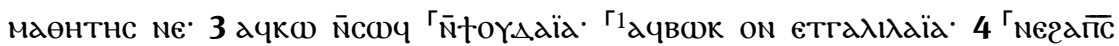

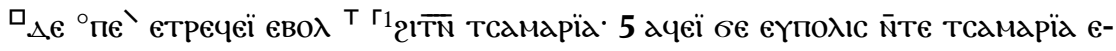

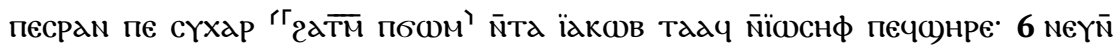

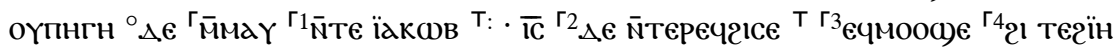

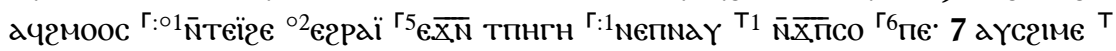

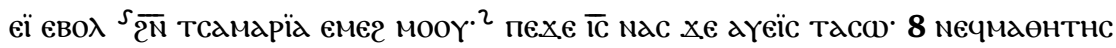

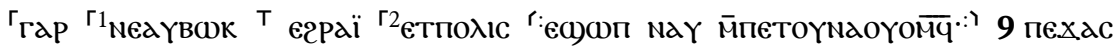

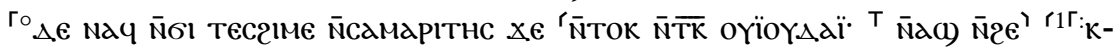

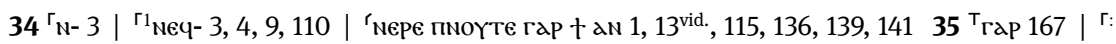

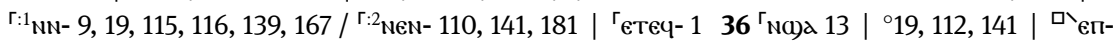

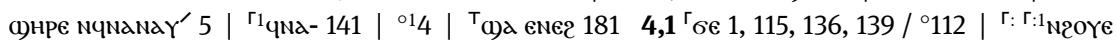
19, 141 / Г:2

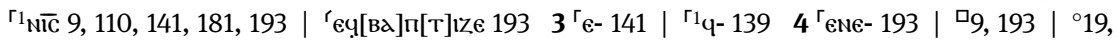

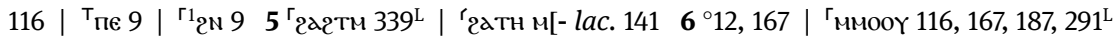

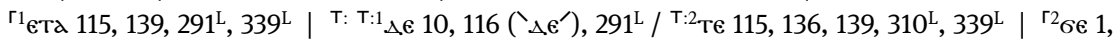

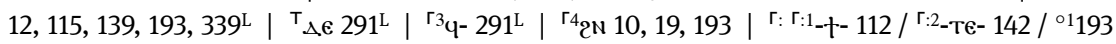

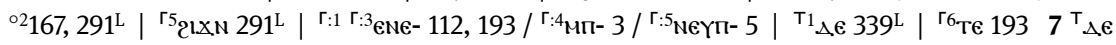

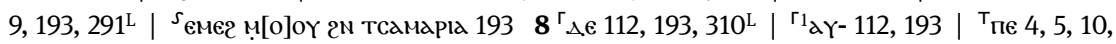
19, 187 | ${ }^{\ulcorner 2}$ еү- 3 | r: r:1 ес)епоєек 3, 4, 5 (окк) 9, 19, 112, 167, 187, 193 / r:2*ес)поєек, corr. in ес)п-

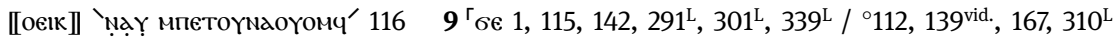

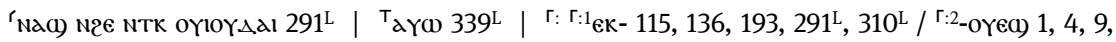

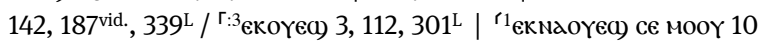

34 м̄ 110, 181 | петекйпстеүе] петмч- 116, 167 / петенеч- 3 / -мч]п!стеєе 112 | торгн] -оркн 112

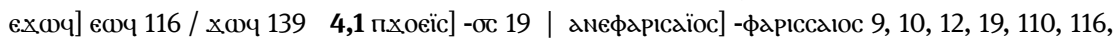

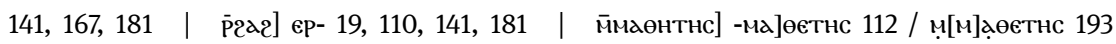

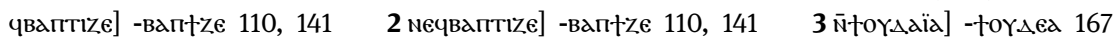

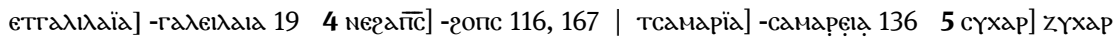

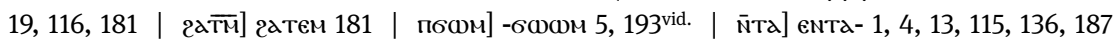

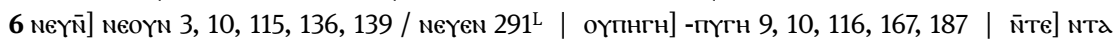

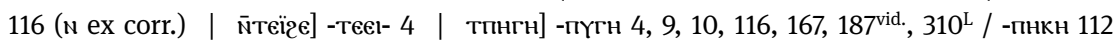

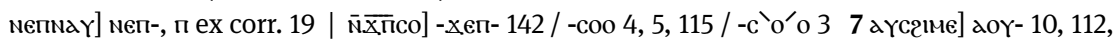

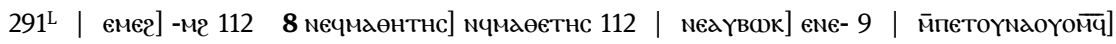

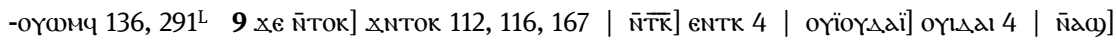
Na()) 193 


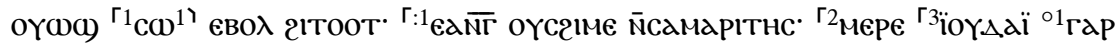

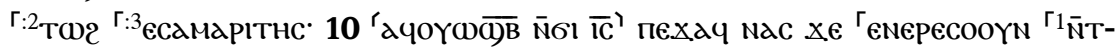

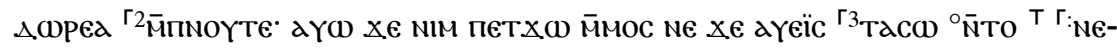

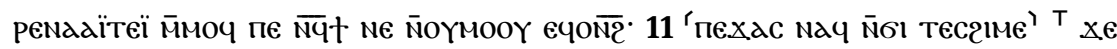

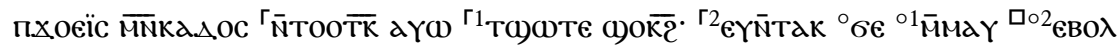

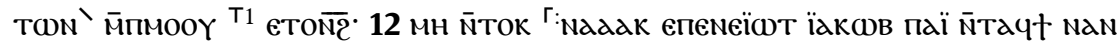

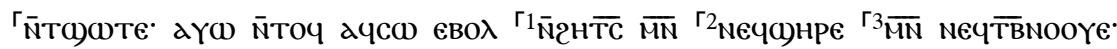

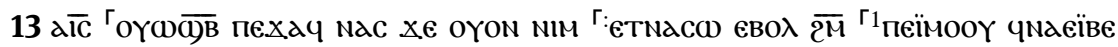

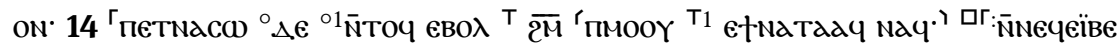

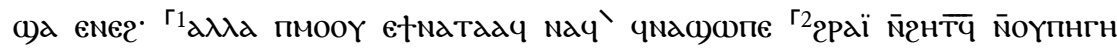

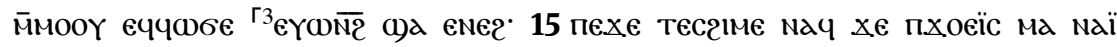

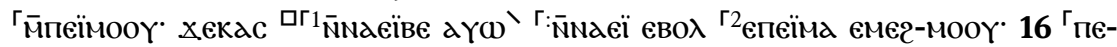

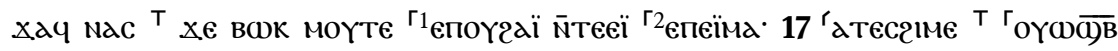

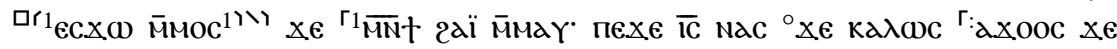

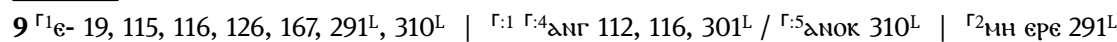

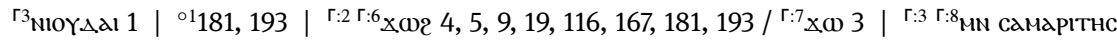

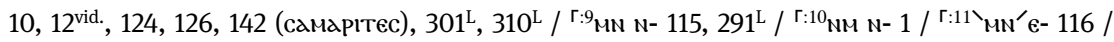

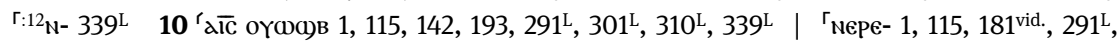

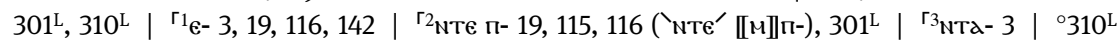

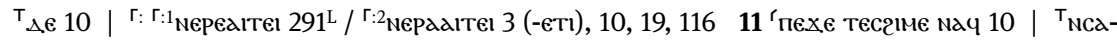

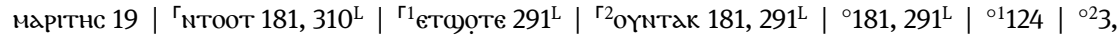

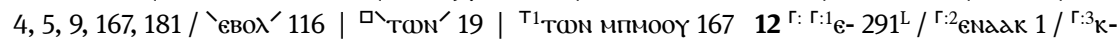

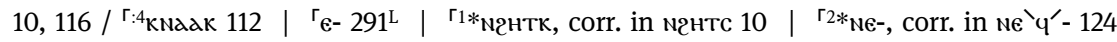

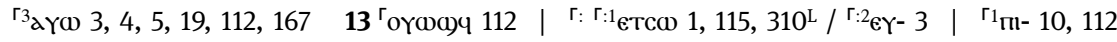

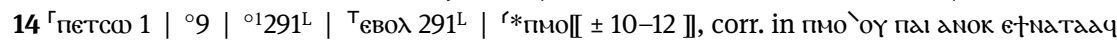

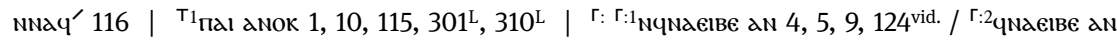

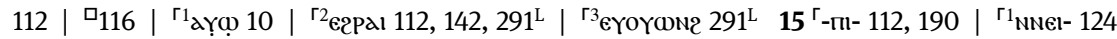

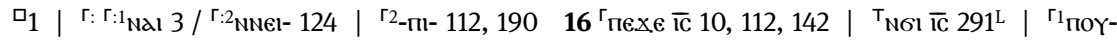

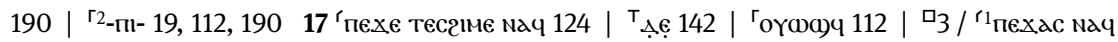

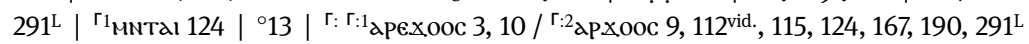

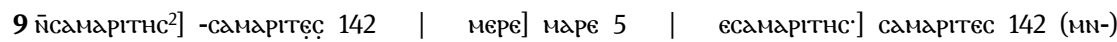

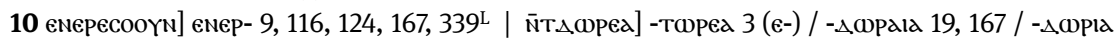

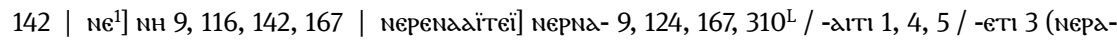

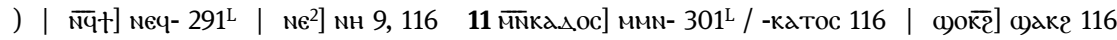
eүN̄Tak] eүentak 116 / eoүntak 167, 301 L 12 nadak] Nadk 3, 4, 115, 124, 181 | епемеїळт] епN-

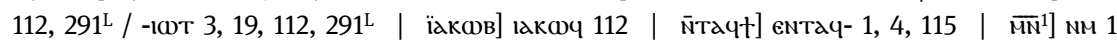

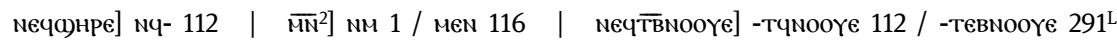

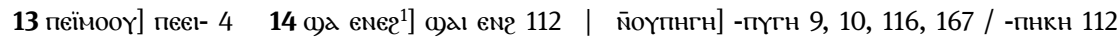

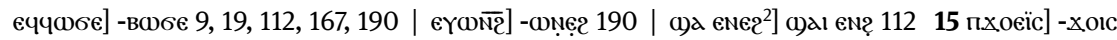

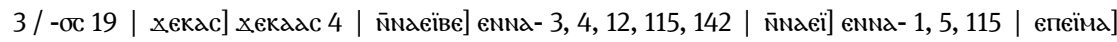

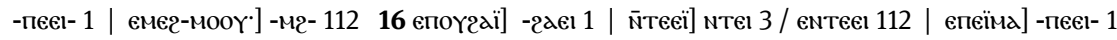

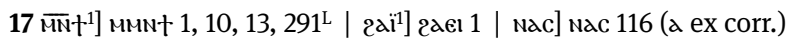




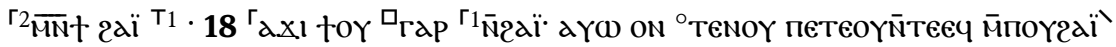

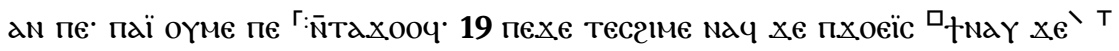

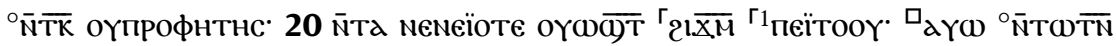

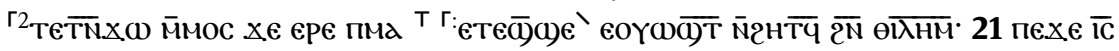

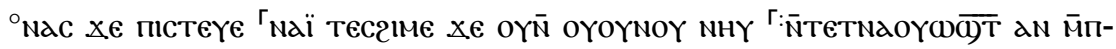

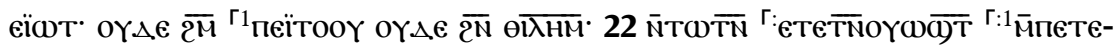

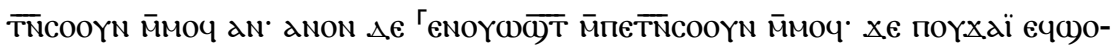

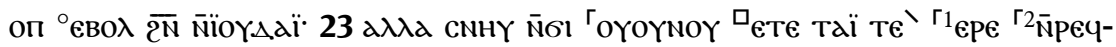

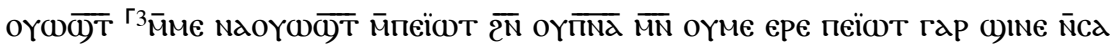

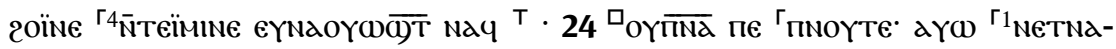

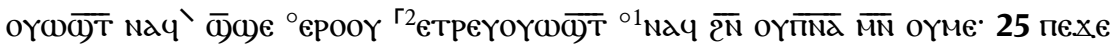

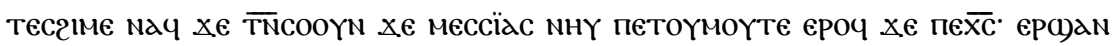

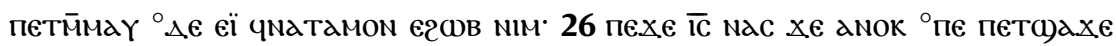

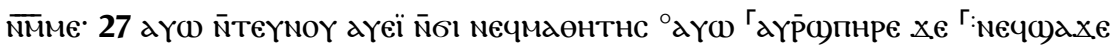

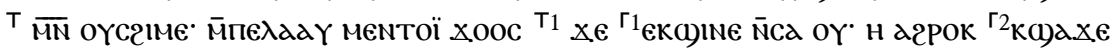

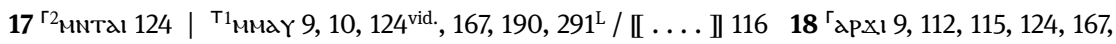

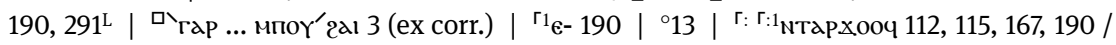

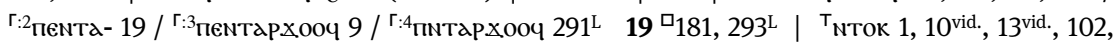

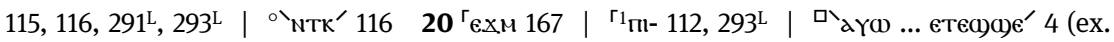

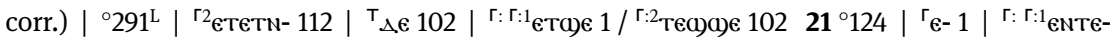
Nd- 1 / Г:2 Г:2 ${ }_{\text {NeTeTN- }} 124$ | Г:1 Г:3

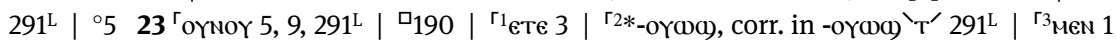

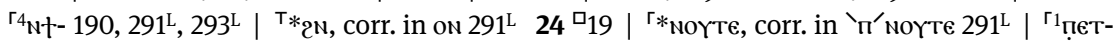

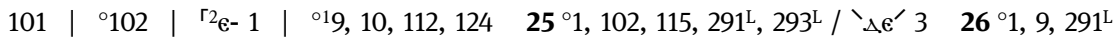

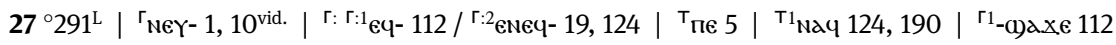
${ }^{\mathrm{r}} \mathrm{eK}-112,124$

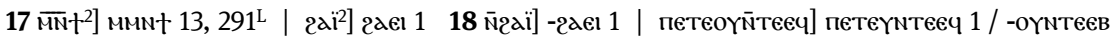

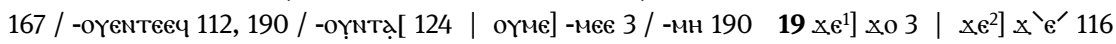

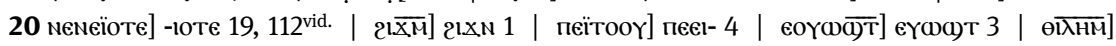

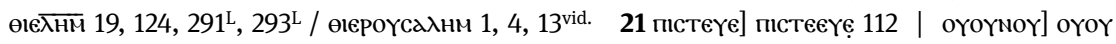

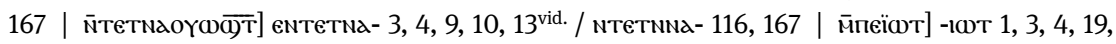

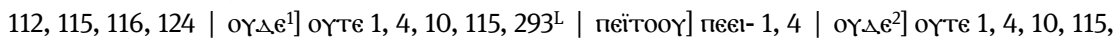

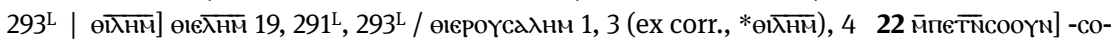

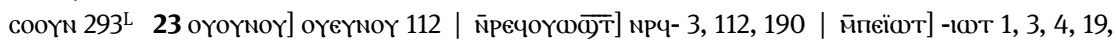

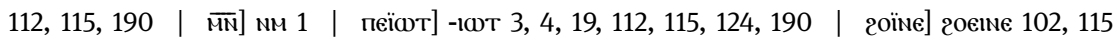

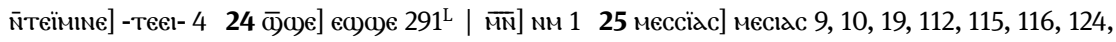

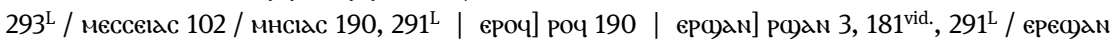

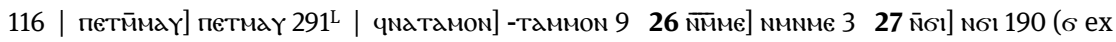

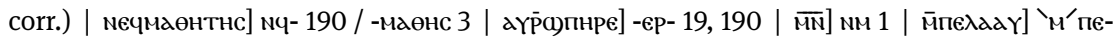

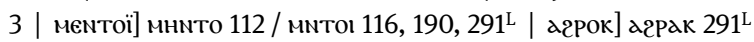




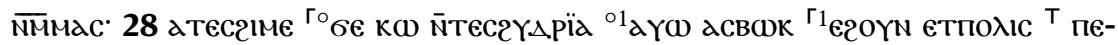

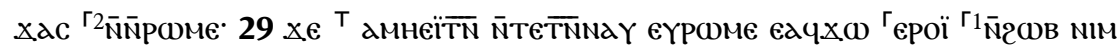

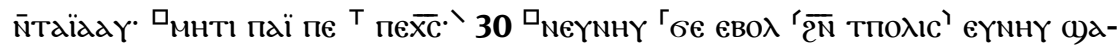

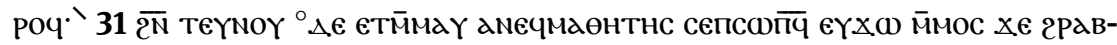

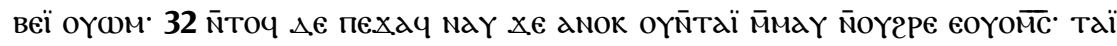

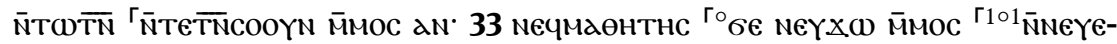

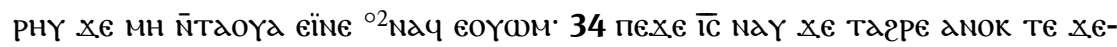

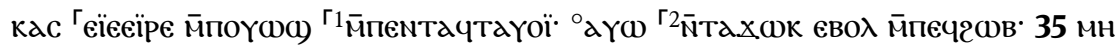

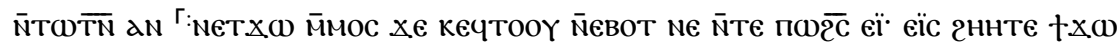

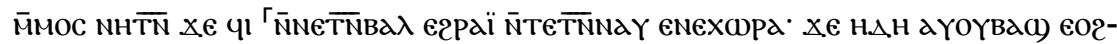

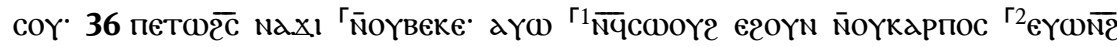

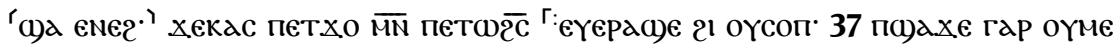

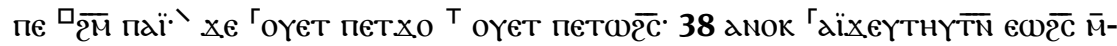

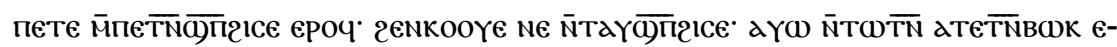

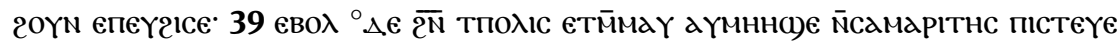

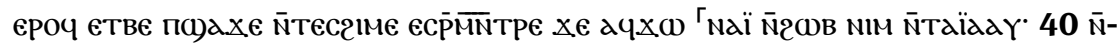

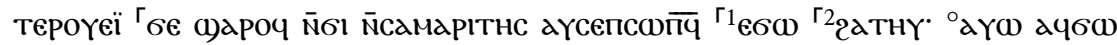

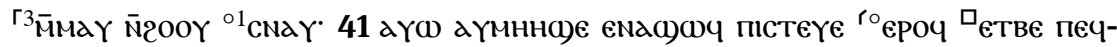

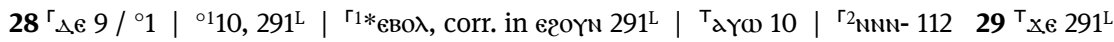

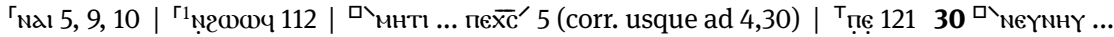

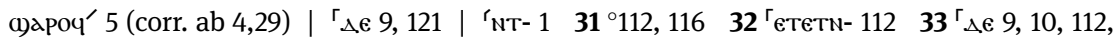

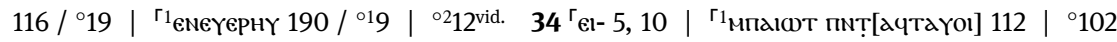

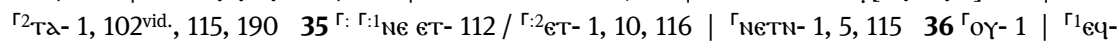

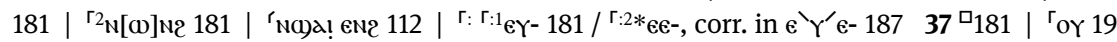
${ }^{\top}$ a

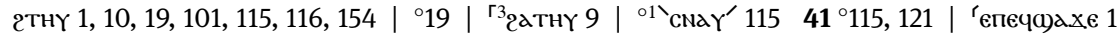

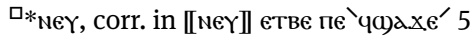

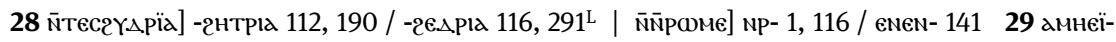

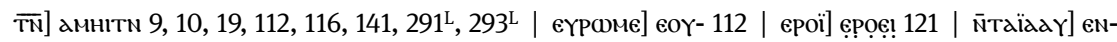
тал- 1, 3, 4, 10, 101, 102, 115, 121 | мнті] мнтег 4, 9, 10, 19, 112, 116, 141, 181, 291 31 дмечмдөн-

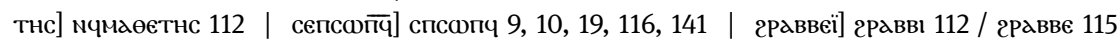

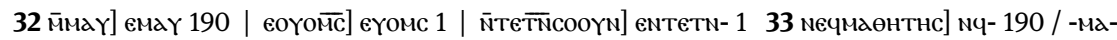

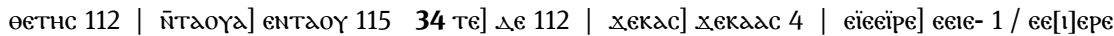

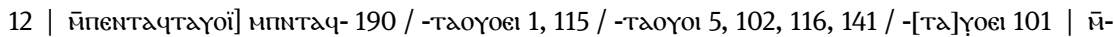

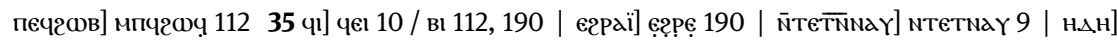

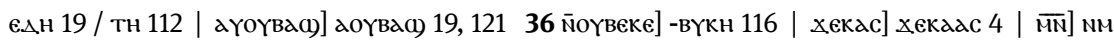

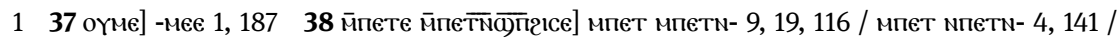

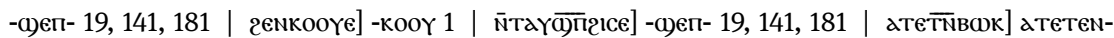

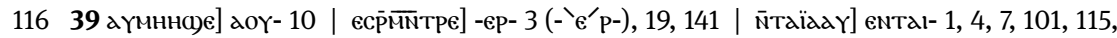

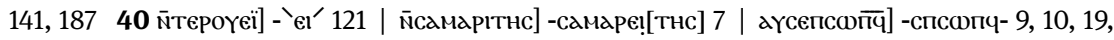

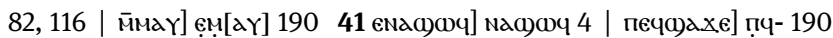




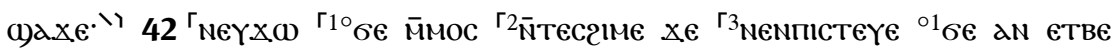

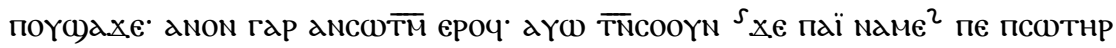

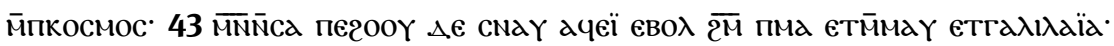

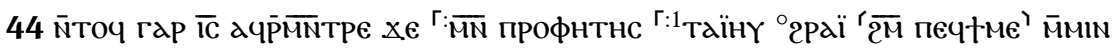

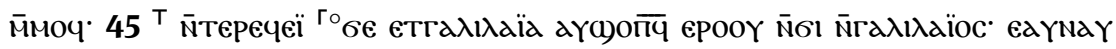

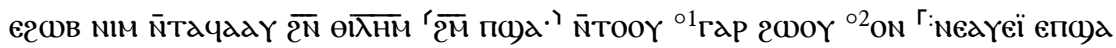

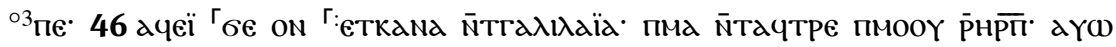

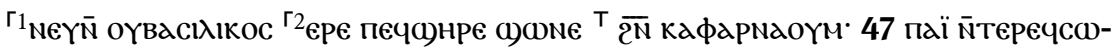

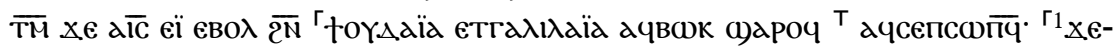

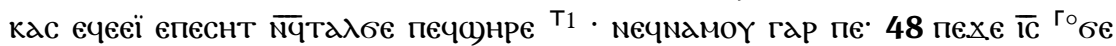

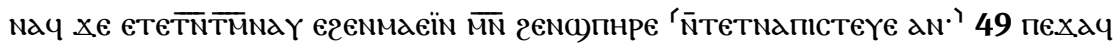

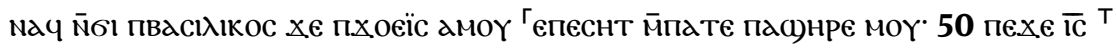

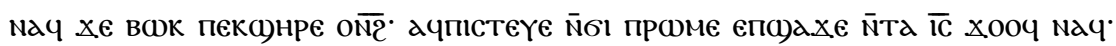

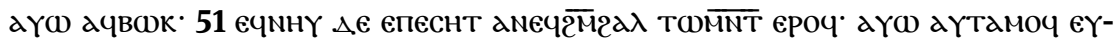

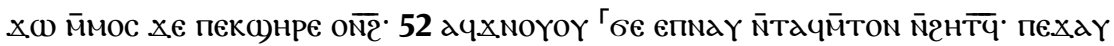

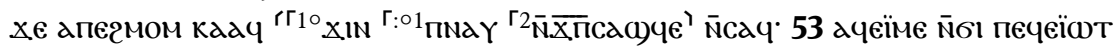

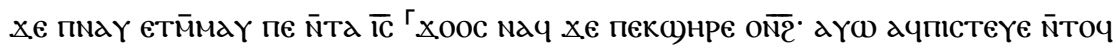

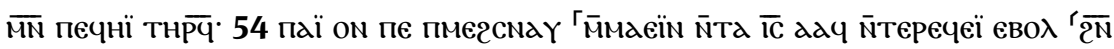

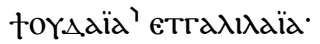

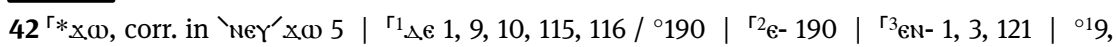

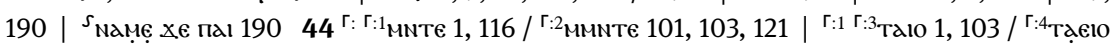

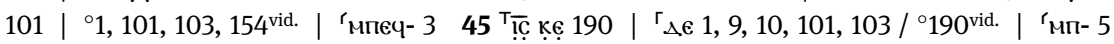

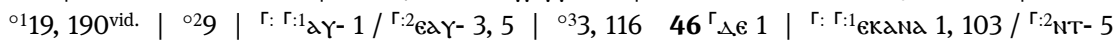

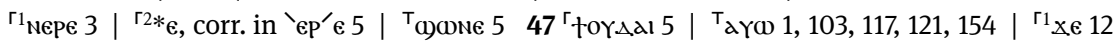

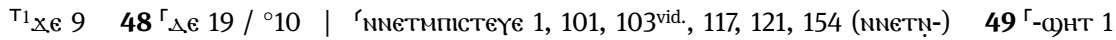

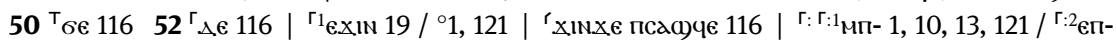

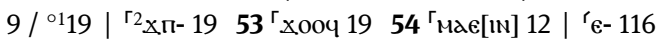

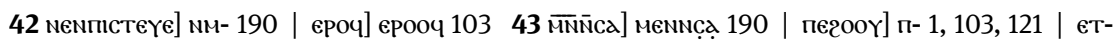

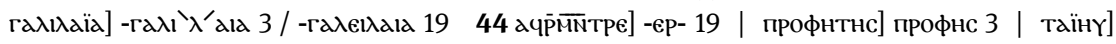

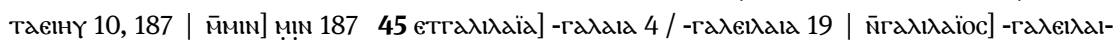

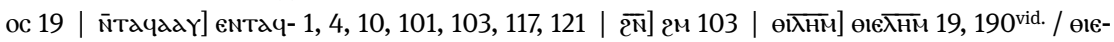

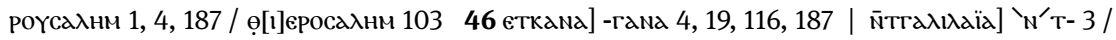

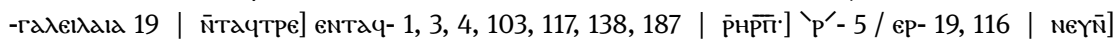

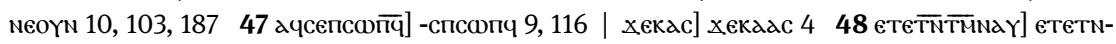

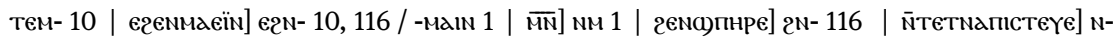

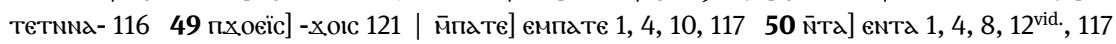
51 томет] томт 121 | аүтамоч] -таммоч 952 мттачм̄тоn] еNтач- 1, 4, 13 vid., 11753 печеїт]

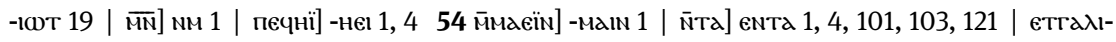

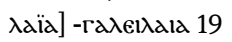




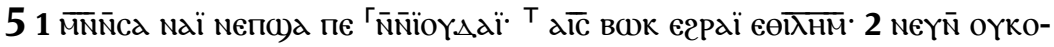

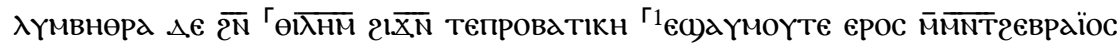

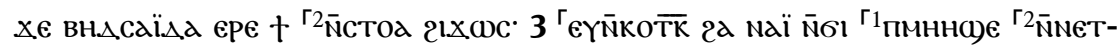

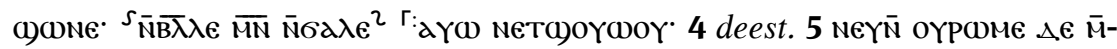

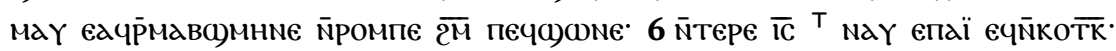

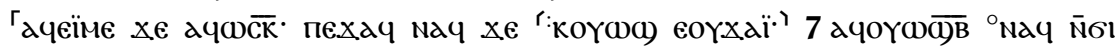

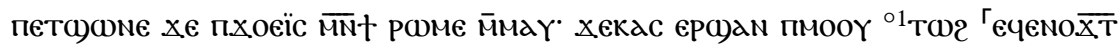

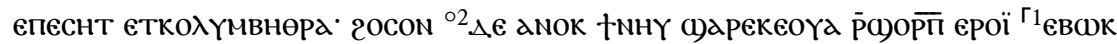

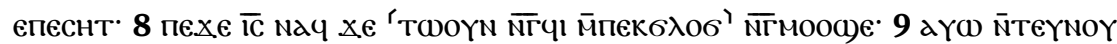
ачоүхаї

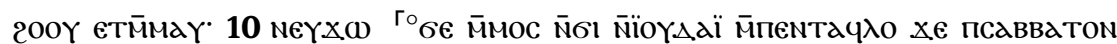

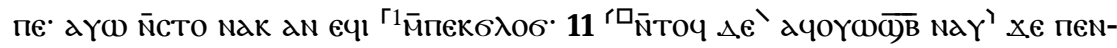

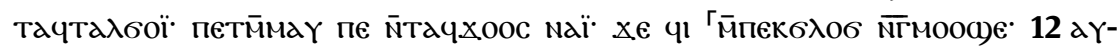

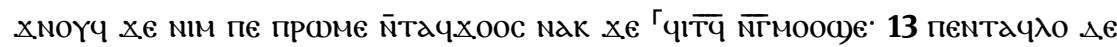

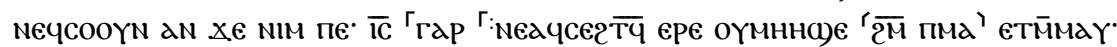

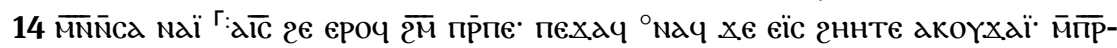

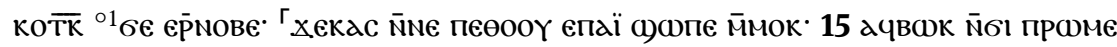

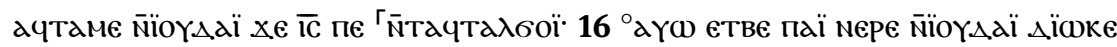

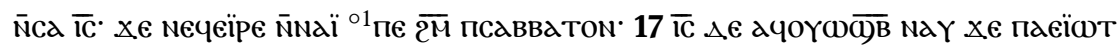

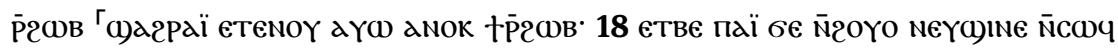

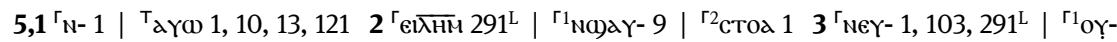

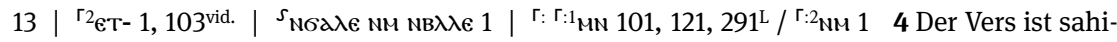

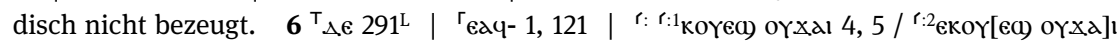

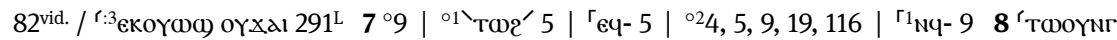

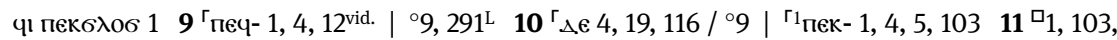

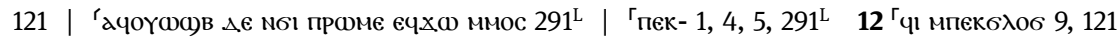

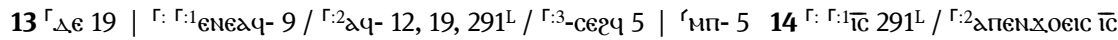

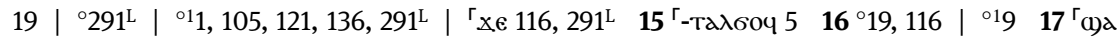
ępal 9

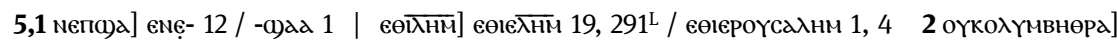

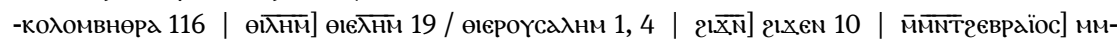

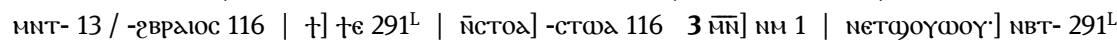

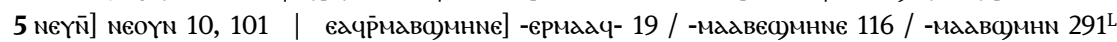

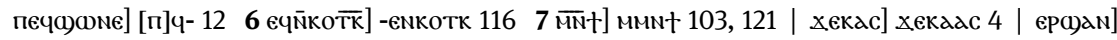

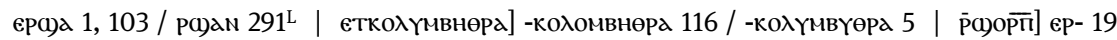

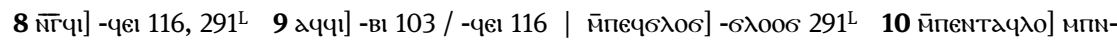

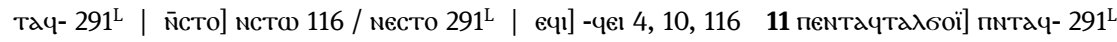

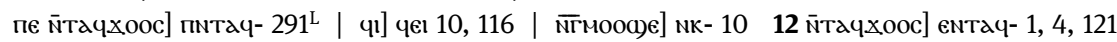

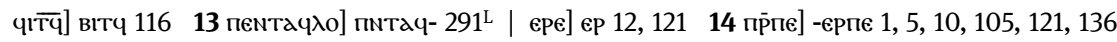

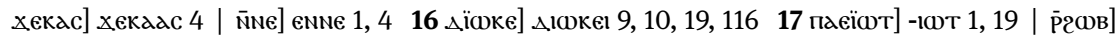

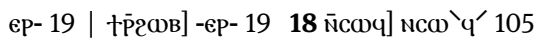




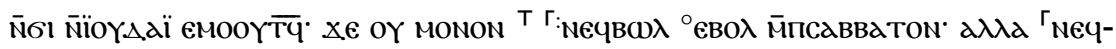

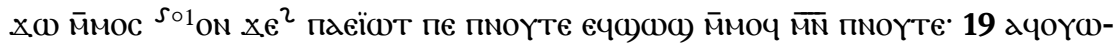

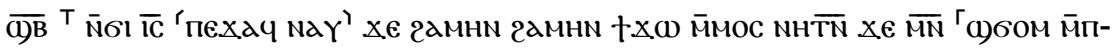

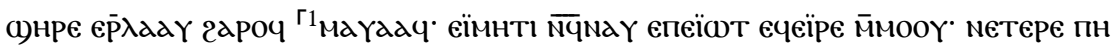

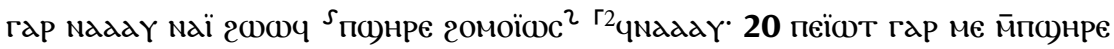

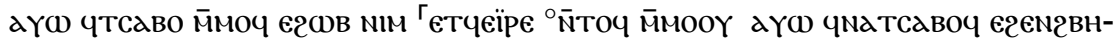

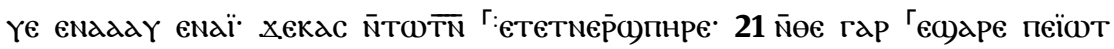

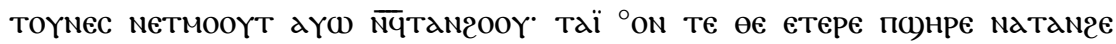

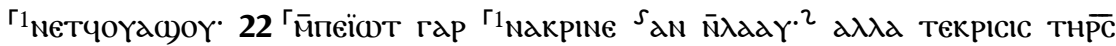

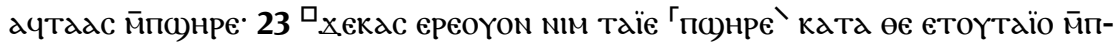

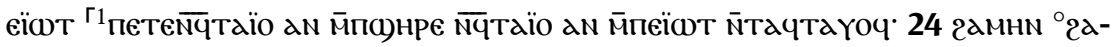

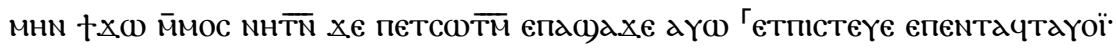

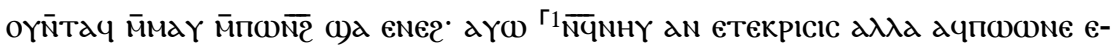

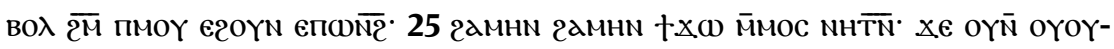

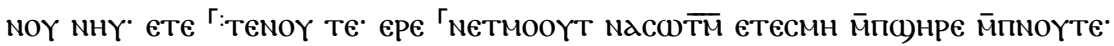

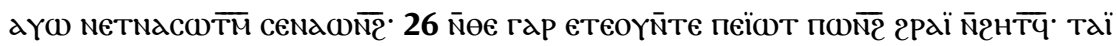

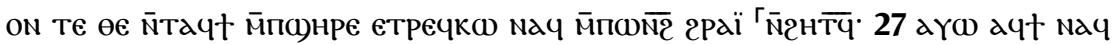

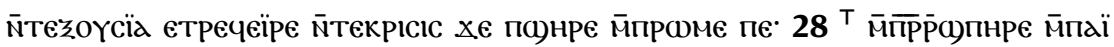

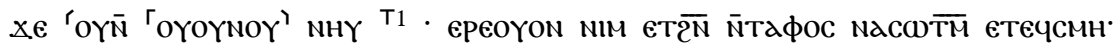

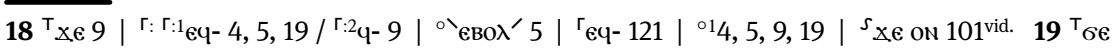

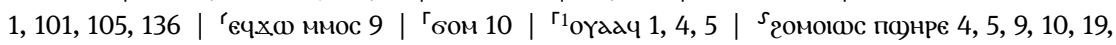

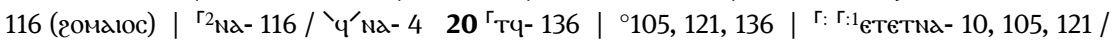

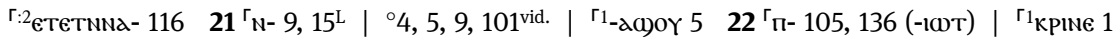

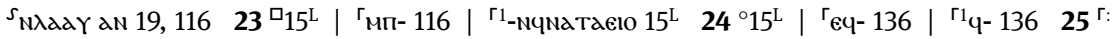

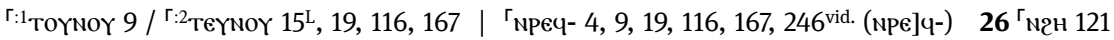

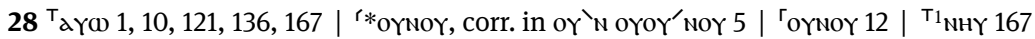

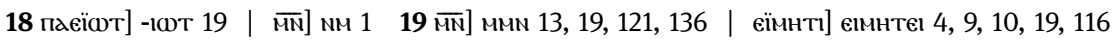

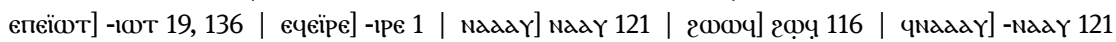

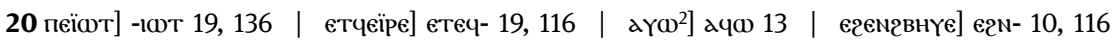

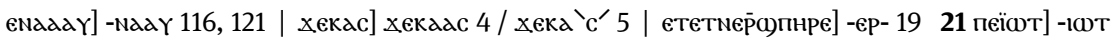

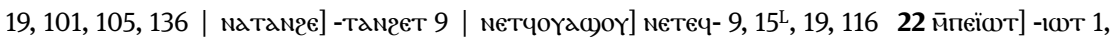

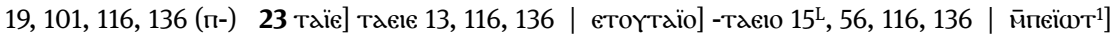

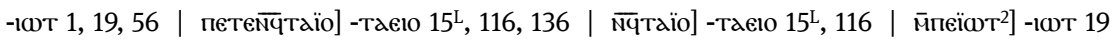

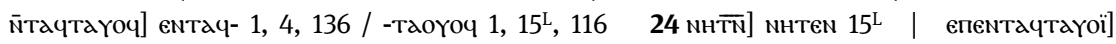

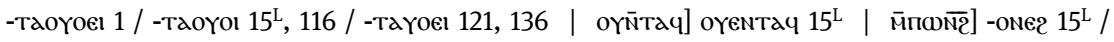

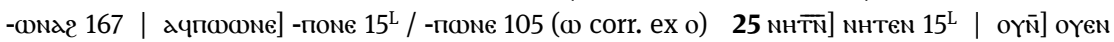

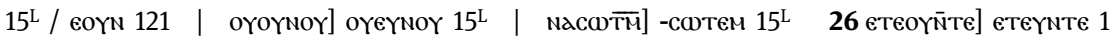

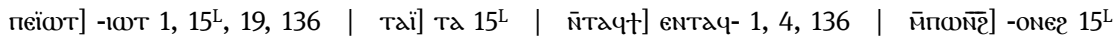

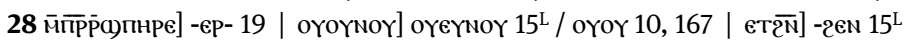




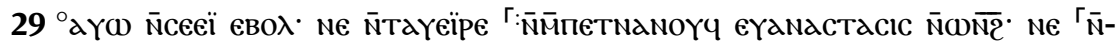

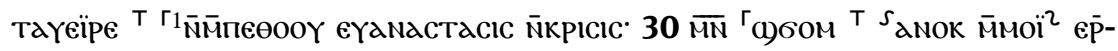

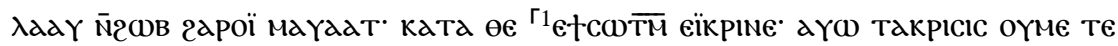

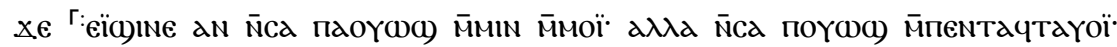

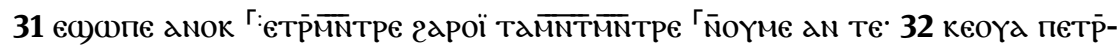

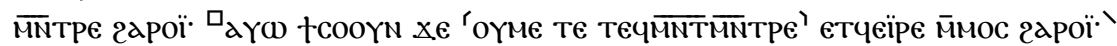

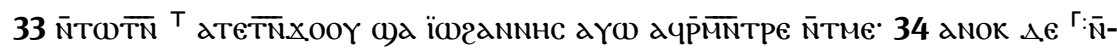

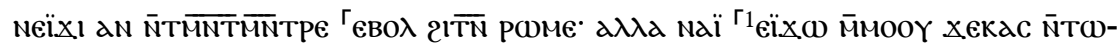

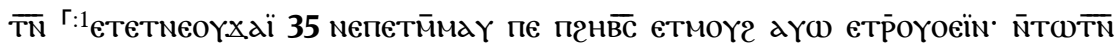

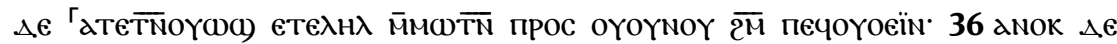

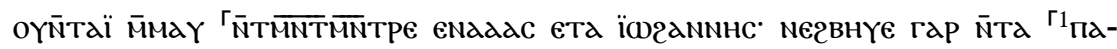

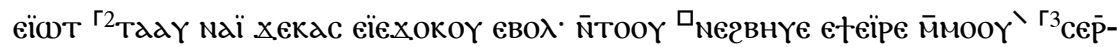

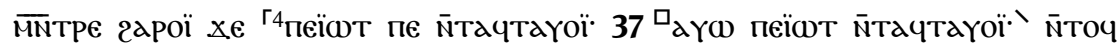

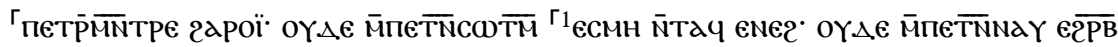

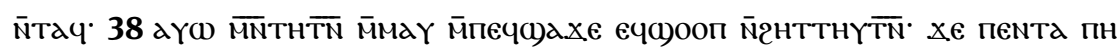

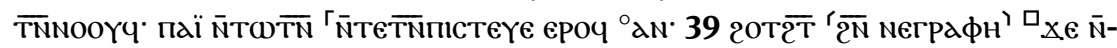

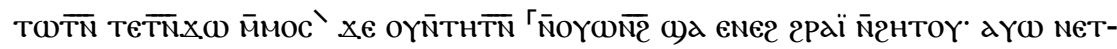

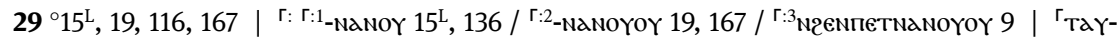

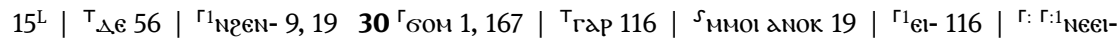

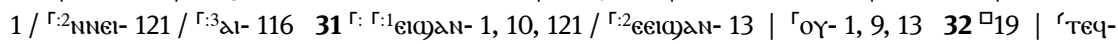
metmitpe [oү]

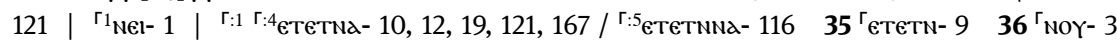

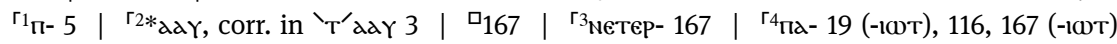

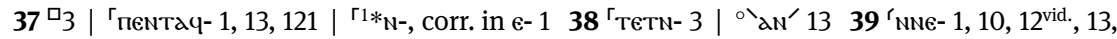

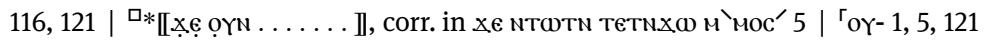

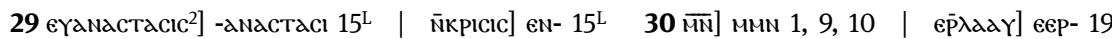

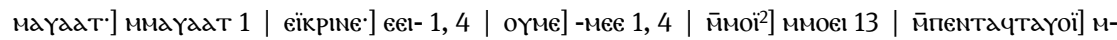

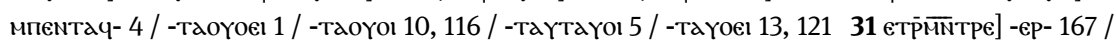

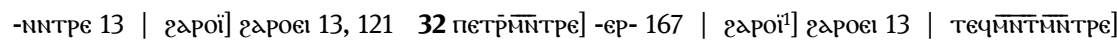

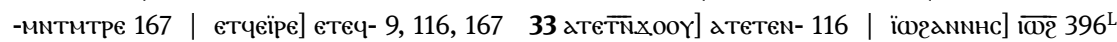

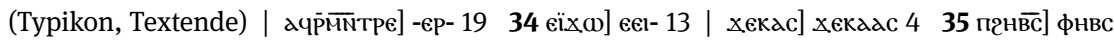

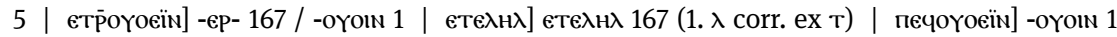

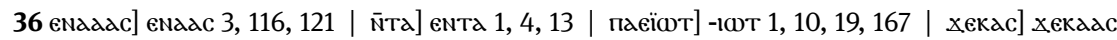

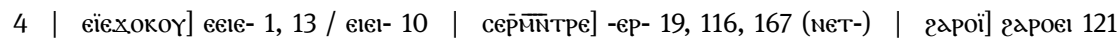

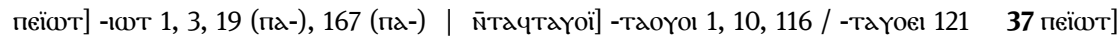

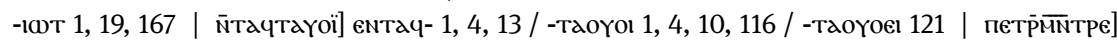

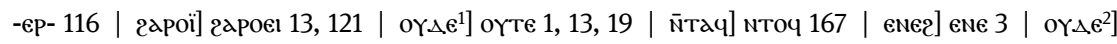

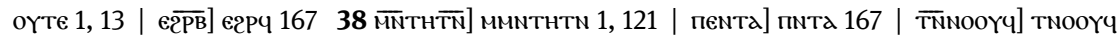

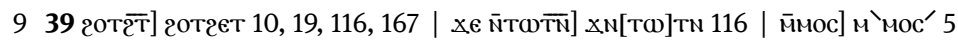




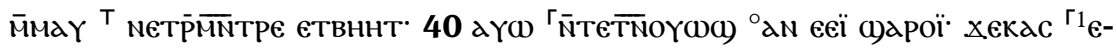

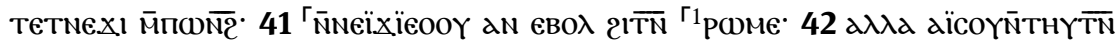

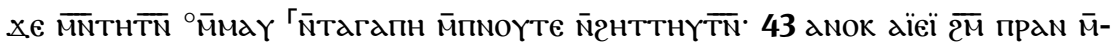

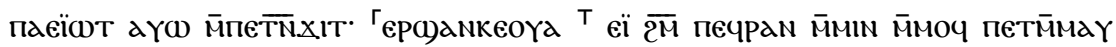

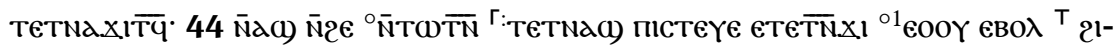
$\overline{T N} \Gamma_{\text {NE }} \overline{T N} \in$ PHY a a

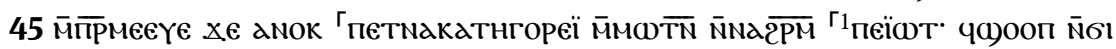

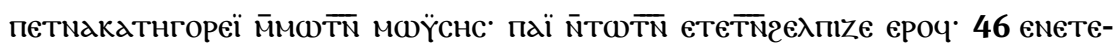

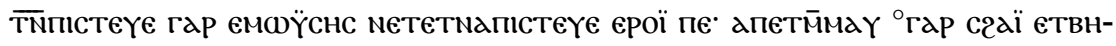

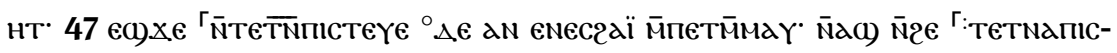
TeYe enac)axe.

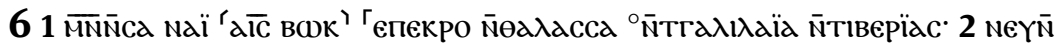

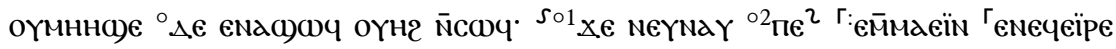

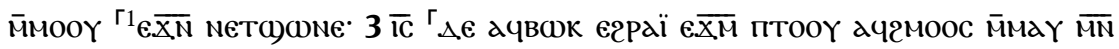

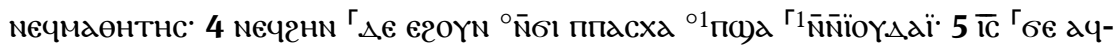

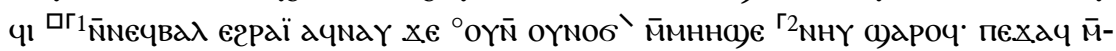

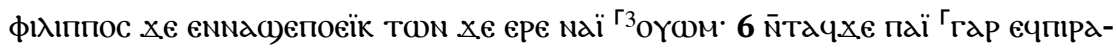

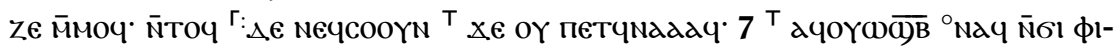

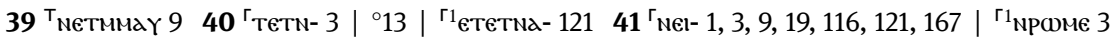
$42{ }^{\circ} 1,9,10,19,121 \mid{ }^{\prime} \mathrm{T}-1,9,10,12143^{\circ}$ 'ec)ape- $\left.1\right|^{\top} \Delta \epsilon$ 9, 13, 19, 116, 121, $16744^{\circ}{ }^{\circ} \mathrm{NT \omega TN}^{\prime}$ 5 | Г: Г:1

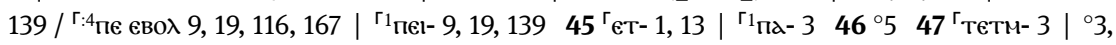

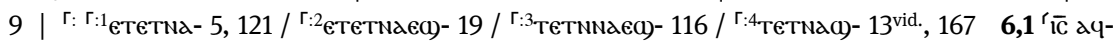
вок 121, 139 | '

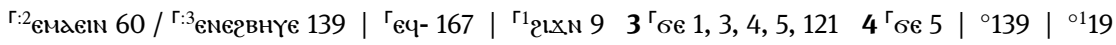

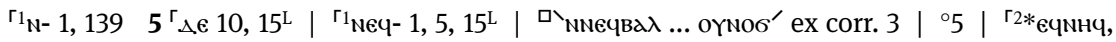

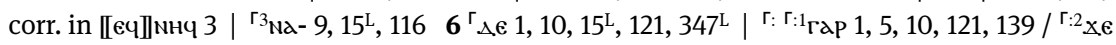

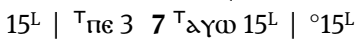

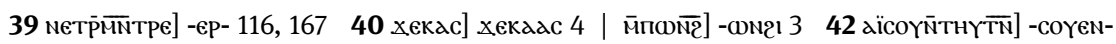

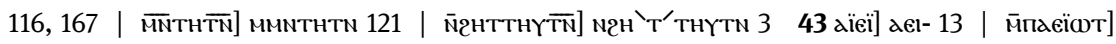

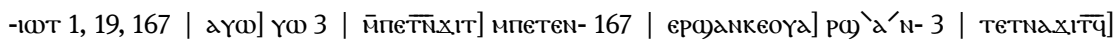

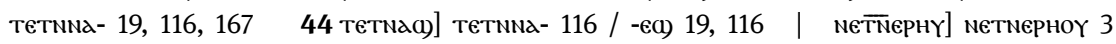

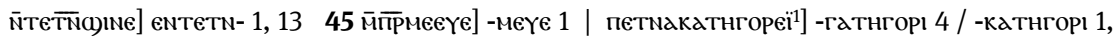

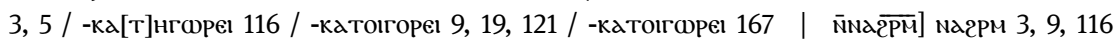
пеїळт] -ıјт 1, 19, 139 | петмакатнгореі²] -гатнгорі 4 / -катнгеı 121 / -катнгорі 1, 3, 5 / -катнгореє 116 / -катоггорег 9, 19, 16746 еметет̄ппстеүе] емететм- 3 | мететнапістеүе] мететN-

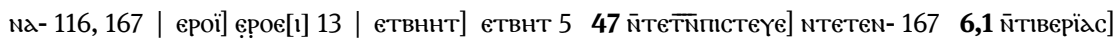

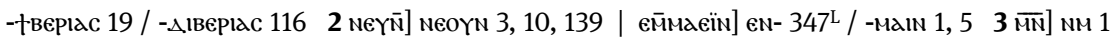

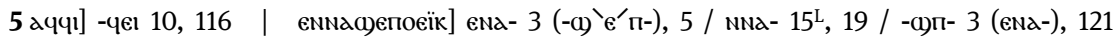

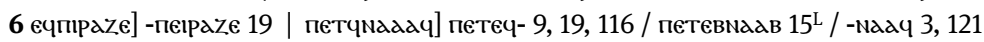




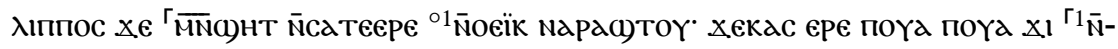

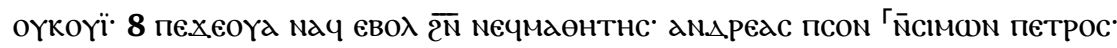

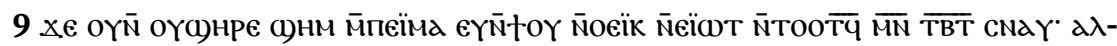

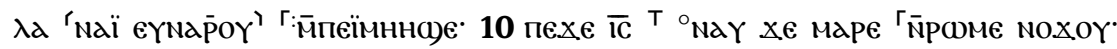

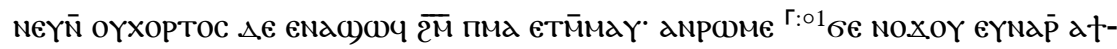

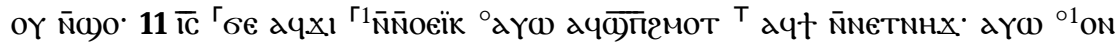

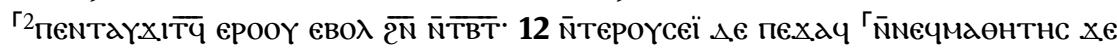

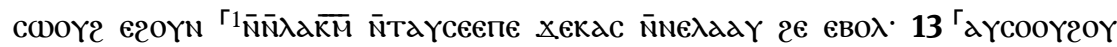

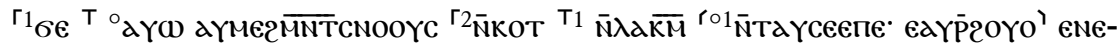

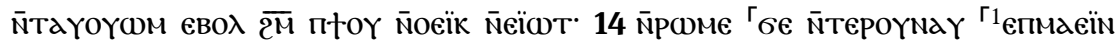

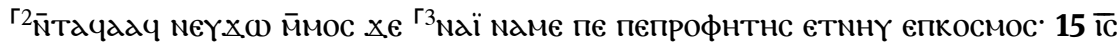

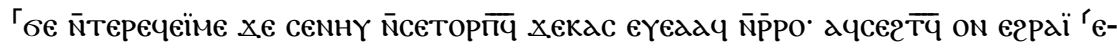

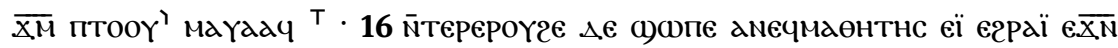

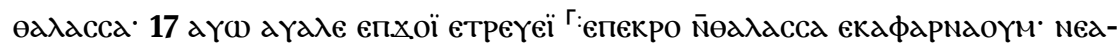

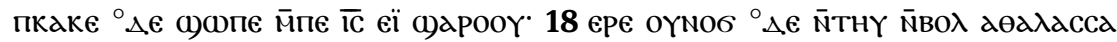

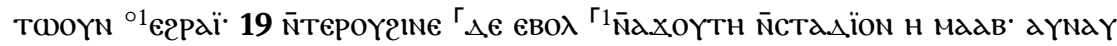

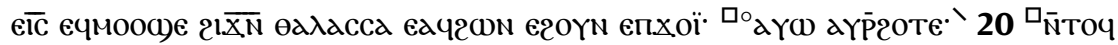

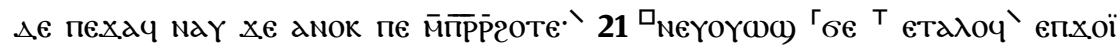

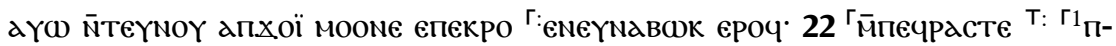

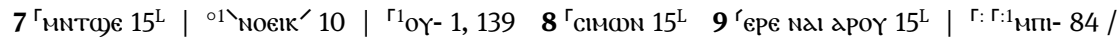

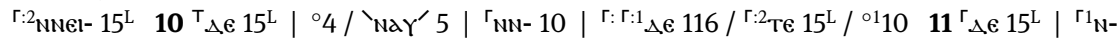

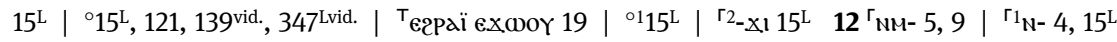

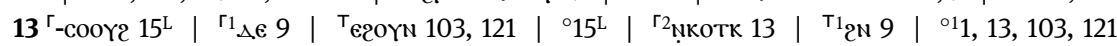

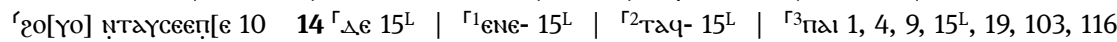

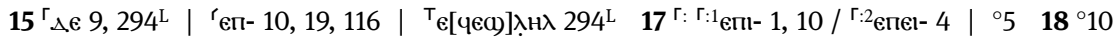

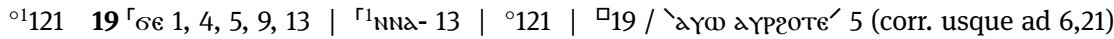

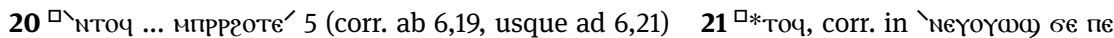

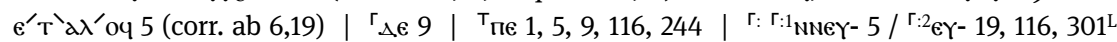

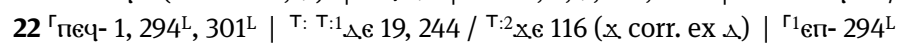

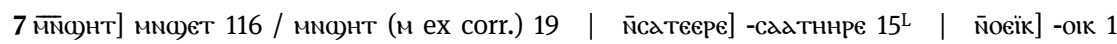

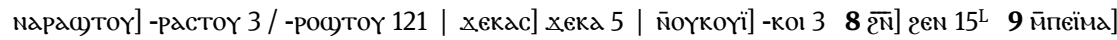

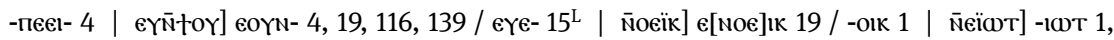

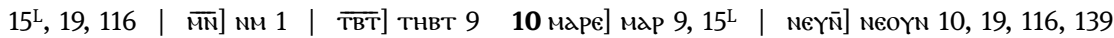

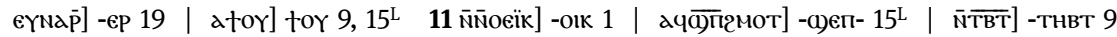

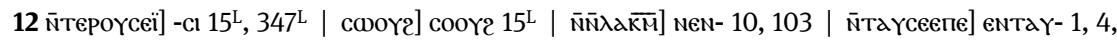

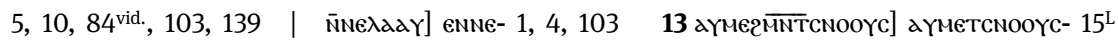

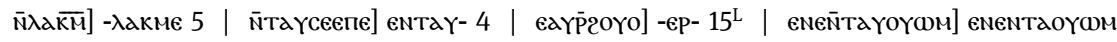

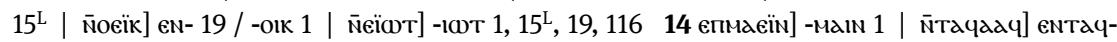

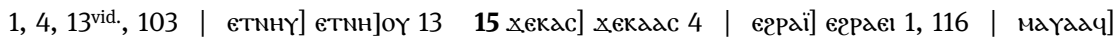

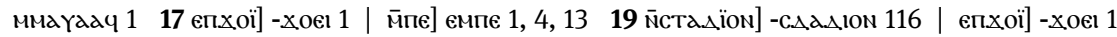

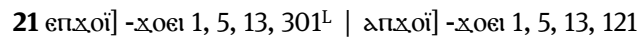




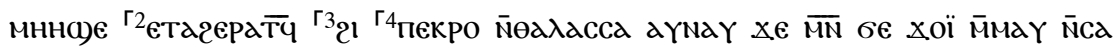

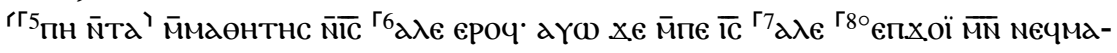

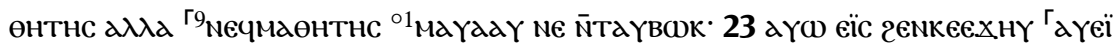

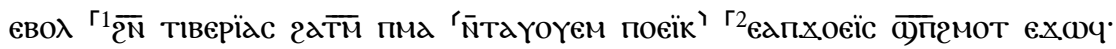

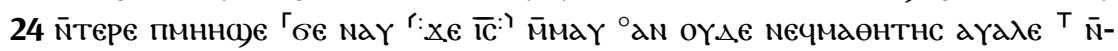

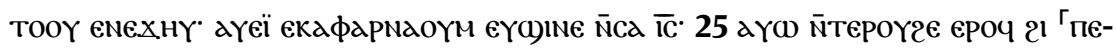

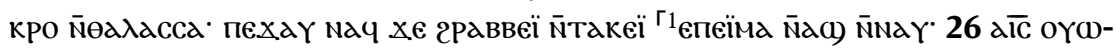

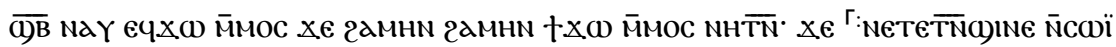

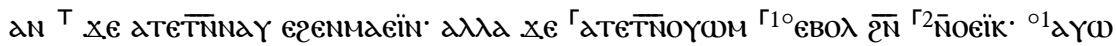

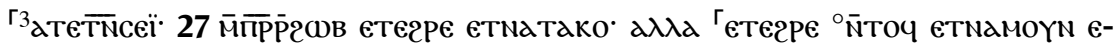

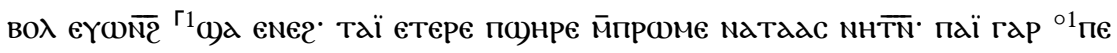

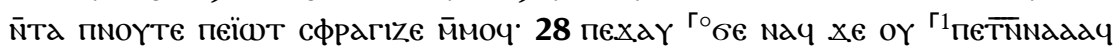

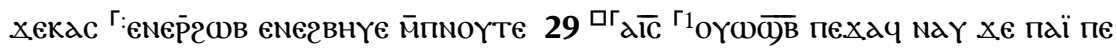

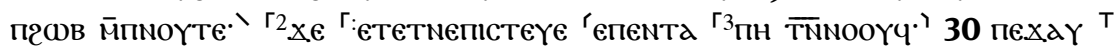

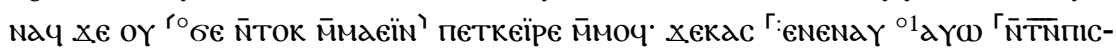

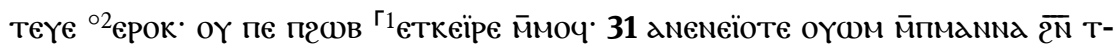

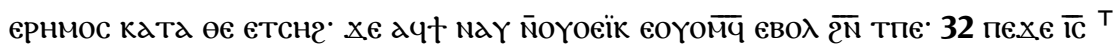

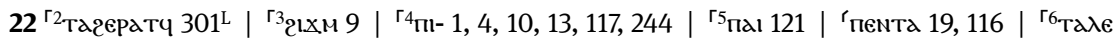

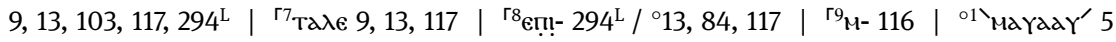

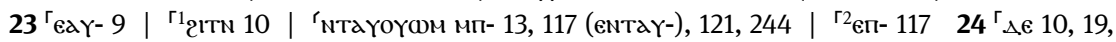

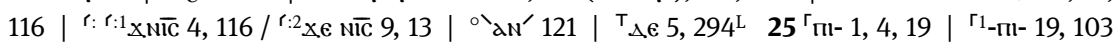

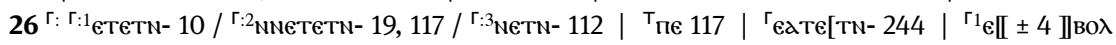

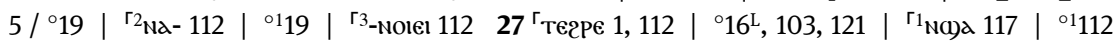

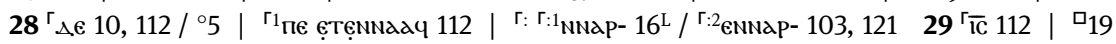

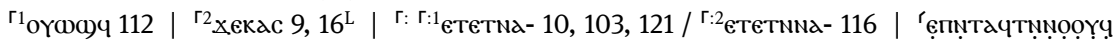

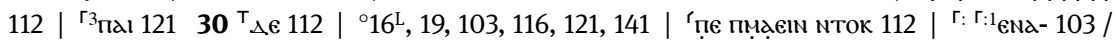

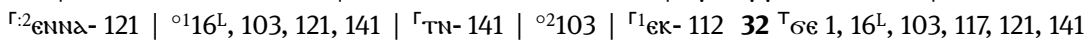

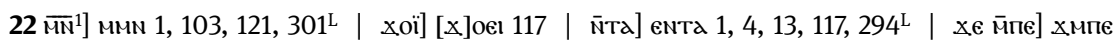

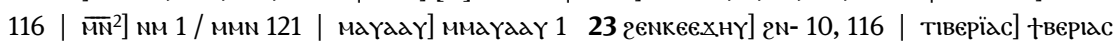

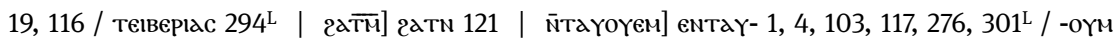

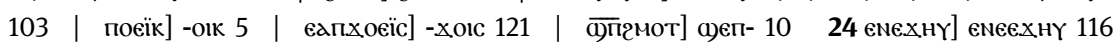

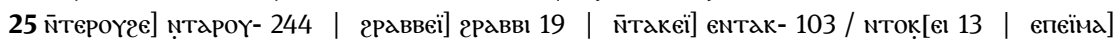

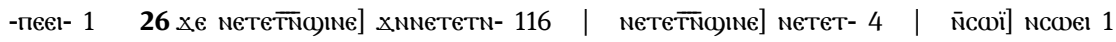

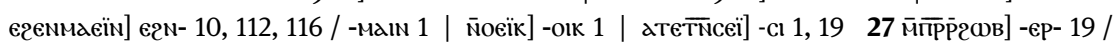

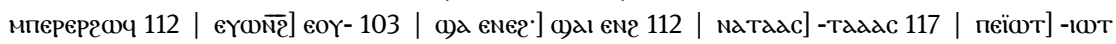

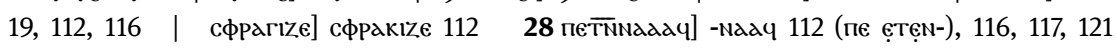

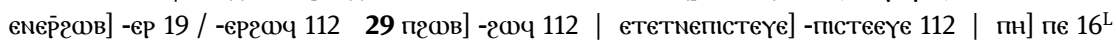

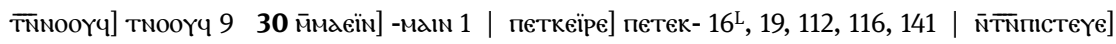

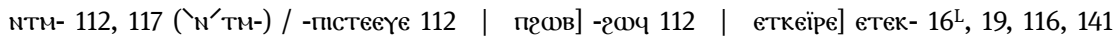
31 амемеїоте] -ооте 19, 112, 141 | тернмос] -еремос 112 | м̄оүоєік] -окк 1, 5 | еоүомч] еүомч 1 


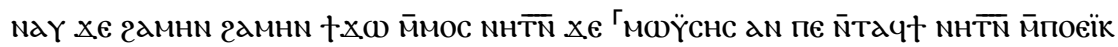

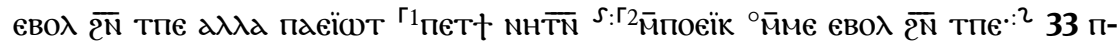

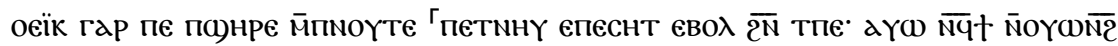

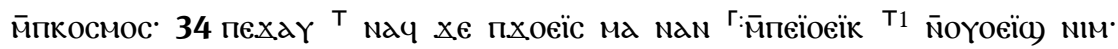

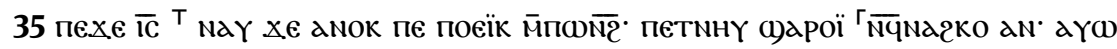

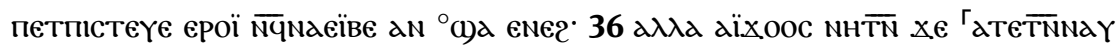

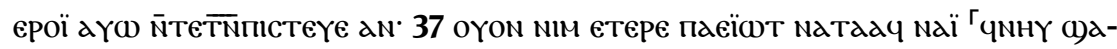

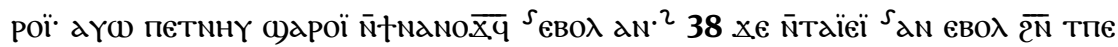

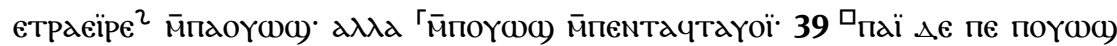

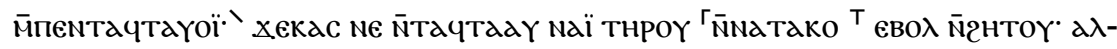

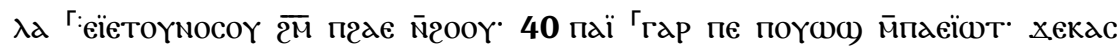

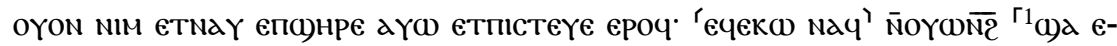

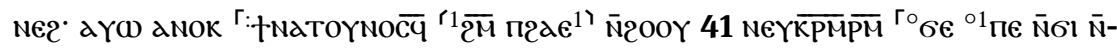

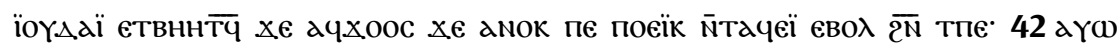

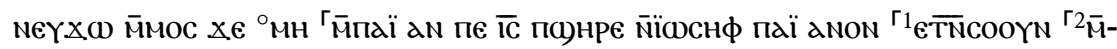

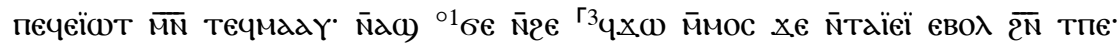

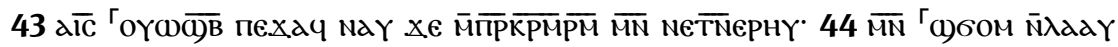

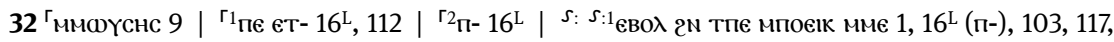

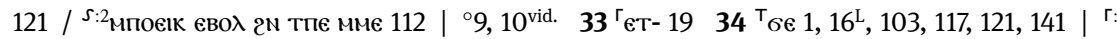

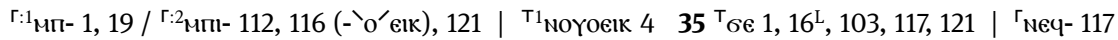

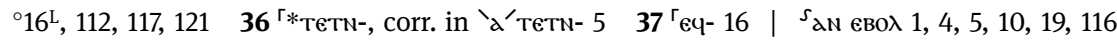

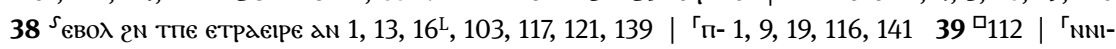

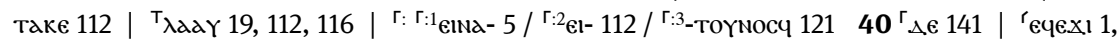

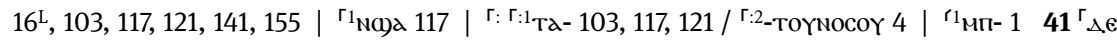

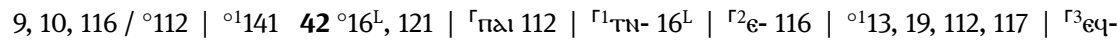

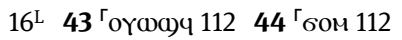

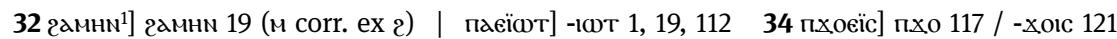

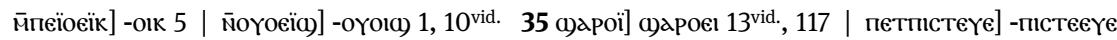

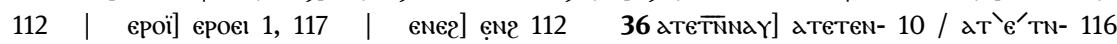

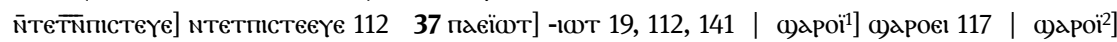

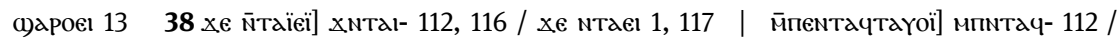

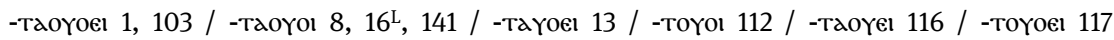

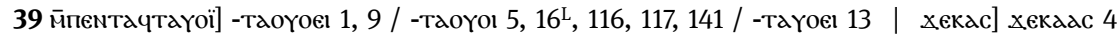

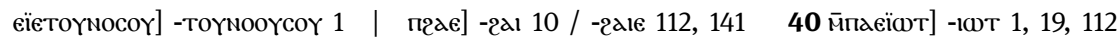

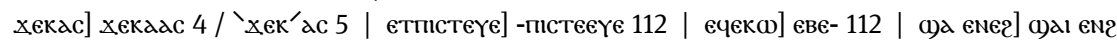

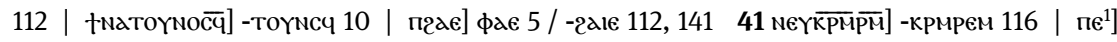

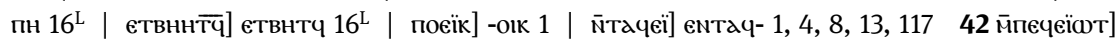

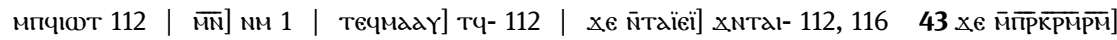

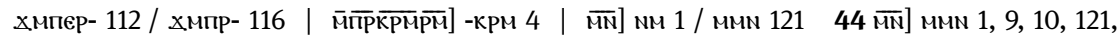
$136^{\text {vid. }} \mid \overline{\mathrm{N}} \lambda$ daY $] \lambda-1$ 


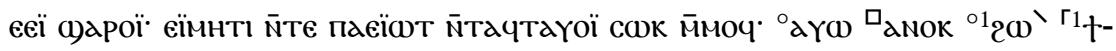

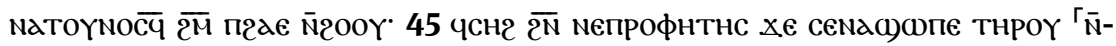

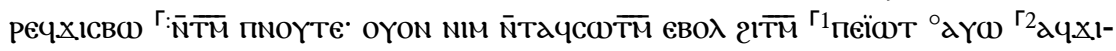

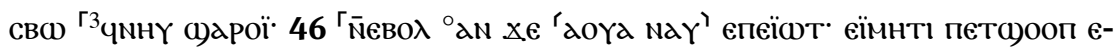

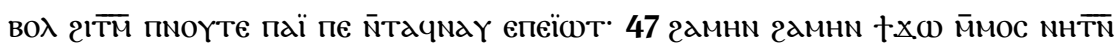

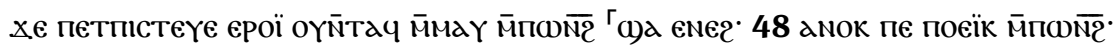

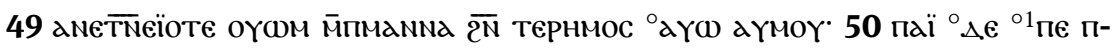

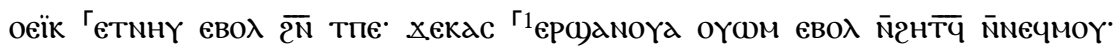

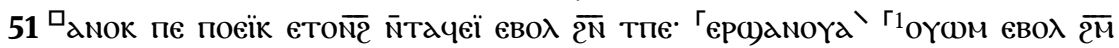

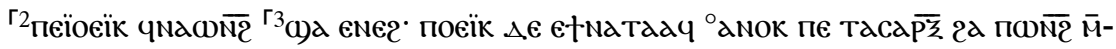

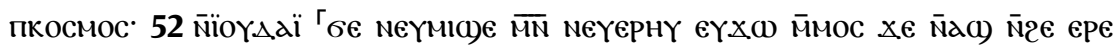

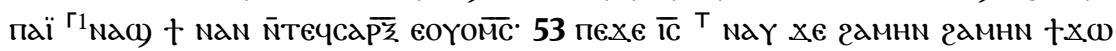

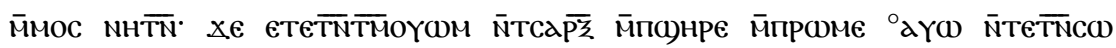

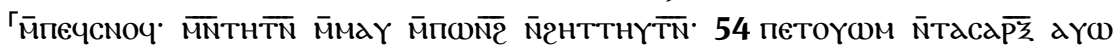

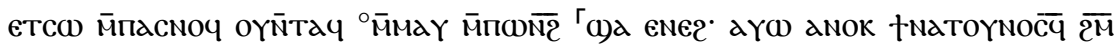

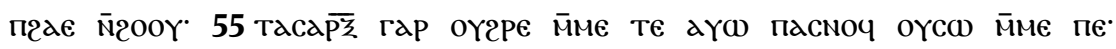

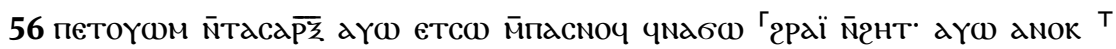

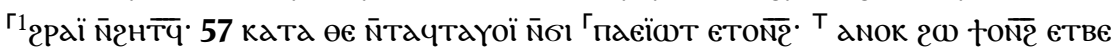

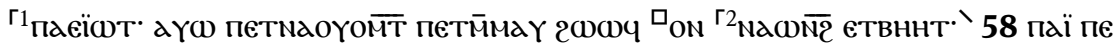

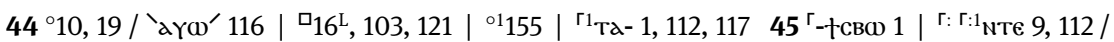

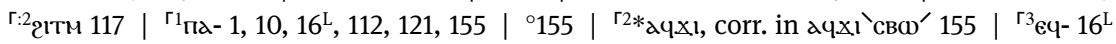

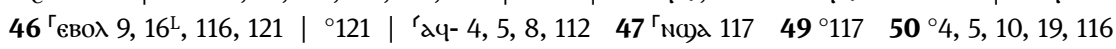

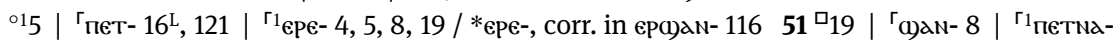

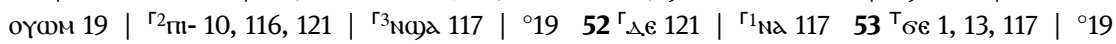
Г

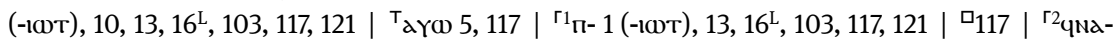
$5,8,9$

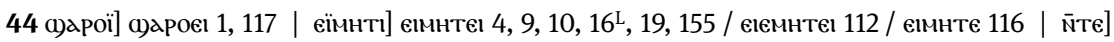

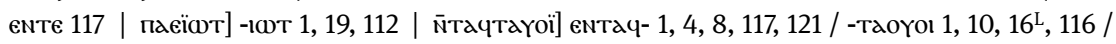

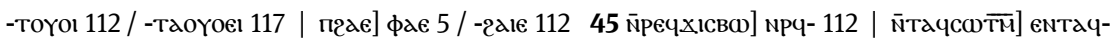

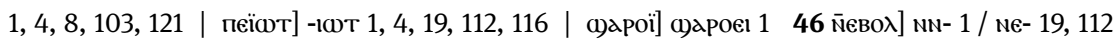

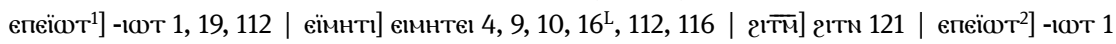

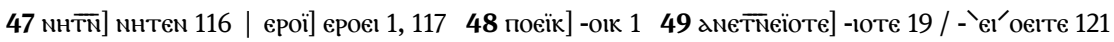

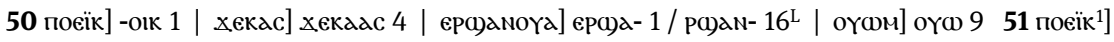

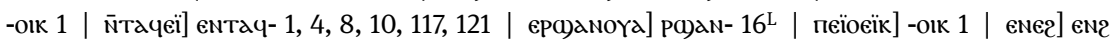

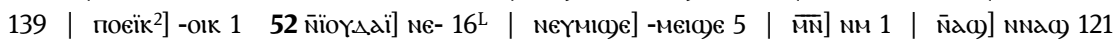

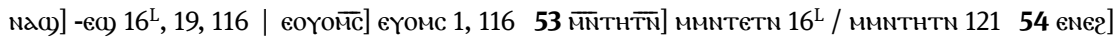

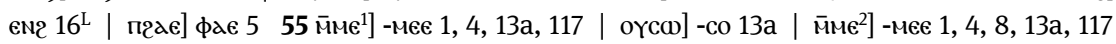

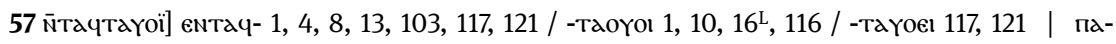

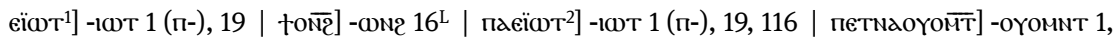
4, 5 / -оүмт 8 | етвннт] етвнт 5 


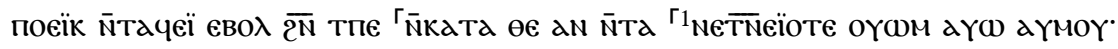

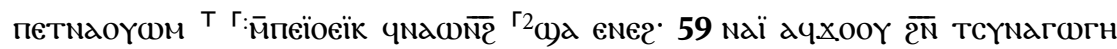

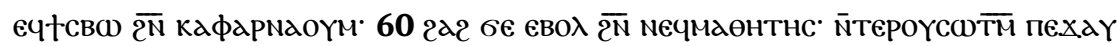

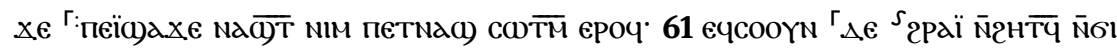

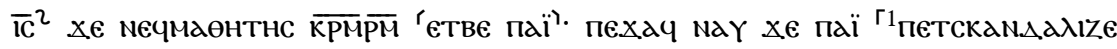

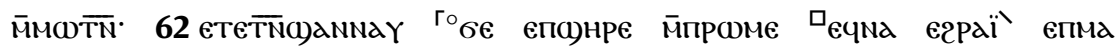

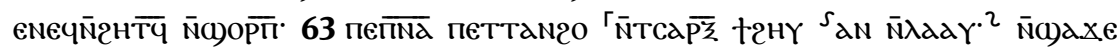

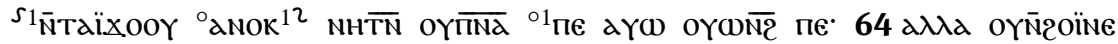

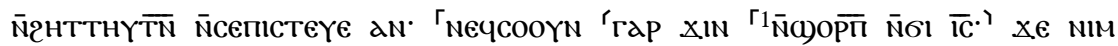

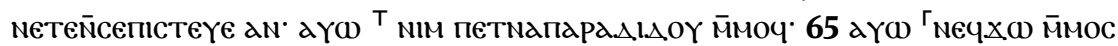
Хє етвє паї аїхоос NHTN $x \in \overline{M N}{ }^{\ulcorner 1}$ ()

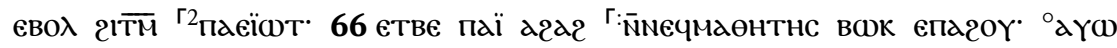

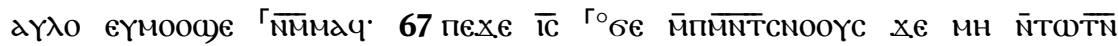

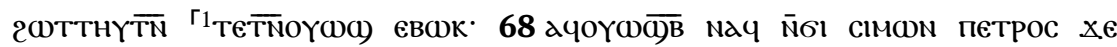

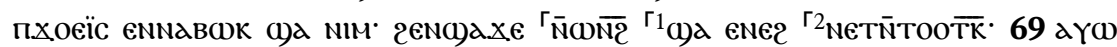

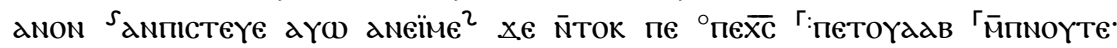

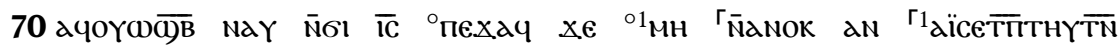
Mா"

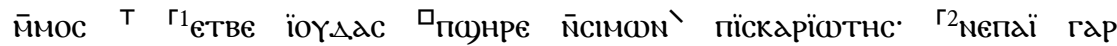

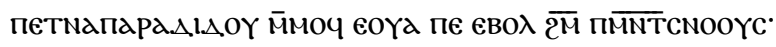

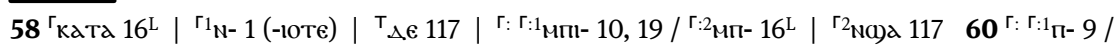

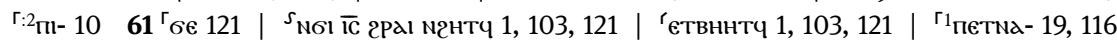

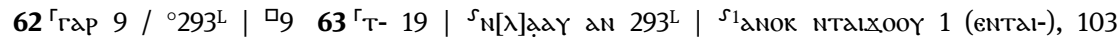

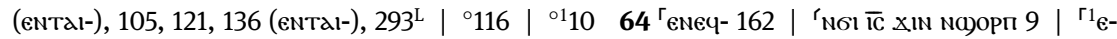

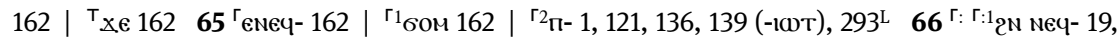

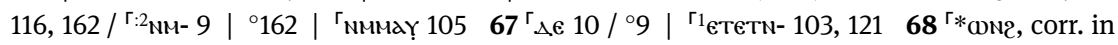

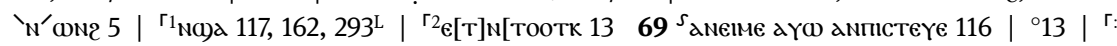

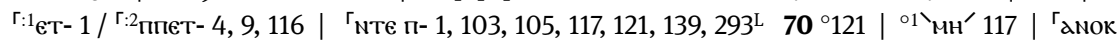
1, 10, 13, 105 | ${ }^{\Gamma 1}$ пє мталсетптнүтм 4, 5, 9, 19, 116 (-септнүтм), 136, $162 \quad 71{ }^{\ulcorner}$емеч- 162 | ${ }^{\circ} 117$

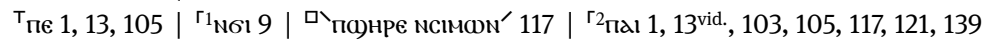

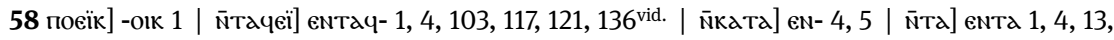

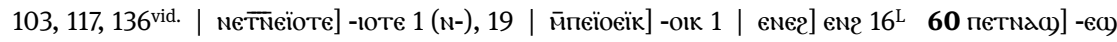

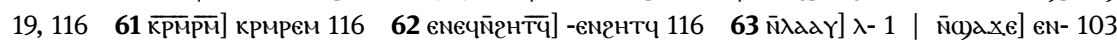

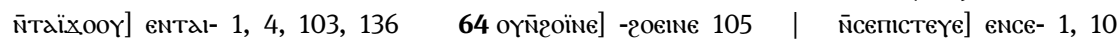
метейсепістеүе] мет- 19, 116 / -пістеү 10365 хе етве] хетве 121 | Мм] ммм 1, 10, 103, 121, 139,

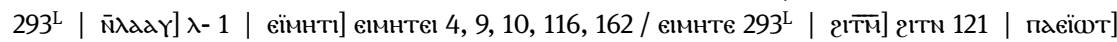

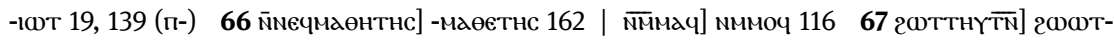

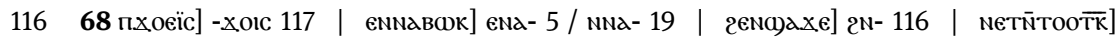

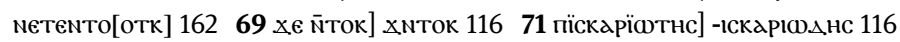




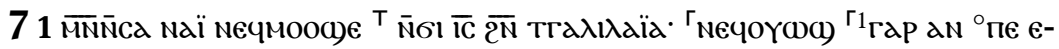

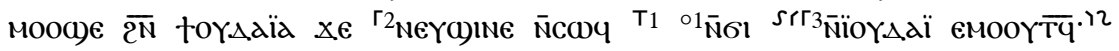

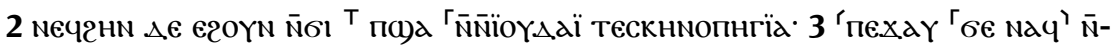

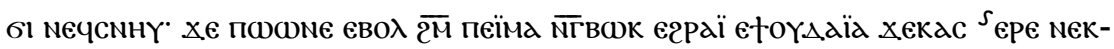

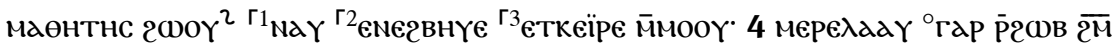

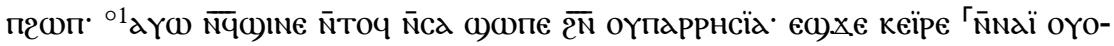

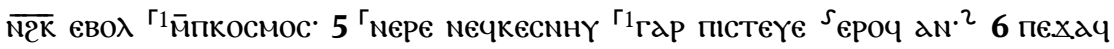

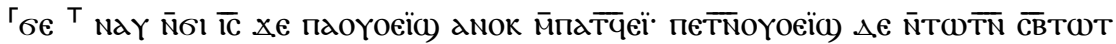

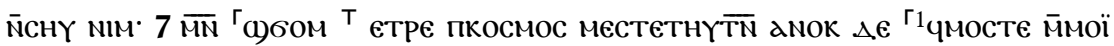

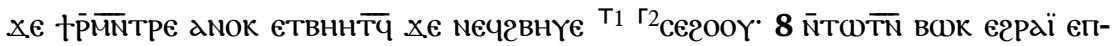

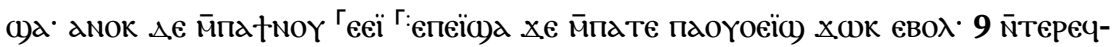

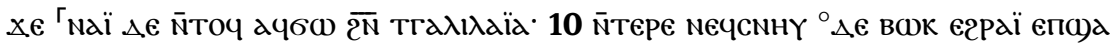

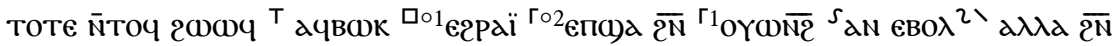

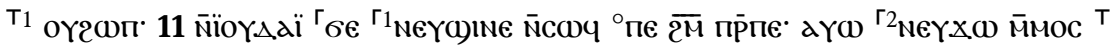

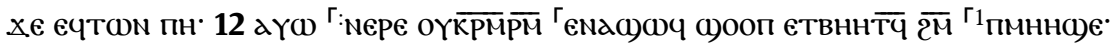

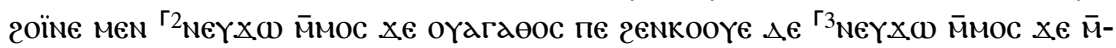

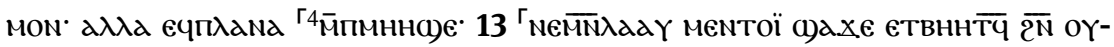

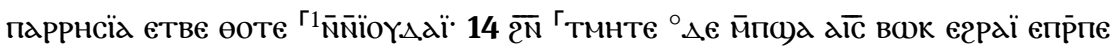

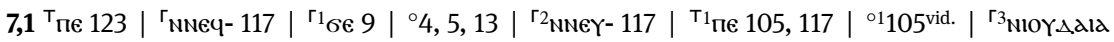

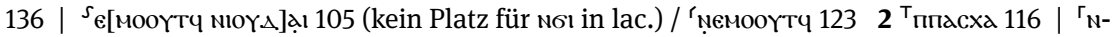

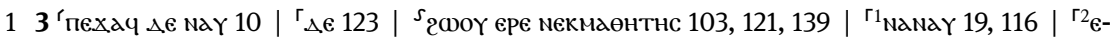

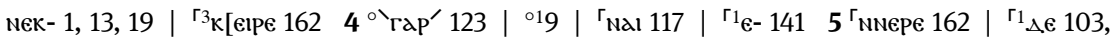

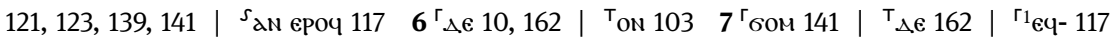

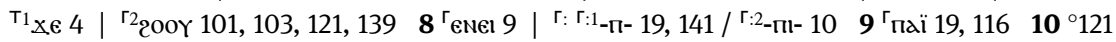

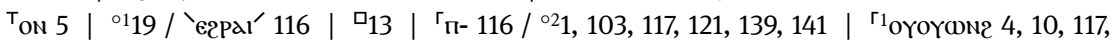

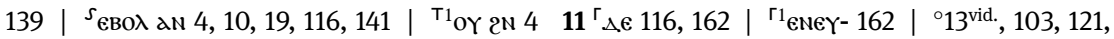

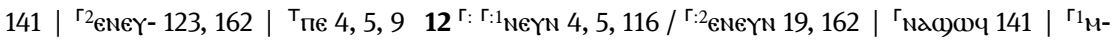

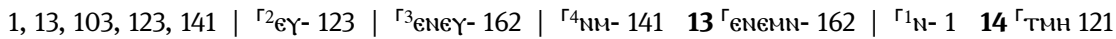
${ }^{\circ} 15^{\mathrm{L}} /{ }^{\prime} \epsilon^{\prime}{ }^{\prime} 19$

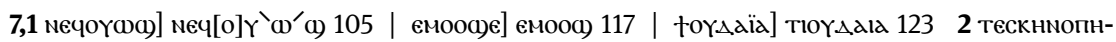
гїа] -скүмопнгіа 9 / -скүмопогга 19 / -скемопегіа 116 / -скнмопүгіа 1233 пеїма] пеєl- 4 | хєекас] хекадс 4 | мекмдөнтнс] мек]мдеєтнс 162 | еткеїе] етек- 9, 19, 116, 1234 реров] ер- 116,

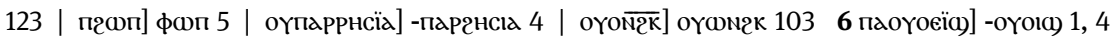

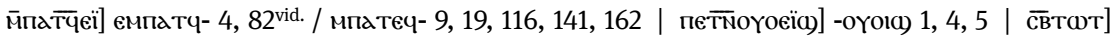

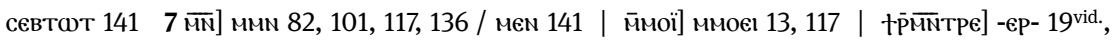

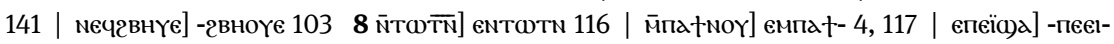

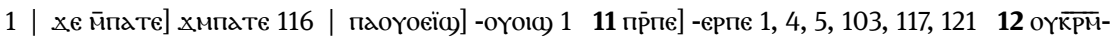

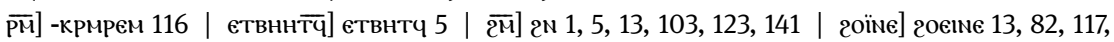

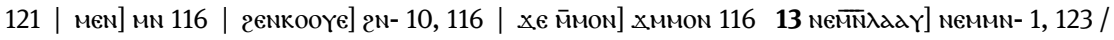

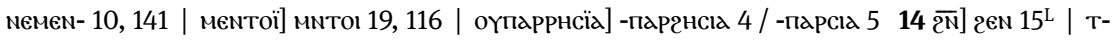

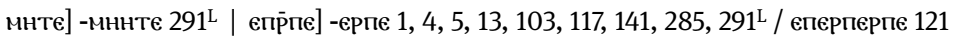




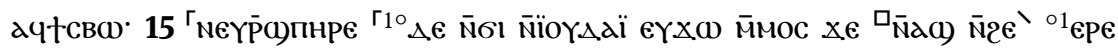

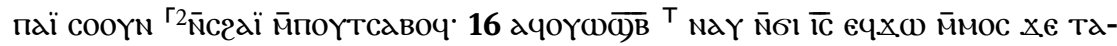

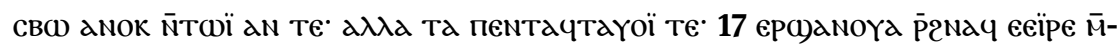

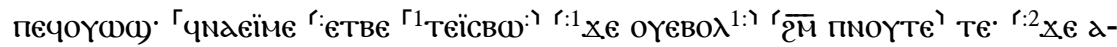

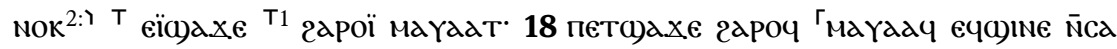

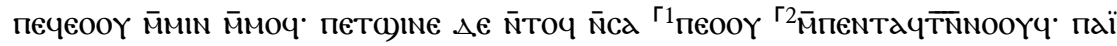

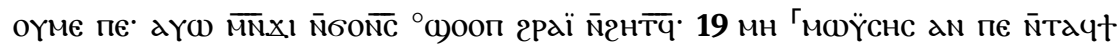

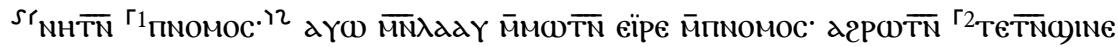

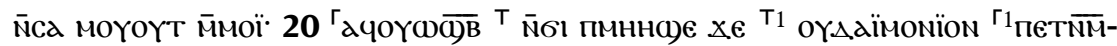

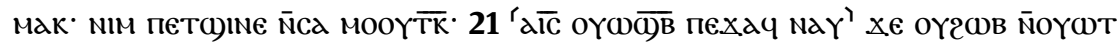

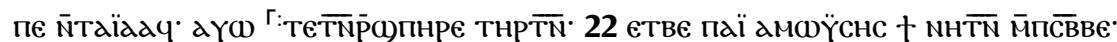

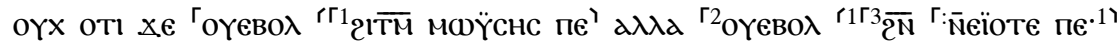

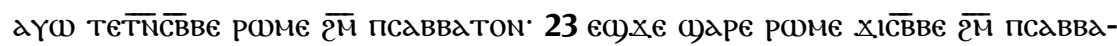

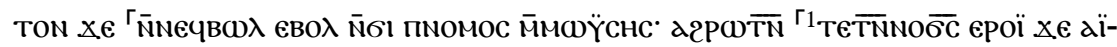

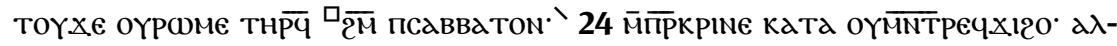

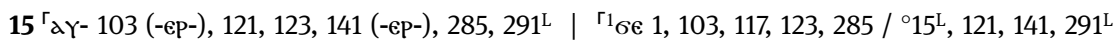

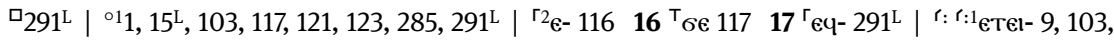

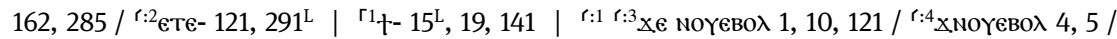

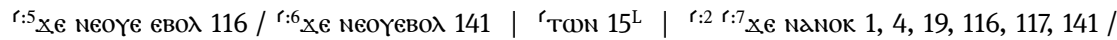

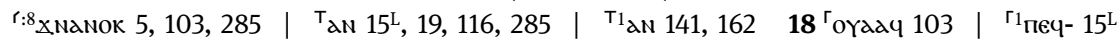

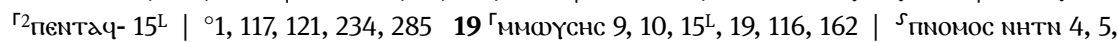

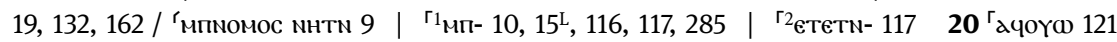

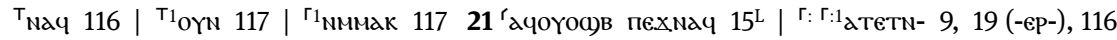

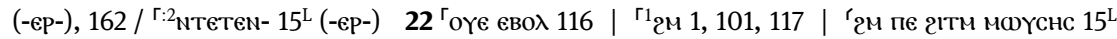

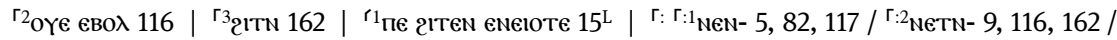

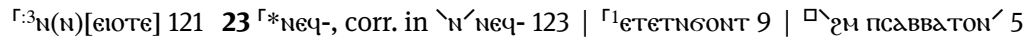

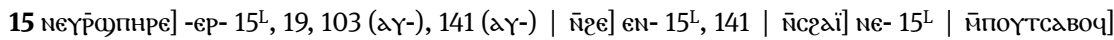

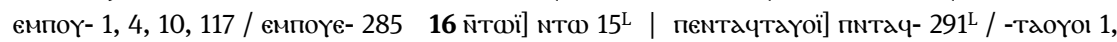

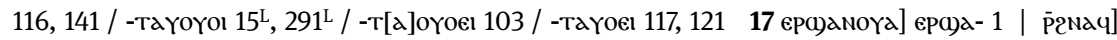

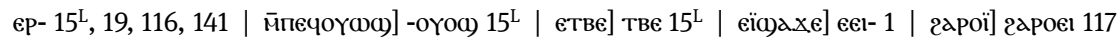

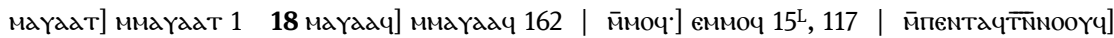

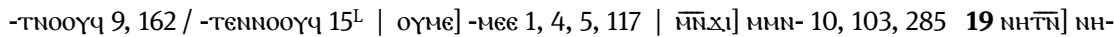

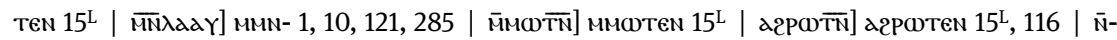

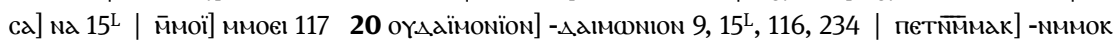

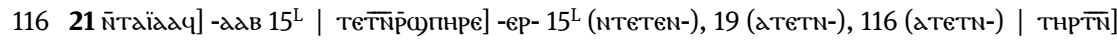

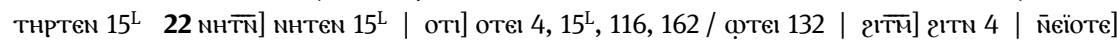

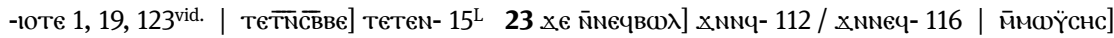

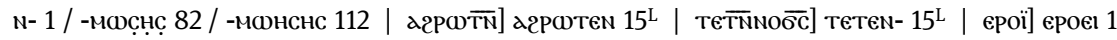

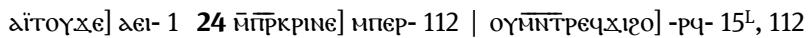




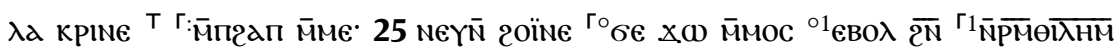

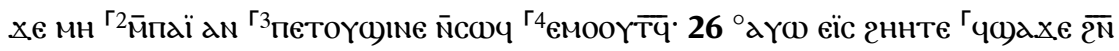

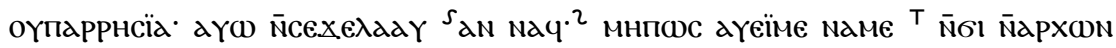

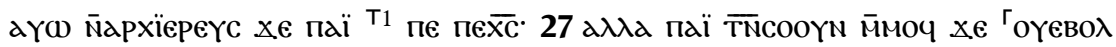

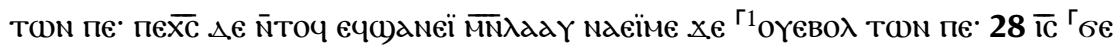

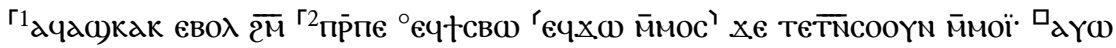

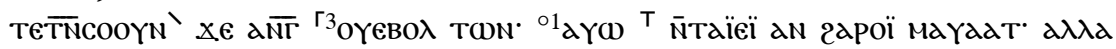

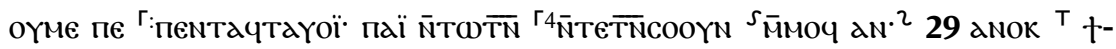

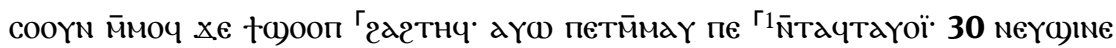

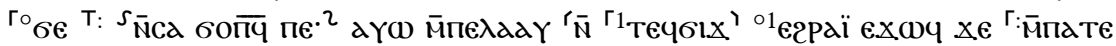

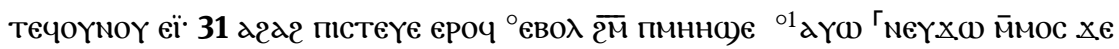

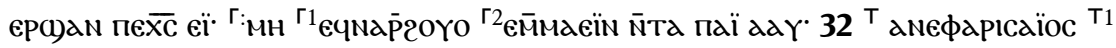

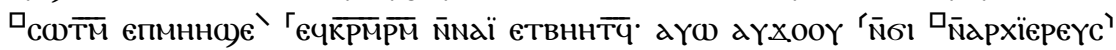

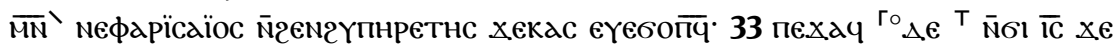

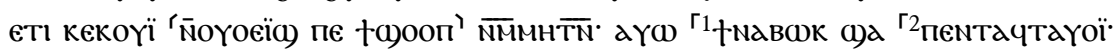

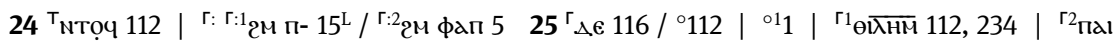

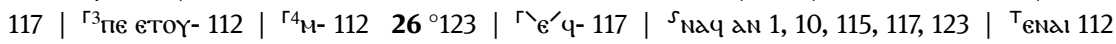

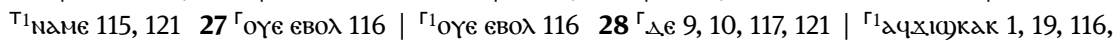

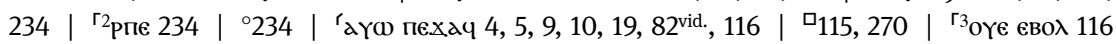

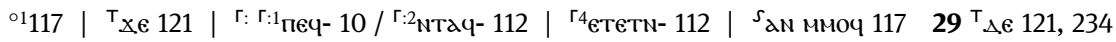

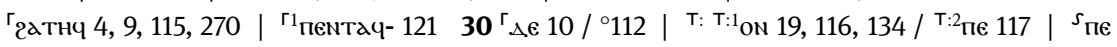

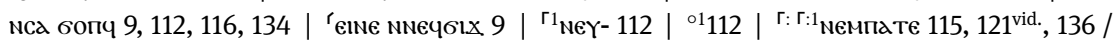
г:2

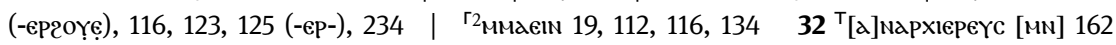

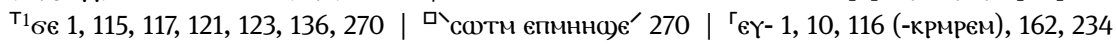

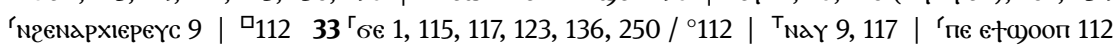

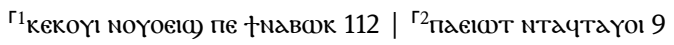

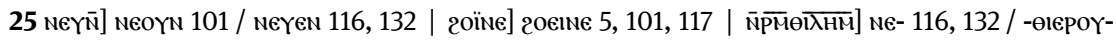
салнм 1, 4 / -өеє

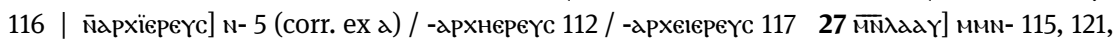

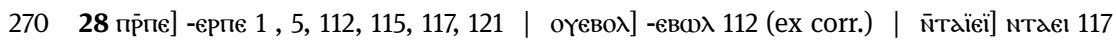

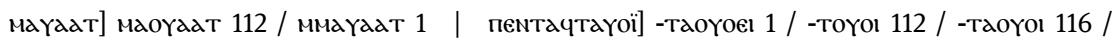

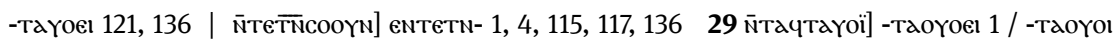

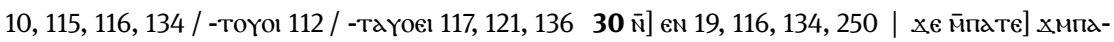

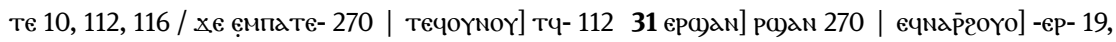

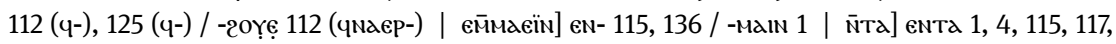

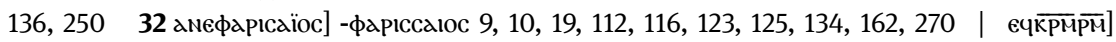

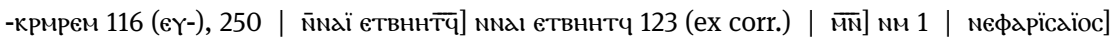

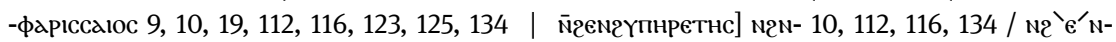
123 / -гүперетнс 9, 10, 116, 123 / -гнперетнс 19 / -геперетнс 112 / -әүпернтнс 125, 23433 еті]

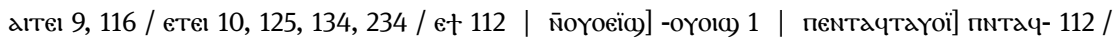

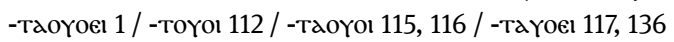




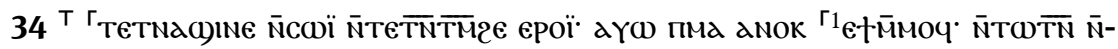

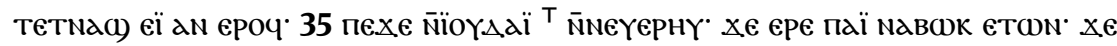

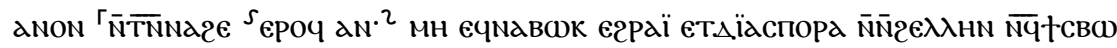

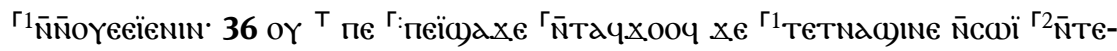

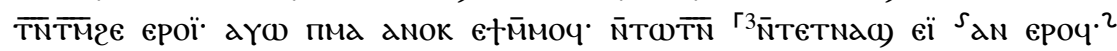

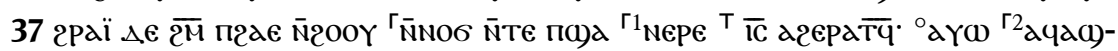

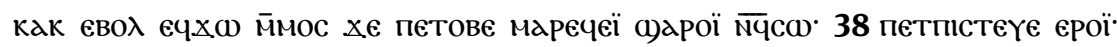

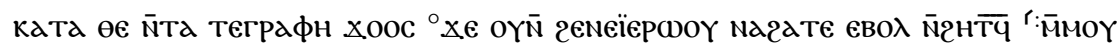

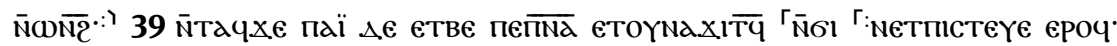

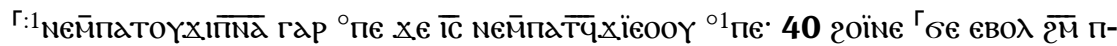

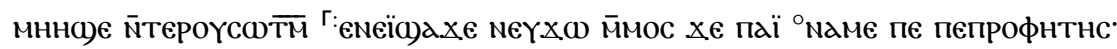

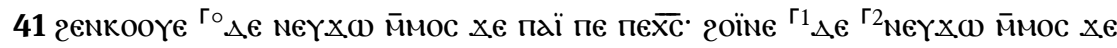

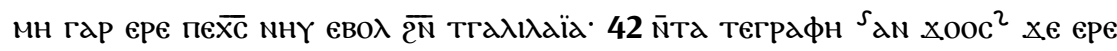

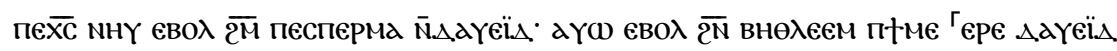

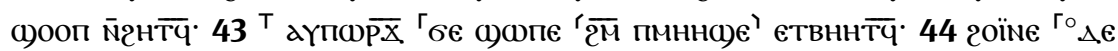

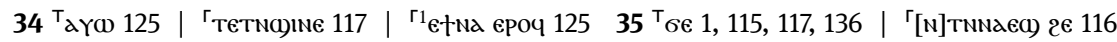

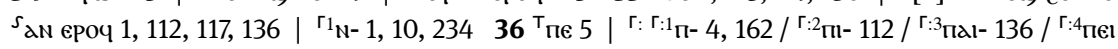

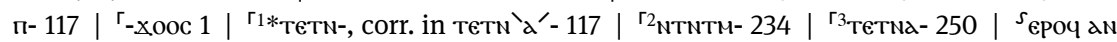

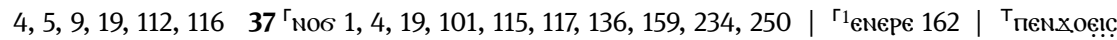

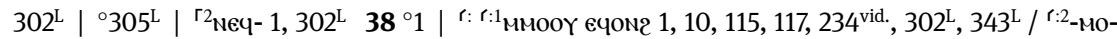

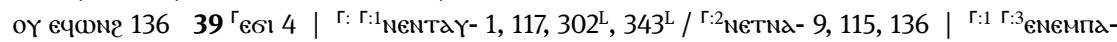

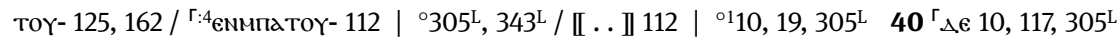

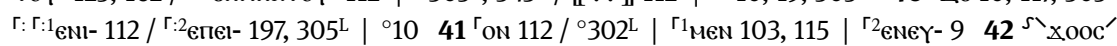
an 125 | ' ' $305^{\mathrm{L}} 44^{\mathrm{r}}{ }^{\circ} \mathrm{G} 9,19,116,197 /{ }^{\circ} 4,5,112,159$

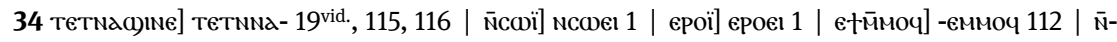

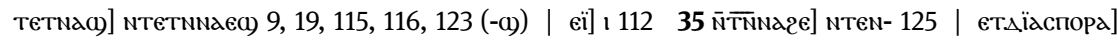

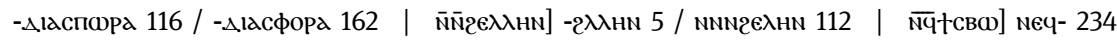

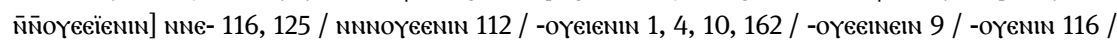
-oүeeinin 12536 йтачхооч] entaq- 1, 4, 101, 115, 117, 136, 250 | тетnacoine] тетnnd- 9, 19, 101,

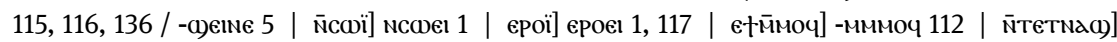

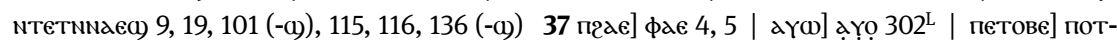

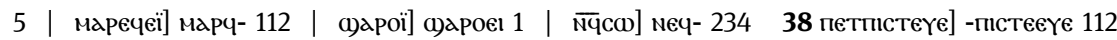

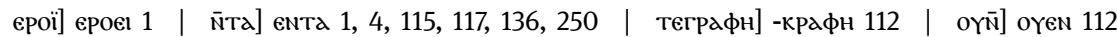

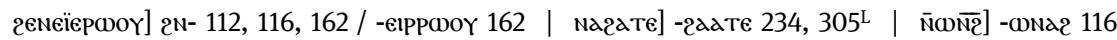

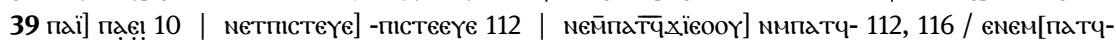

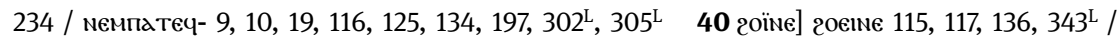

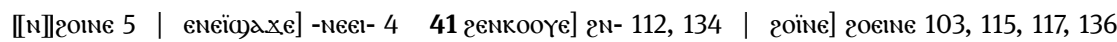

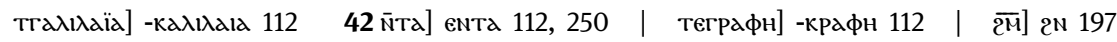

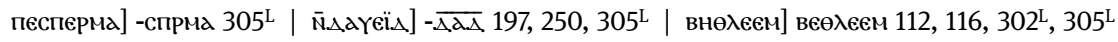

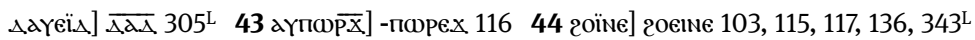




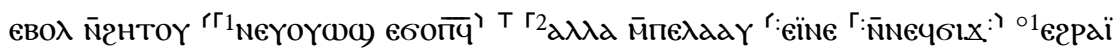

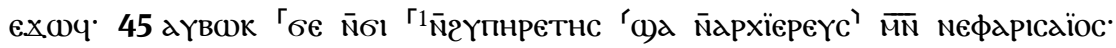

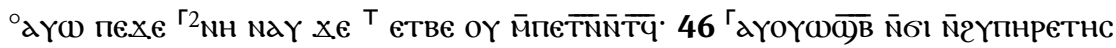

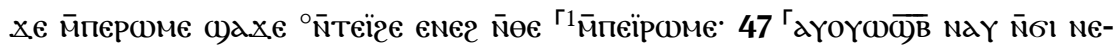

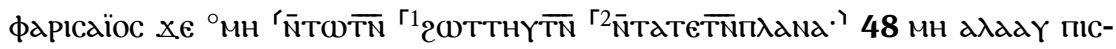

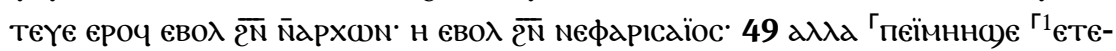

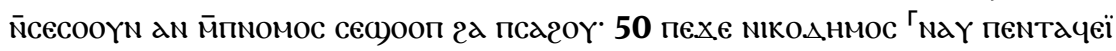

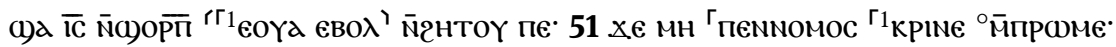

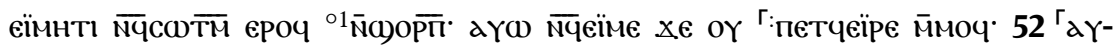

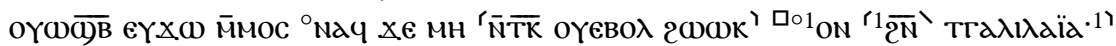

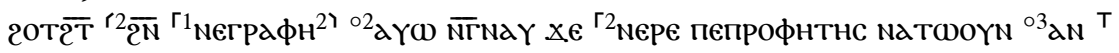

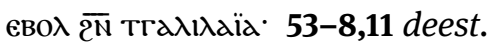

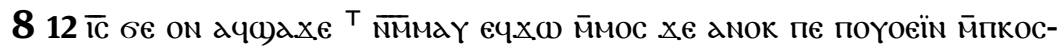

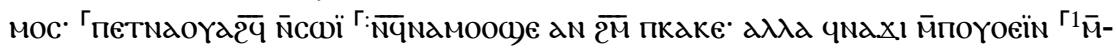

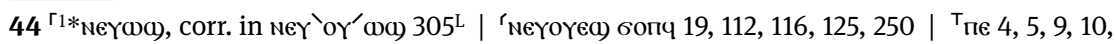

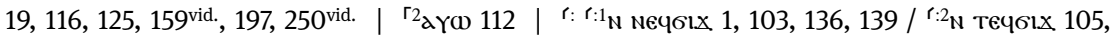

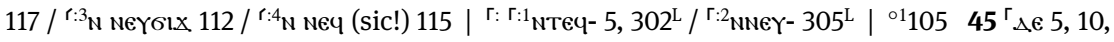

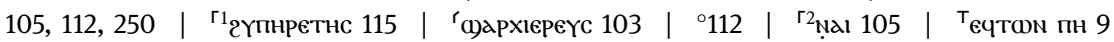

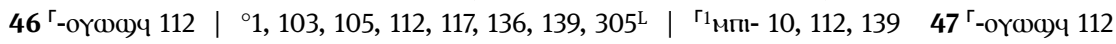

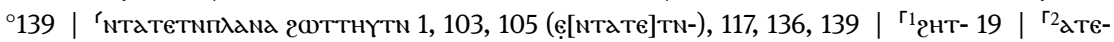

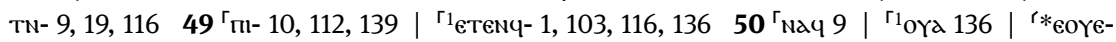

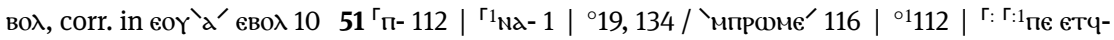

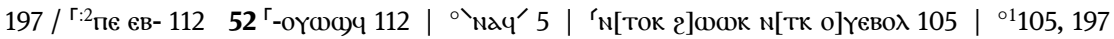

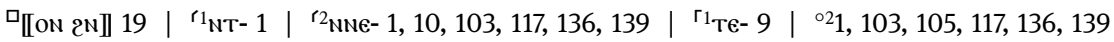

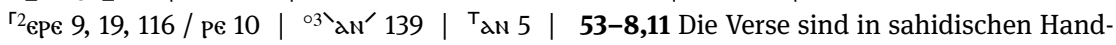

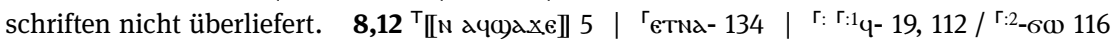
${ }^{\Gamma 1}$ a)d ene? $16^{\mathrm{L}}$

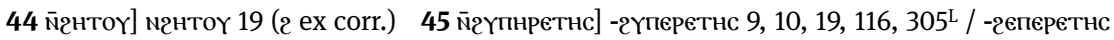

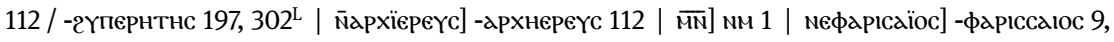

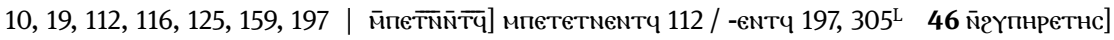
-әүперетнс 9, 10, 19, 116 / -геперетнс 112 / -әүпернтнс 197, 305L | хе м̄персме] хмпе- 112, 116,

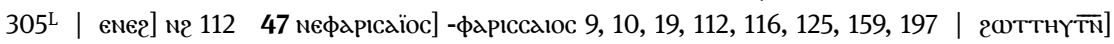

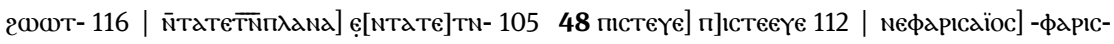
caloc 9, 10, 19, 82, 112, 116, 125, 134, 139, 159, 19749 етейсесооүм] етпсе- $10 \quad 50$ міко $\triangle$ нмос] меікоднмос 19 / мнкотнмас 112 | пентачеi] пнтач- 11251 еїнті] еімнтеі 9, 10, 19, 112, 116,

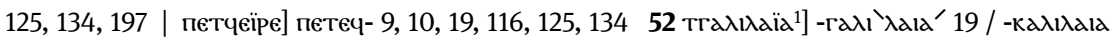

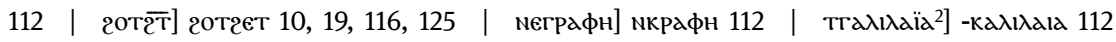

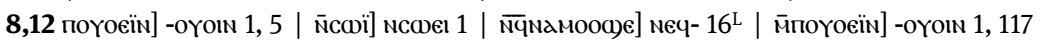




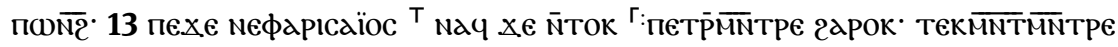

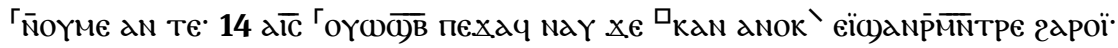

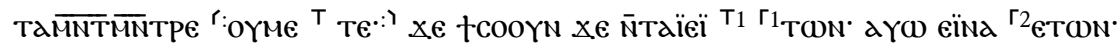

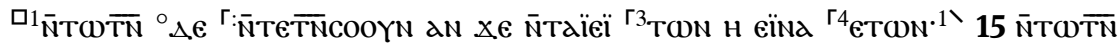

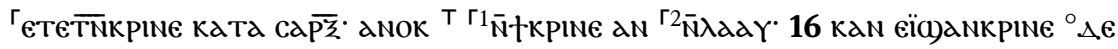

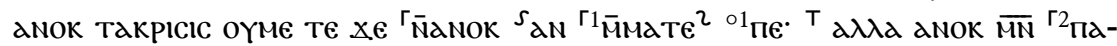

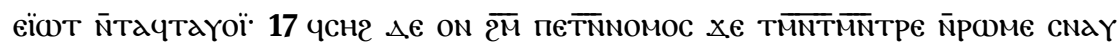

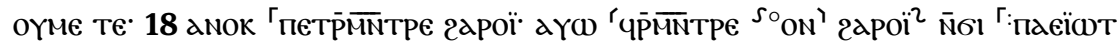

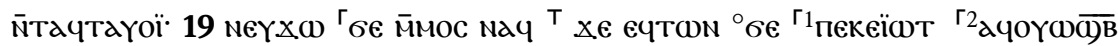

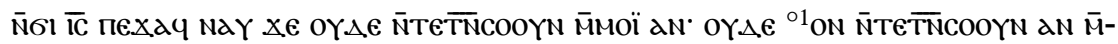

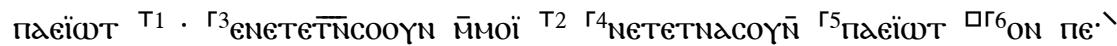

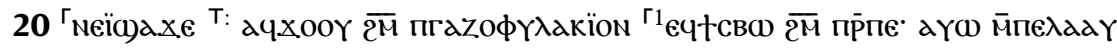

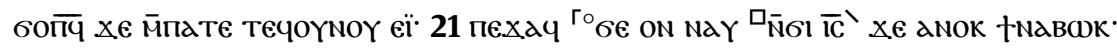

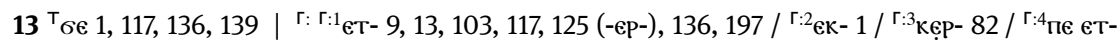
197 | '

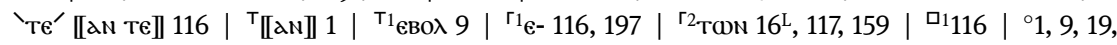

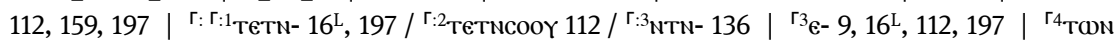

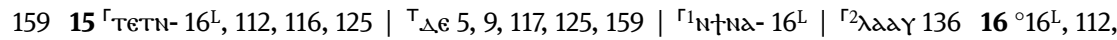

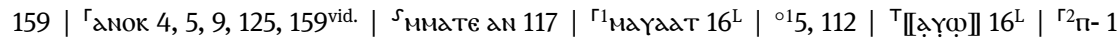

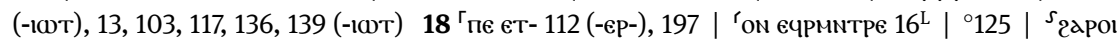

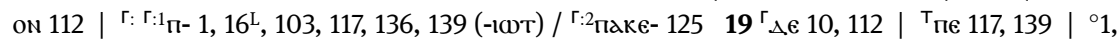

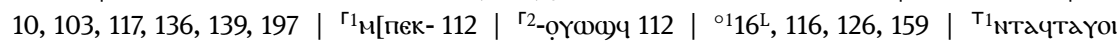

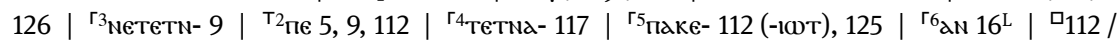

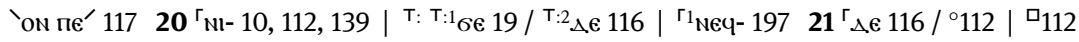

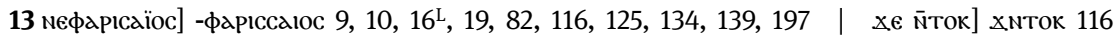

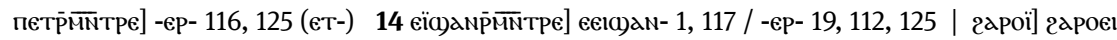

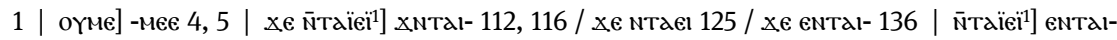

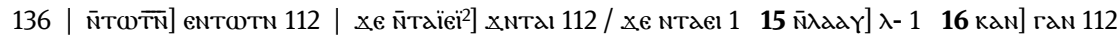

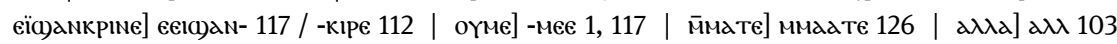

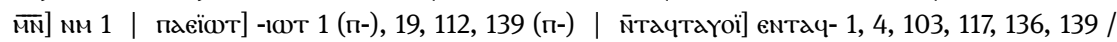

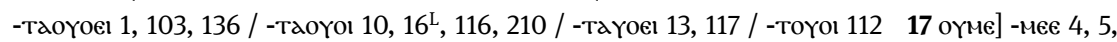

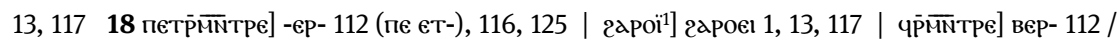

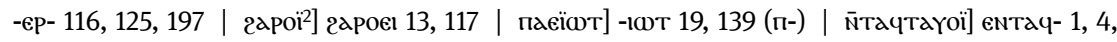

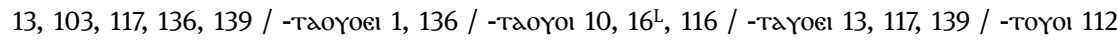
19 oү $\left.\Delta \epsilon^{1}\right]$ оүте $1,4,5,13,19,116,126,136,139,197$ | оү $\left.\Delta \epsilon^{2}\right]$ оүте 1, 13, 19, 126, 139 | м̄паеїт]

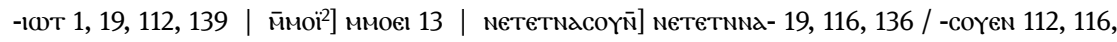

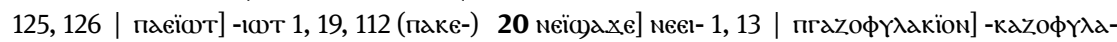

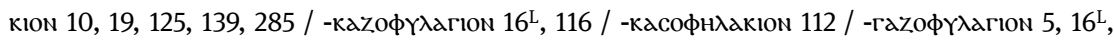
116, 139, 285 / -газофндакіом 112 | прпе] -ерпе 1, 5, 13, 103, 112, 117, 125, 136, 139, 197, 285 | хе мппатє] Хмпате 116 / хмпа 112 / хє мпапатє 117 


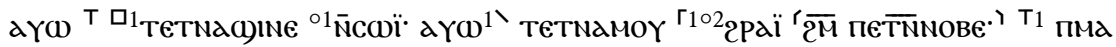

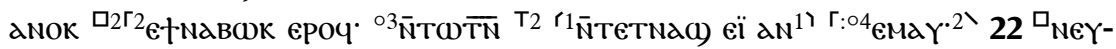

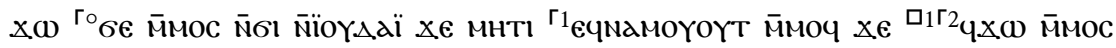

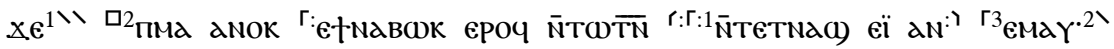

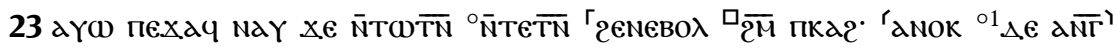

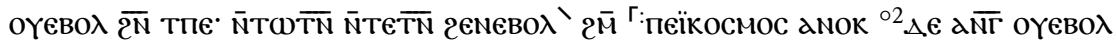

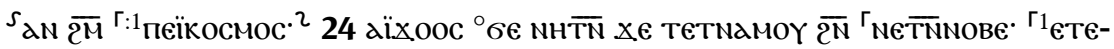

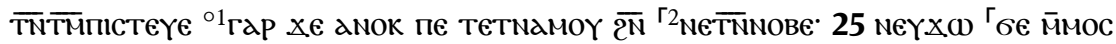

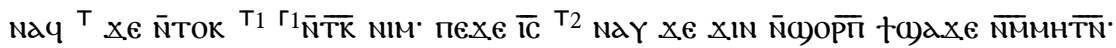

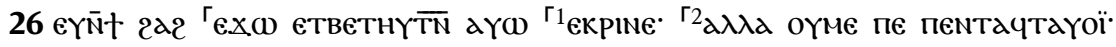

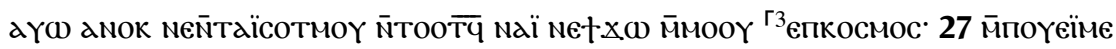

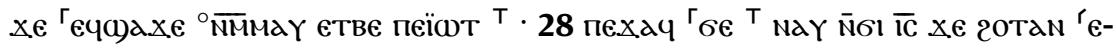

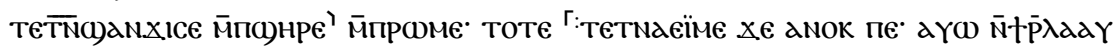

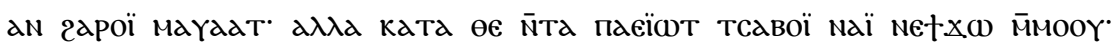

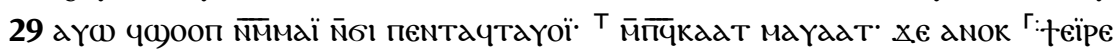

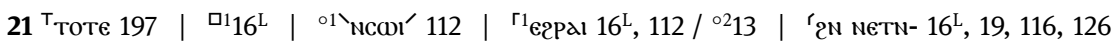

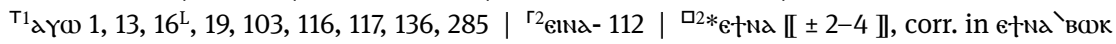

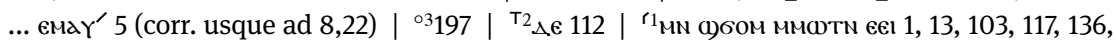

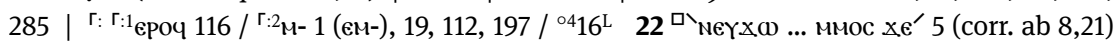

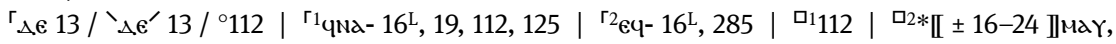

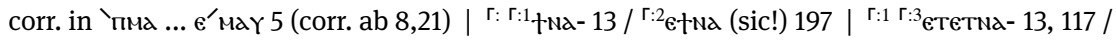

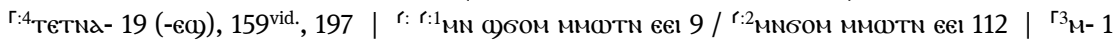

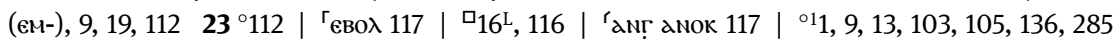

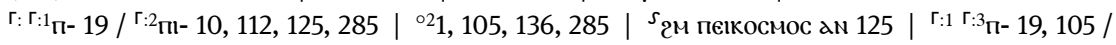

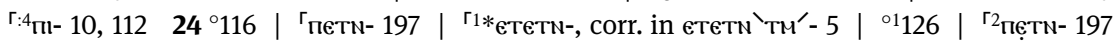

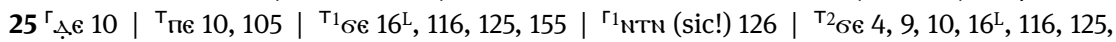

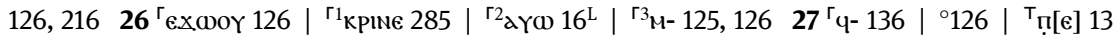

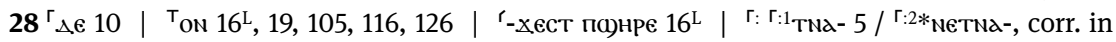

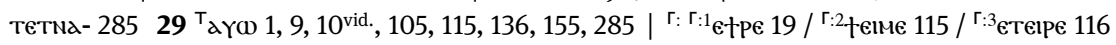

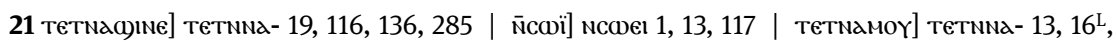

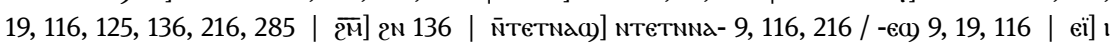
12522 мнт1] мнтег 4, 9, 10, 16L $, 19,112,116,125,197,285$ / мн† 126 | ечмамоүоүт] -мооүт

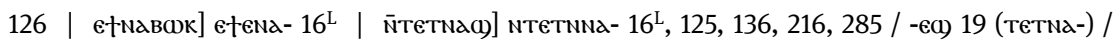

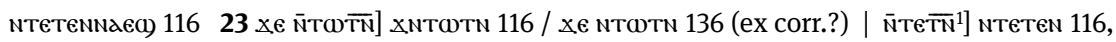

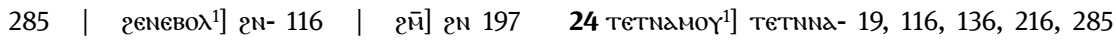

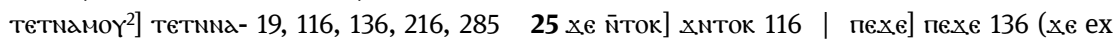

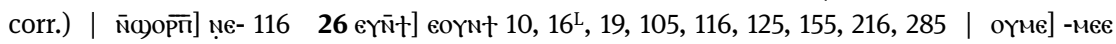

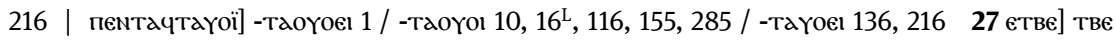

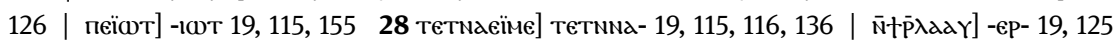

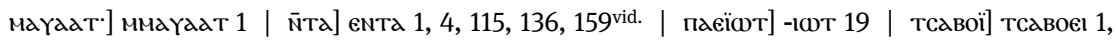
13629 пептачтаүоі] -таоүо 1, 115, 116, 285 / -таүоё 136 | м̄̄̄чкадт] мпеч- 9, 19, 116, 125, 136, 155, 285 / емпч- 159 | маүаdт·] ммаүаdт 1 


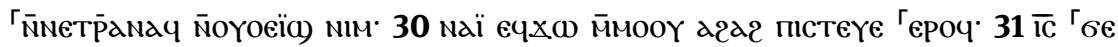
${ }^{\Gamma 1}{ }_{\text {Neq }}$.

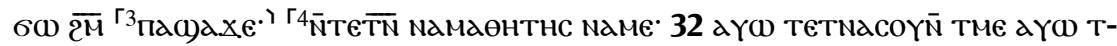

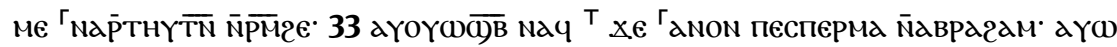

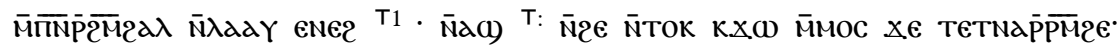

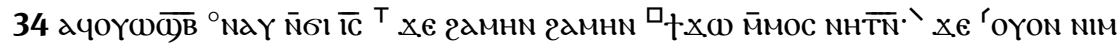

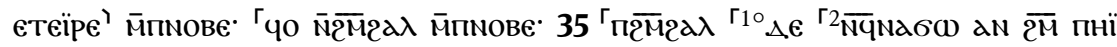

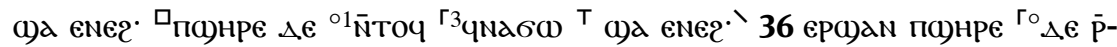

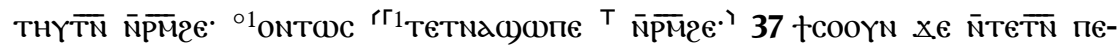

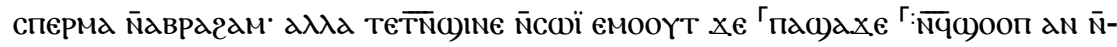

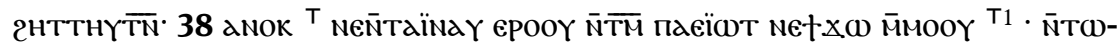

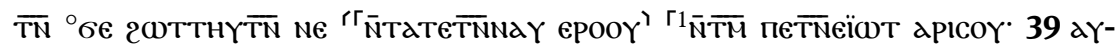

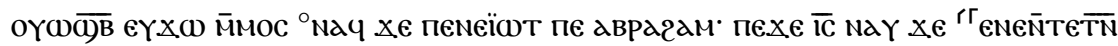

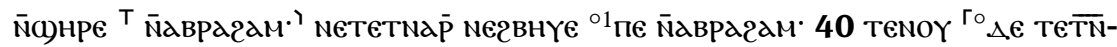

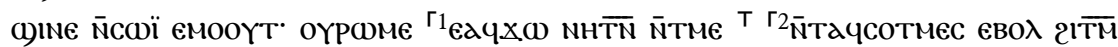

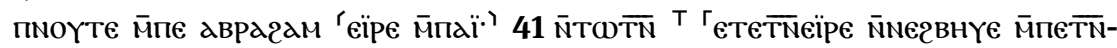

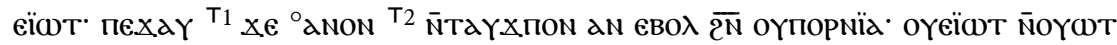

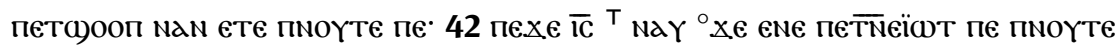

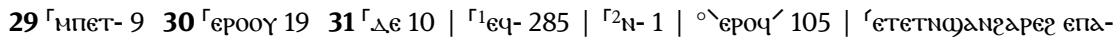

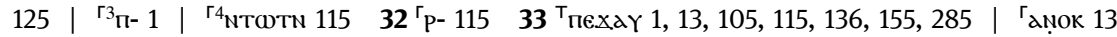

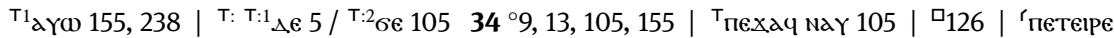

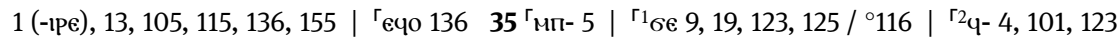

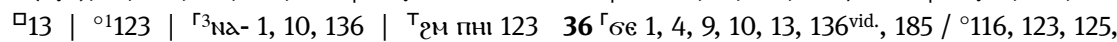

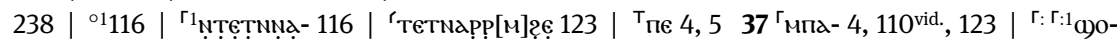

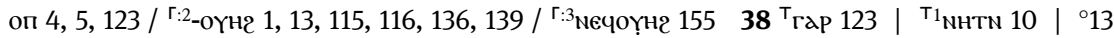

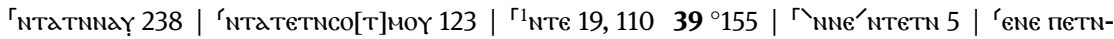

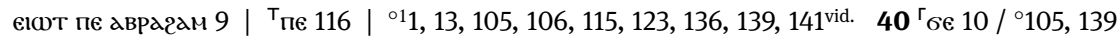

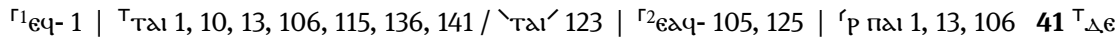

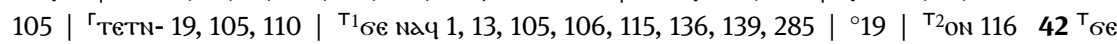
$1,105,106,115,136,139,\left.285\right|^{\circ} 4,5,10$

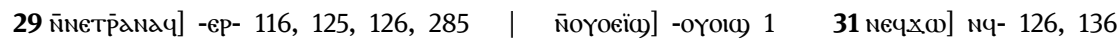

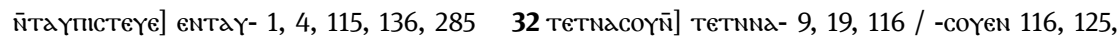

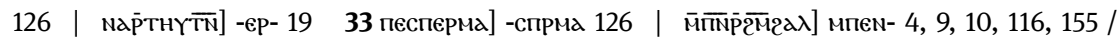

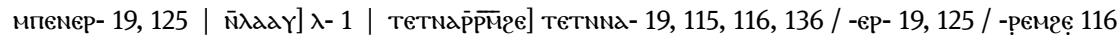

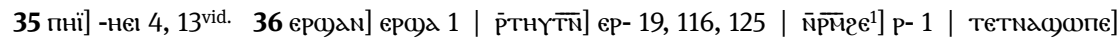

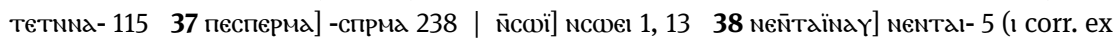

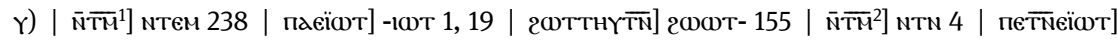

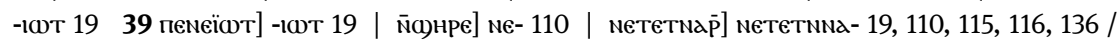

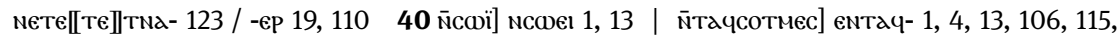

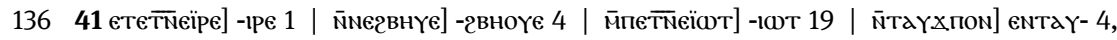

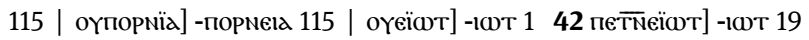




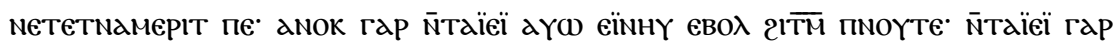

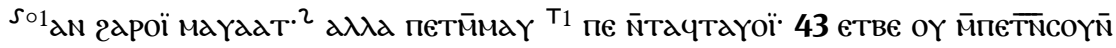

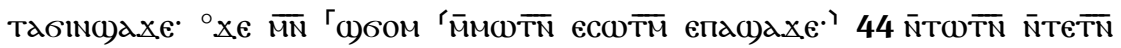

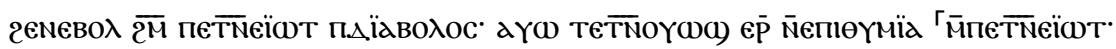

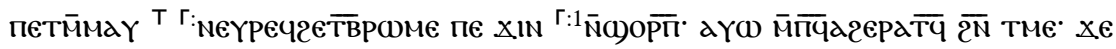

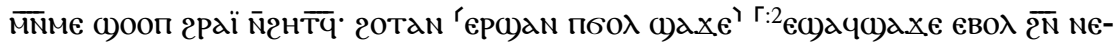

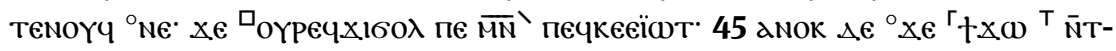

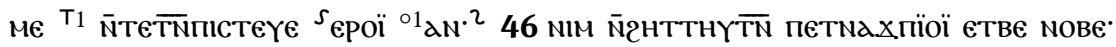

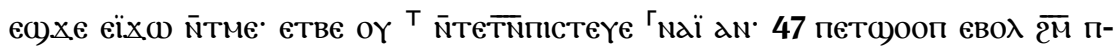

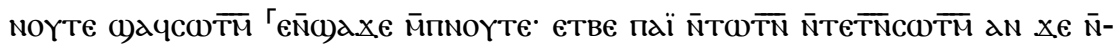

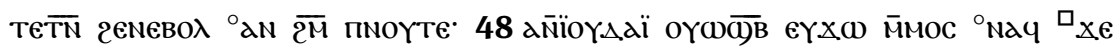

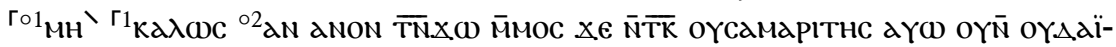

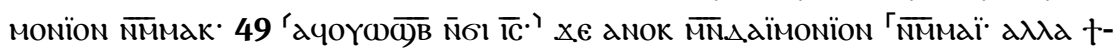

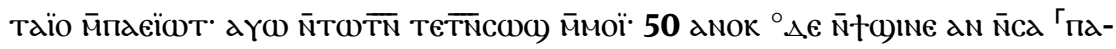

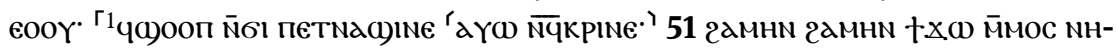

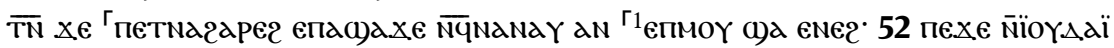

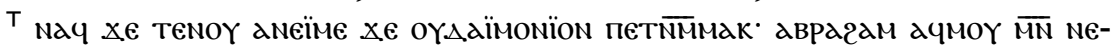

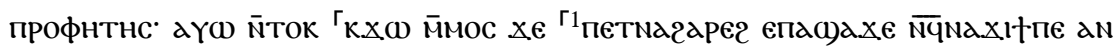

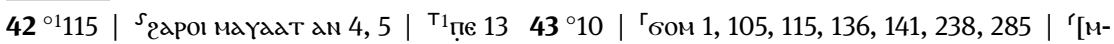

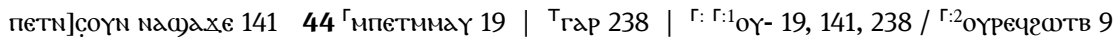

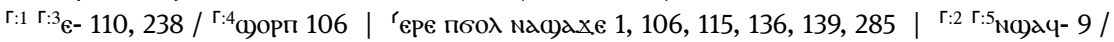

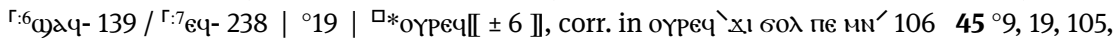

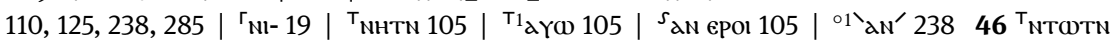

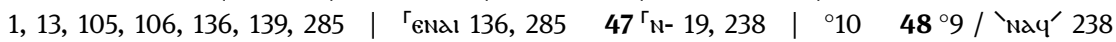

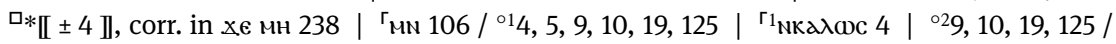

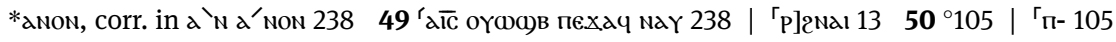

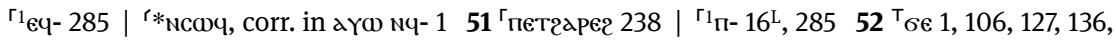
$285 \mid{ }^{\top}$ eK- $16^{\mathrm{L}} \mid{ }^{\mathrm{I}}$ петедаре2 $16^{\mathrm{L}}$

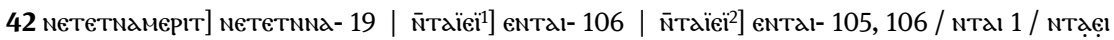

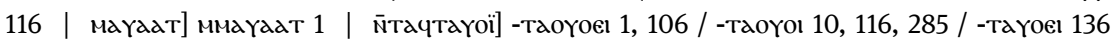

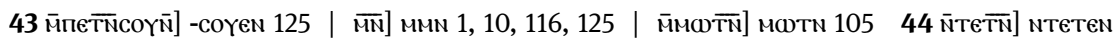

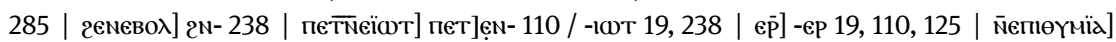

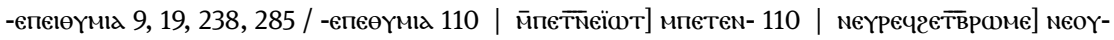

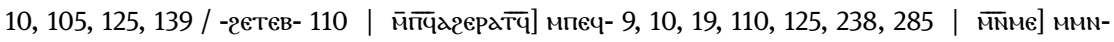

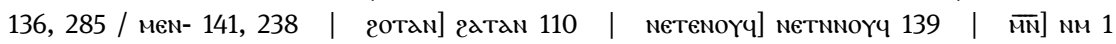

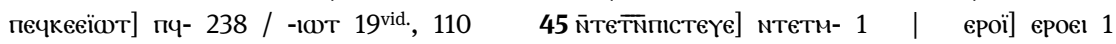
46 пєтнахпїоi] -хпюеє 1, 106, 136 / -хпеіо 9 | еїх

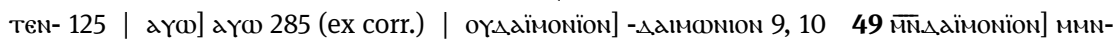

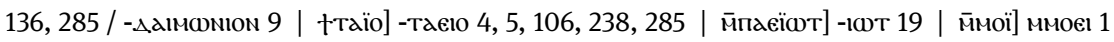

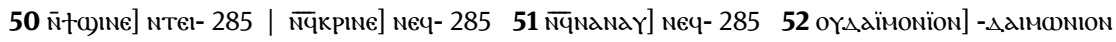

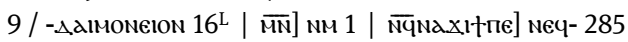




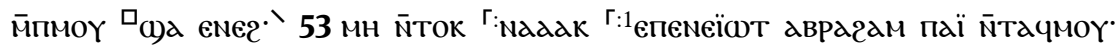

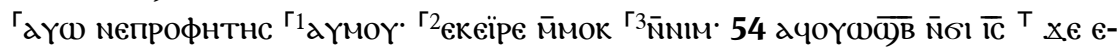

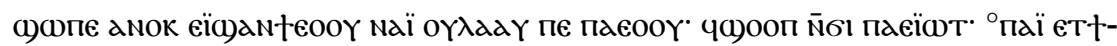

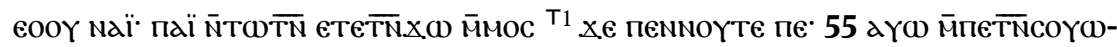

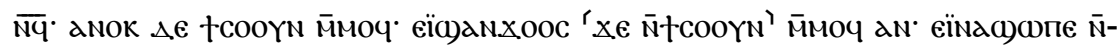

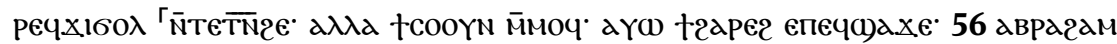

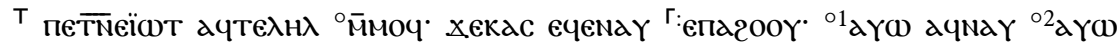

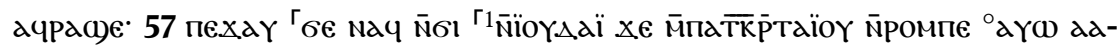

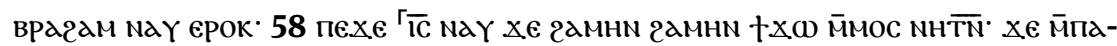

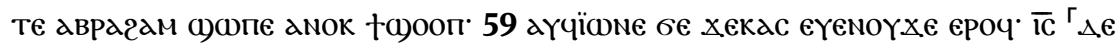

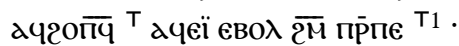

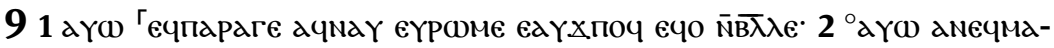

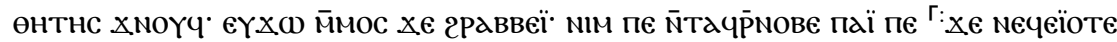

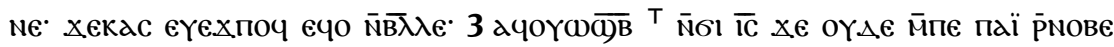

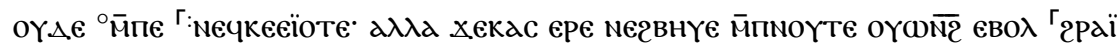

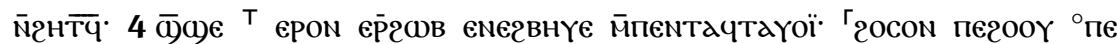

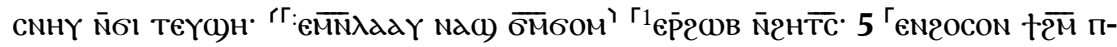

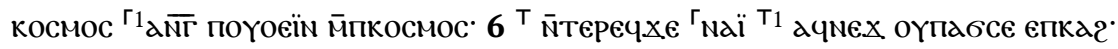

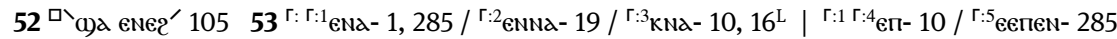

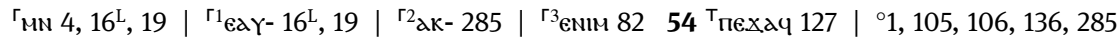

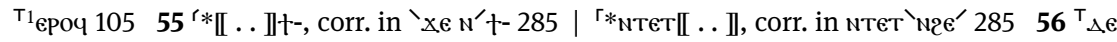

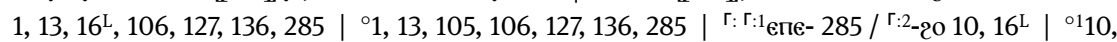

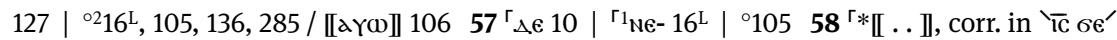

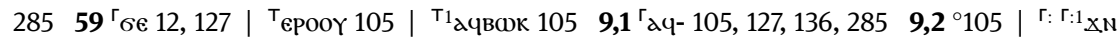

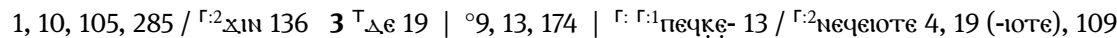

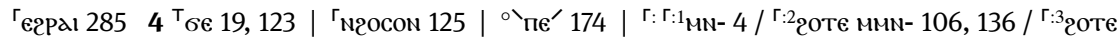

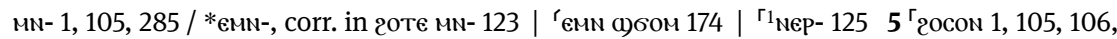

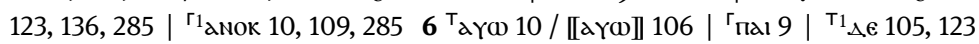

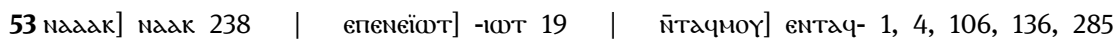

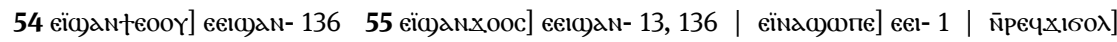

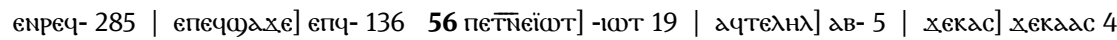
57 м̄паткрттаїо] емпатк- 106 / мпатек- 9, 10, 16L, 127, 285 / мпатекер- 19, 125 / -таеіо 13, 136

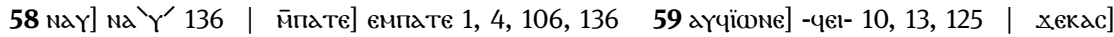
хекадс 4 | прпп] -ерпє 1, 5, 13, 106, 109, 125, 136, 285 9,2 амєчмдөнтнс] д- 5 (а corr. ех м)

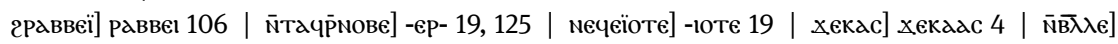
в- 13 оү $\left.\Delta \epsilon^{1}\right]$ оүте 1, 4, 13, 19, 106, 109, 127, 136, 174 | рंмове] ер- 19, 125 | оү $\left.\Delta \epsilon^{2}\right]$ оүте 1, 4, 13, 106, 109, 127 / оүт 19 | мечкеєіоте] мечіоте 19 | Хекас] Хекаaс 4 | мегвнүе] -гвноүе 109

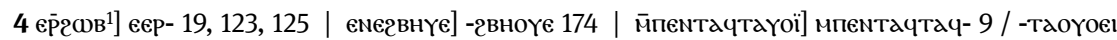

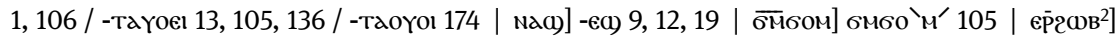

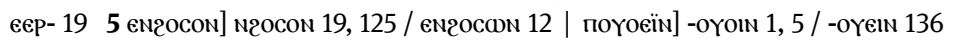




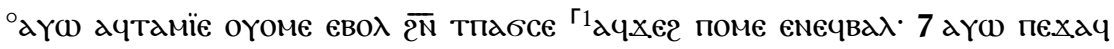

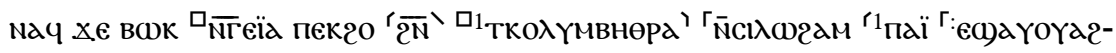

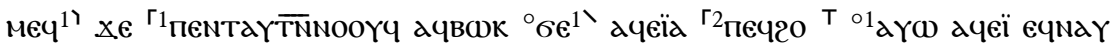

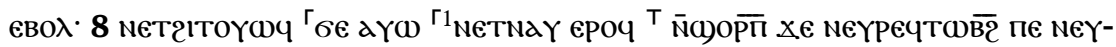

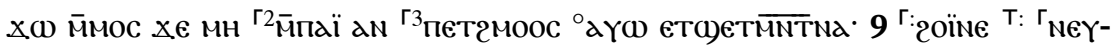

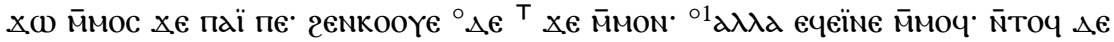
Nєчх

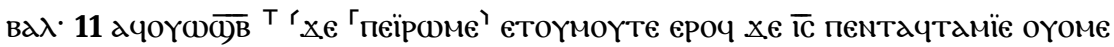

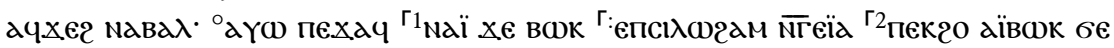

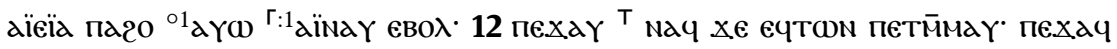

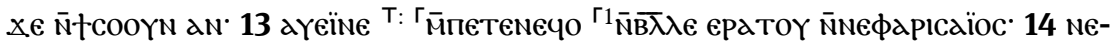

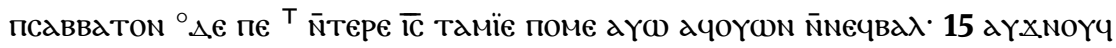

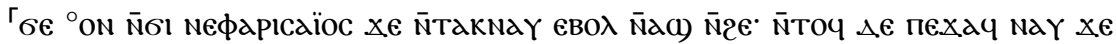

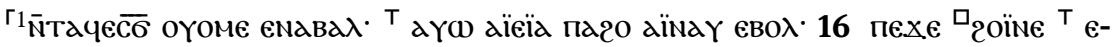

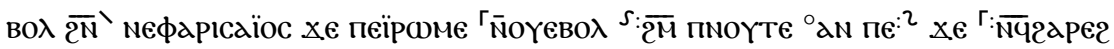

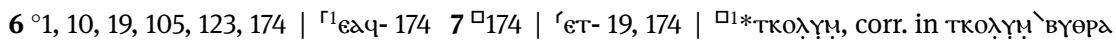

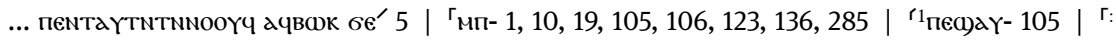

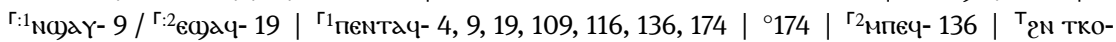

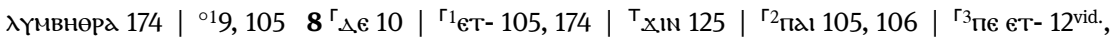

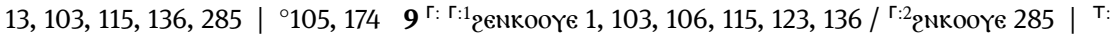

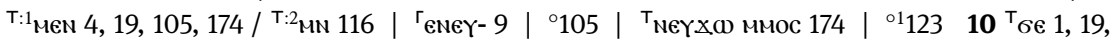

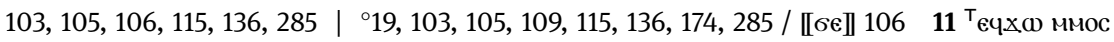

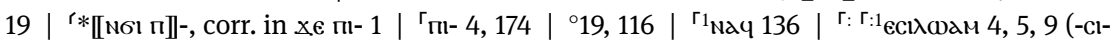
入оүадм), 19, 109, 116, 125 / Г:2

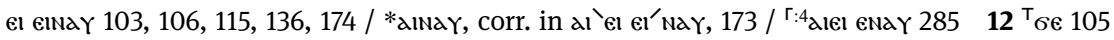

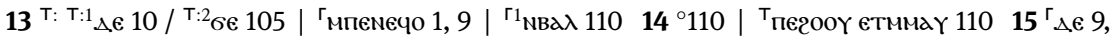

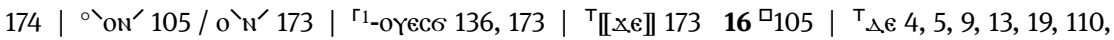

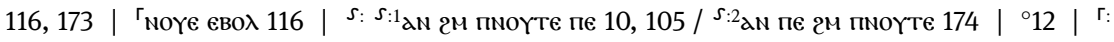
г:1 eNq- 174 / r:2 $\mathrm{Neq}$ - 19, 116, 285

6 ачтаміе] -тамеєе 9 | оүоме] -ооме 106, 174 | поме] -ооме 1747 тколүмвнөра] -колүмвүөра 5, 123, 285 / -коломвнера 116 | і̄сілшгам] -сілюам 1 | ес)аүоүагмеч] -оүомеч 106, 116

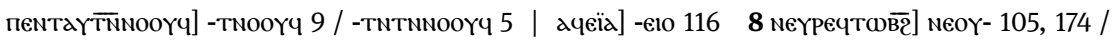

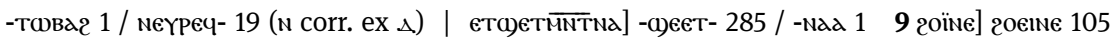
генкооүе] ге(N)коо 109 / гN- 116 | хе м̈моn] хммом 11611 пентачтамї] пентаме 103 / -тамеіе 9, 105 | оүоме] -ооме 106, 174 / -дме 116 | епсілшгам] -сілюам 1 / -сілоүгам 9 (е-)

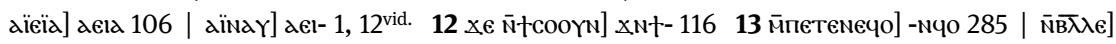

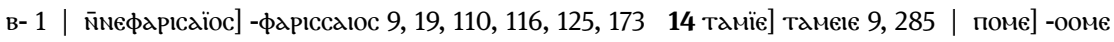

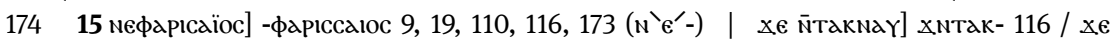

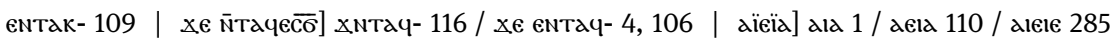
16 гоїм] гоєіме 102, 106, 115, 136 / zolм 110 | nефарісаїос] -фаріссаıсо 9, 10, 19, 110, 116,

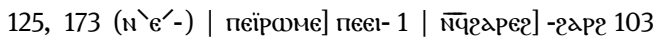




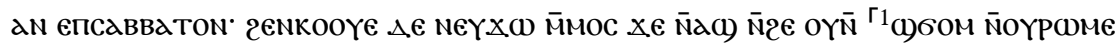

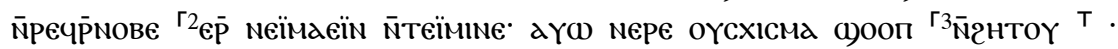

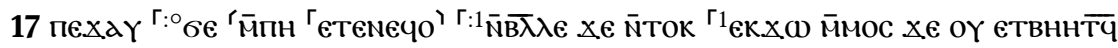

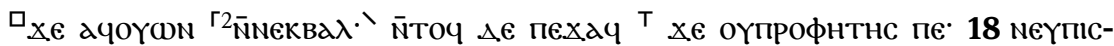

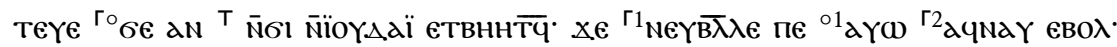

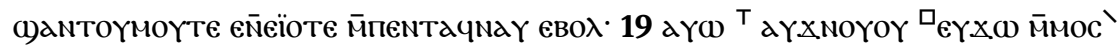

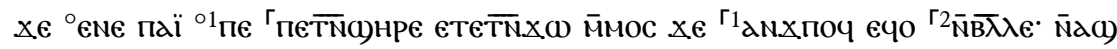

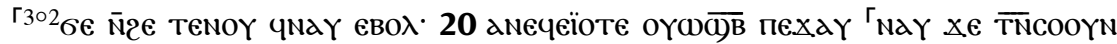

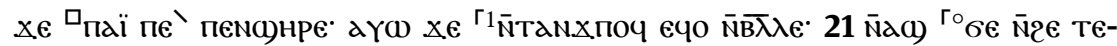

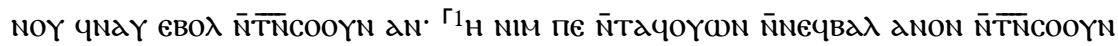

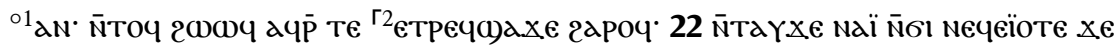

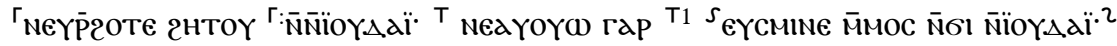

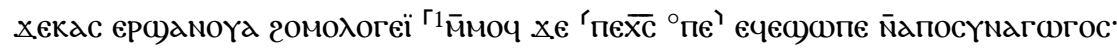

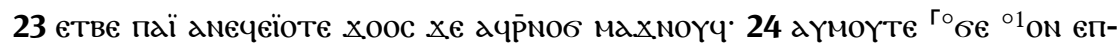

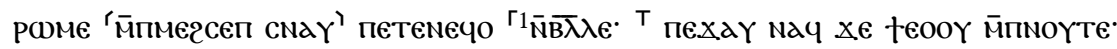

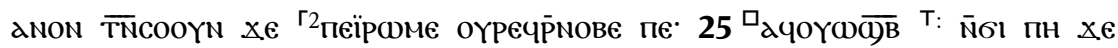

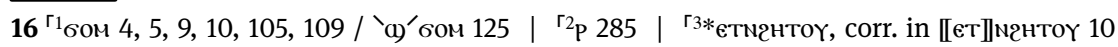

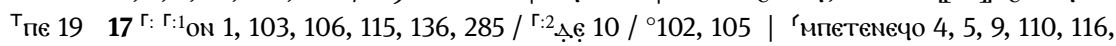

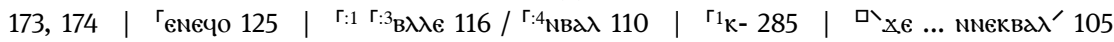

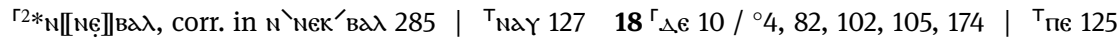

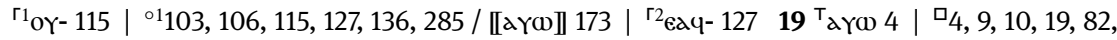

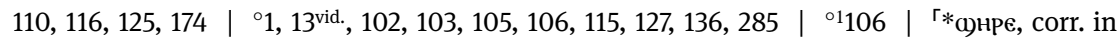

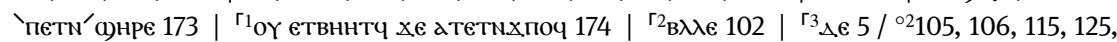

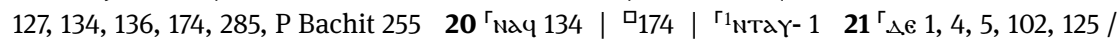

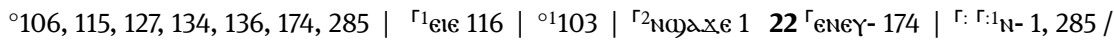

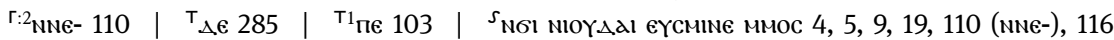

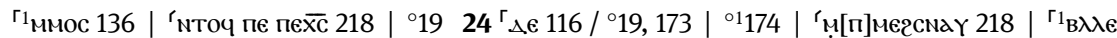

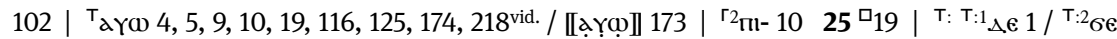

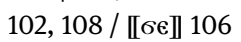

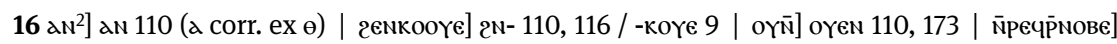
-ер- 19, 110, 125 | ере] еєр 110 | меїмаеї] -маıм 1 | оүсхісма] -схіма 10 / -сxı 'c'ма 13617 ете-

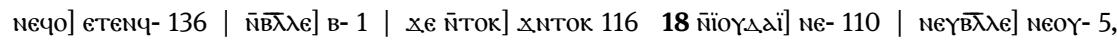

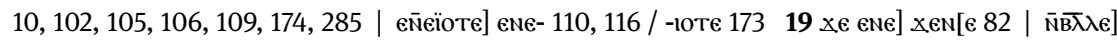

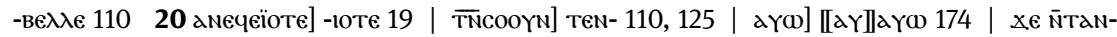

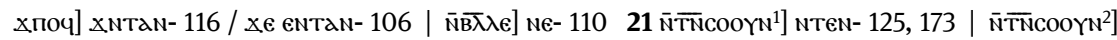

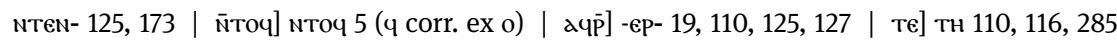

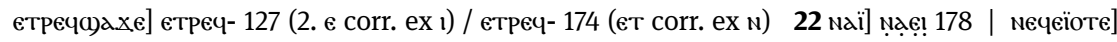

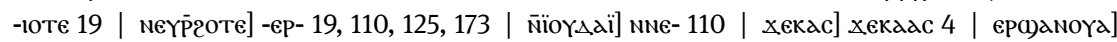

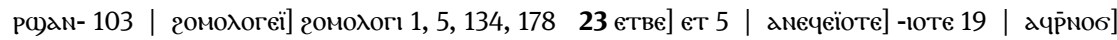
-ер- 19, 125, 17324 мппмегсеп] -сп 9, 116, 127 / -соп 105, 106, 174 | м̈пмоүте] мпмте 105 | ТNсооүм] тен- 125, 173 | пеірсме] пєєе- 1 | оүрєчремовє] оүреч- 127 (є corr. ех о) / -ер- 19, 125, 173 


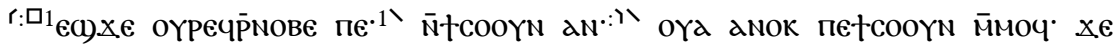

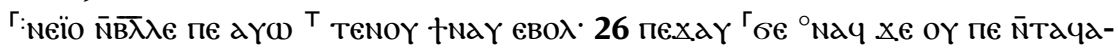

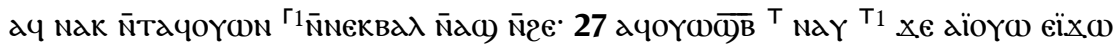

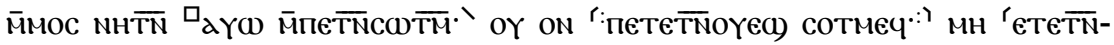

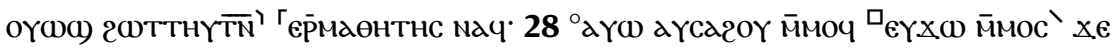

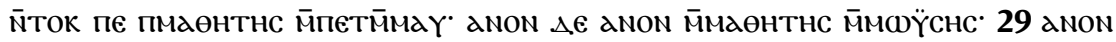

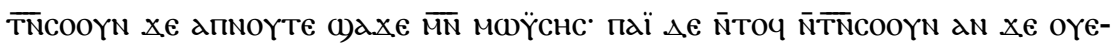

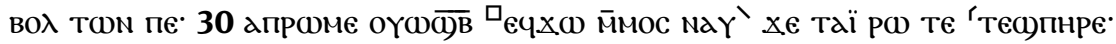

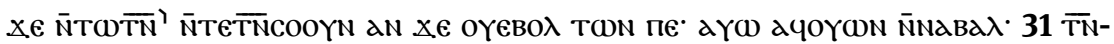

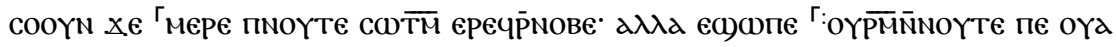

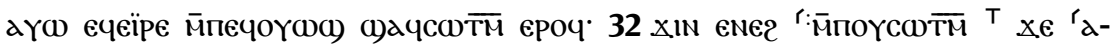

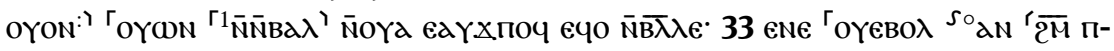

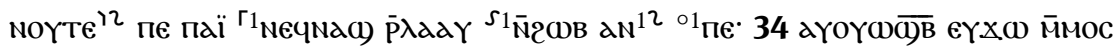

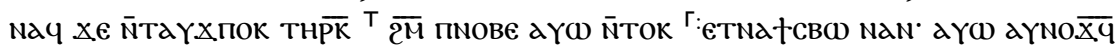

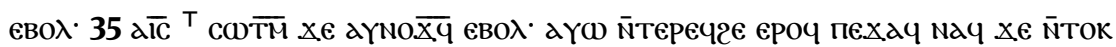

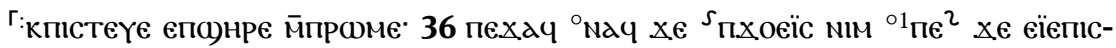

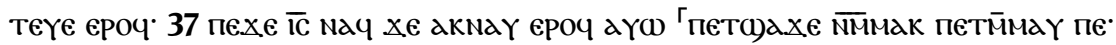

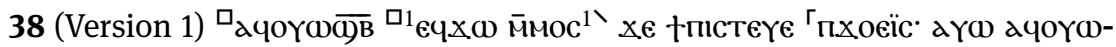

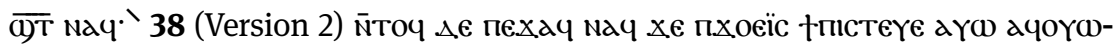

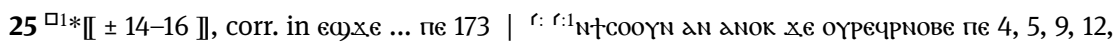

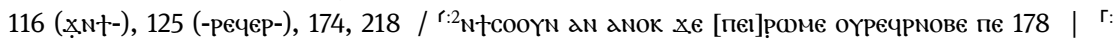

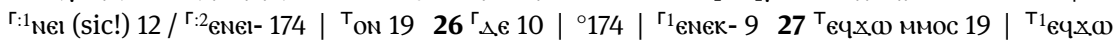

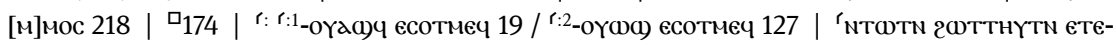

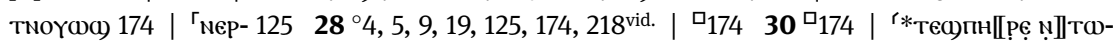

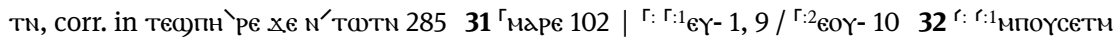

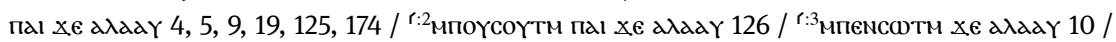

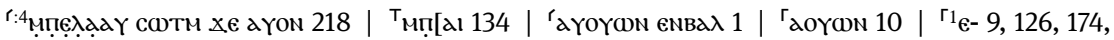

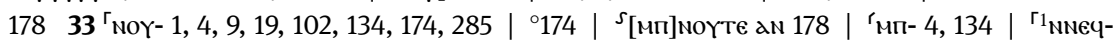
5 | ${ }^{S 1}$ ам нгов 4, 5, 9, 19, 127 (1. N corr. ех к), 174, $218 \mid{ }^{\circ 1} 1934^{\top}$ евол 4, 5, 9, 19, 108, $125^{\text {vid. }}$,

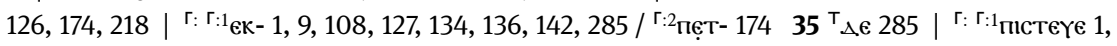

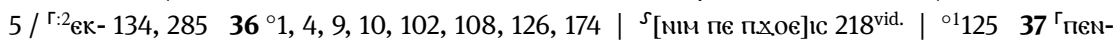
Tdy- 103 38(1) ${ }^{\square_{1}}$ (om. usque ad 9,39) | ${ }^{\square_{1}} 174 \mid{ }^{\ulcorner}$enxolc 4

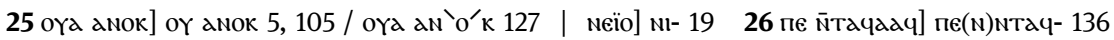

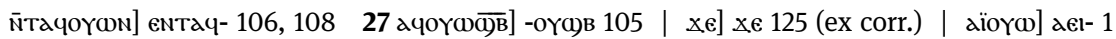

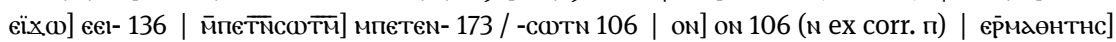

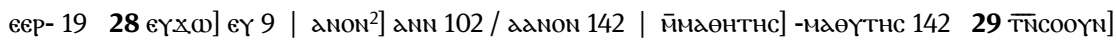

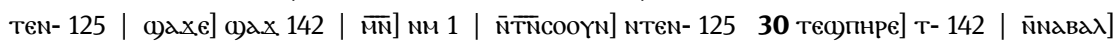

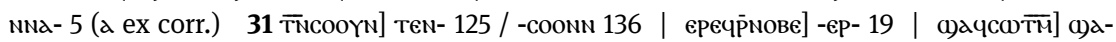

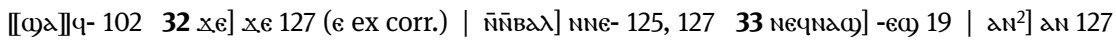

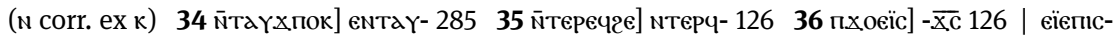

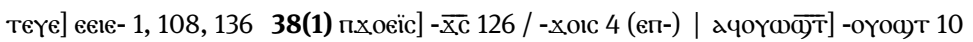




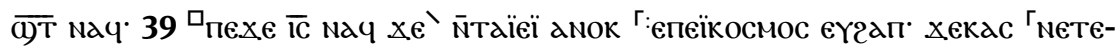

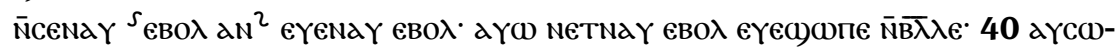

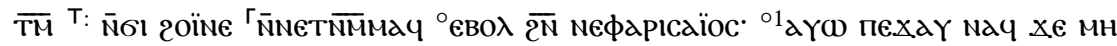

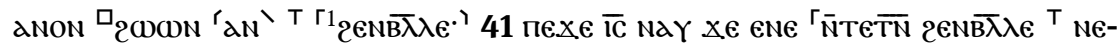

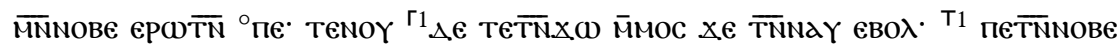
д2єрд $\overline{\mathrm{Tq}}$.

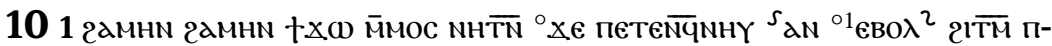

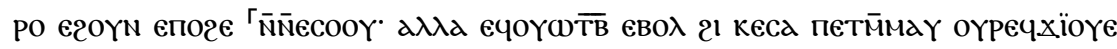

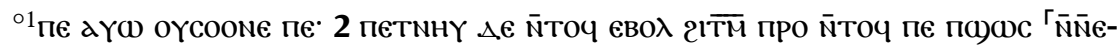

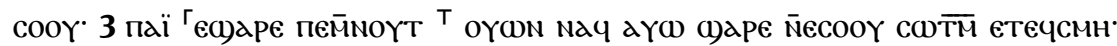

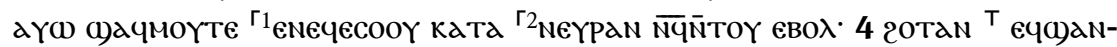

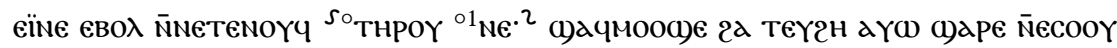

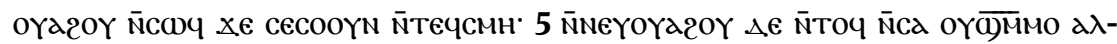

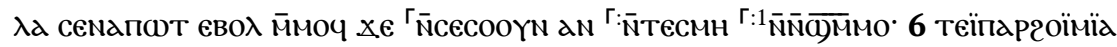

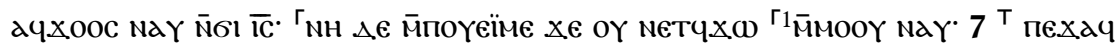

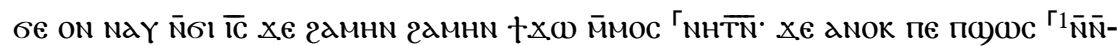

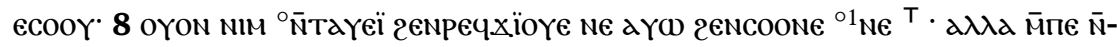

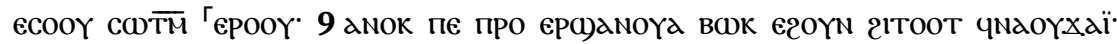

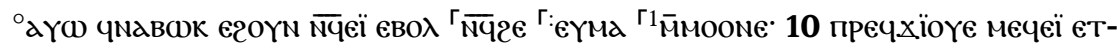

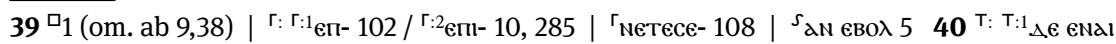
19, 125 / T:2 емал 4, 5, 9, 126, 134 vid., 174 | '

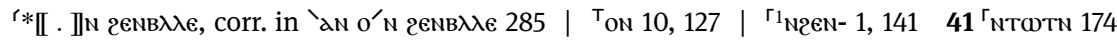

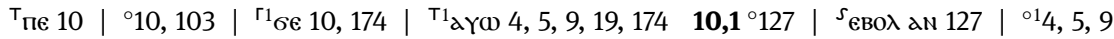

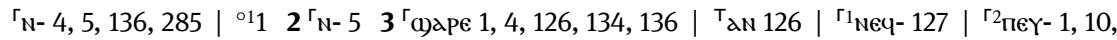

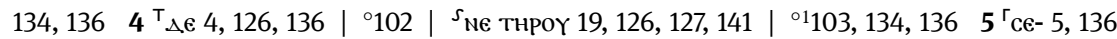

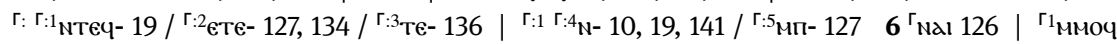

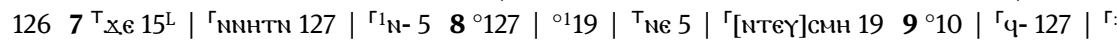
Г:1

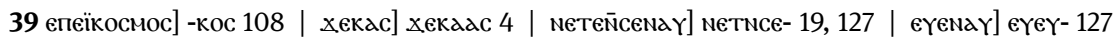

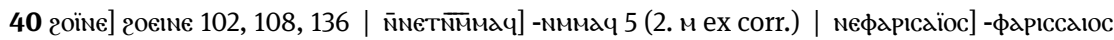

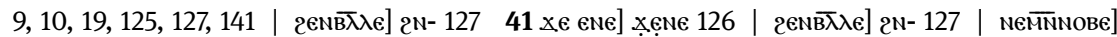

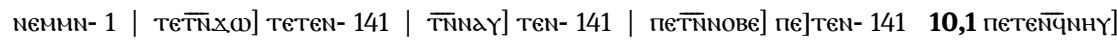

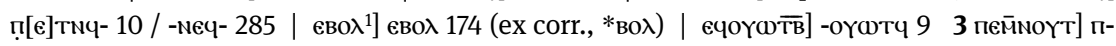

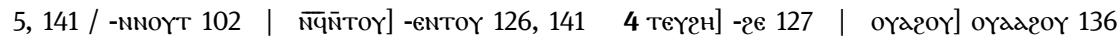
6 теїпаргоїмї] теєі- 1 / -парромміа 5, 10, 102 / -паррнміа 19, 126 | мєтчхб] мєтеч- 9, 19, 134,

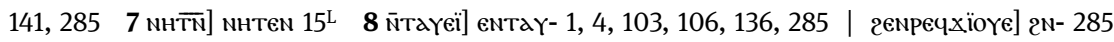

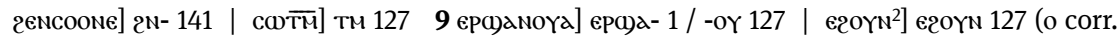

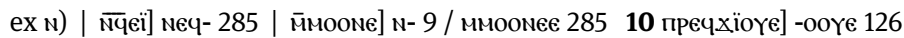




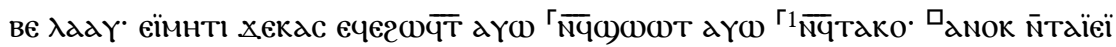

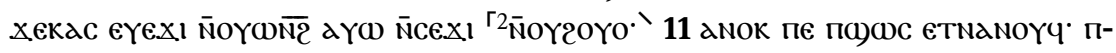

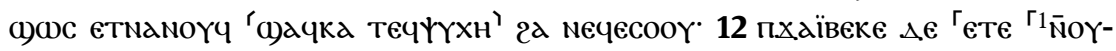

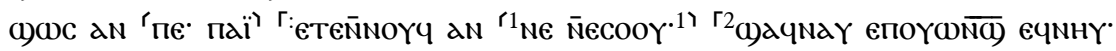

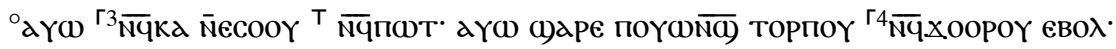

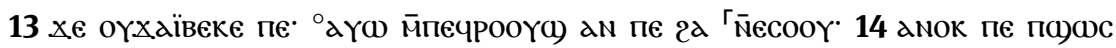

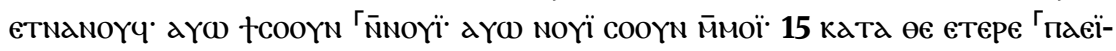

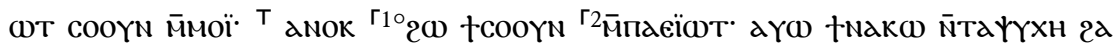

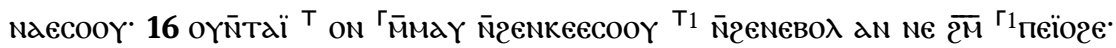

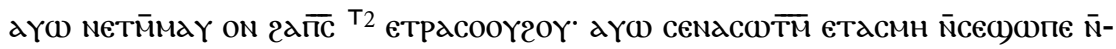

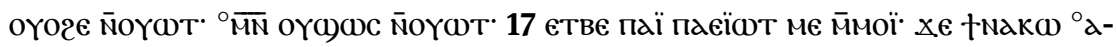

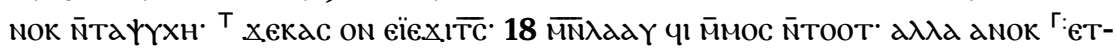

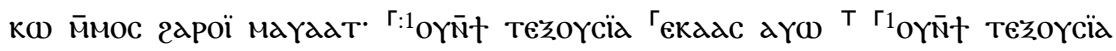

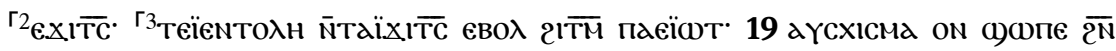

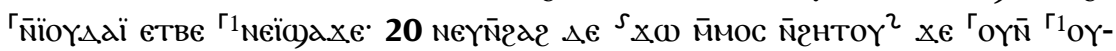

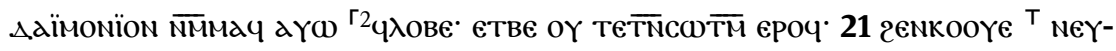

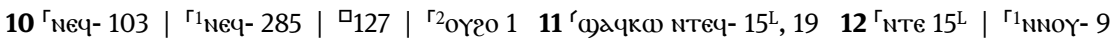

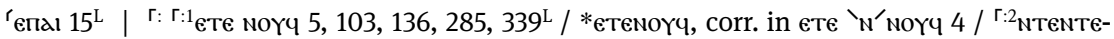

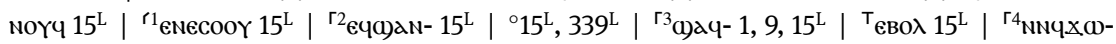

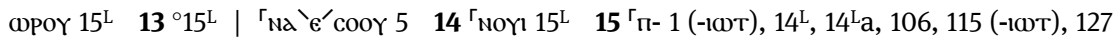

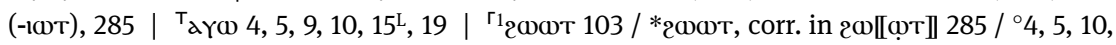

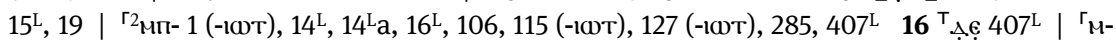

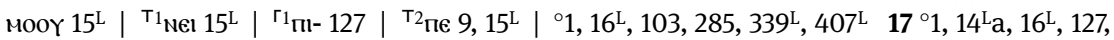

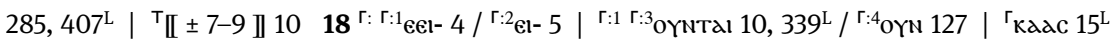

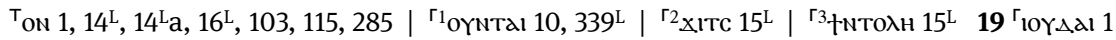

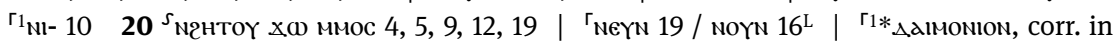
'ơ' ${ }^{\prime}$ גimonion $\left.1\right|^{\Gamma 2}$ eq- $16^{\mathrm{L}} 21^{\top} \triangle \epsilon$ 4, 5, 9, $16^{\mathrm{L}}, 19$

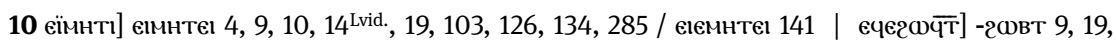

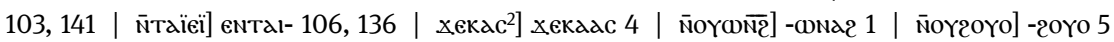

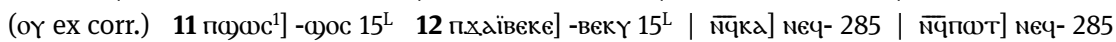

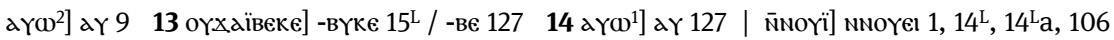

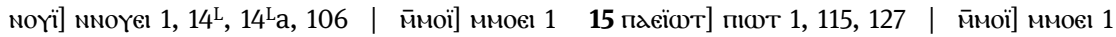

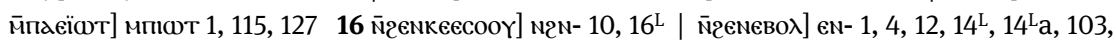

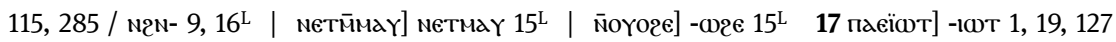

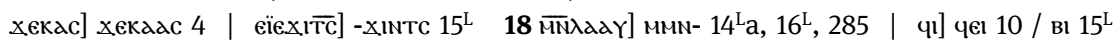

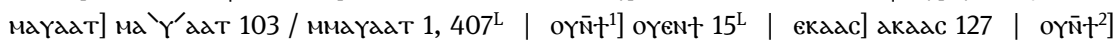

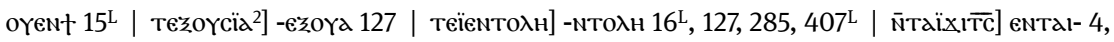

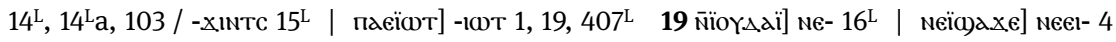

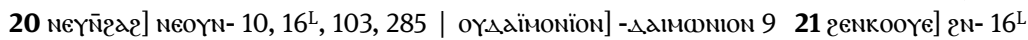




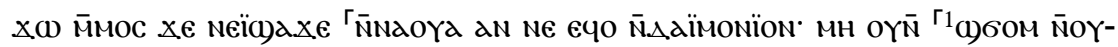

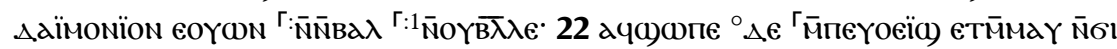

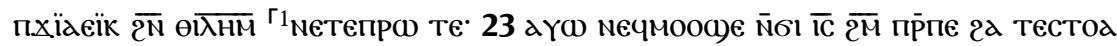

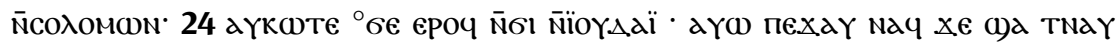

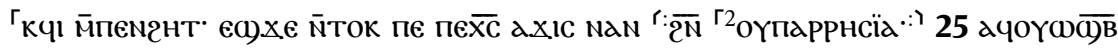

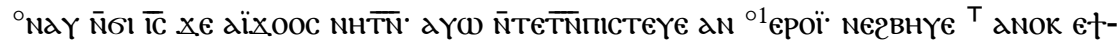

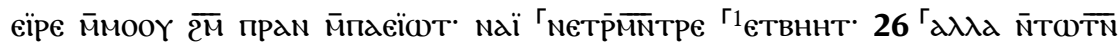

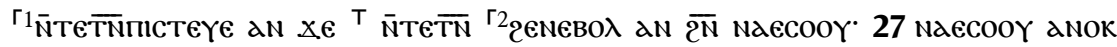

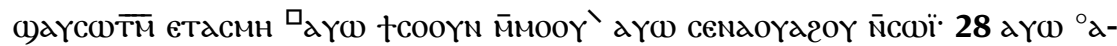

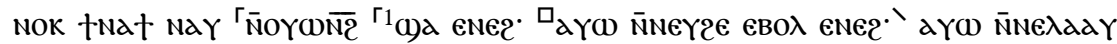

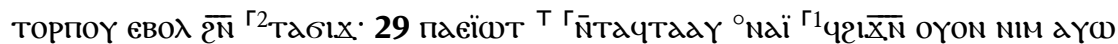

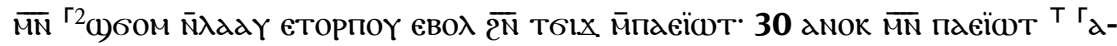

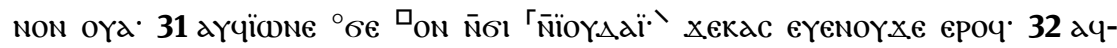

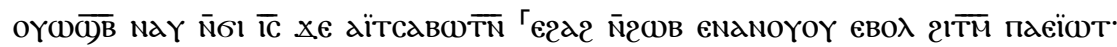

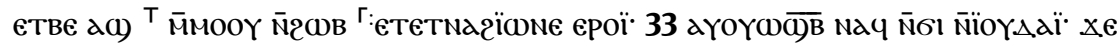

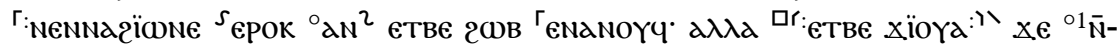

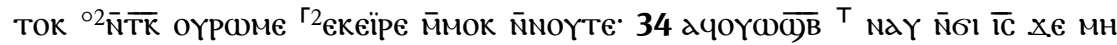

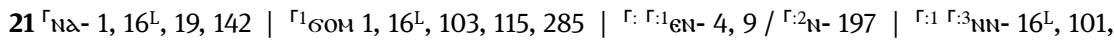

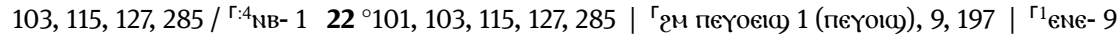

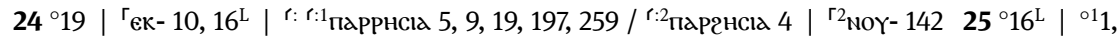

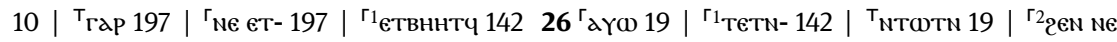

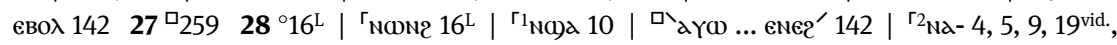

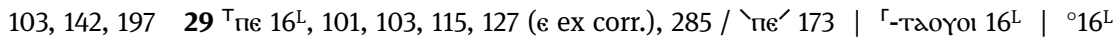

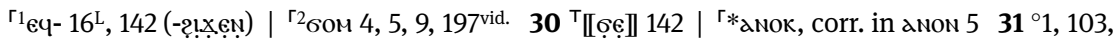

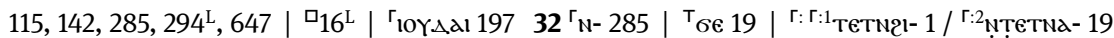

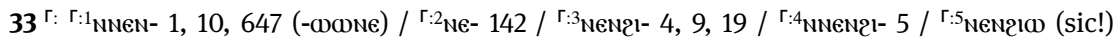

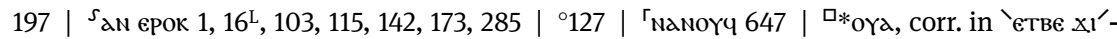

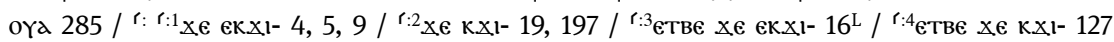
${ }^{\circ 1} 16^{\mathrm{L}}{ }^{\circ 2} 19 \mid{ }^{\mathrm{r}} \mathrm{K}-1,5 \quad 34^{\mathrm{T}} \mathrm{ON} 197$

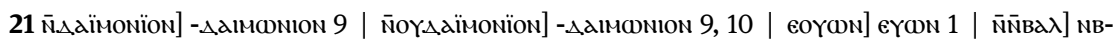

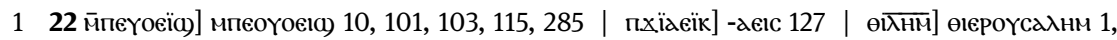

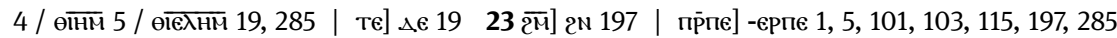

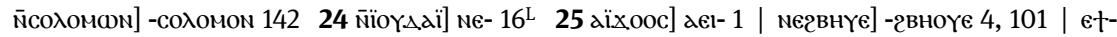

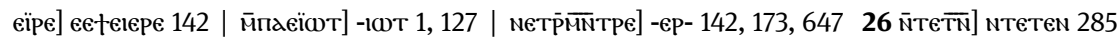

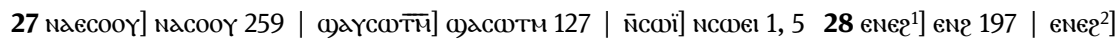

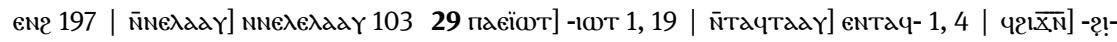

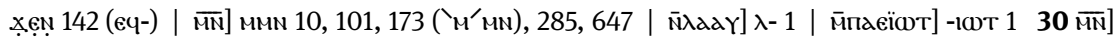

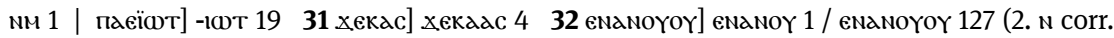

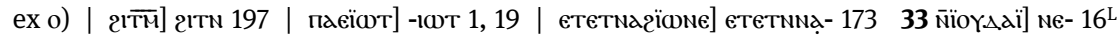

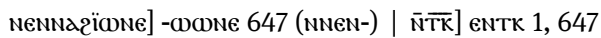




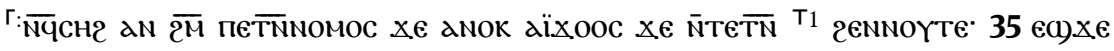

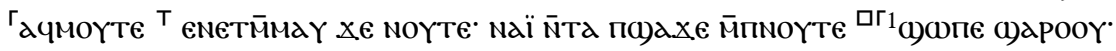

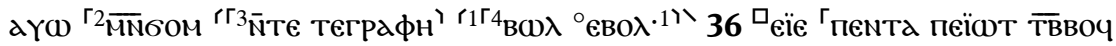

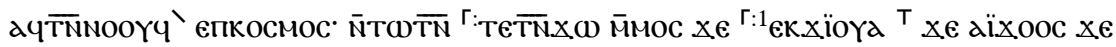

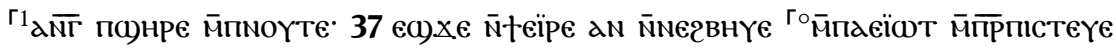

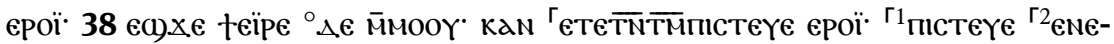

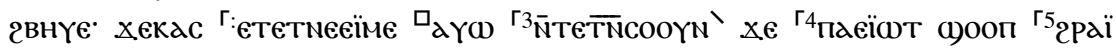

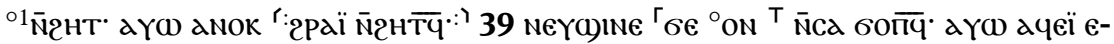

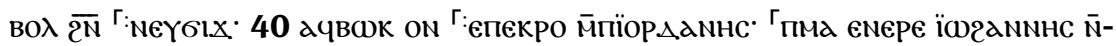

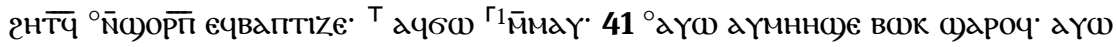

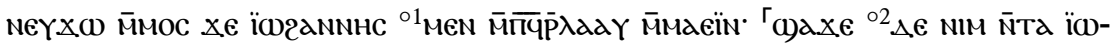

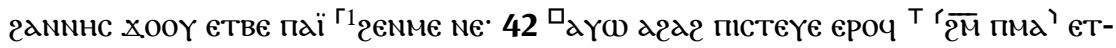
$\bar{M} M A Y^{\prime}$

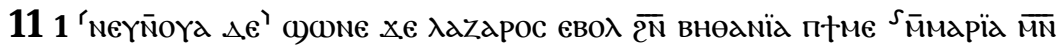

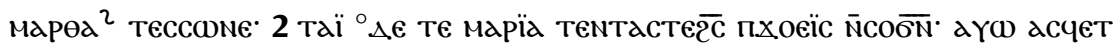

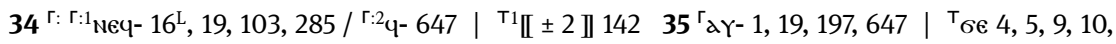

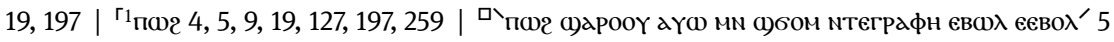

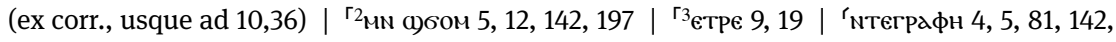

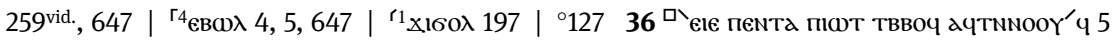

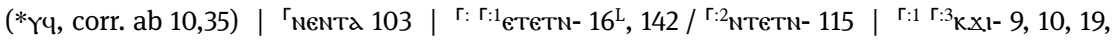

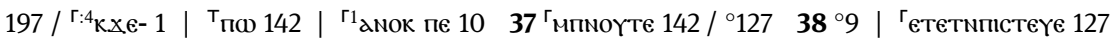

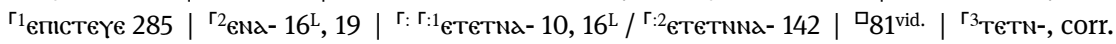

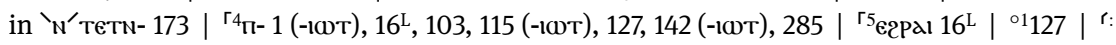

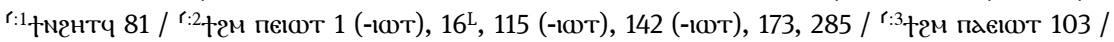

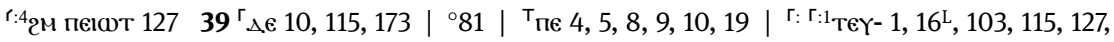

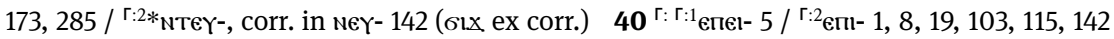
(*епккоро, corr. in епикро) | '

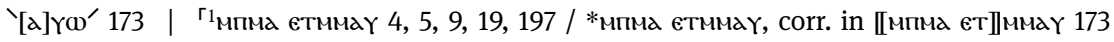

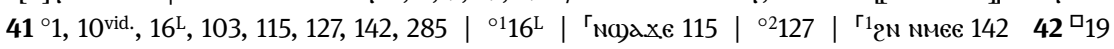

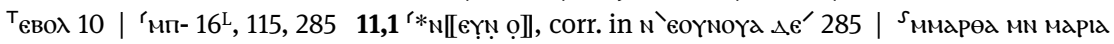
$19 \mathbf{2}^{\circ} 9,10,197$

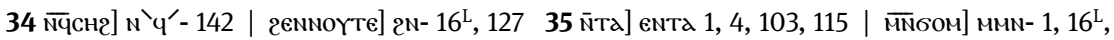

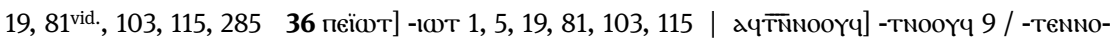

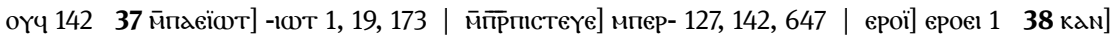

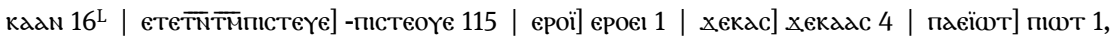

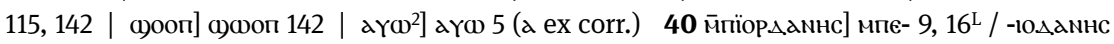

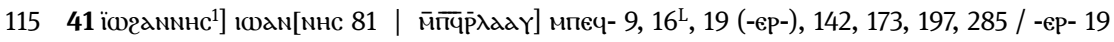

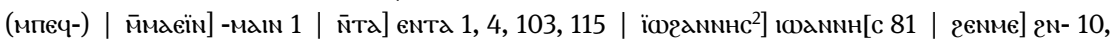

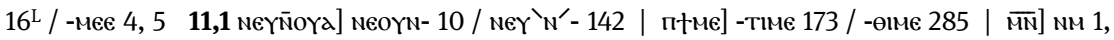

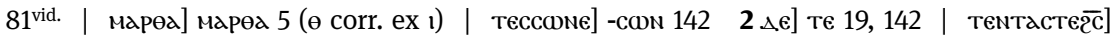
тNтас- 19 / -теге 142 | асчет] -вет 9, 103, 127, 197 


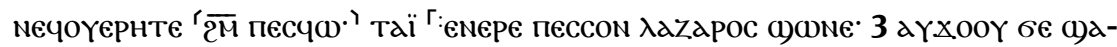

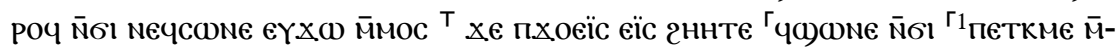

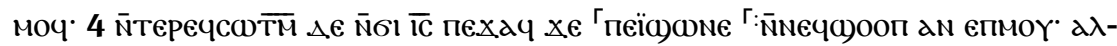

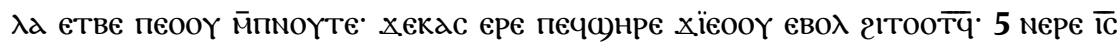

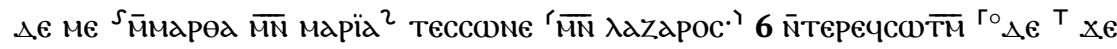
${ }^{\Gamma 1}{ }^{1}$ qO)

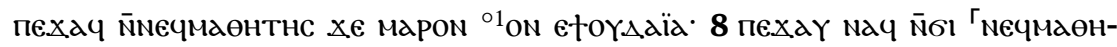

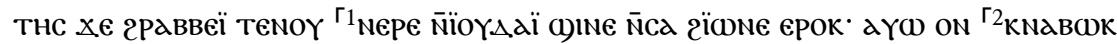

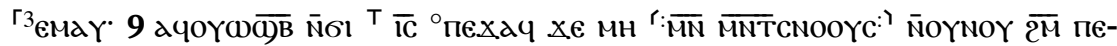

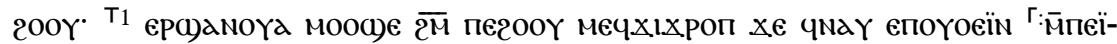

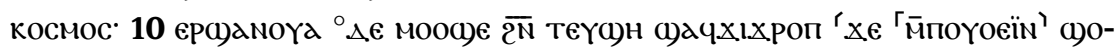

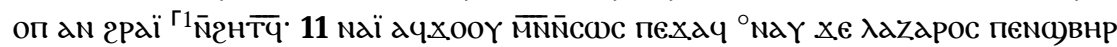

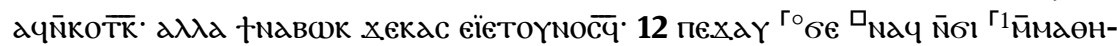

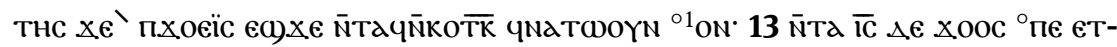

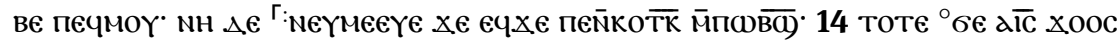

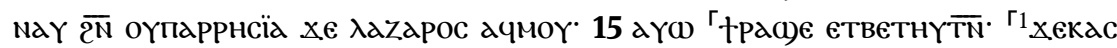

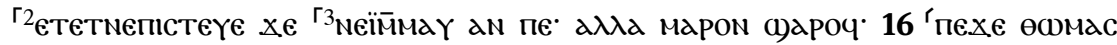

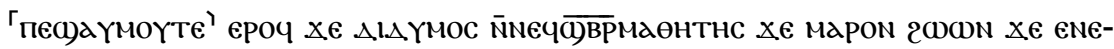

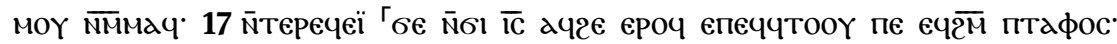

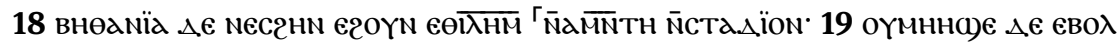

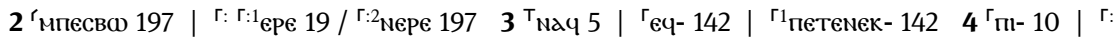

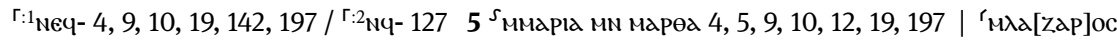

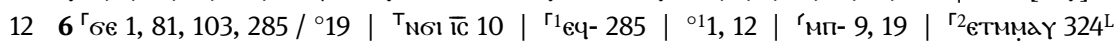

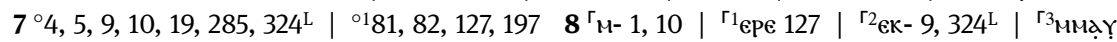

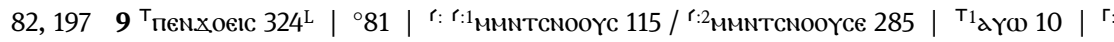

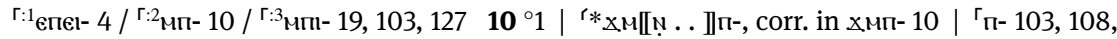

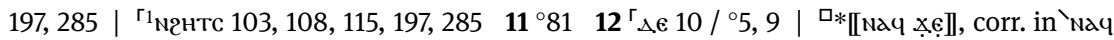

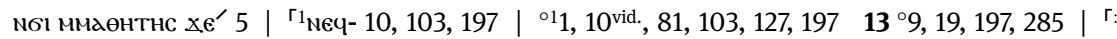

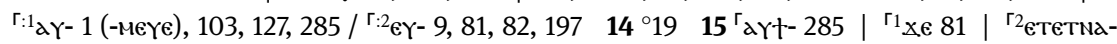

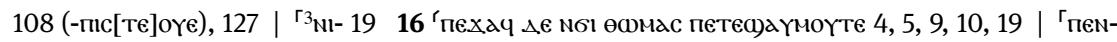

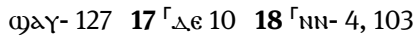

2 песчр] -вш 9, 19, 127, 142, 197 (мпес-) | пессом] *-єом, corr. in -сом 1423 гннте] гннпє 1, 103, 127 | петкмє] петек- 9, 10, 19, 127, 197, $285 \quad 4$ хекас] Хекадс 45 м̈марөа] ммд 'р'өа 127

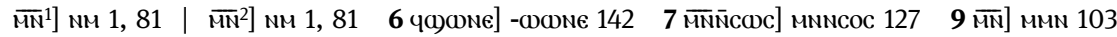

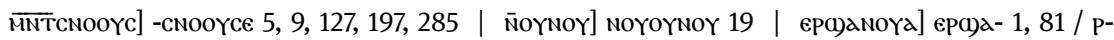

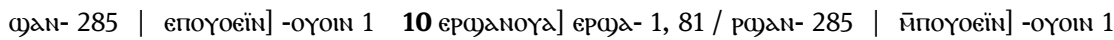

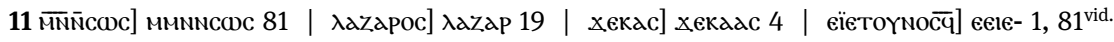

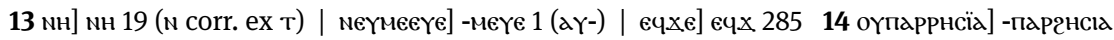

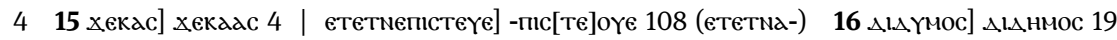

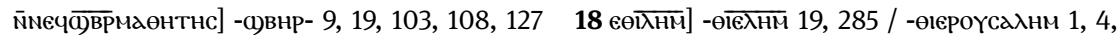

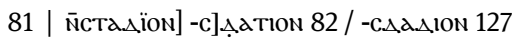




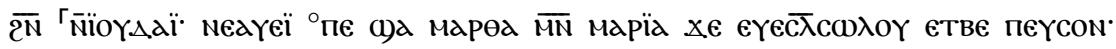

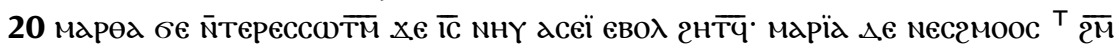

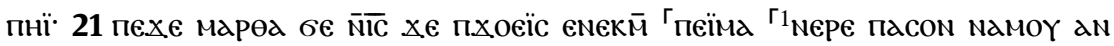

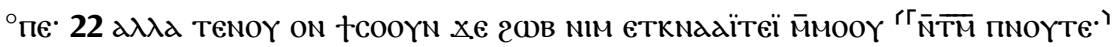

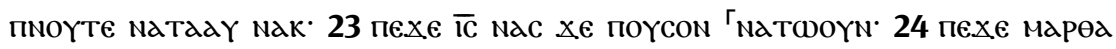

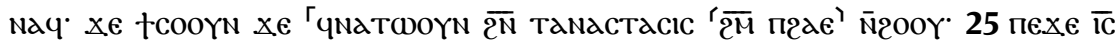

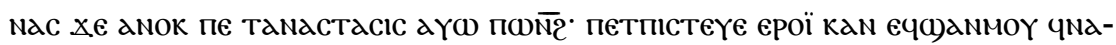

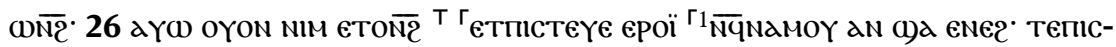

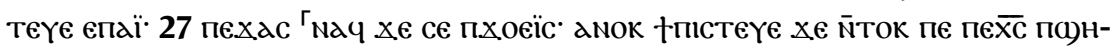

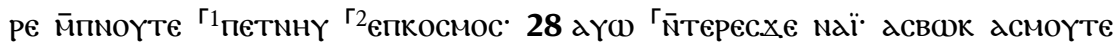

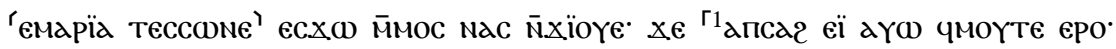

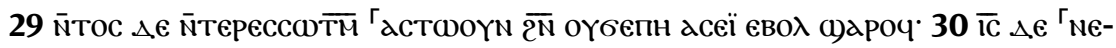

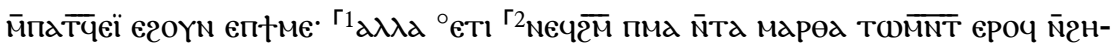

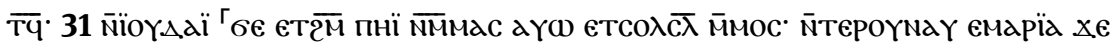

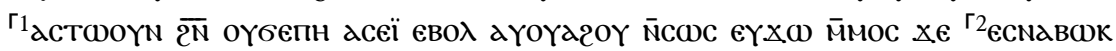

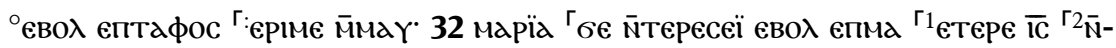

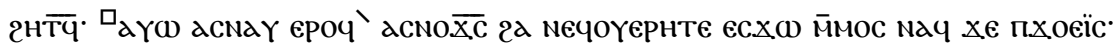

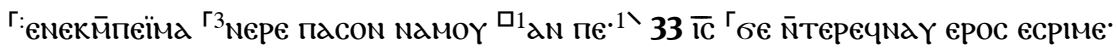

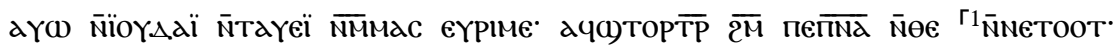

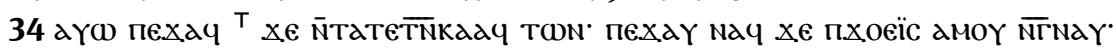

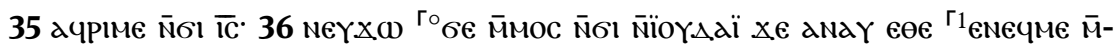

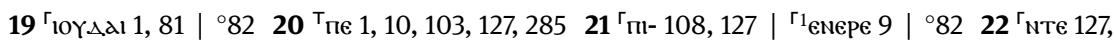

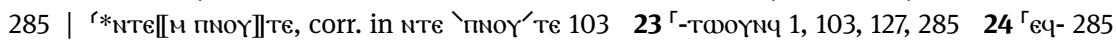

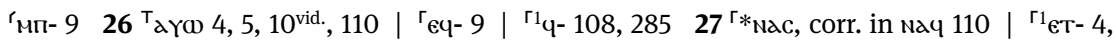

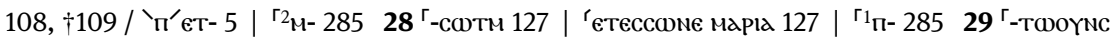

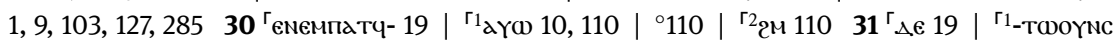

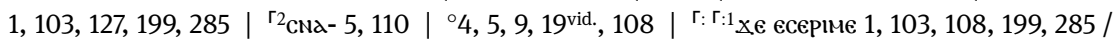

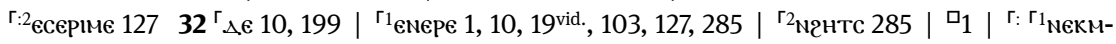

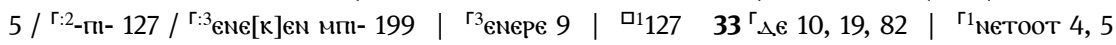

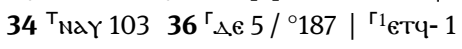

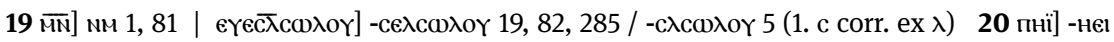
1, 8121 пеїа] пеєі- 422 еткмадїтеі] етек- 9, 19, 127, 285 / -aıтı 1, 4, 5, 81 vid. 24 пгае] фає 4,

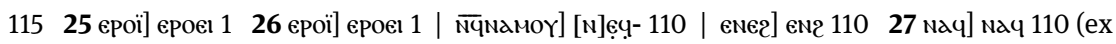

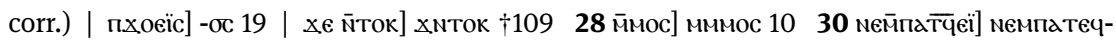

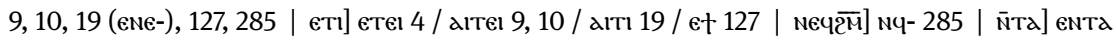

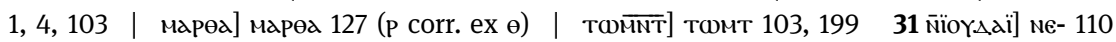

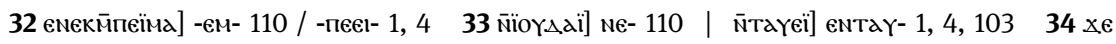

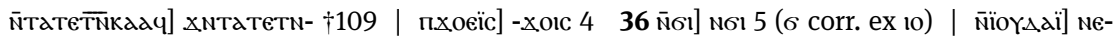
110 


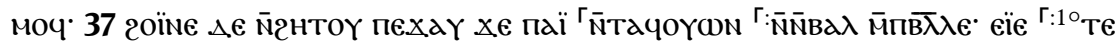

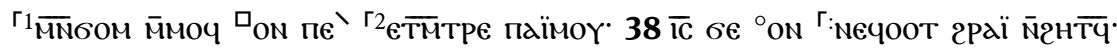
ачєї ептафос. '

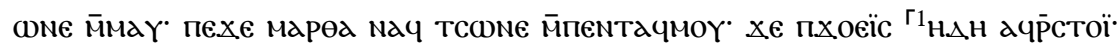

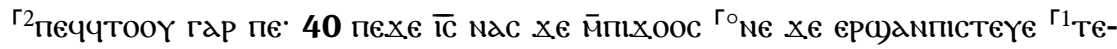

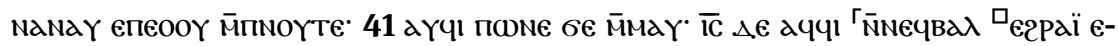

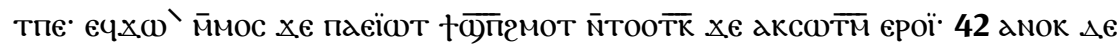

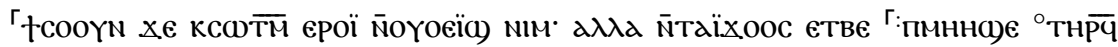

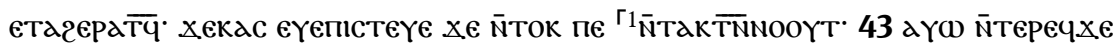

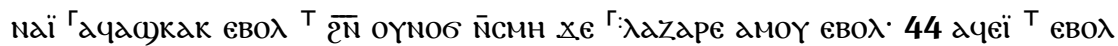

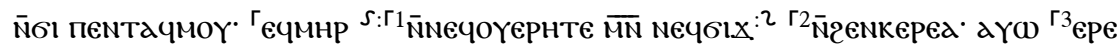

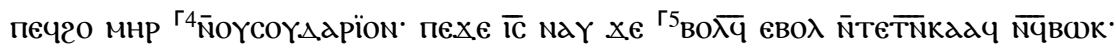

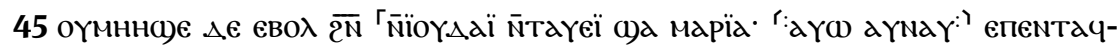

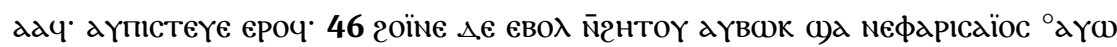

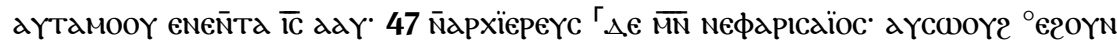

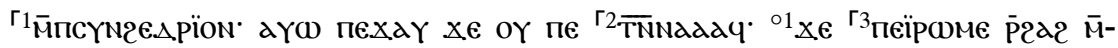

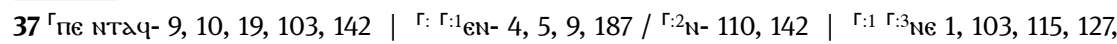

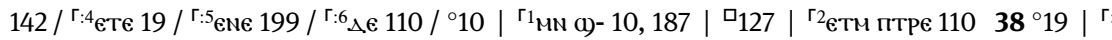

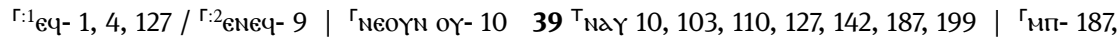

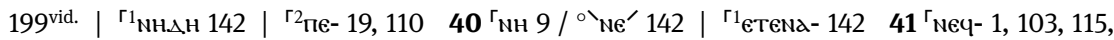

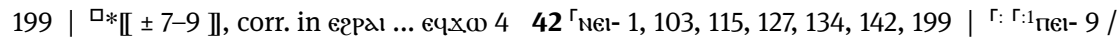

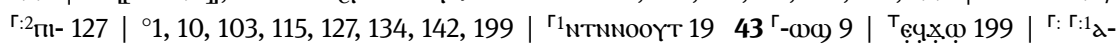

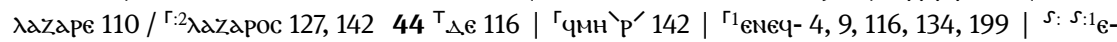

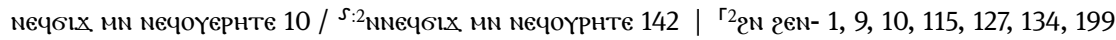

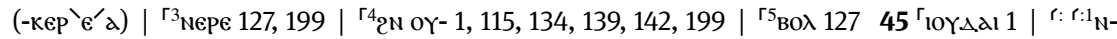

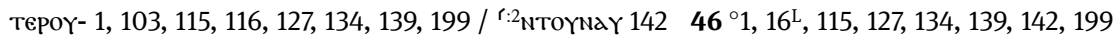

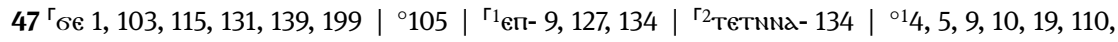
116 | ${ }^{\mathrm{r}} \mathrm{mll}-10,139,199$

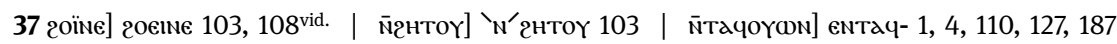

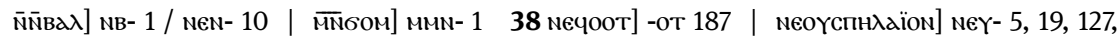

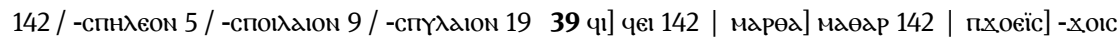
4 | ачрістоі] -ер- 19, 11040 м̄пхоос] мпеі- 9, 19, 82, 110, 142 | еро)анпістеүе] ро)ан- 142 | те-

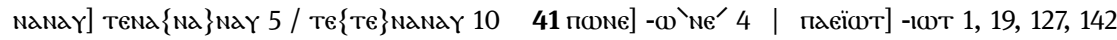

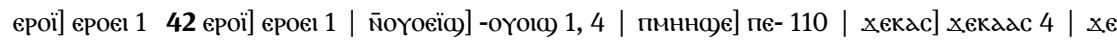

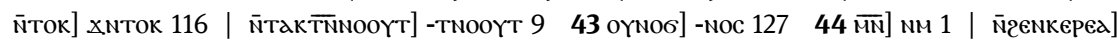

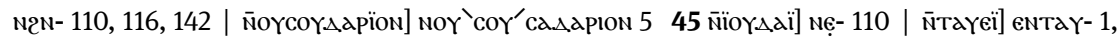
4, 103, 110, 115, 139, 187 | аүпістеүе] -пістеоүе 11546 2оїме] гоєіме 12, 103, 115, 139, 187 мефарісаїос] -фарісса1ос 9, 10, 16 $, 19,110,116,127,134,139$ | аүтамооү] -таммооү $947 \overline{\mathrm{MN}}]$

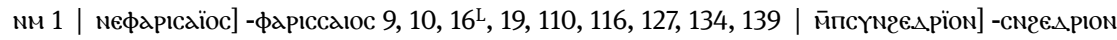

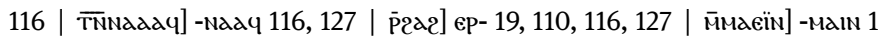




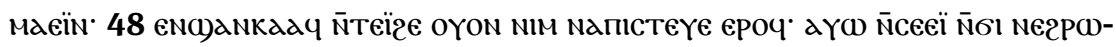

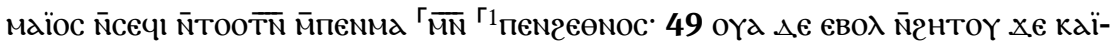

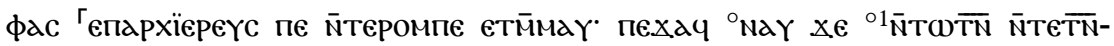

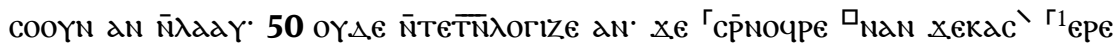

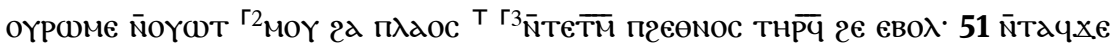

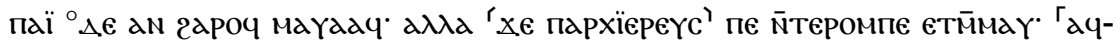

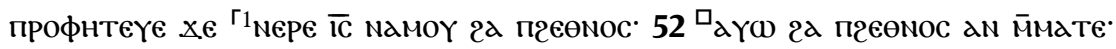

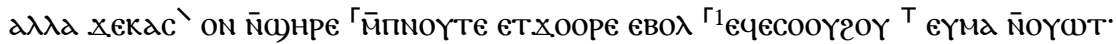

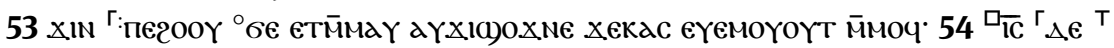

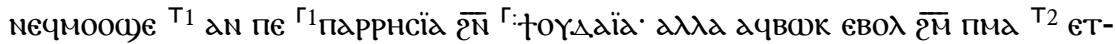

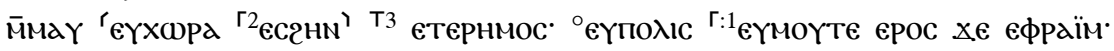

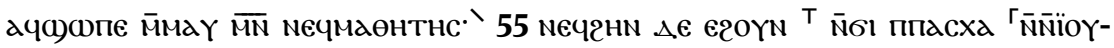

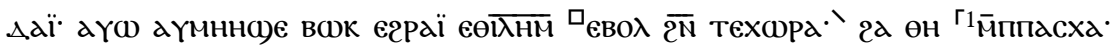

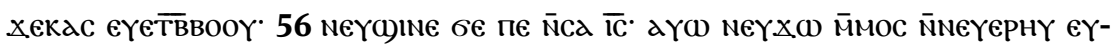

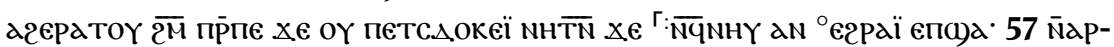

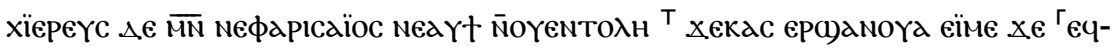

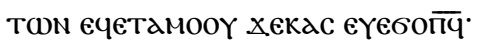

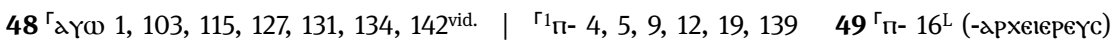

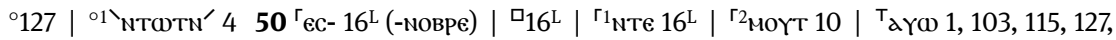

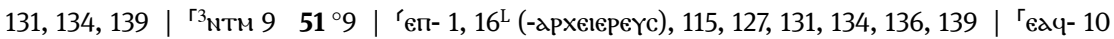

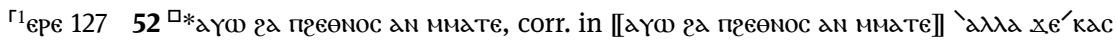

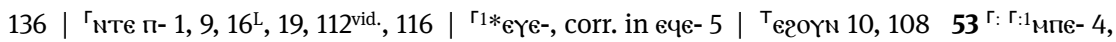
19, 116 / Г:2

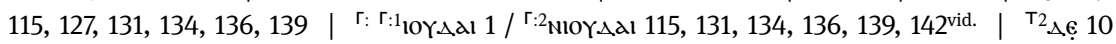

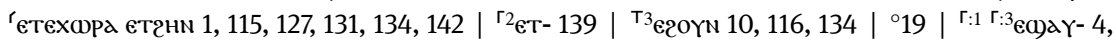

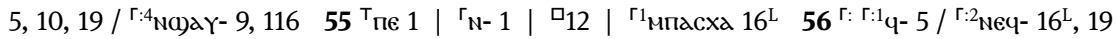
'е2pal' $13457^{\top} \pi \in 1,16$ L $, 131,134,136,139,154$ | 'q- 127

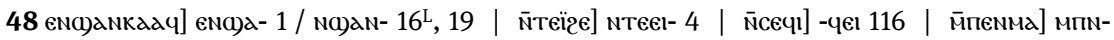

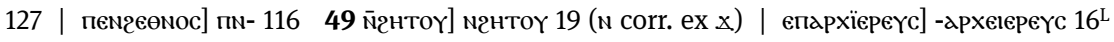

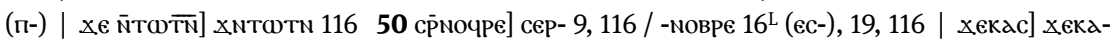

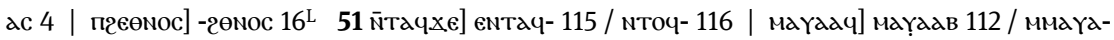

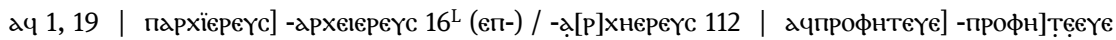

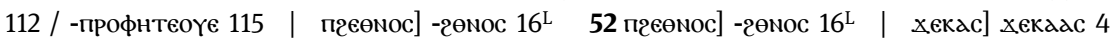

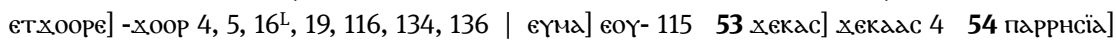

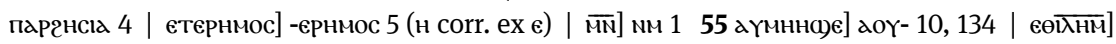

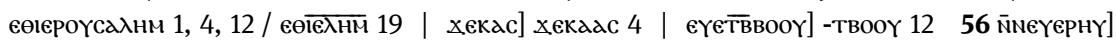

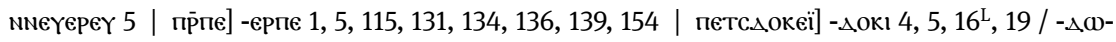

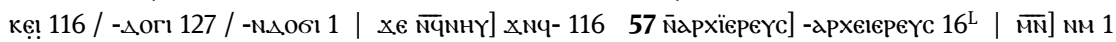

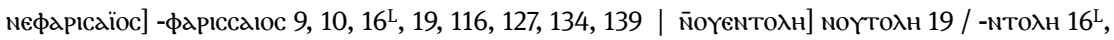

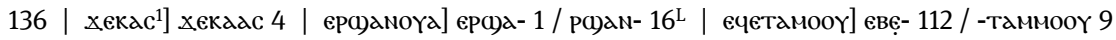
$\left.x \in \operatorname{Kac}^{2}\right]$ xeKadc 4 


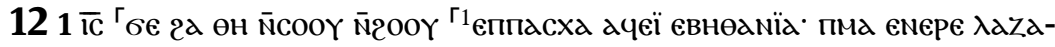

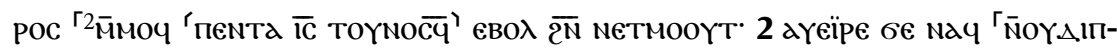

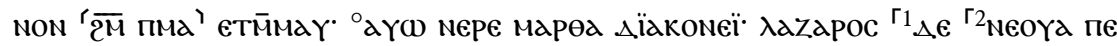

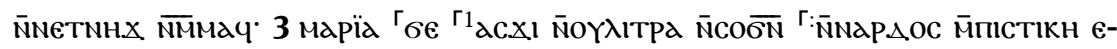

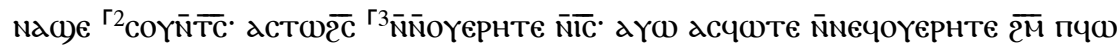

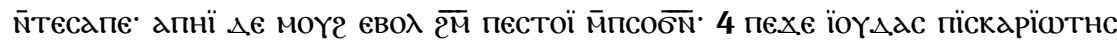

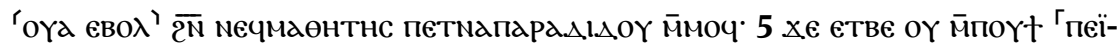

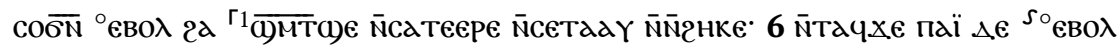

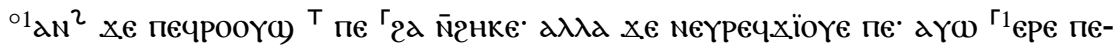

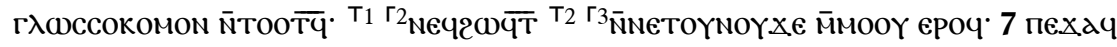

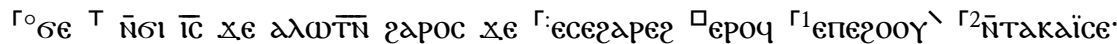

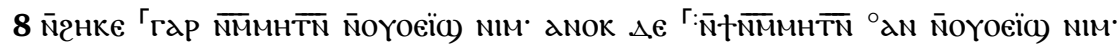

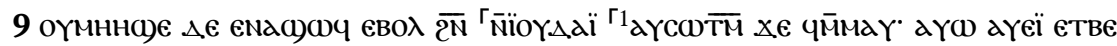

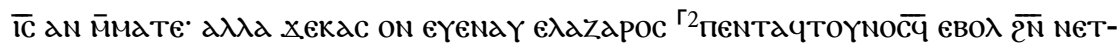

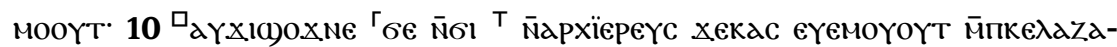

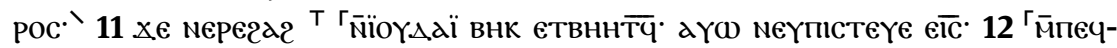

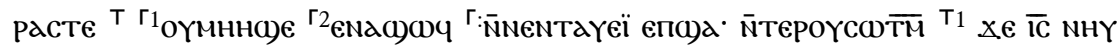

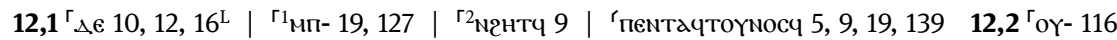

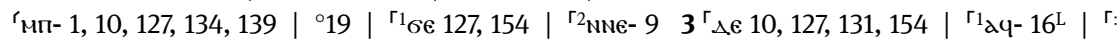

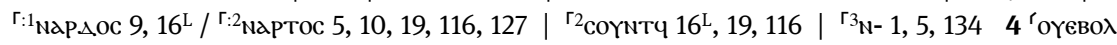

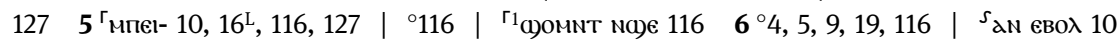

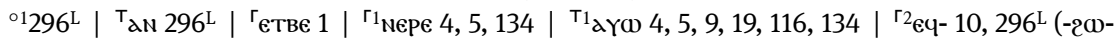

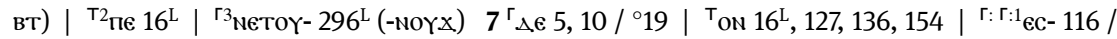

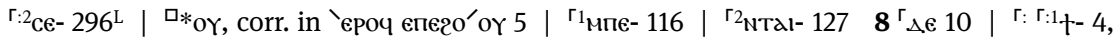

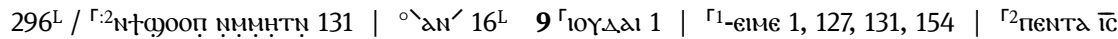

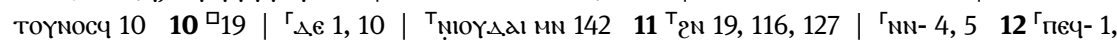

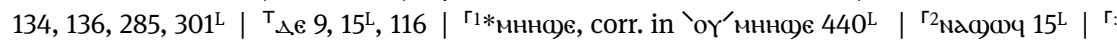

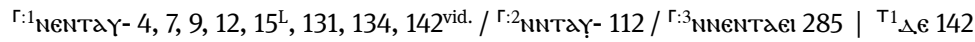

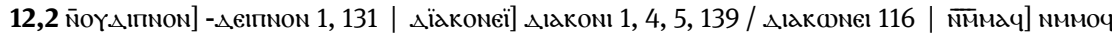
1163 мппстікн] -пистеІкн 16 / -пІстнкн 134 | асчбте] -воте 116 | пчб] -во 9, 19, 116, 127

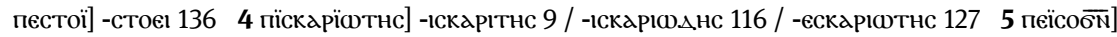

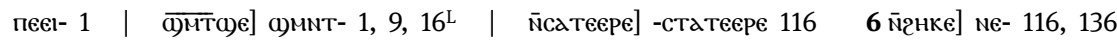

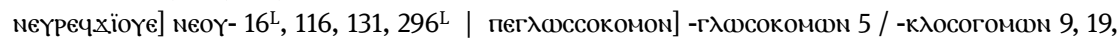

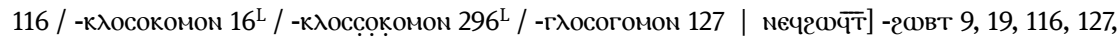

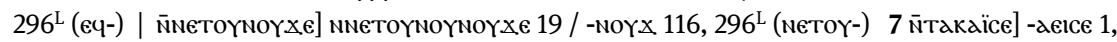

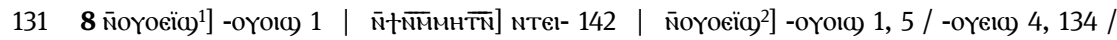

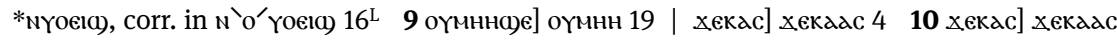

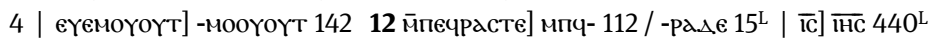




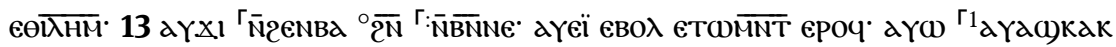

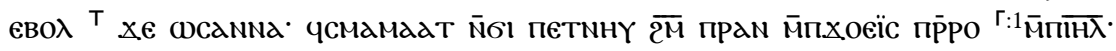

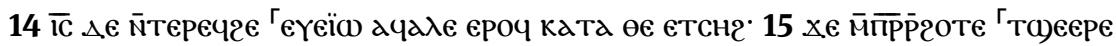

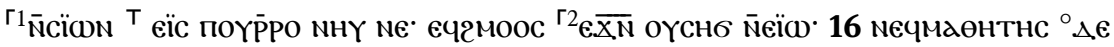

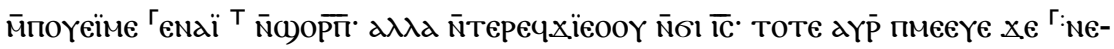

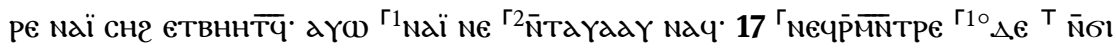

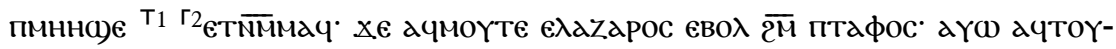

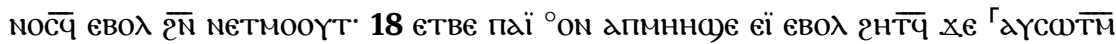

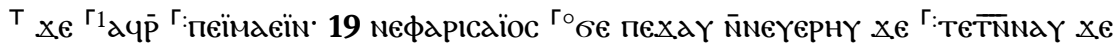

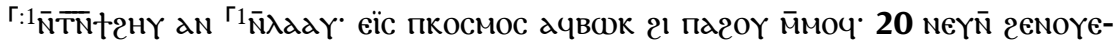

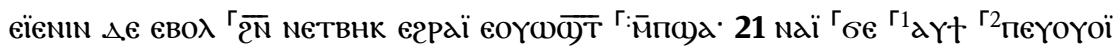

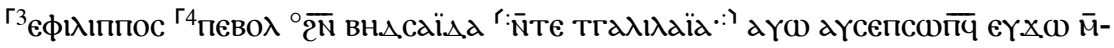

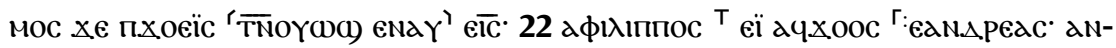

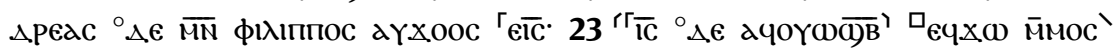

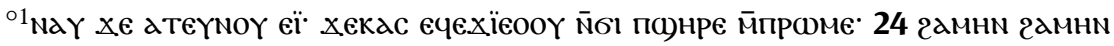

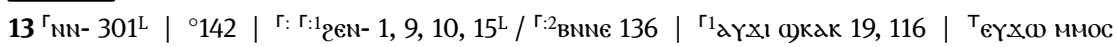

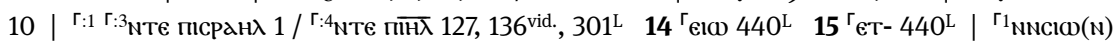

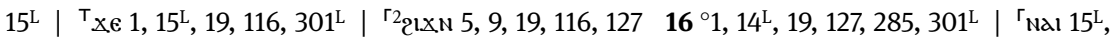

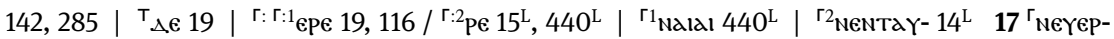

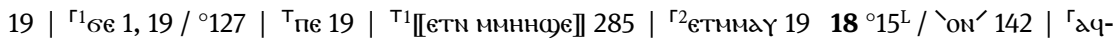

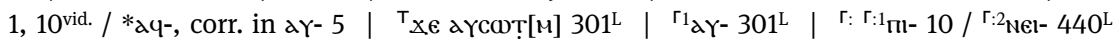

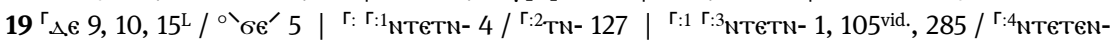

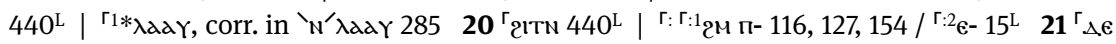

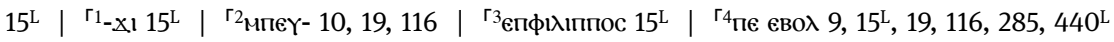

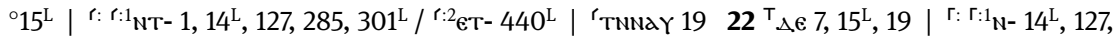

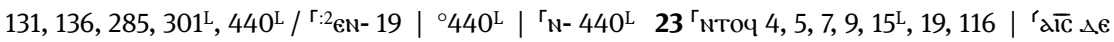
оүш()в $440^{\mathrm{L}}\left|{ }^{\circ} 15^{\mathrm{L}}\right|{ }^{\mathrm{D}} 127{ }^{\circ}{ }^{\circ}{ }^{\mathrm{NaY}} \gamma^{\prime} 10$

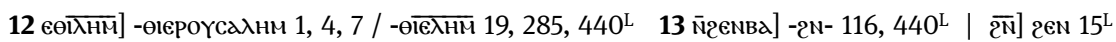

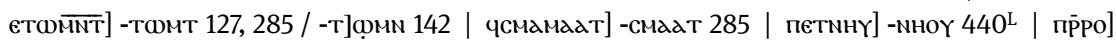

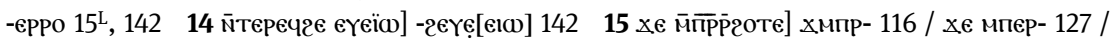

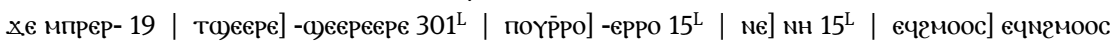

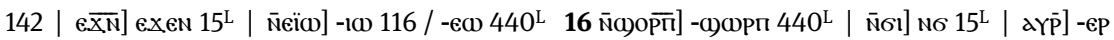

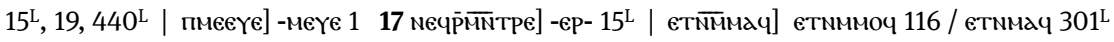

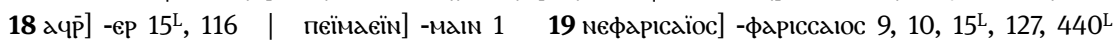

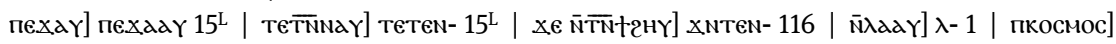

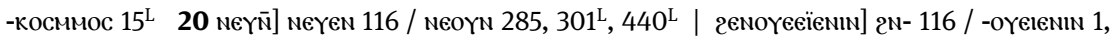

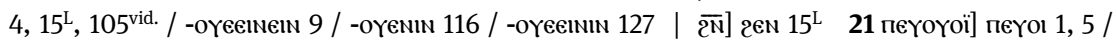

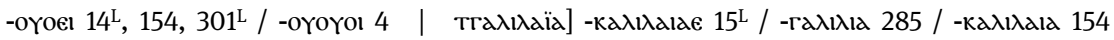

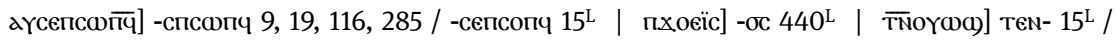
-оүe() 154 / -оү() $301^{\mathrm{L}} 22 \overline{\mathrm{MN}}$ ] NM 123 хекас] ХeKadc 4 


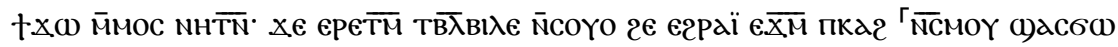

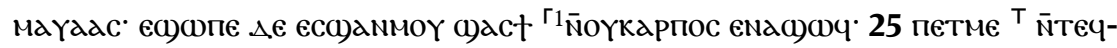

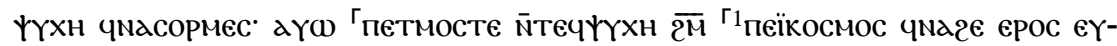

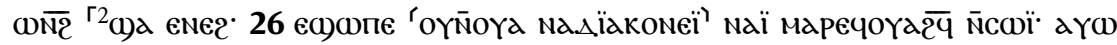
пма аNок е†тммоч' пакеАїакоNос '

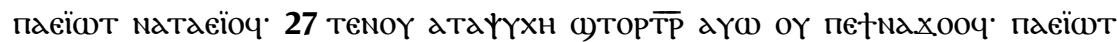

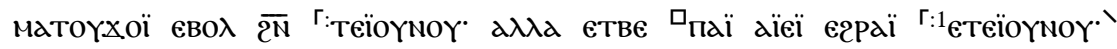

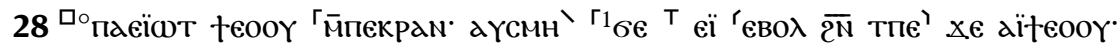

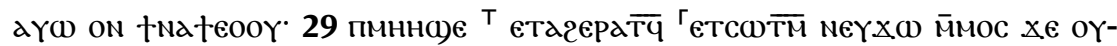

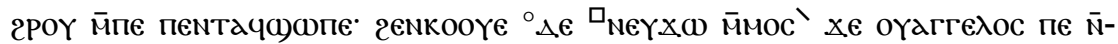

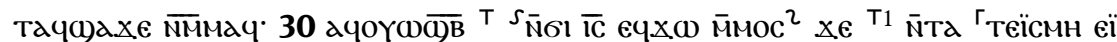

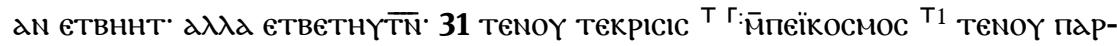

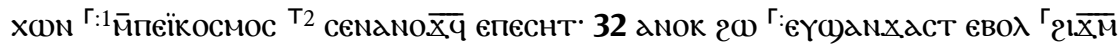

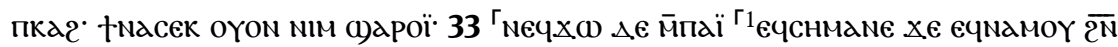

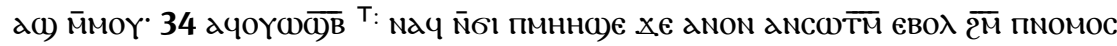

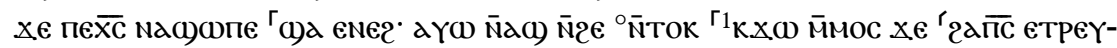

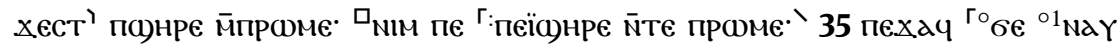

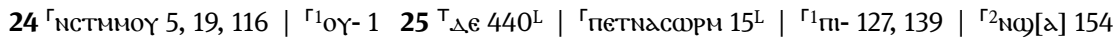

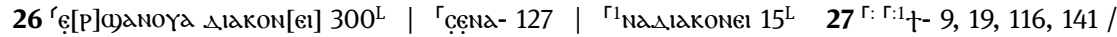

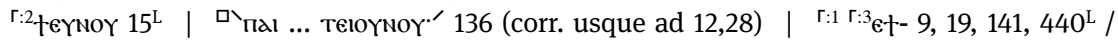

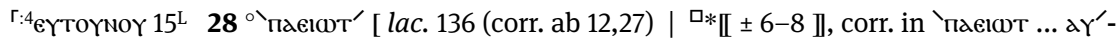

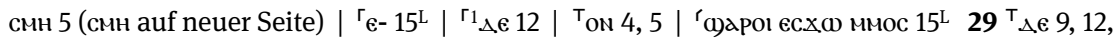

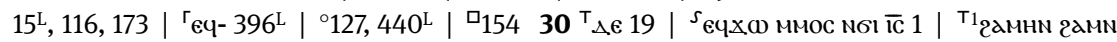

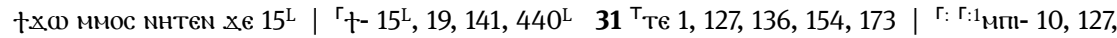

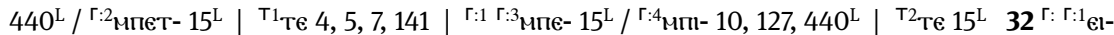

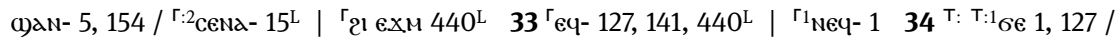

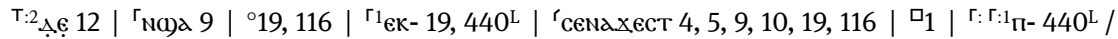
г:2 $\mathrm{ml}-10,19,12735^{\Gamma_{\Delta \epsilon}} 10 /\left.{ }^{\circ}{ }_{6 \epsilon} \epsilon^{\prime} 16^{\mathrm{L}}\right|^{\circ}{ }^{\circ} 305^{\mathrm{L}}$

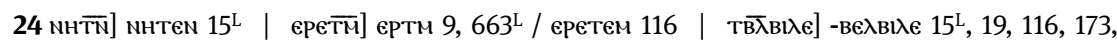

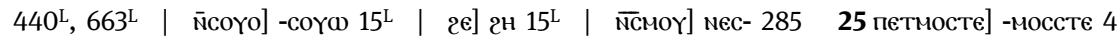

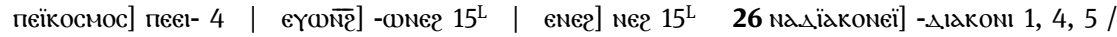

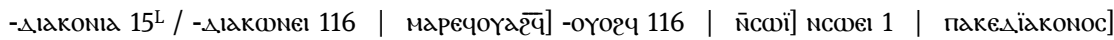

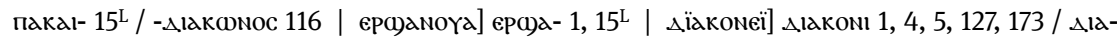

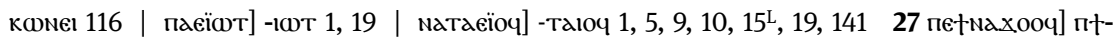

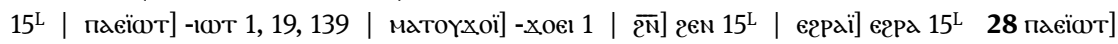

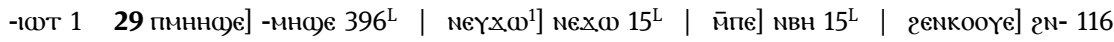

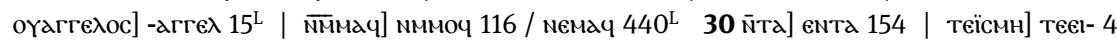

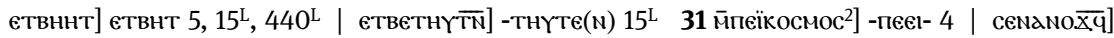

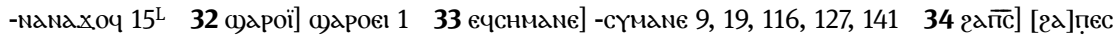
106 


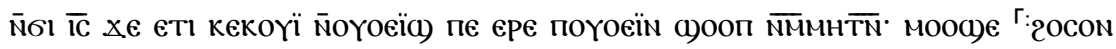

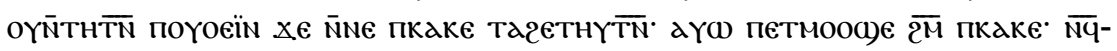

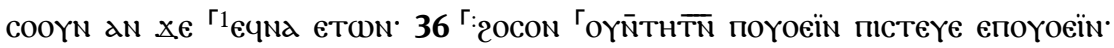
Хекас ${ }^{\text {Г:1 }}$ eтетнео)

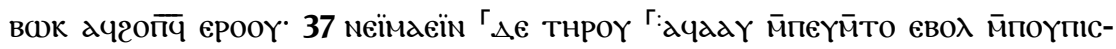

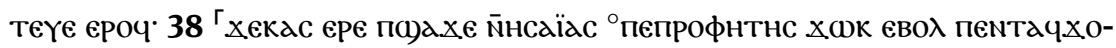

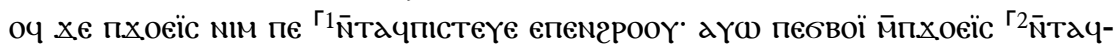

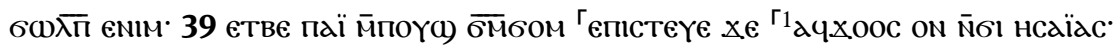

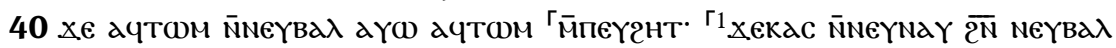

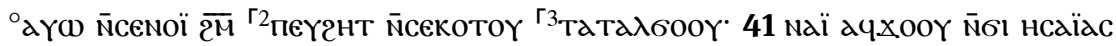

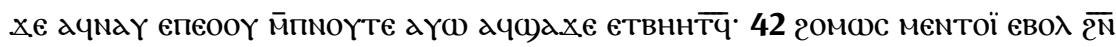

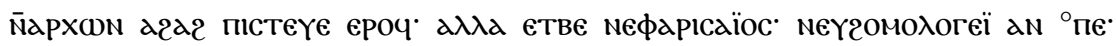

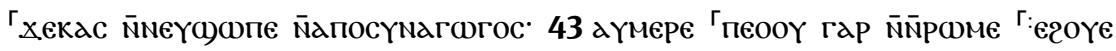

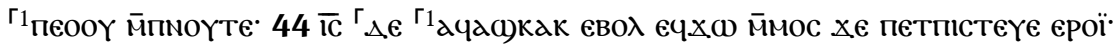

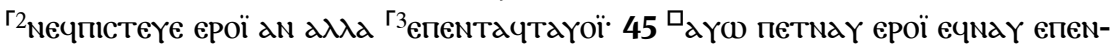

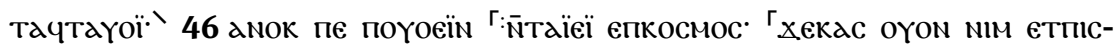

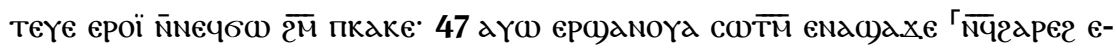

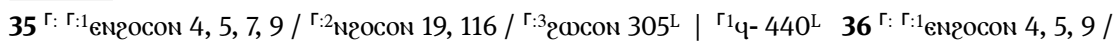
г:2

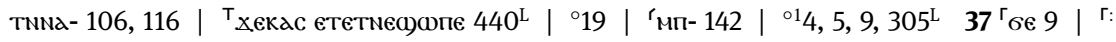

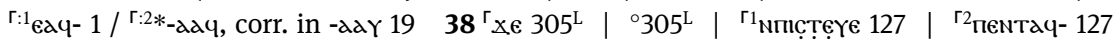

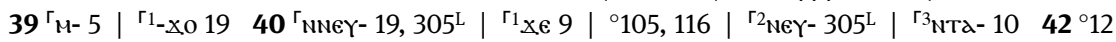

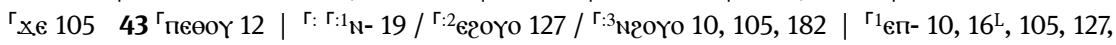

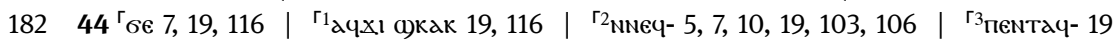

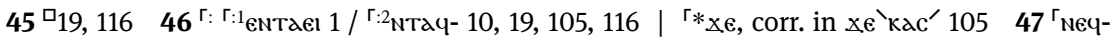
103

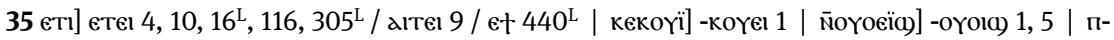

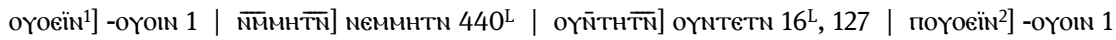

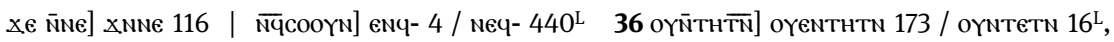

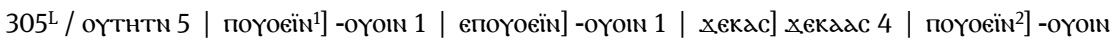

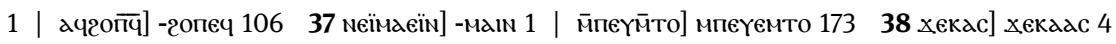

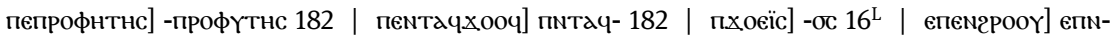

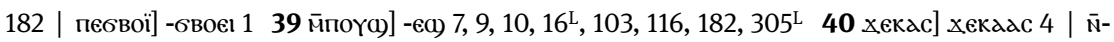

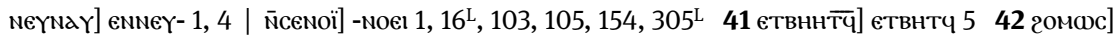
гомоюс 1 / гомос 16 $, 127,305^{\mathrm{L}}$ / гомос 116 / гомеос 182 | ментоі] мnто 16 $, 19,142,182$ / мNтал 116 | пистеүе] пістеоүе 103 | ероч] P[оч] 182, 305 | мефарісаїос] -фаріссаıос 9, 16L, 19,

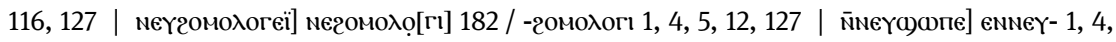

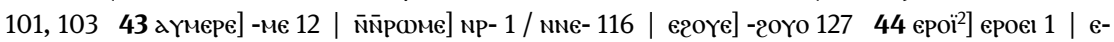

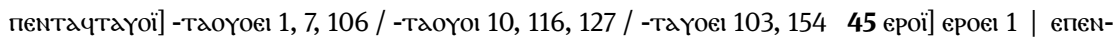

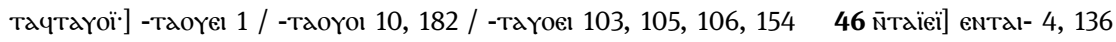

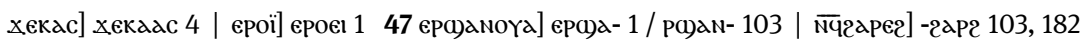




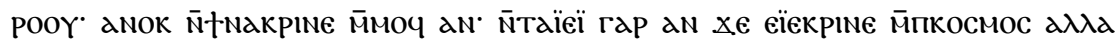

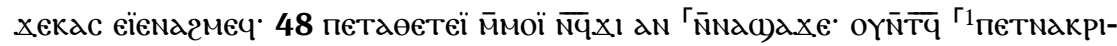

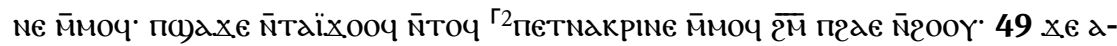

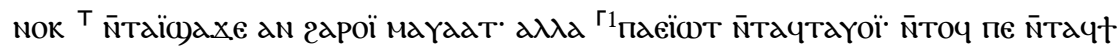

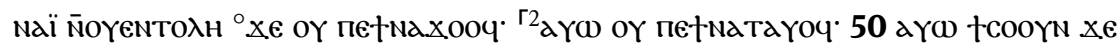

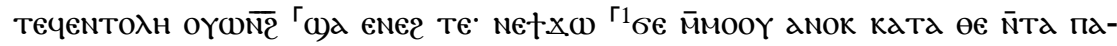

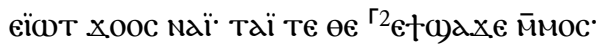

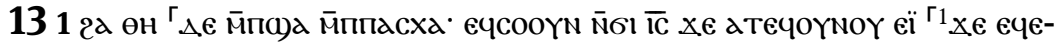

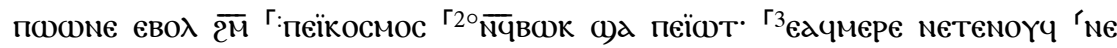

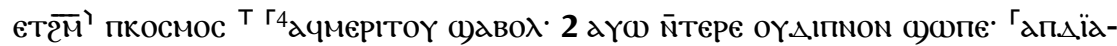

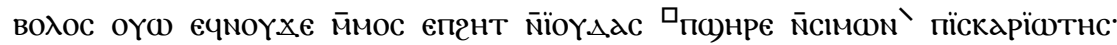

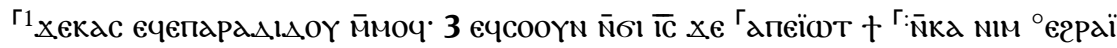

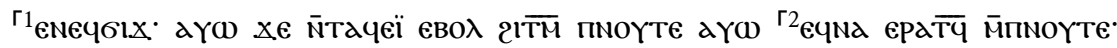

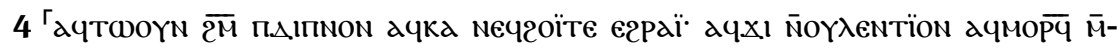

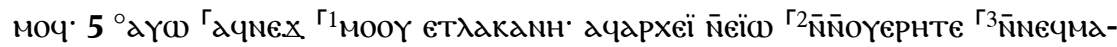

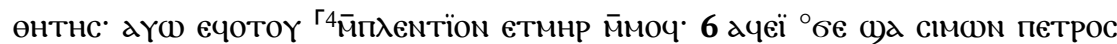

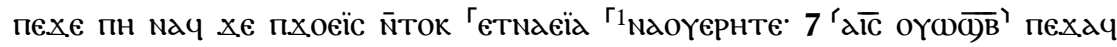

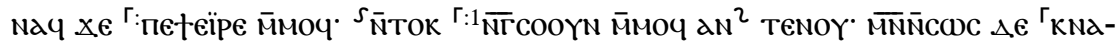

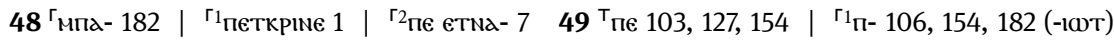

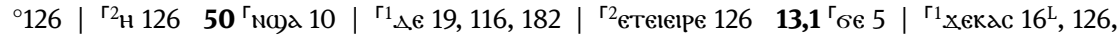

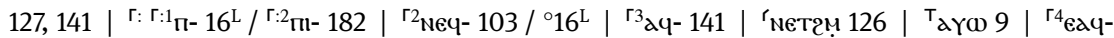

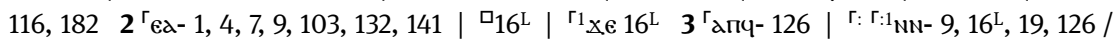

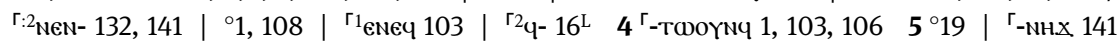

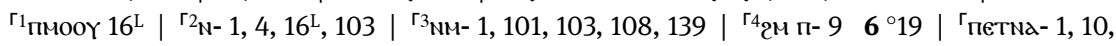

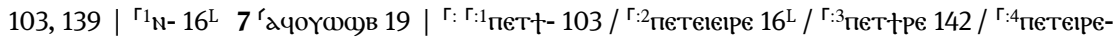

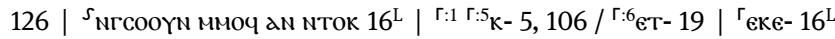

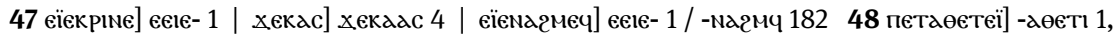

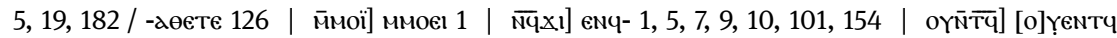

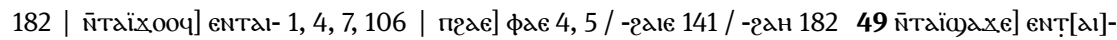

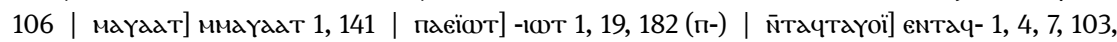

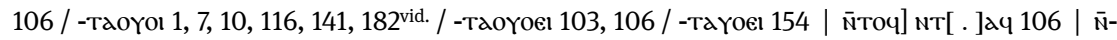

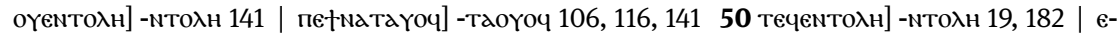

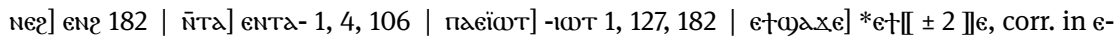

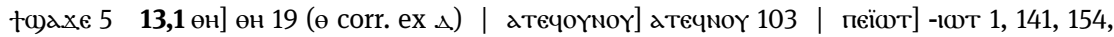

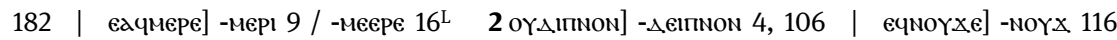

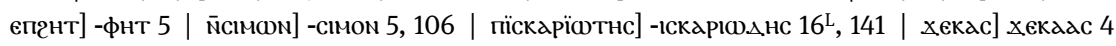

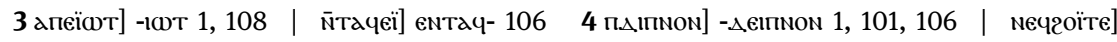

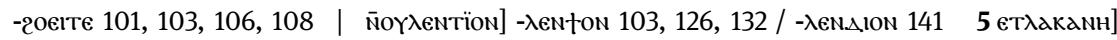

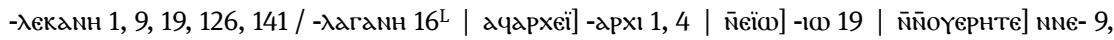

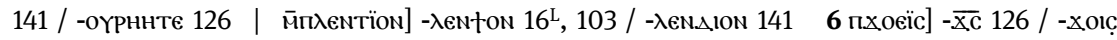
180 | маоүернте] -оүрннте $1267 \overline{\mathrm{MN}} \overline{\mathrm{N}} \mathrm{coc}]$ мNс0е 142 


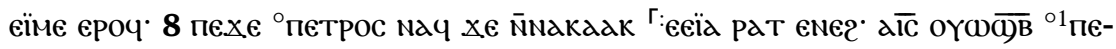

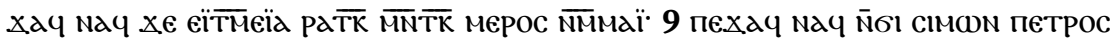

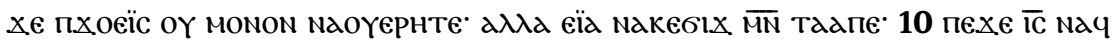

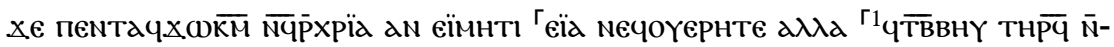

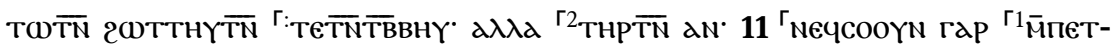

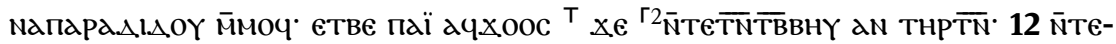

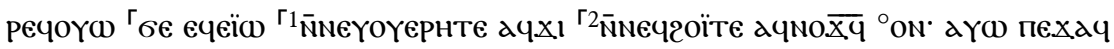

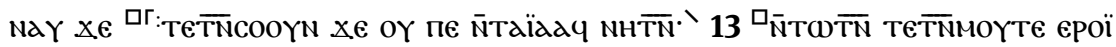

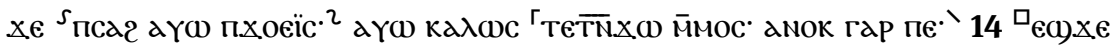

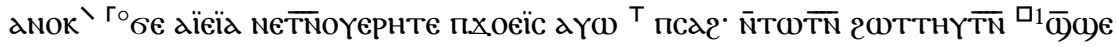

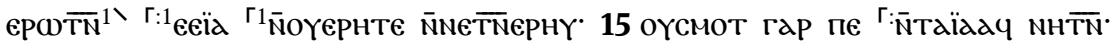

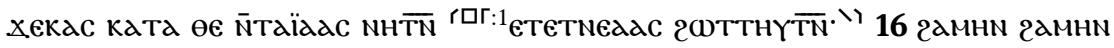

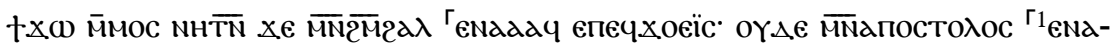

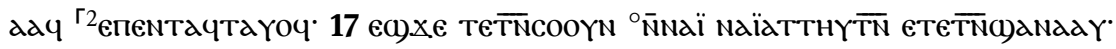
18 वг:

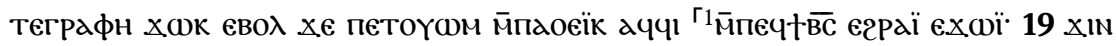

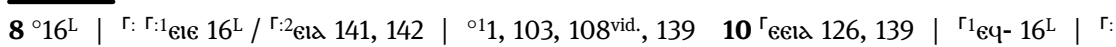

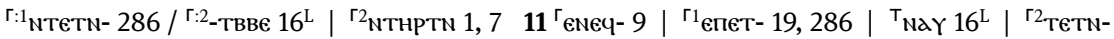

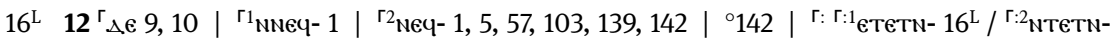

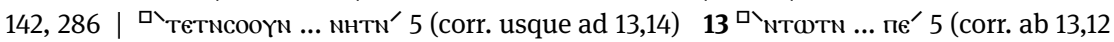

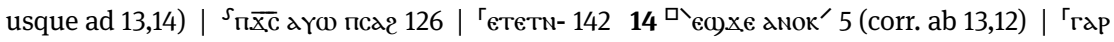

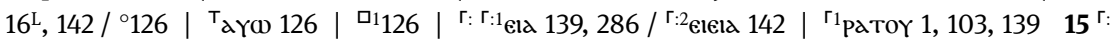

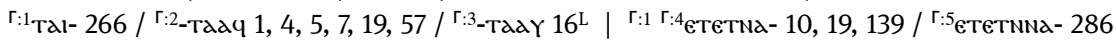

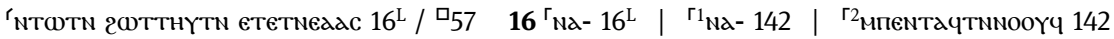

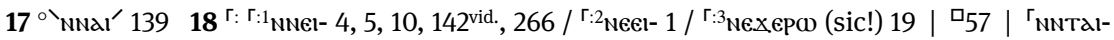
$9 \mid{ }^{\Gamma 1}$ пєч- 1,10

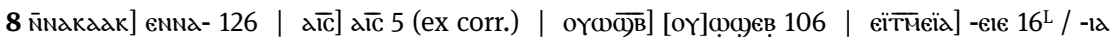

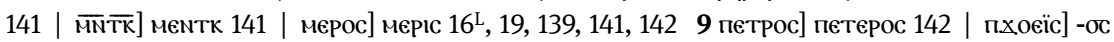

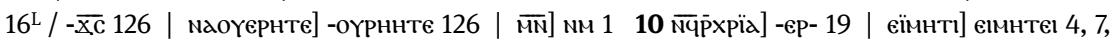

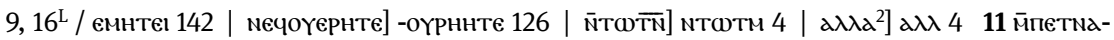

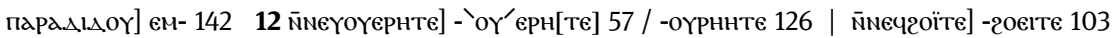

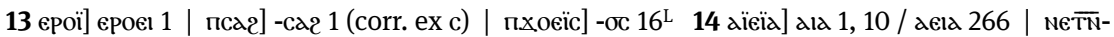

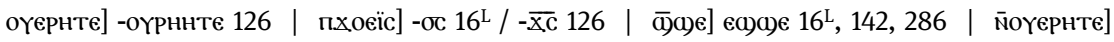

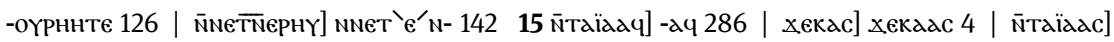

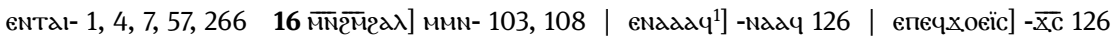

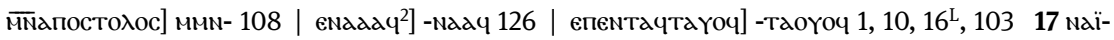

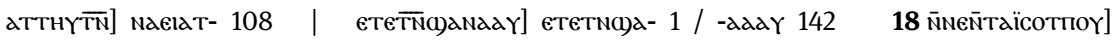
емме[м]та1- 103 | хекас] хекадс 4 | теграфн] -г]ратфү 57 | петоүом] -оүом 103 | мппаоеік]

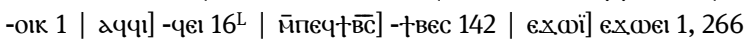




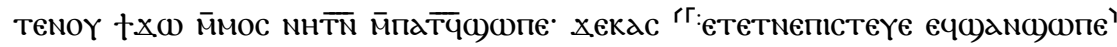

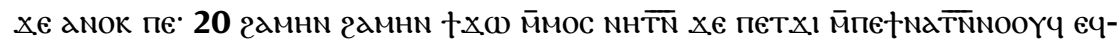

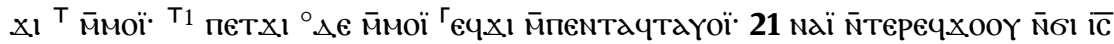

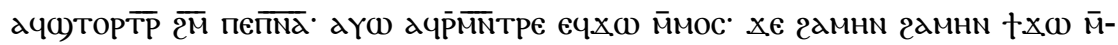

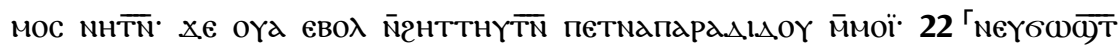

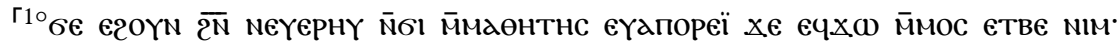

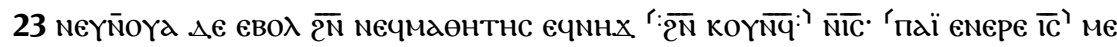

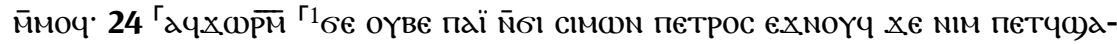

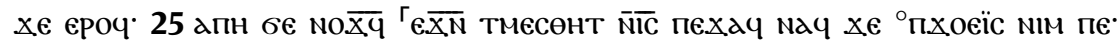

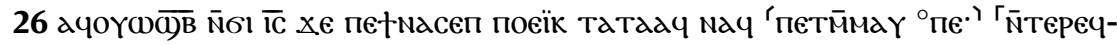

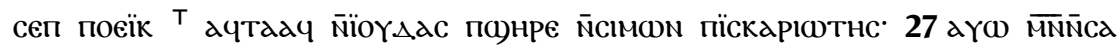

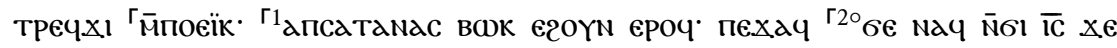

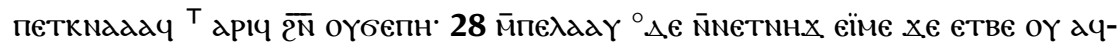

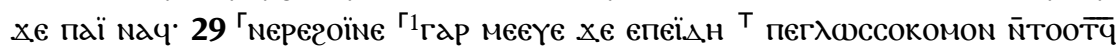

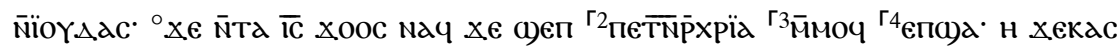

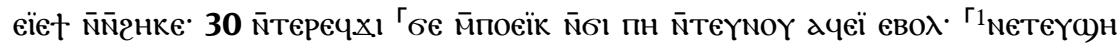

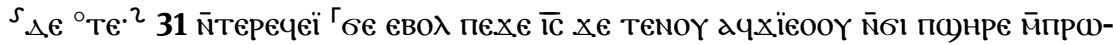

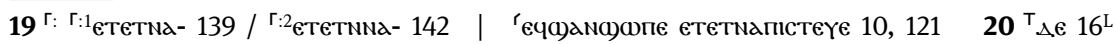

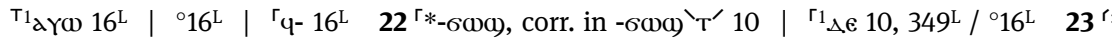
r:1екоүнч 1, 108 / 'r:2екоүоүмч 103, 139, 154 | 'петере ic 1, 10 vid., 103, 108, 121, 139, 142, 154

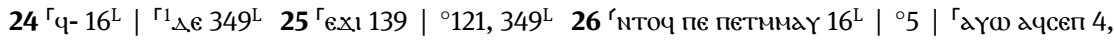

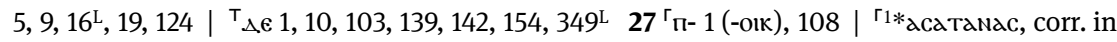

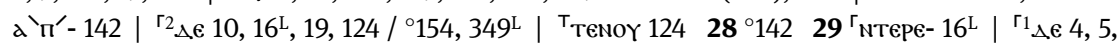

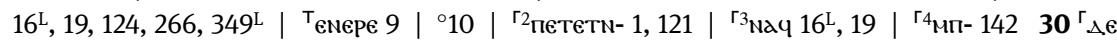

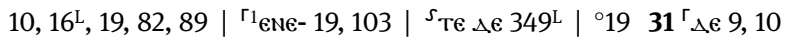

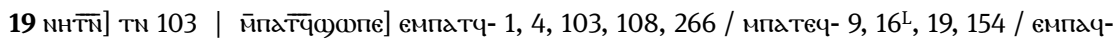

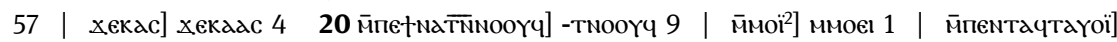

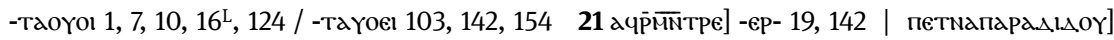

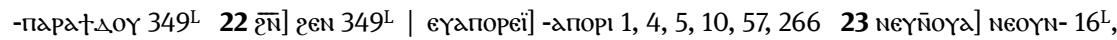

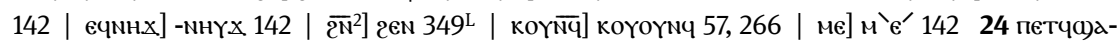

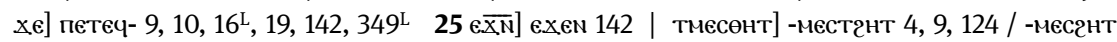

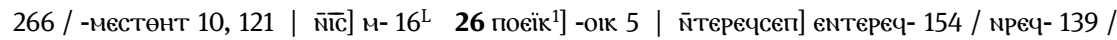

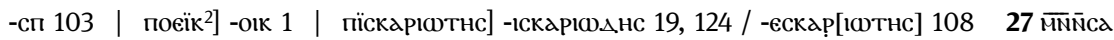

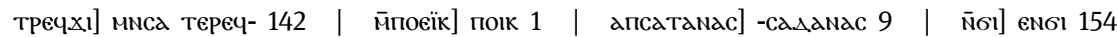

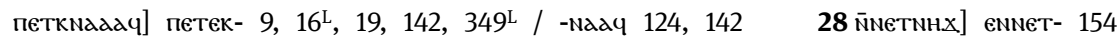
29 nерегоїме] -zоєіме 103, 154 | меєүе] меүє 1, 142 | епєї.н] епі.нн 1, 19, 121, 124, 139, 154

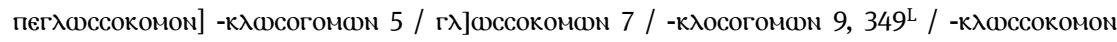

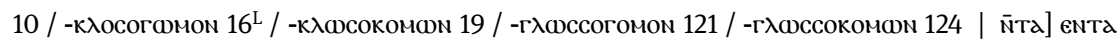

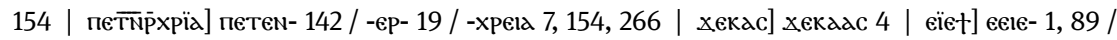

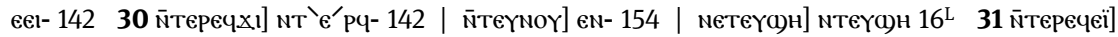
eNTEPEY- 154 


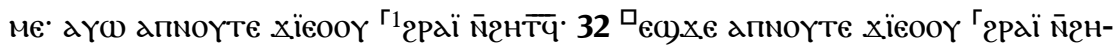

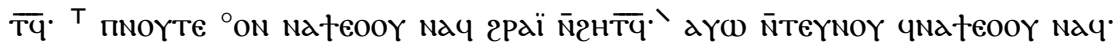

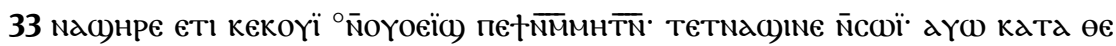

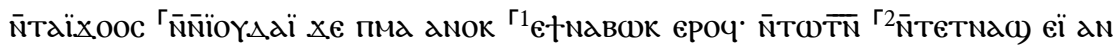

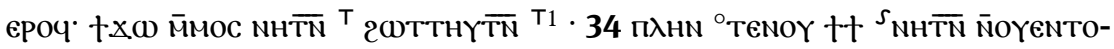

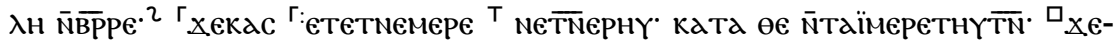

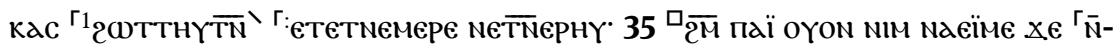

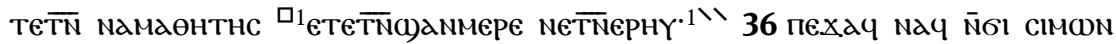

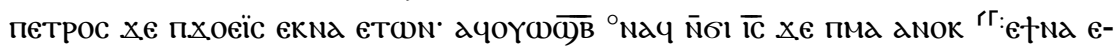

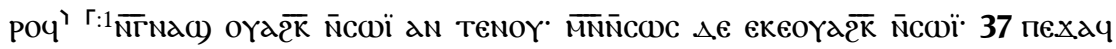

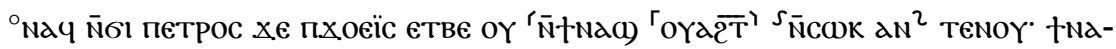

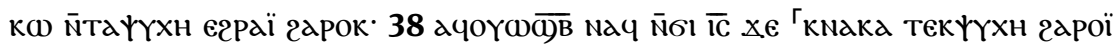

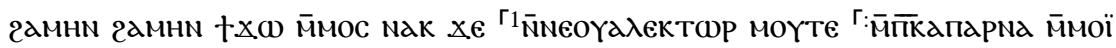
$\overline{\mathrm{N}}$ )O $\overline{\mathrm{MNT}} \overline{\mathrm{N}} \mathrm{CO \Pi}$

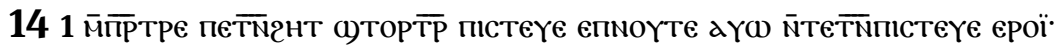

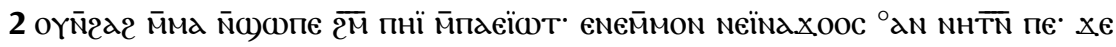

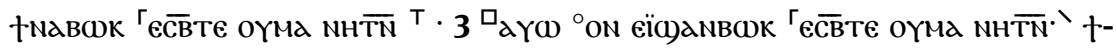

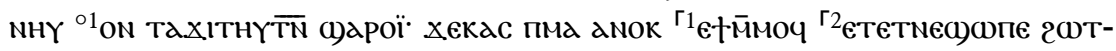

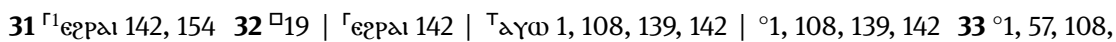

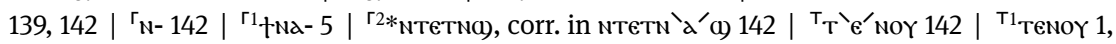

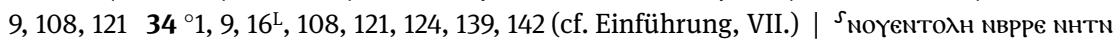

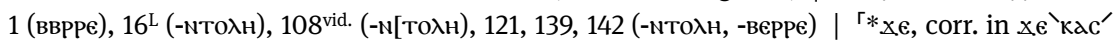

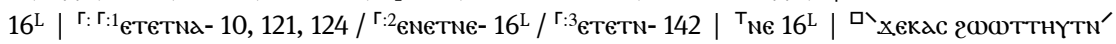

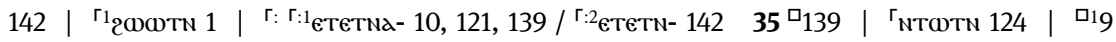

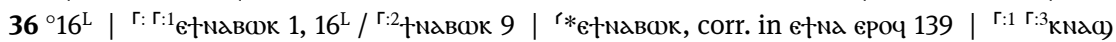

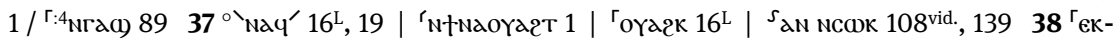

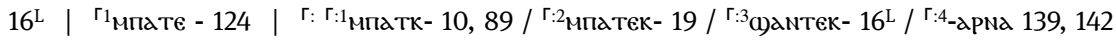

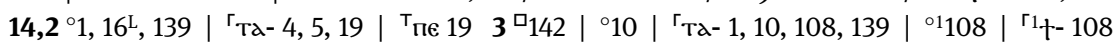
${ }^{{ }^{2}}$ ететN- $10,16^{\mathrm{L}}, 139$

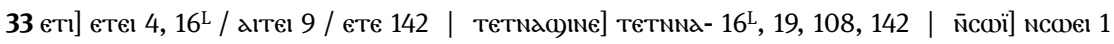

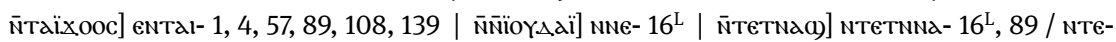

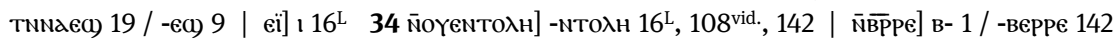

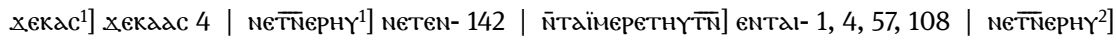

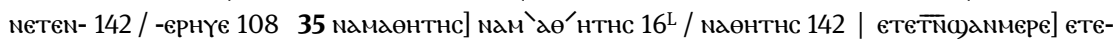

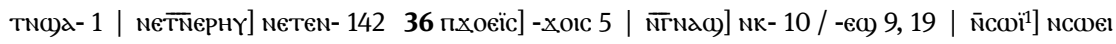

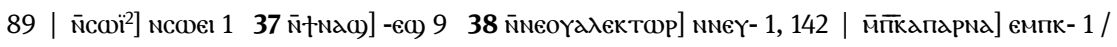

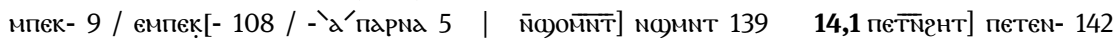

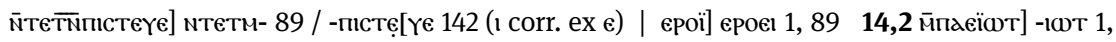

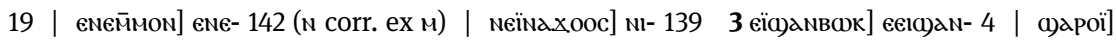
c)apoeı 1 | хекас] хекаac 4 


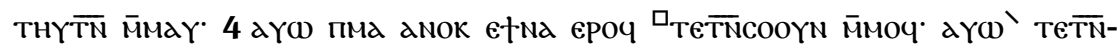

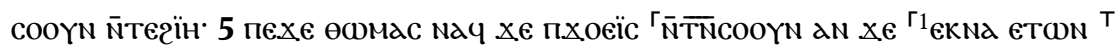

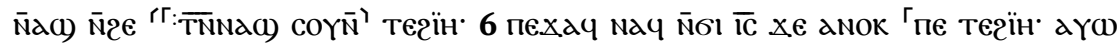

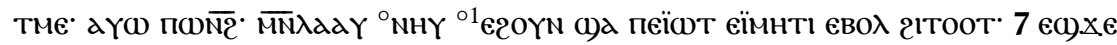

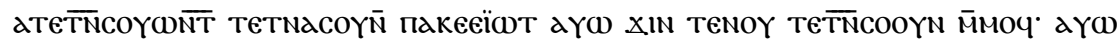

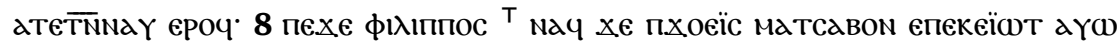

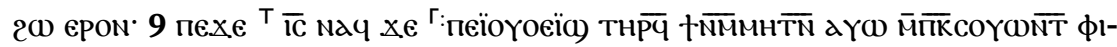

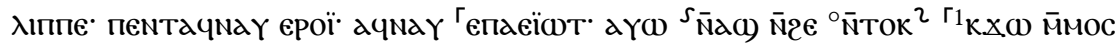

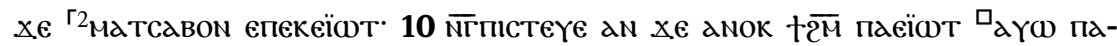

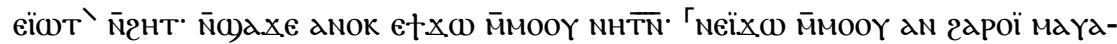

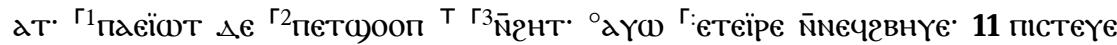

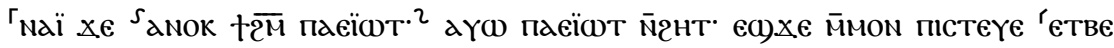

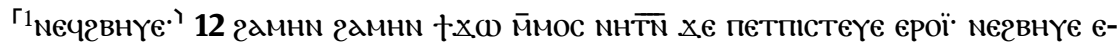

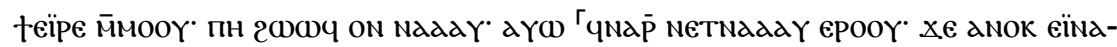

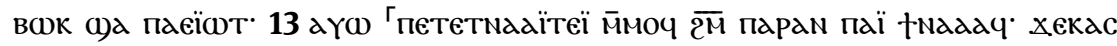

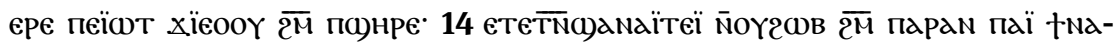
dач' 15 етет̄

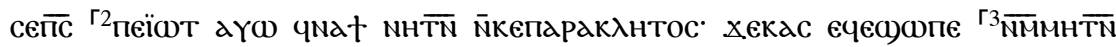

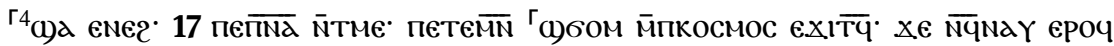

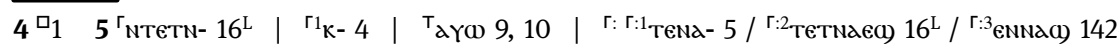

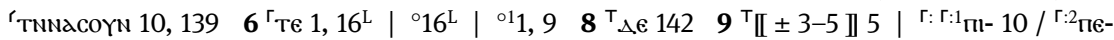

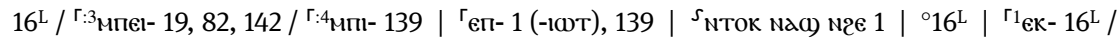

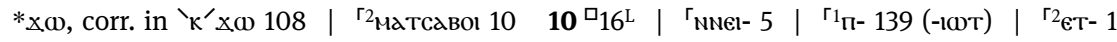

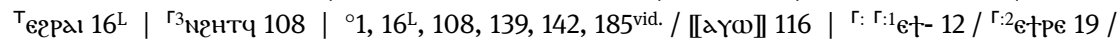

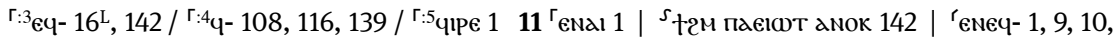

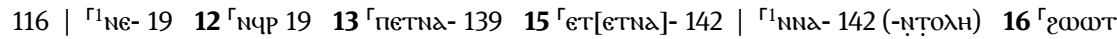

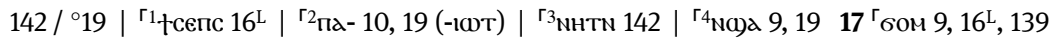

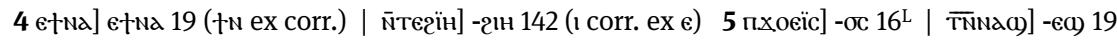

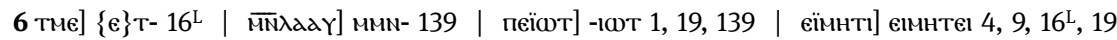

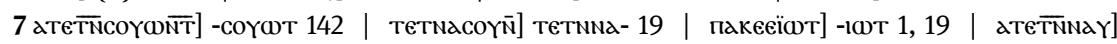

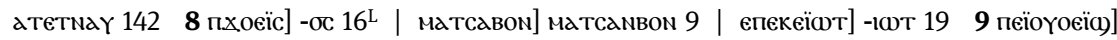

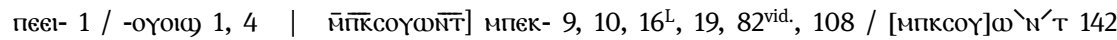

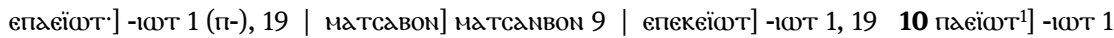

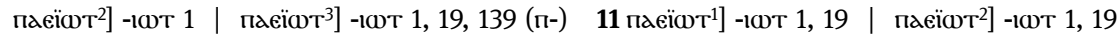

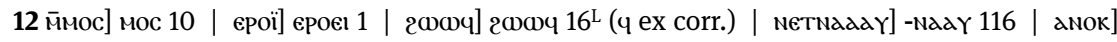

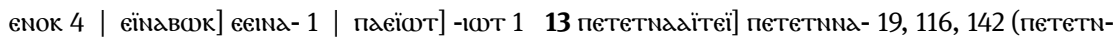

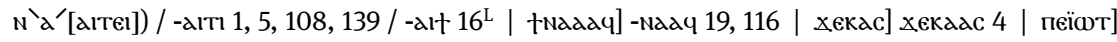

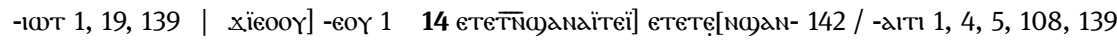

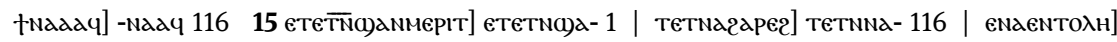

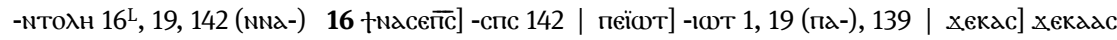

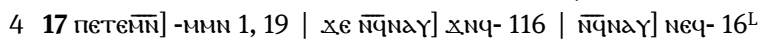




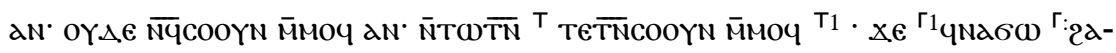

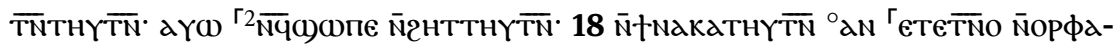

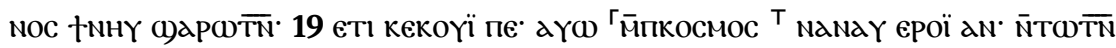

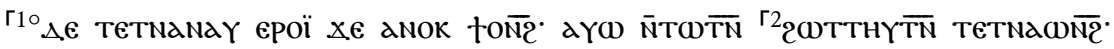

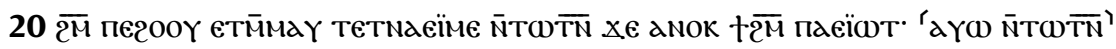

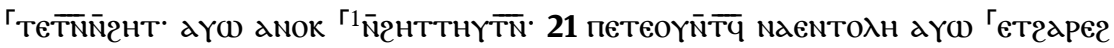

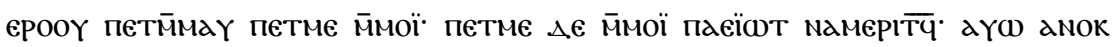

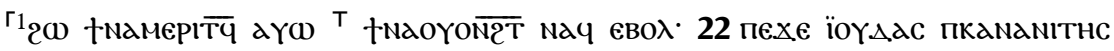

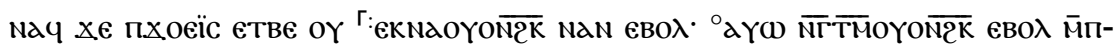

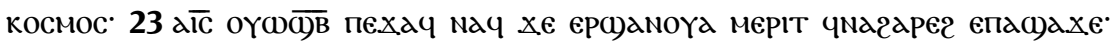

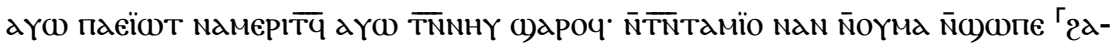

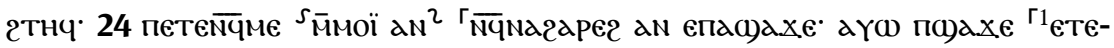

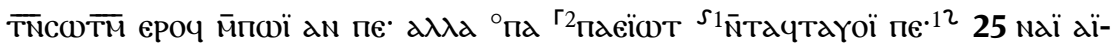

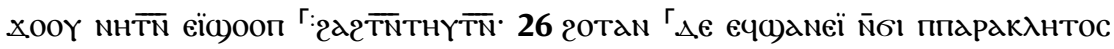

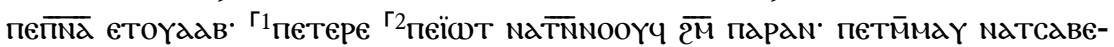
THYTN

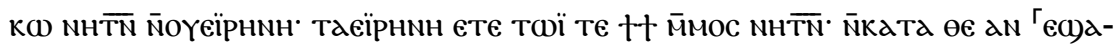

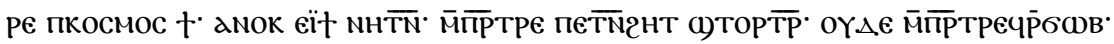

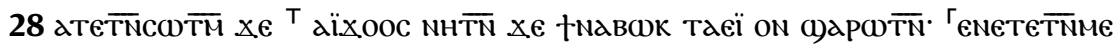

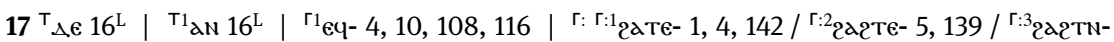

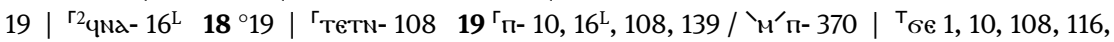

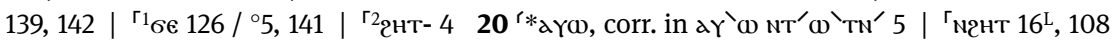

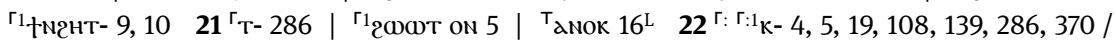

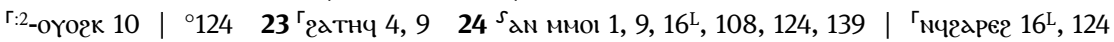

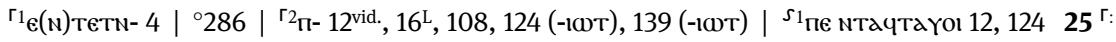

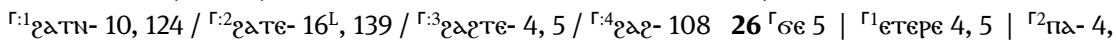
5, 19 (-ІІет), 124, 286 | Г: Г:1

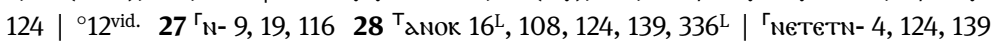

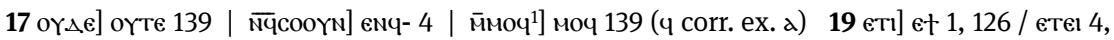

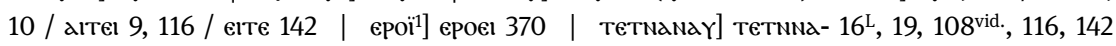

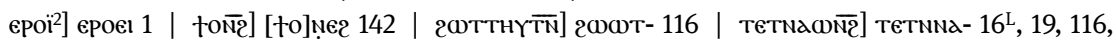

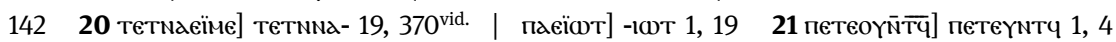

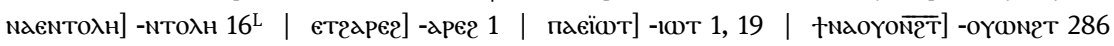

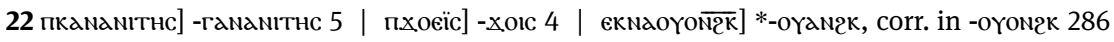

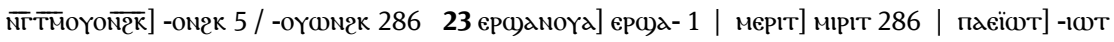

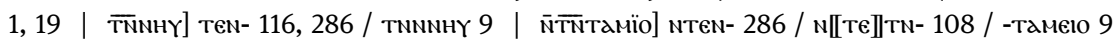

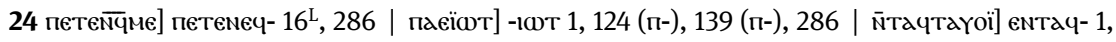

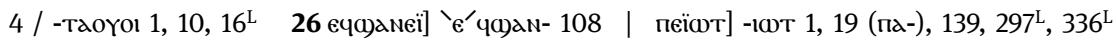

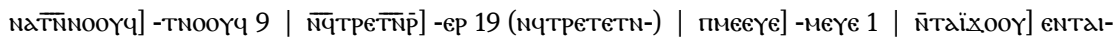

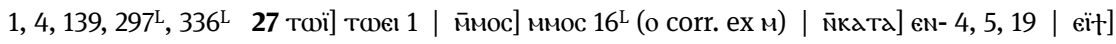

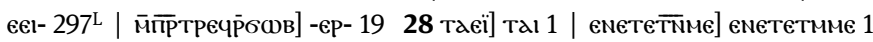




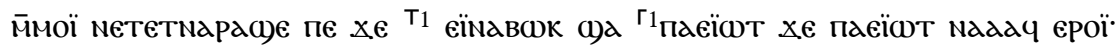

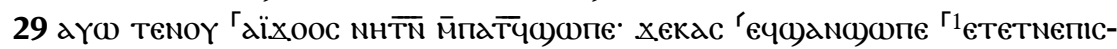

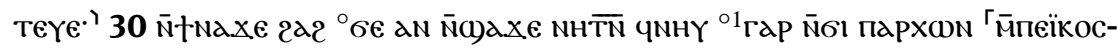

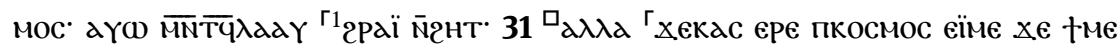

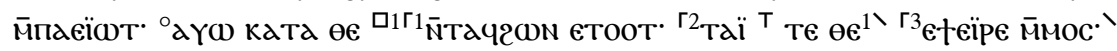

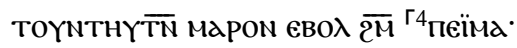

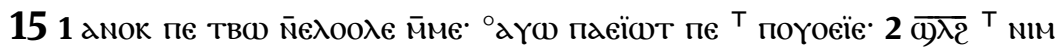

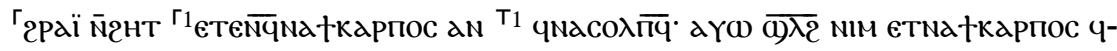

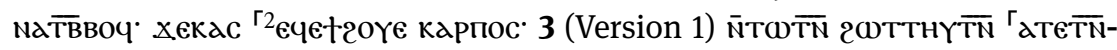

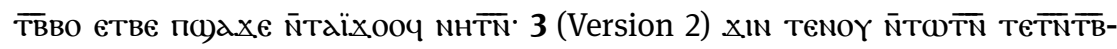

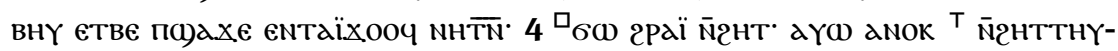

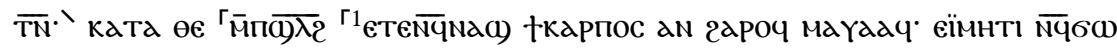

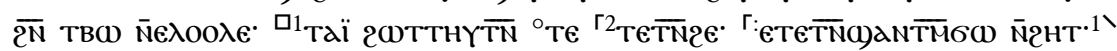

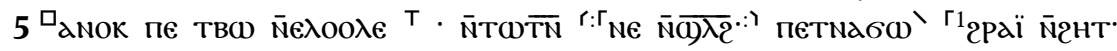

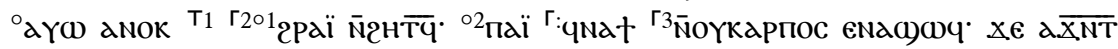

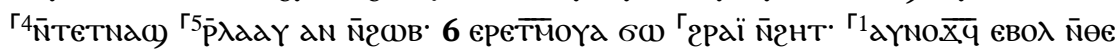

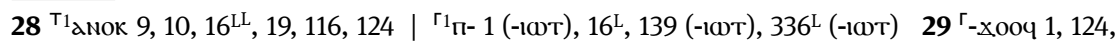

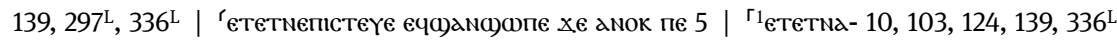

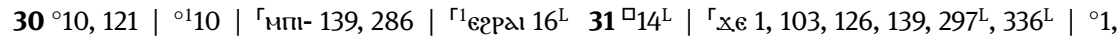

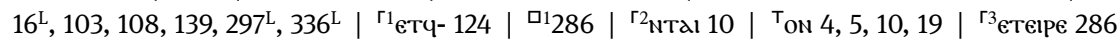

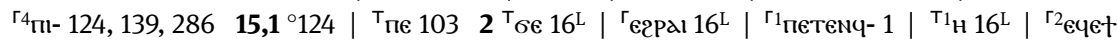

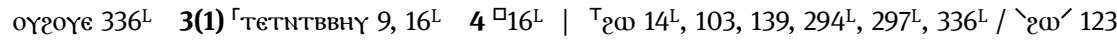

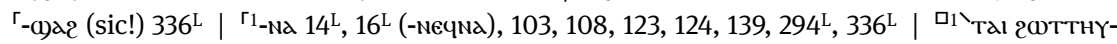

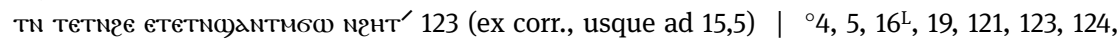

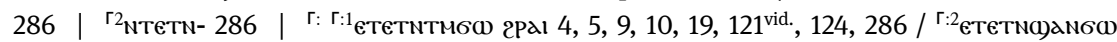

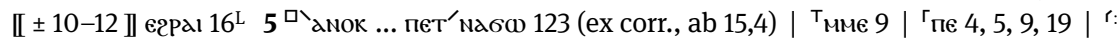

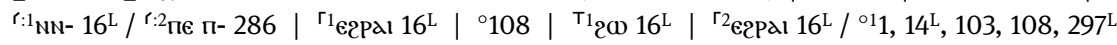

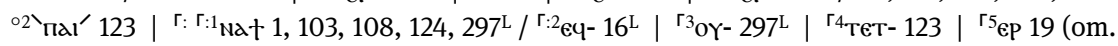

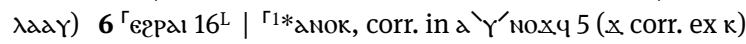

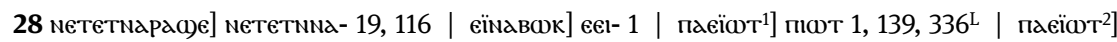

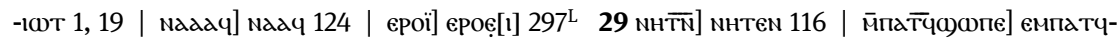

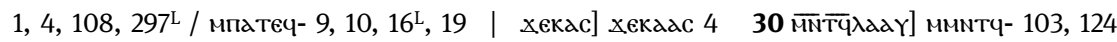

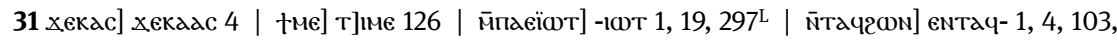

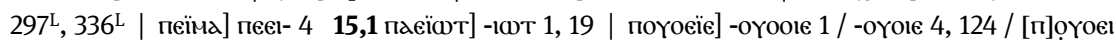

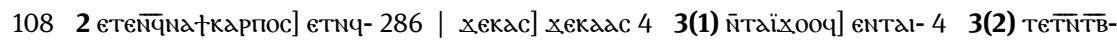

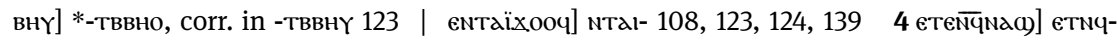

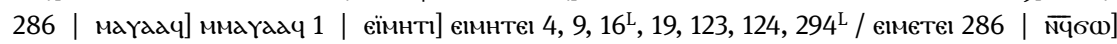

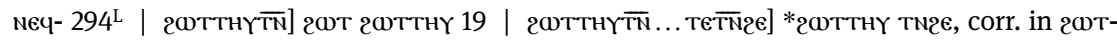

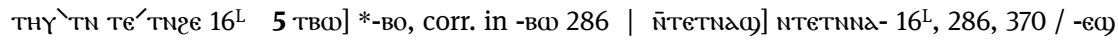

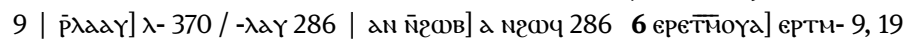




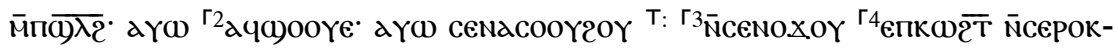

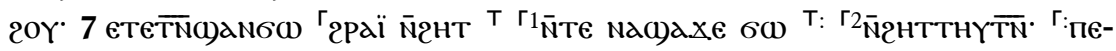

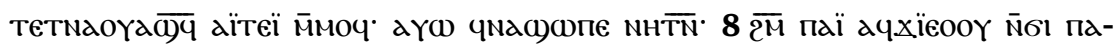

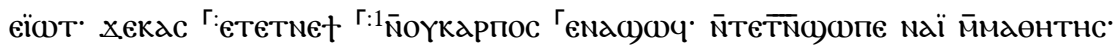

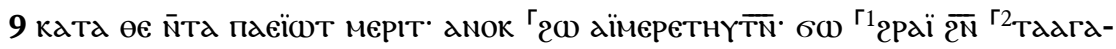

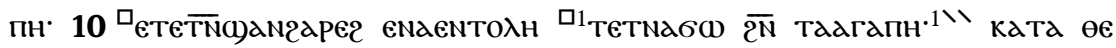

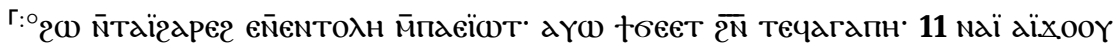
NHTN. Х

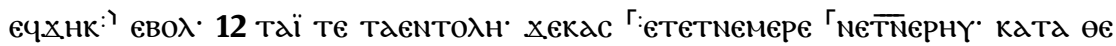

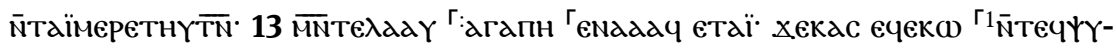

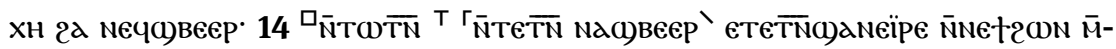

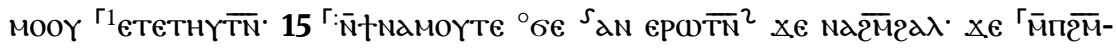

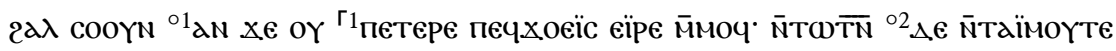

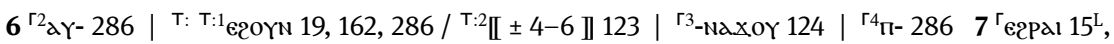

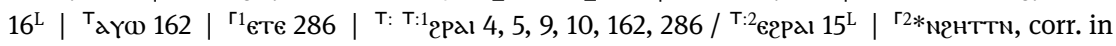

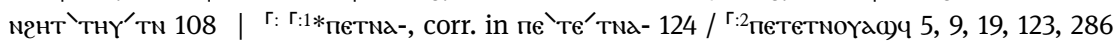

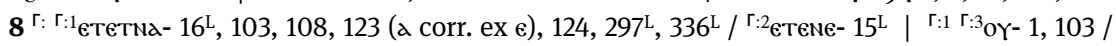
Г:4 карпос 162 | Г⿳а㇒⿲丶丶㇒木

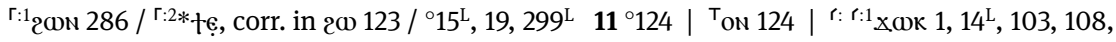

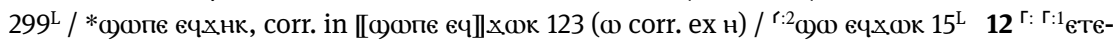

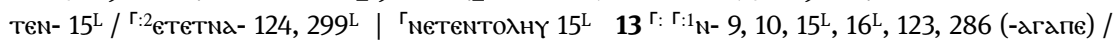

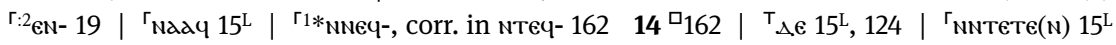

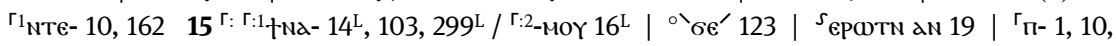
$16^{\mathrm{L}}, 124,286\left|{ }^{\circ} 286\right|{ }^{\circ 1}$ пете $103 \mid{ }^{\circ 2} 16^{\mathrm{L}}, 123$

6 cenacoorroY] -cooroY 5 |

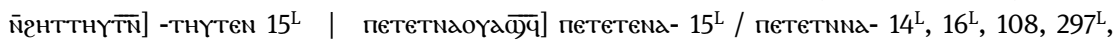

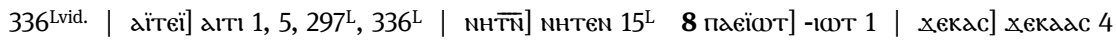

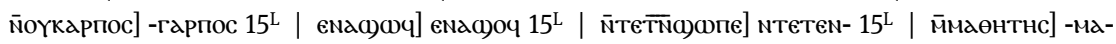

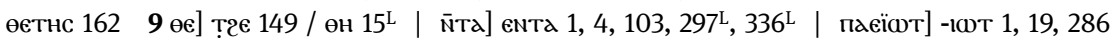

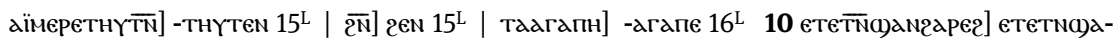

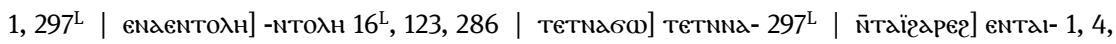

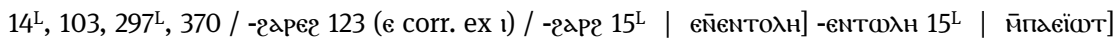

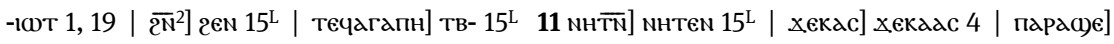

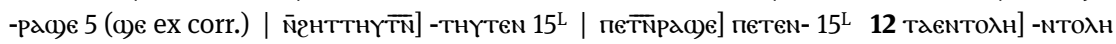

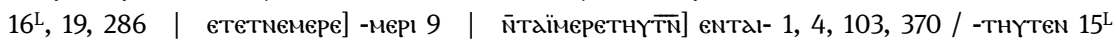

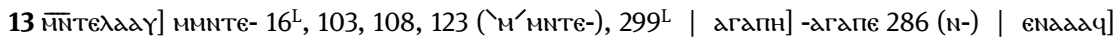

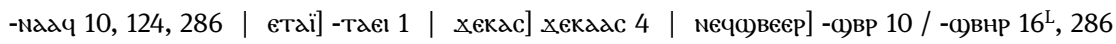

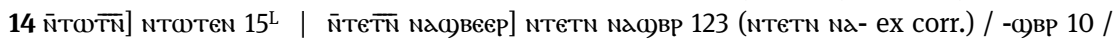

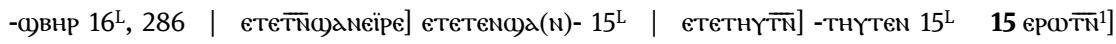

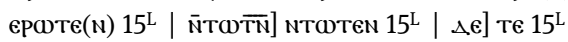




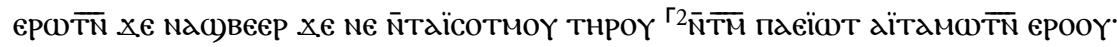

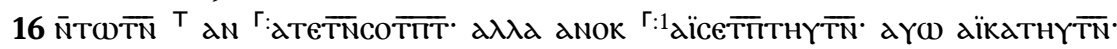

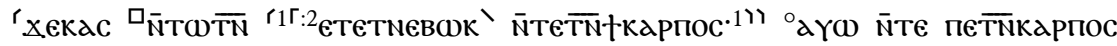

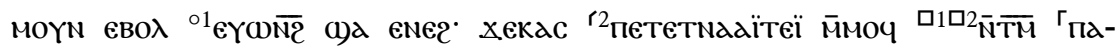

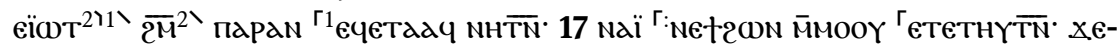

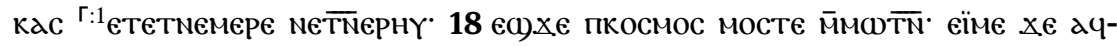

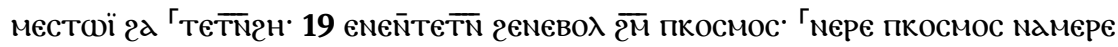

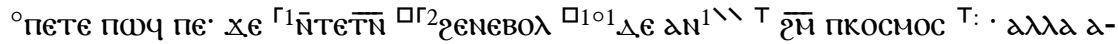

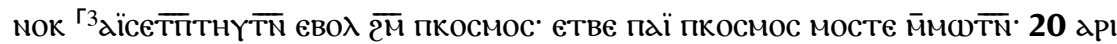

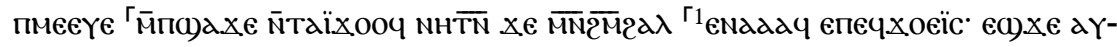

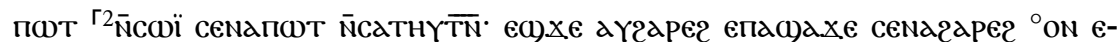

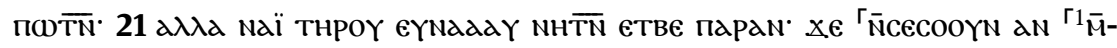

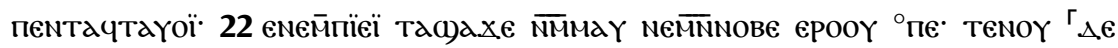

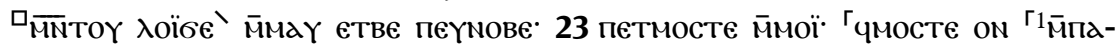

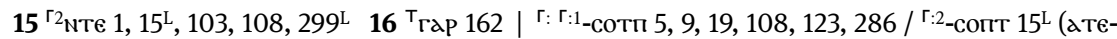

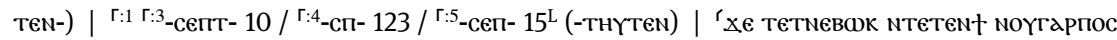

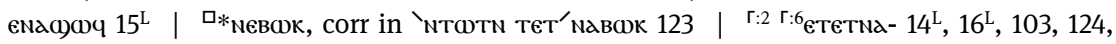

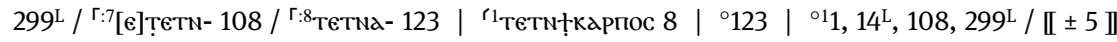

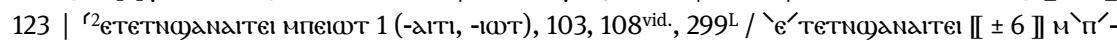

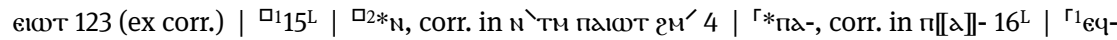

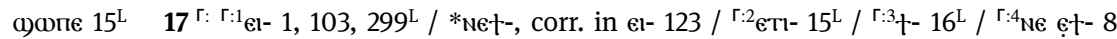

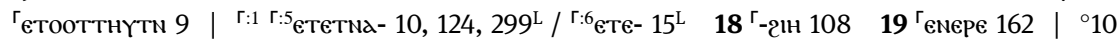

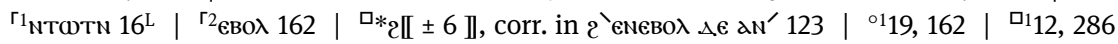

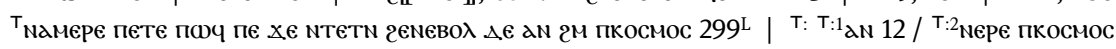

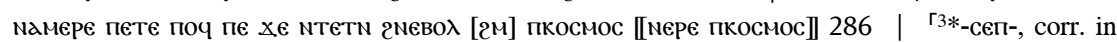

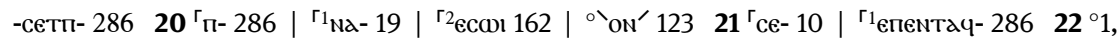

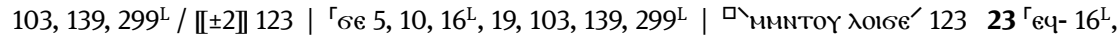
$\left.286\right|^{\ulcorner 1}$ мпаке- 19 (-І10т), 162

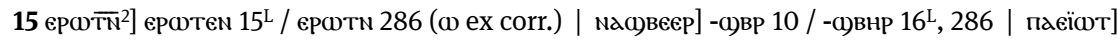

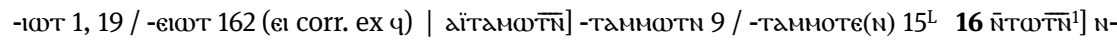

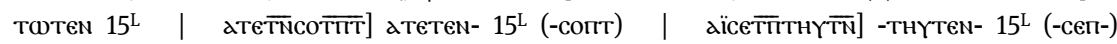

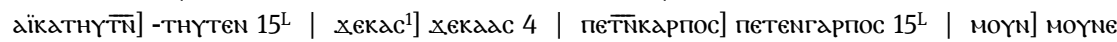

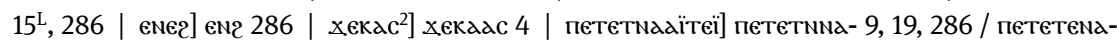

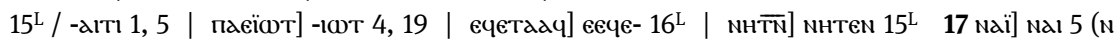

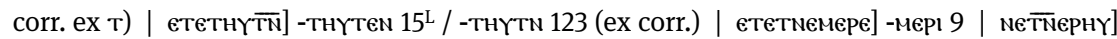

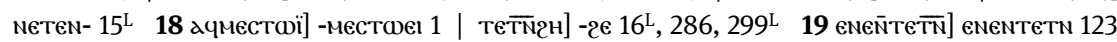

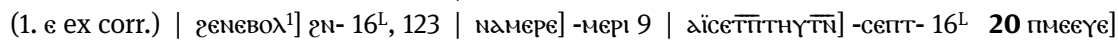

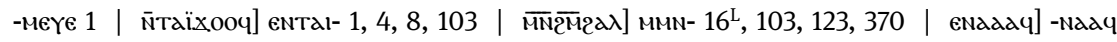

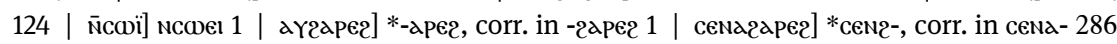

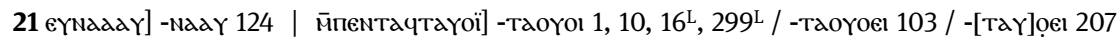

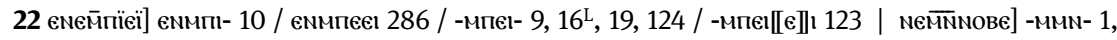

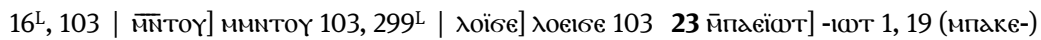




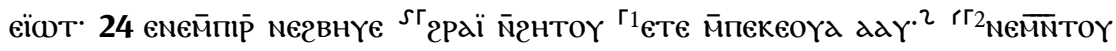

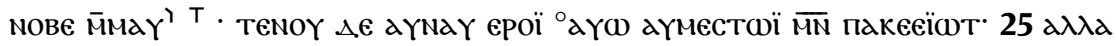

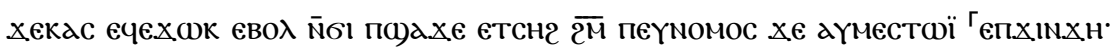

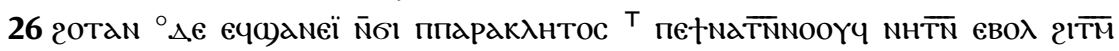

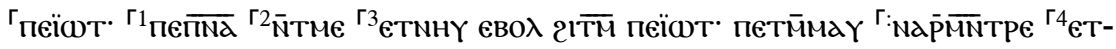

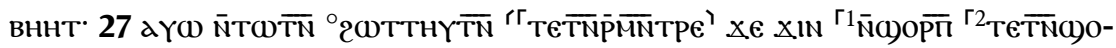
оп ज़Mмаї

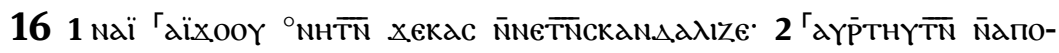

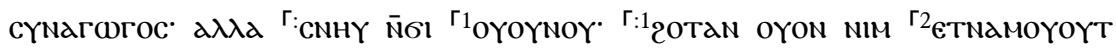

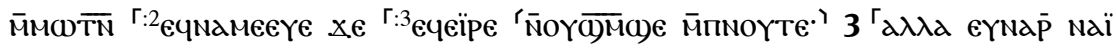

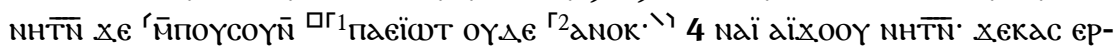

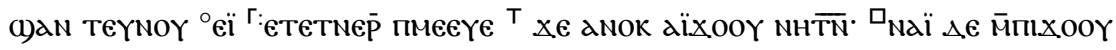

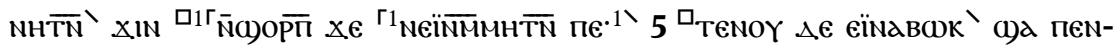

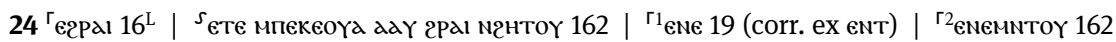

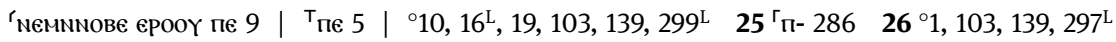

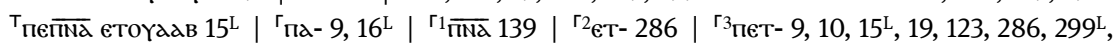

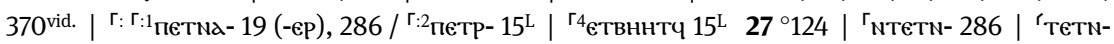

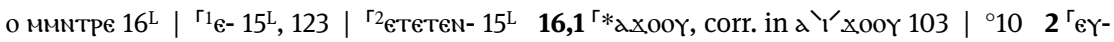

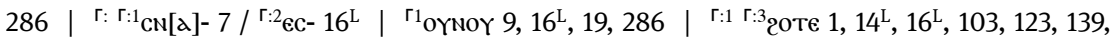

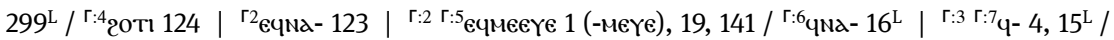

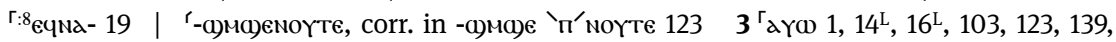

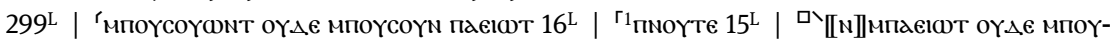

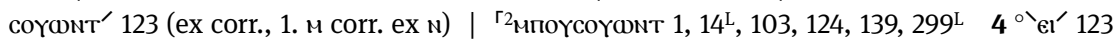

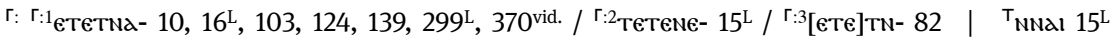

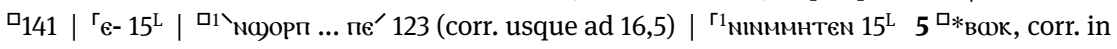
'теnоY $\Delta \epsilon$ eind' вюк 123 (corr. ab 16,4)

24 емем̄пір̄] еммпі- 10 / -мпеІ- 7, 9, 16 , 19, 123, 124 / -ер 19 | мегвнүе] -гвнү 7 | ете] ет 9, 123

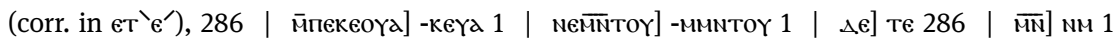

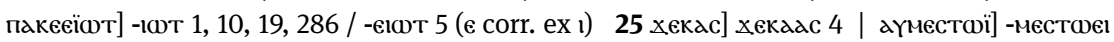

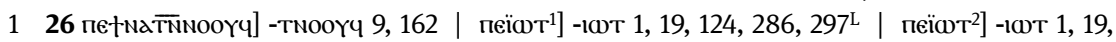

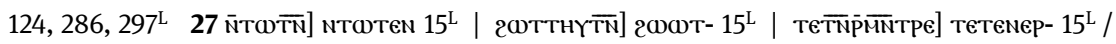

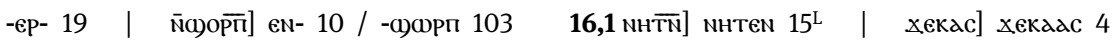

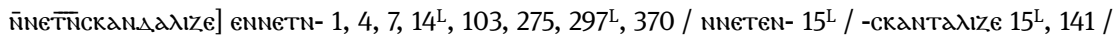

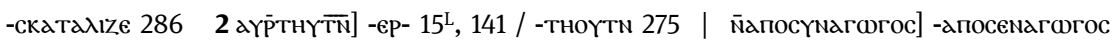

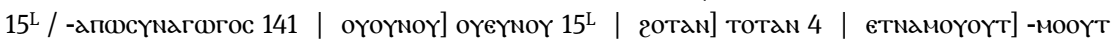

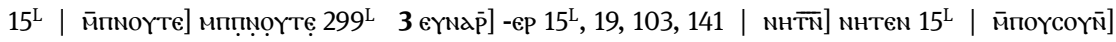

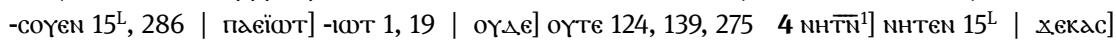

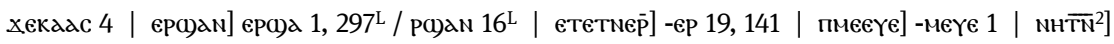

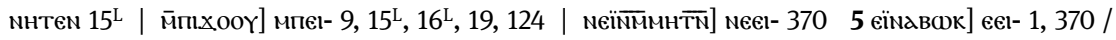

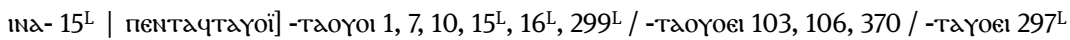




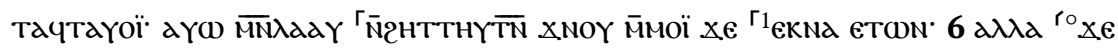

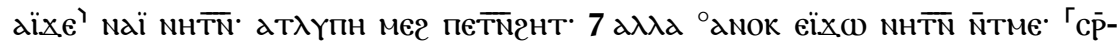

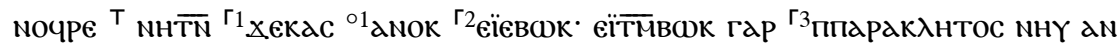

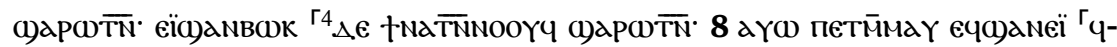
Naхпї пкосмос етве ${ }^{\ulcorner 1}$ пмове ${ }^{\top}$ етве тАікаїосүмн ${ }^{\top 1}$ етве текрісіс 9 етве п-

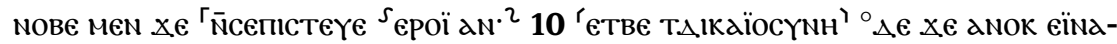

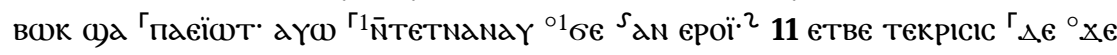

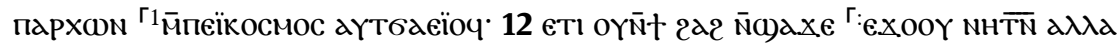

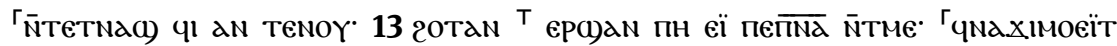

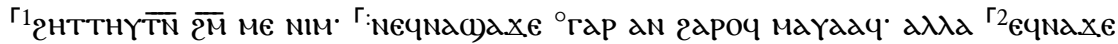

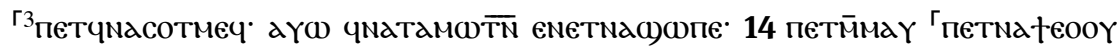

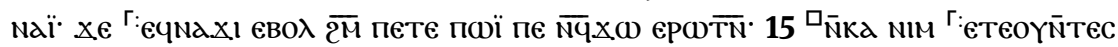

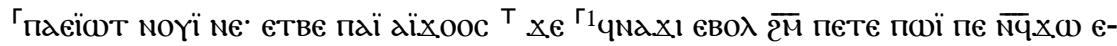

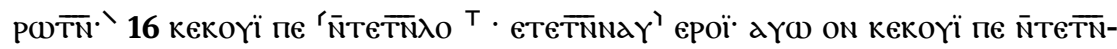

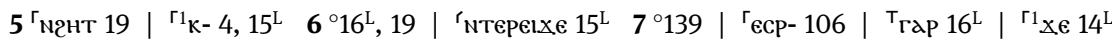

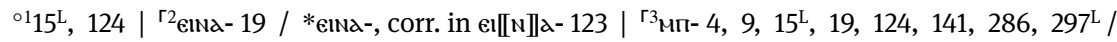

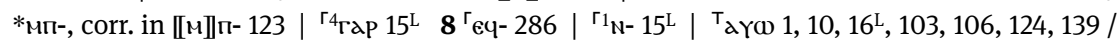

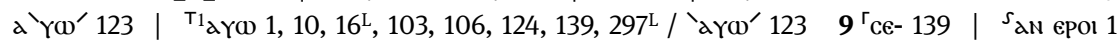

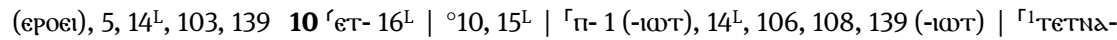

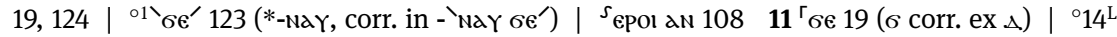

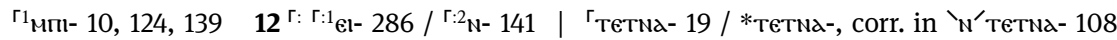

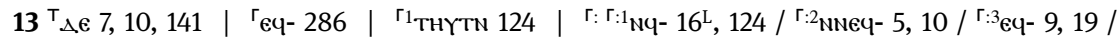

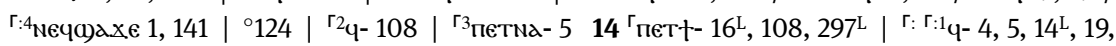

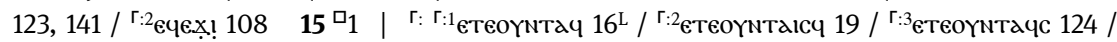

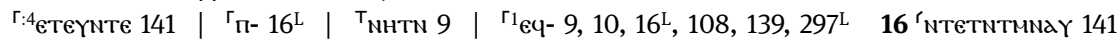
TEтетN丶о 108

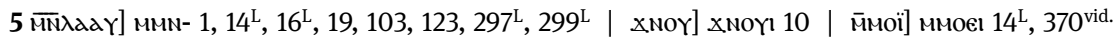

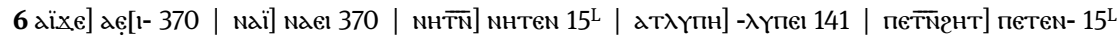

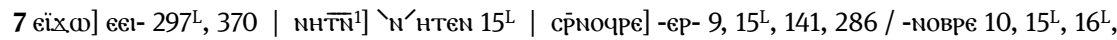

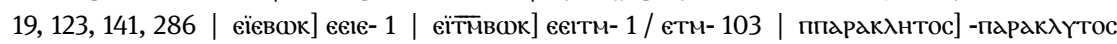

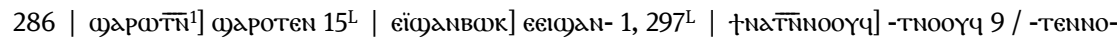

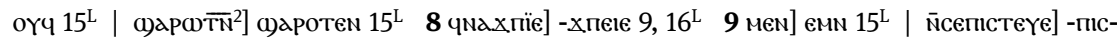

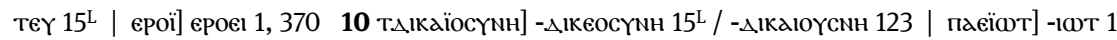

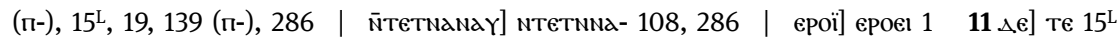

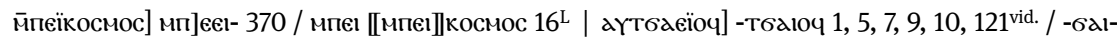

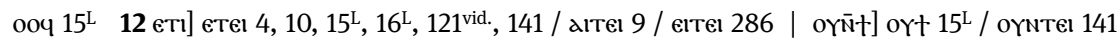

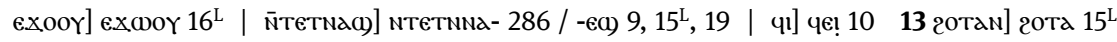

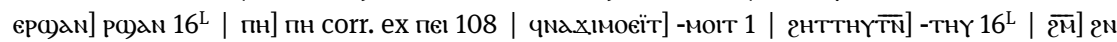

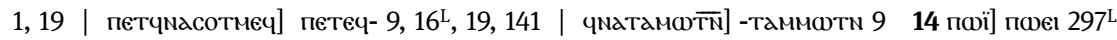

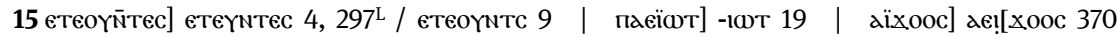

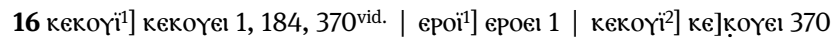




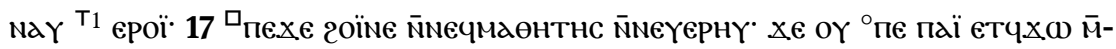

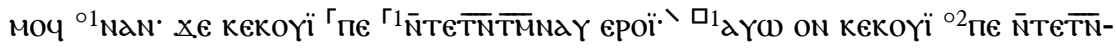

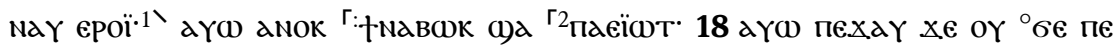

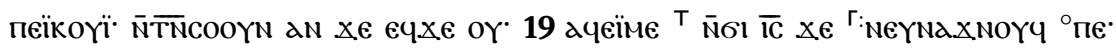

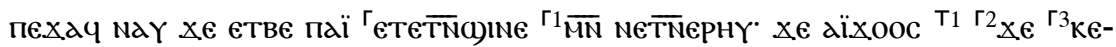

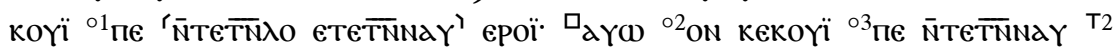

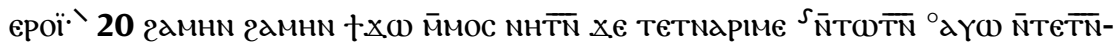

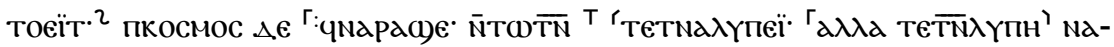

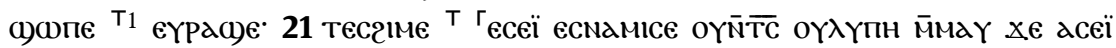

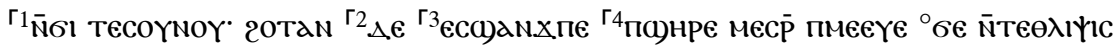

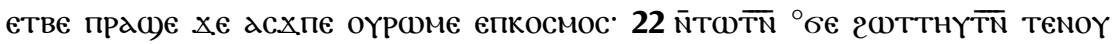

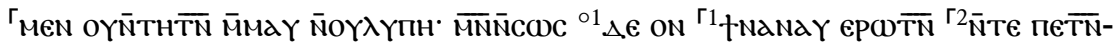

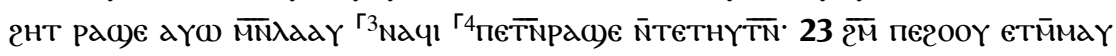

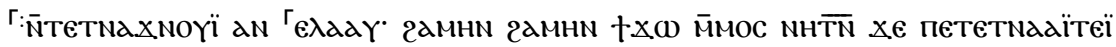

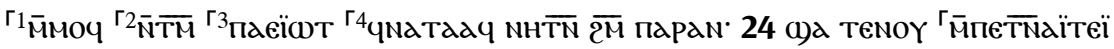

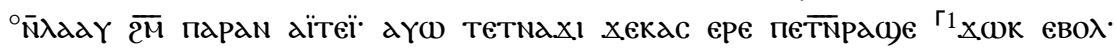

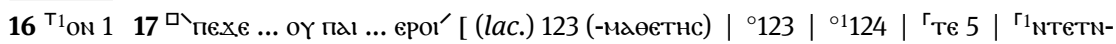

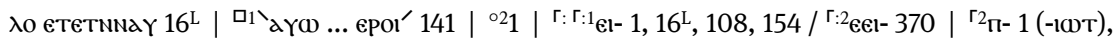

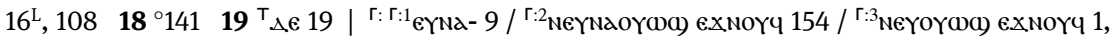

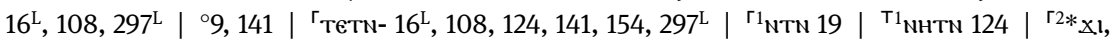

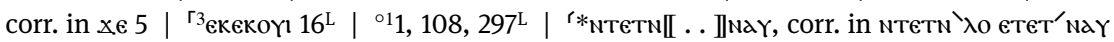

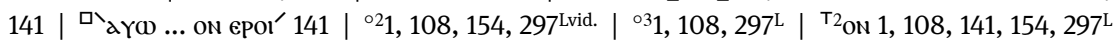

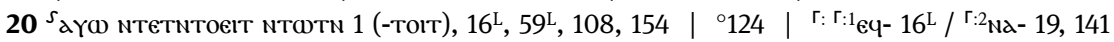

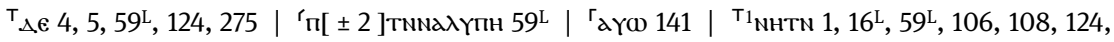

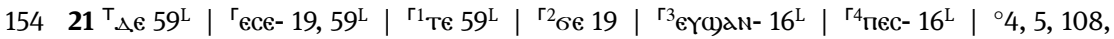

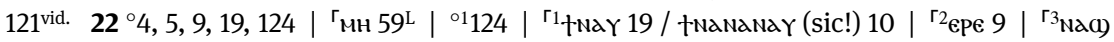

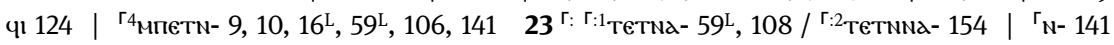

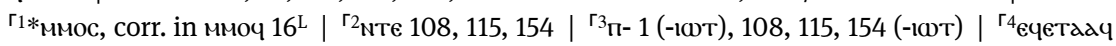
12424 'мпатетN- 9, 10, 16 ${ }^{\mathrm{L}}, 124,141\left|{ }^{\circ} 124\right|{ }^{\Gamma 1}$ с)

16 єрої2] ероєı 1, 37017 гоїме] гоєіме 7, 108, 154 | і̄мечмдөнтнс] -мдөєтнс 123 | етчхо] етеч-

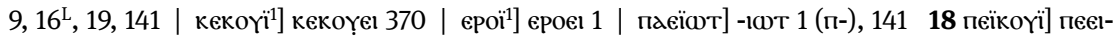

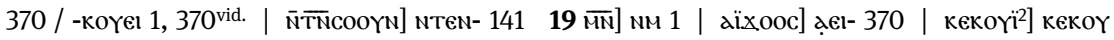

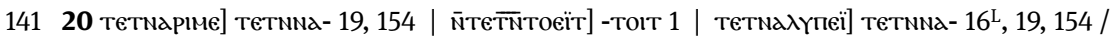

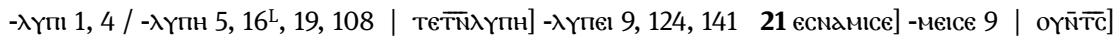

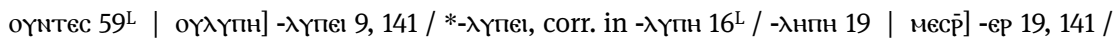
- 'е' 141 / -

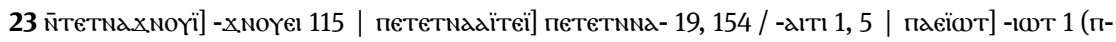

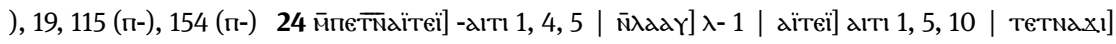
TeтNNa- 19, 154 | хeKac] ХeKada 4 


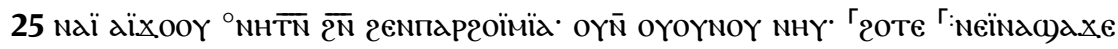

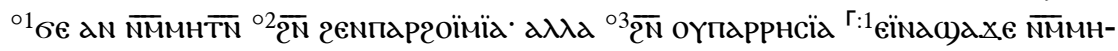

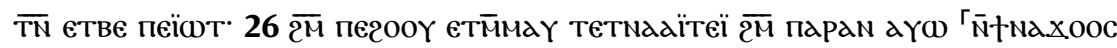

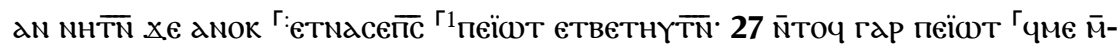

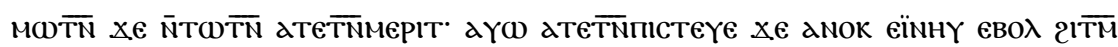

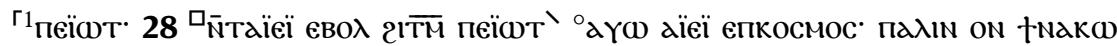

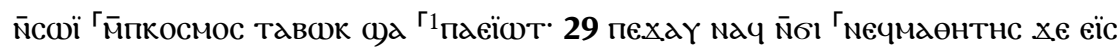

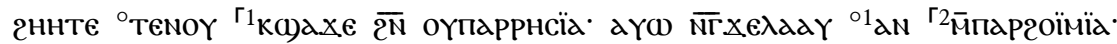

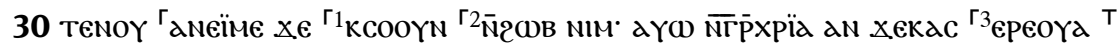

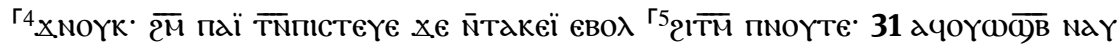

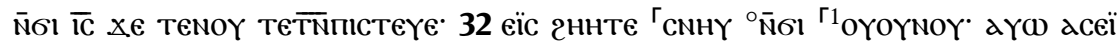

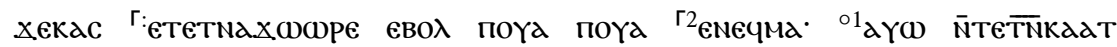

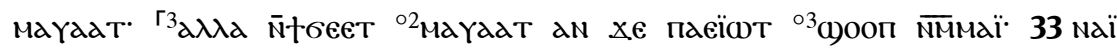

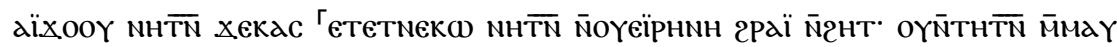

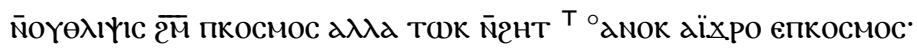

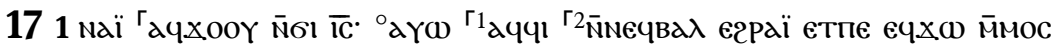

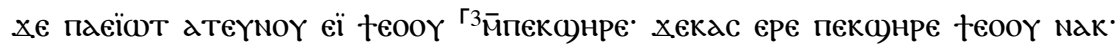

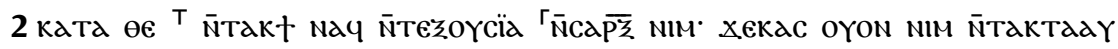

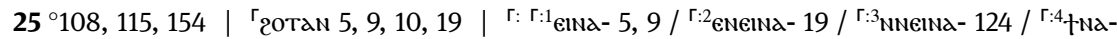

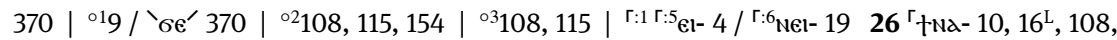

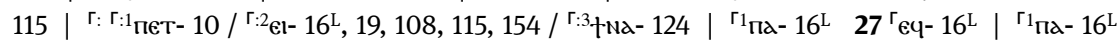

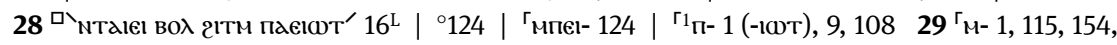

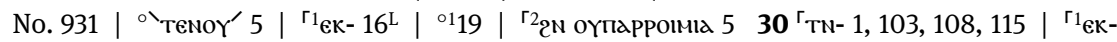

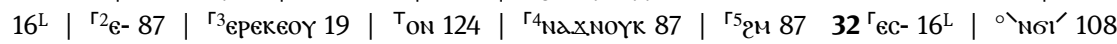

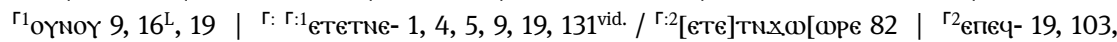

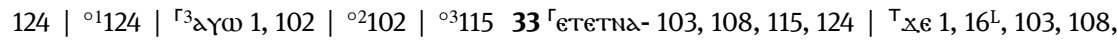

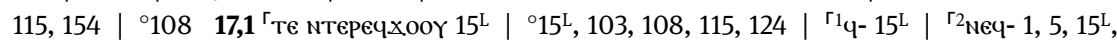

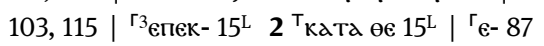

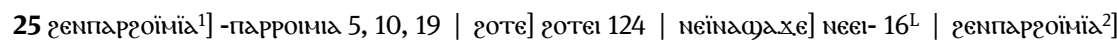
-парроіміа 5, 10, 19 | оүпаррнсїа] -паргнсіа 4 | пеїт] -іют 19, 115, 124, 15426 тетмадїтеї]

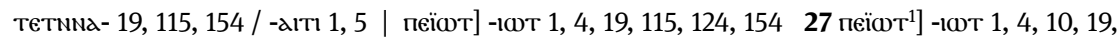

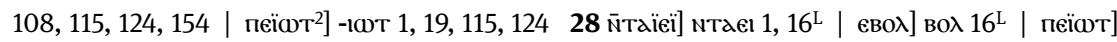
-10т 1, 19, 115, 124, 154 | аїеі] al 1 | паеїळт] -іют 1 (п-) 29 гннте] гннте 108 | оүпаррнсїа] -паргнсіа 4, 87 | мппаргоїііа] -пагомміа 4 / -парроіміа 19 / -паррнміа 87 / -парго1\{201\}міа 16

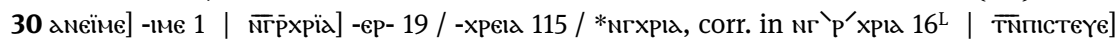
тем- 8731 тетипістеүе] тетм- 1, 108 / -пістеүе 16 (п corr. ех є) 32 хекас] хекаac 4

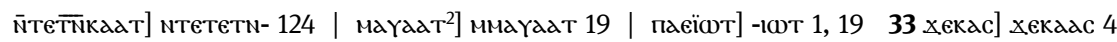

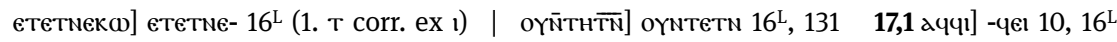

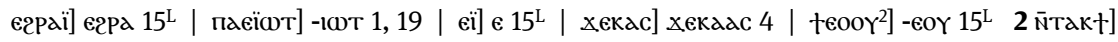

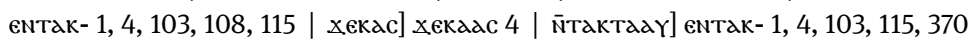




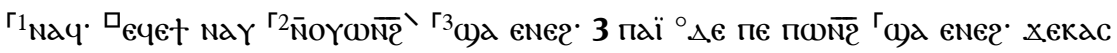

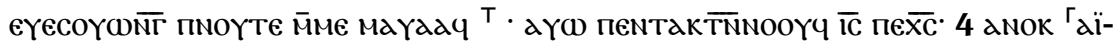

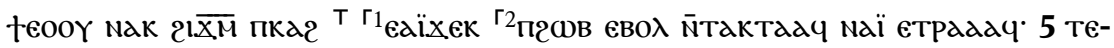

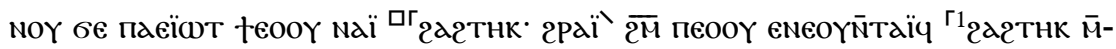

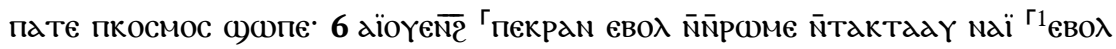

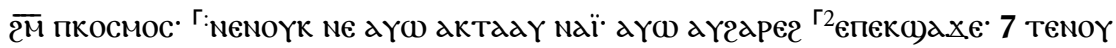

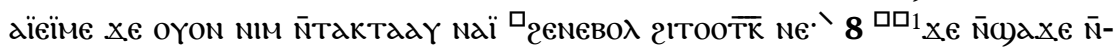
TaKTdaY' Naï1 '

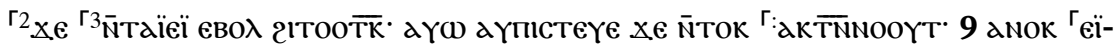

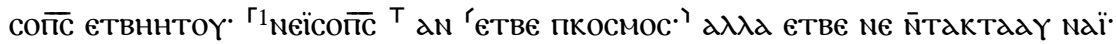

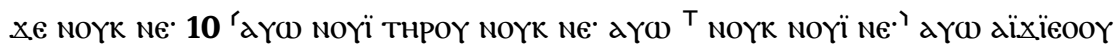

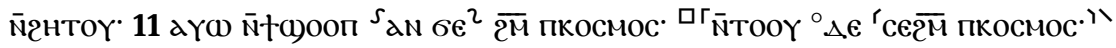

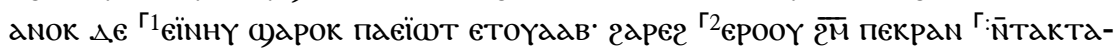

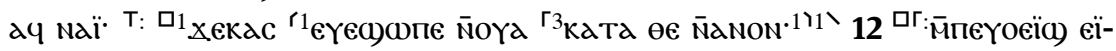

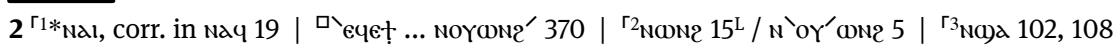

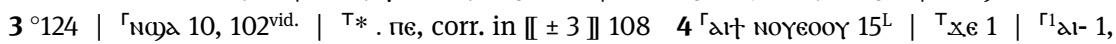

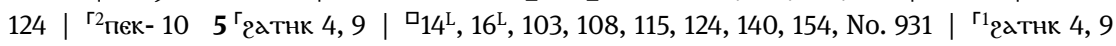

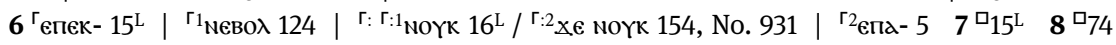

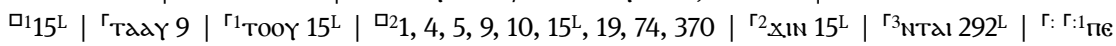

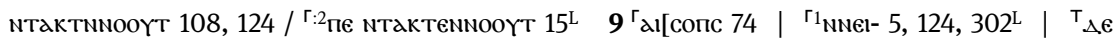

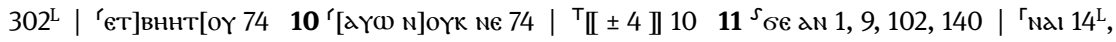

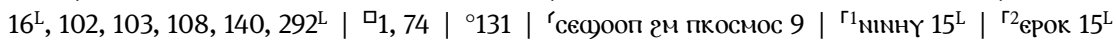

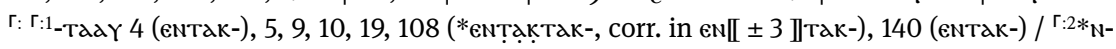

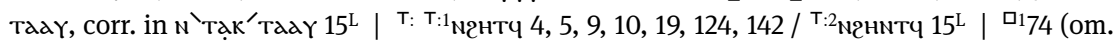

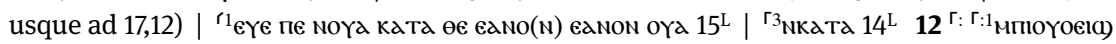

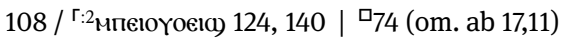

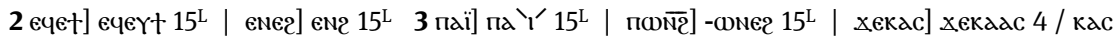

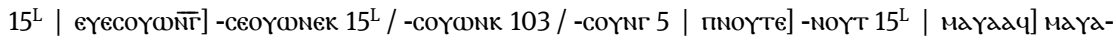

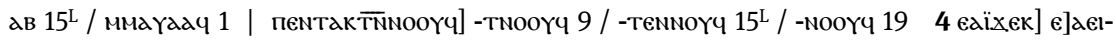

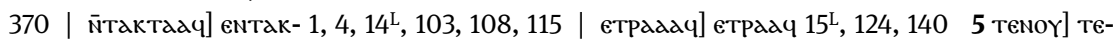

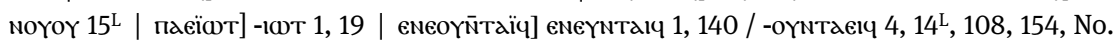

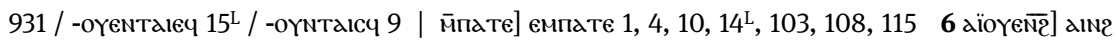

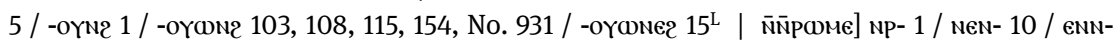

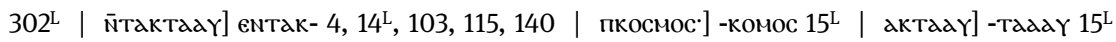

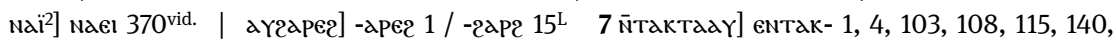

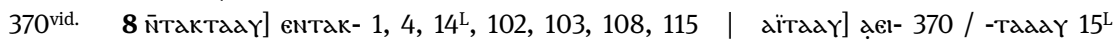

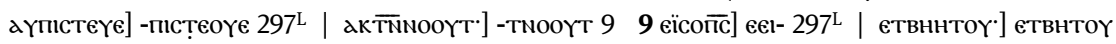

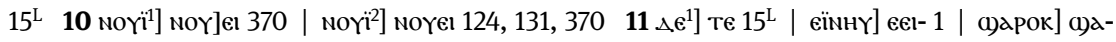

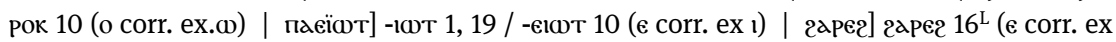

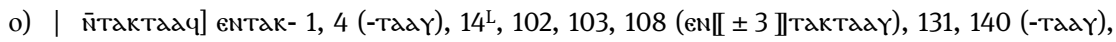

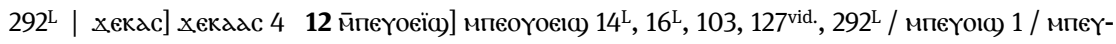

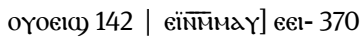




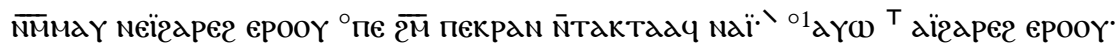

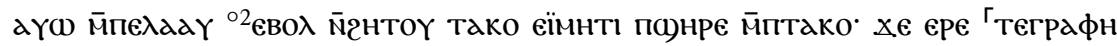

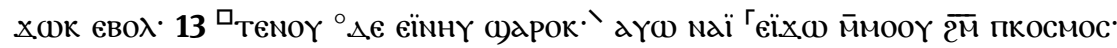

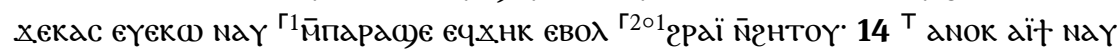

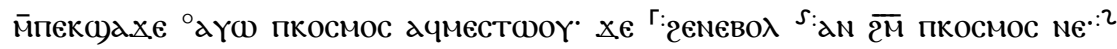

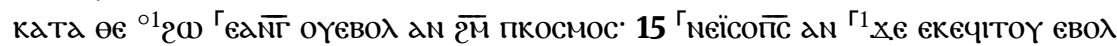

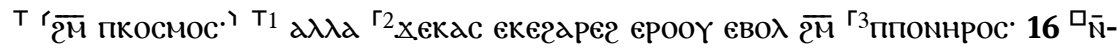

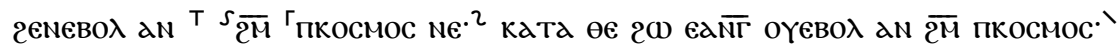

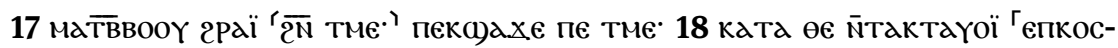

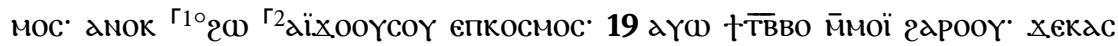

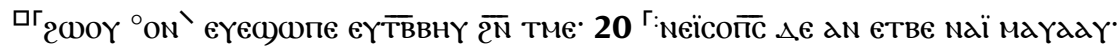

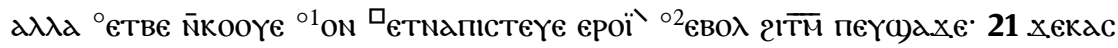

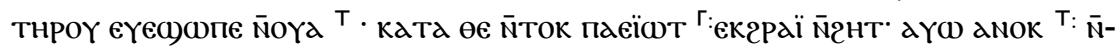

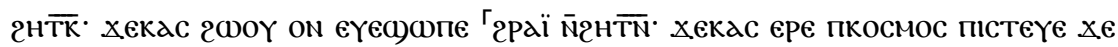

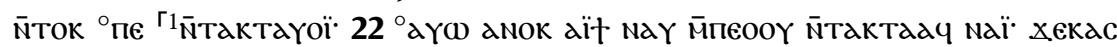
eүe⿻)

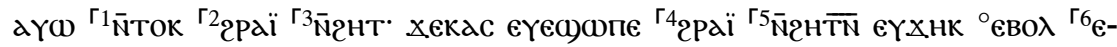

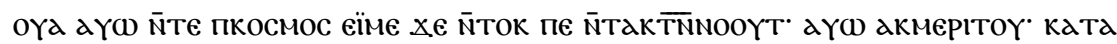

$12{ }^{\circ} 5,9,19,124\left|{ }^{\circ 1} 108\right|{ }^{\top}$ данок $74\left|{ }^{\circ 24}, 5,9,19,74\right|{ }^{\circ}$ тек- $10813^{\circ} 74 \mid{ }^{\circ} 14^{\mathrm{L}}, 103,108,142$,

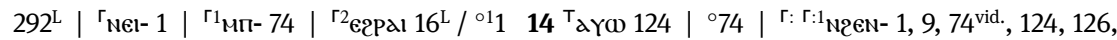

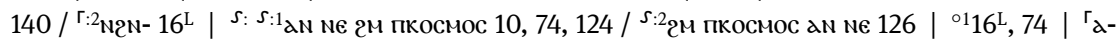

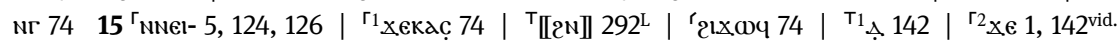

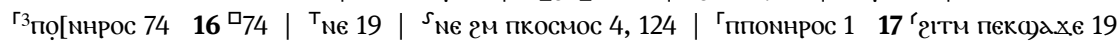

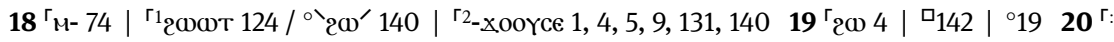

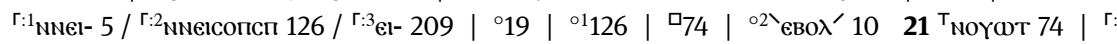

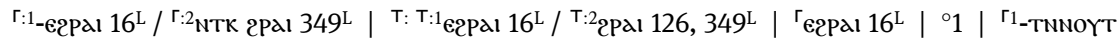

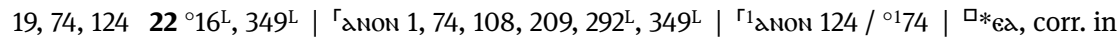

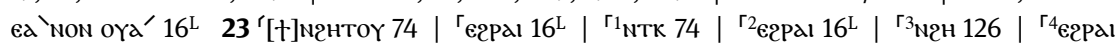
$16^{\mathrm{L}}\left|{ }^{55_{\mathrm{N}} \mathrm{HT}} 1,16^{\mathrm{L}}, 74,108,140\right|{ }^{\circ}{ }_{\mathrm{eBO}} \lambda^{\prime} 10 \mid{ }^{56}{ }_{\mathrm{N}}-9,19,74,349^{\mathrm{L}}$

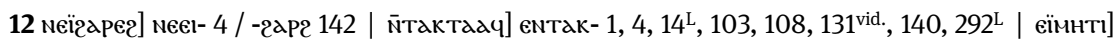

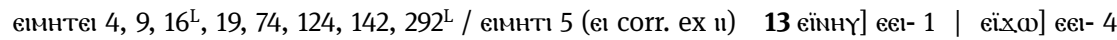

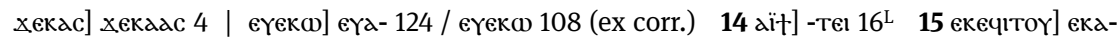

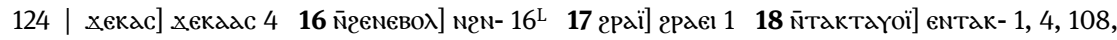

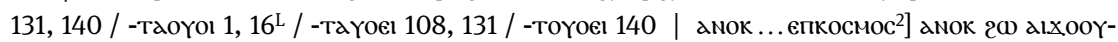

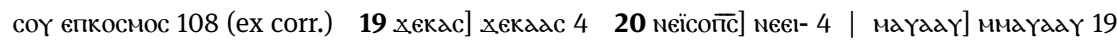

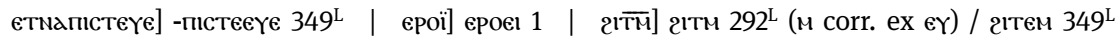

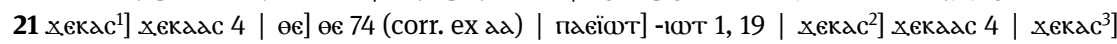

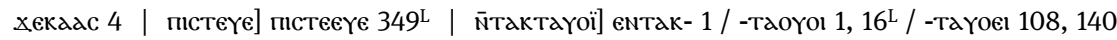
22 мппеоо] мпє\{Ү\}oоY 9 |

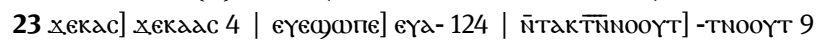




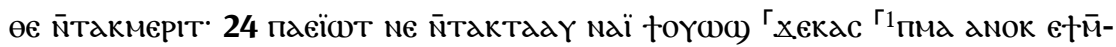

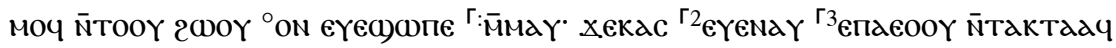

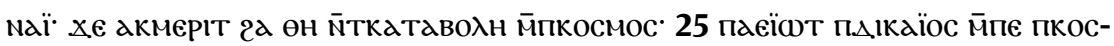

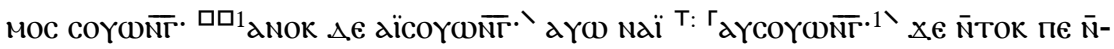

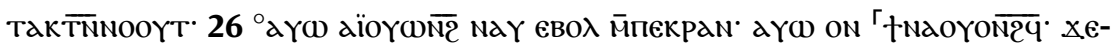

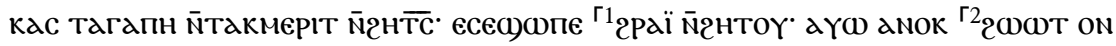
' $\overline{\text { N}}$ нитоҮ'

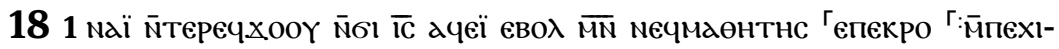

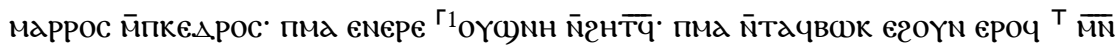

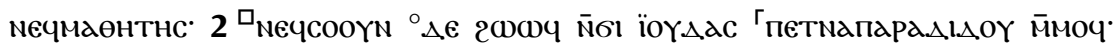

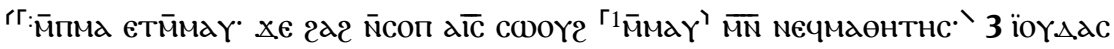

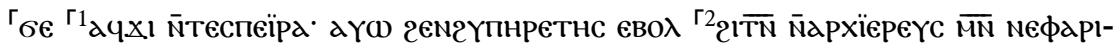

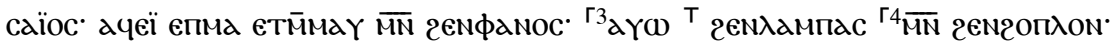

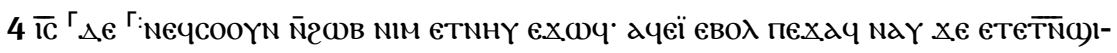

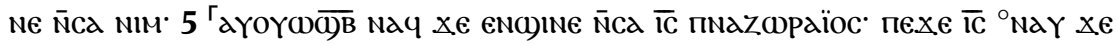

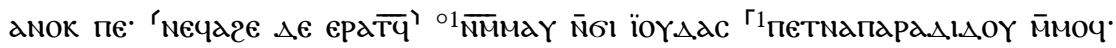

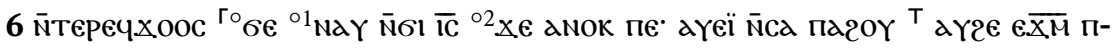

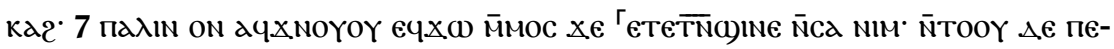

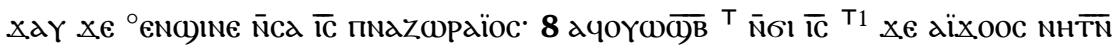

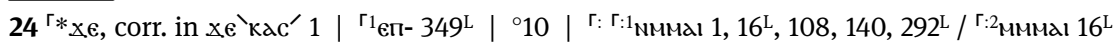

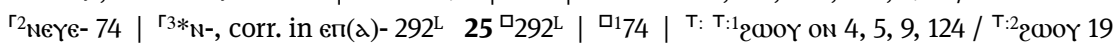

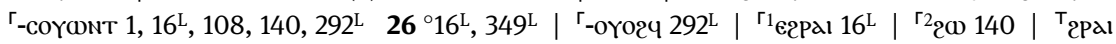

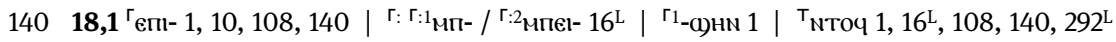

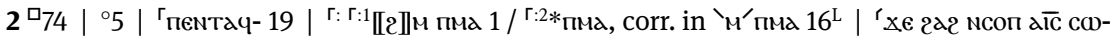

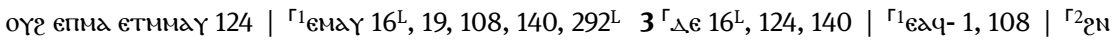

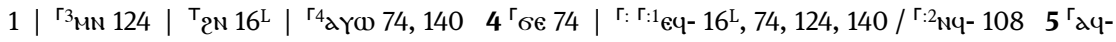

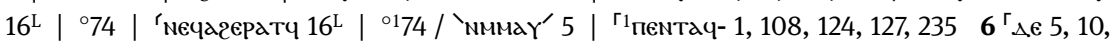

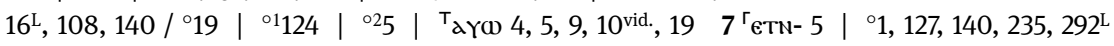
$8^{\mathrm{T}} \mathrm{NaY} 1,19,74,127,235,\left.292^{\mathrm{L}}\right|^{\mathrm{T}}{ }^{1}$ пехач $\mathrm{NaY} 16^{\mathrm{L}}$

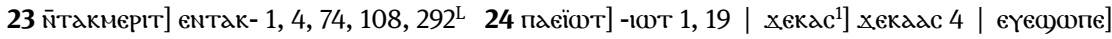

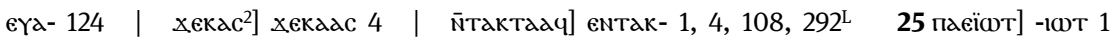

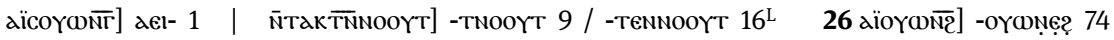

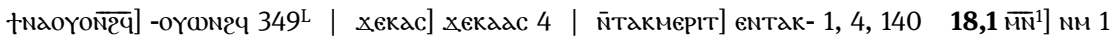

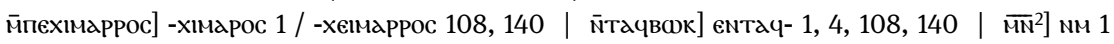
2 мечсооүм] мч- 16

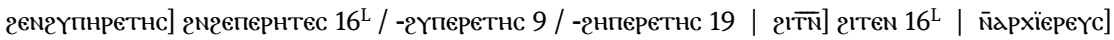

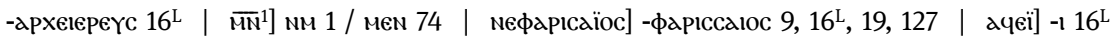

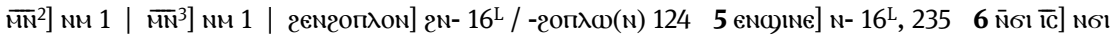

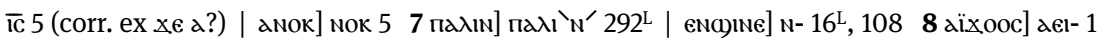




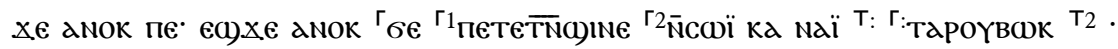

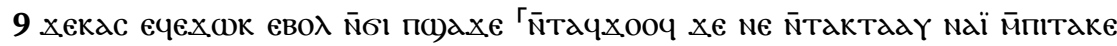

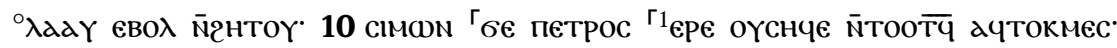

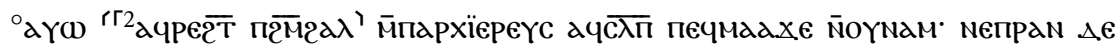

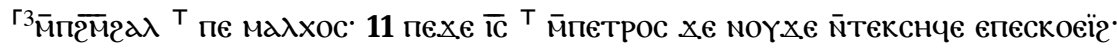

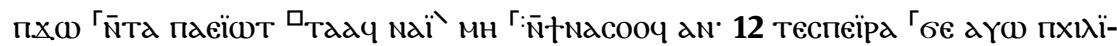

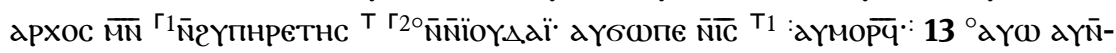

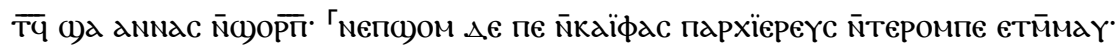

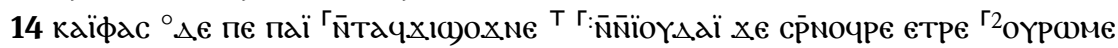

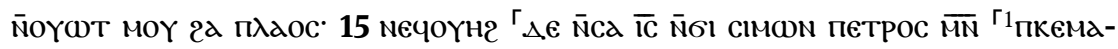

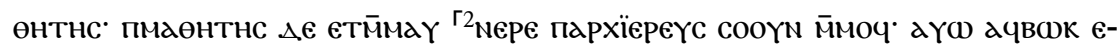

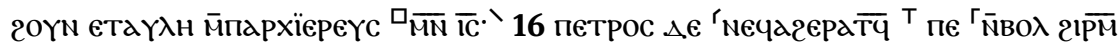

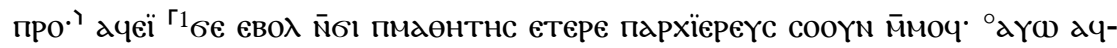

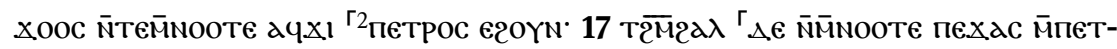

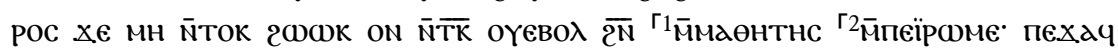

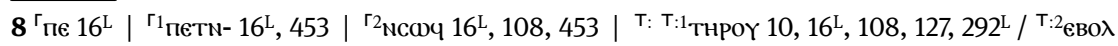
453 | Г: Г:1

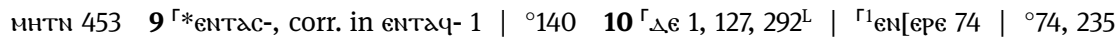

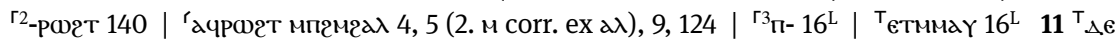

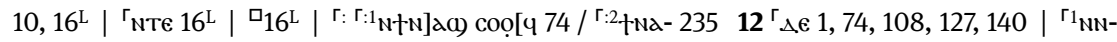

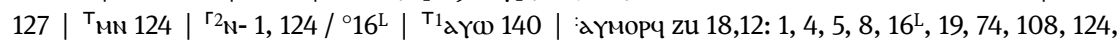

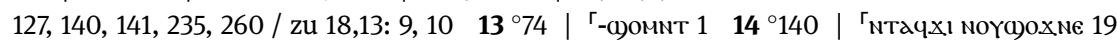

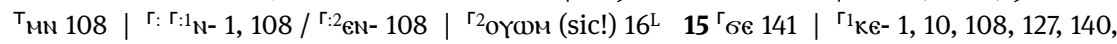

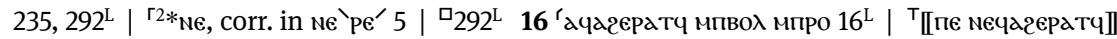

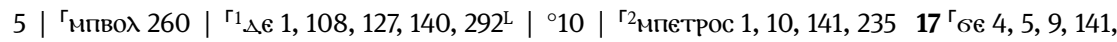
$260\left|{ }^{\ulcorner 1} \Pi-16^{\mathrm{L}}\right|{ }^{\ulcorner 2} \mathrm{M} \Pi-10,140$

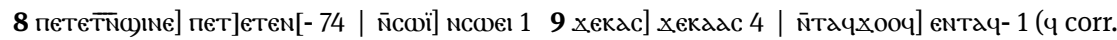
ех c), 4 | мпптаке] мпєе- 9, 16, 23510 оүснчє] -снвє 10, 127 | ачтокмес] -такмес 127

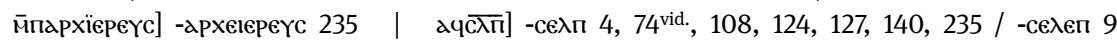

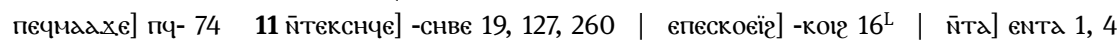

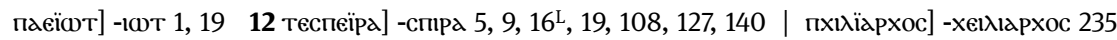

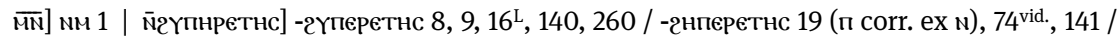

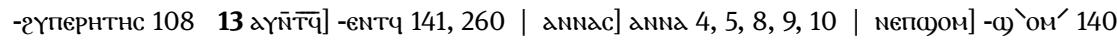

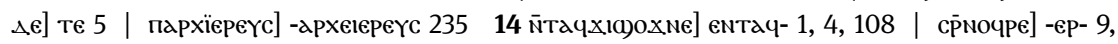

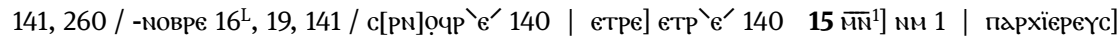

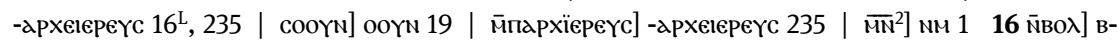

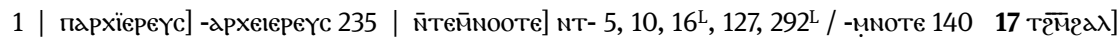

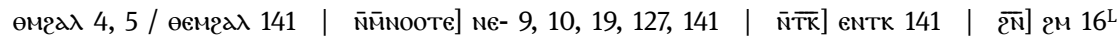
мпеїромє] -пєєা- 4 


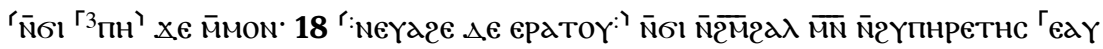

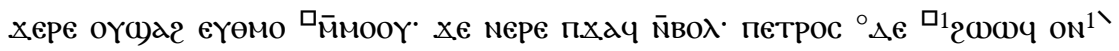

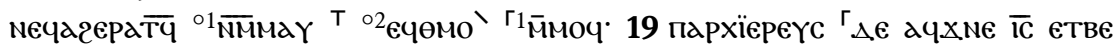

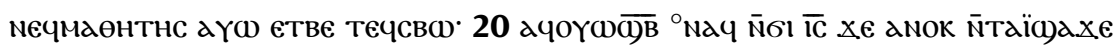

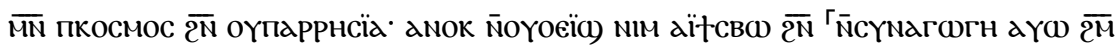
прпє. Г1 пма ${ }^{\Gamma 2}$ ec)ape

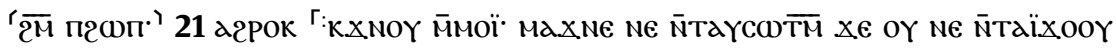

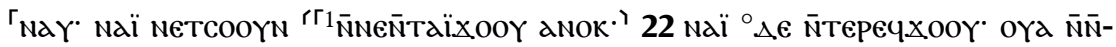

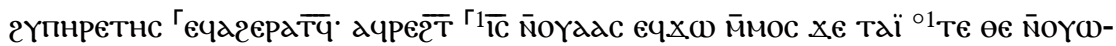

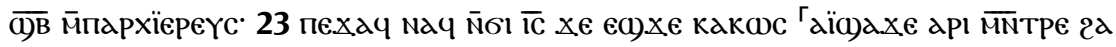

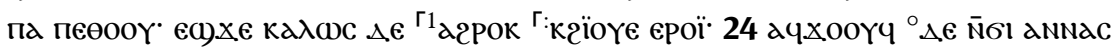

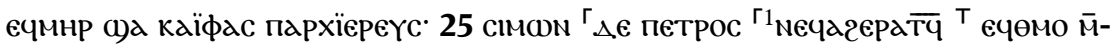

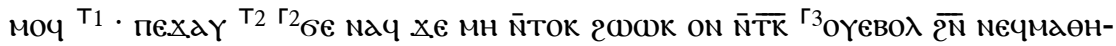

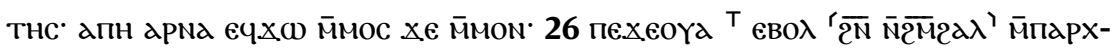

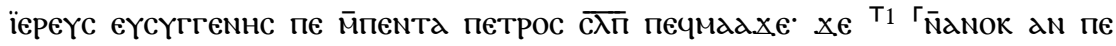

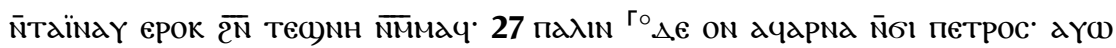

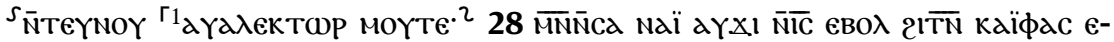

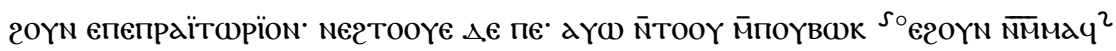

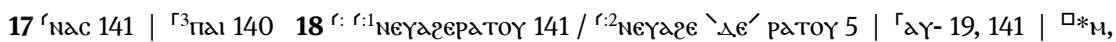

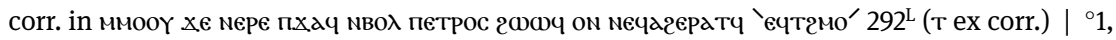

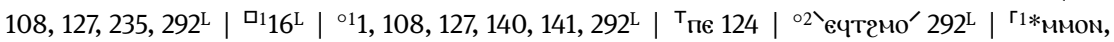

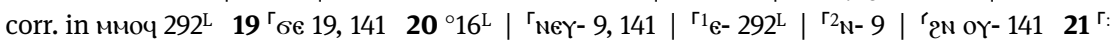

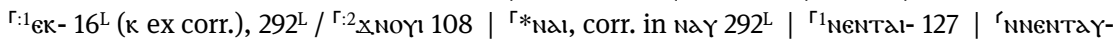

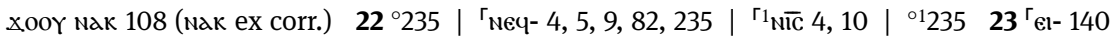

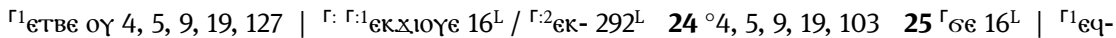

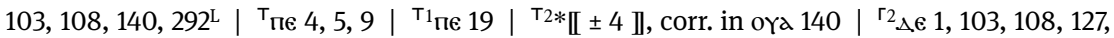

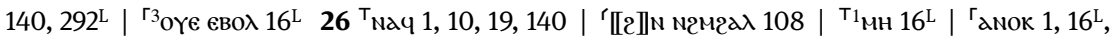

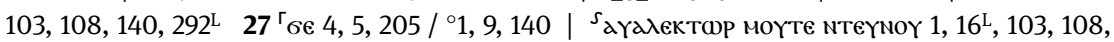

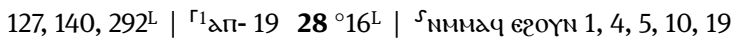

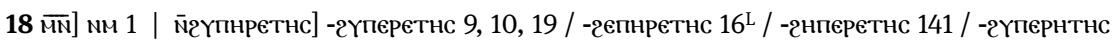
292 / -әүпнрєтнс 140 (є ех corr.) | еүөмо] еү- 19 (ү ех corr.) / -өммо 9, 260 / -тгмо 108, 127,

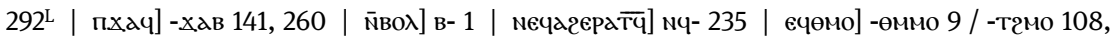
127, 292L ('ечтгмо') 19 пархїереүс] -дрхіере 140 / -дрхеєереүс 23520 м̄таїодахе] еnтаl- 292

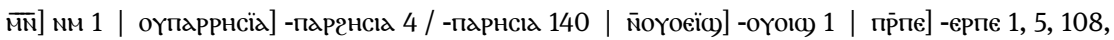

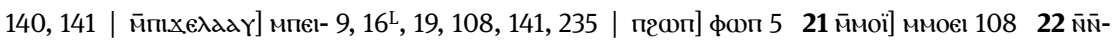
әүпнретнс] -әүперетнс 9, 10, 19 / -гепнретнс 16L / -әүпернтнс 82, 292 / -гнперетнс 141 / -2ҮпнреАнс 235 | мппархїереүс] -археіереүс 23523 пеөооү] петгоо 108 | ероі] ероєь 1, 140, 37024 пархїереүс] -археєереүс 23525 ечөмо] -өммо $9 /$-тямо 103, 108, 127, 292 L 26 мппарх-

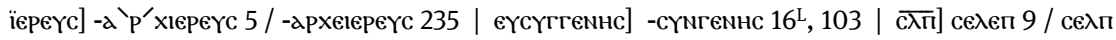

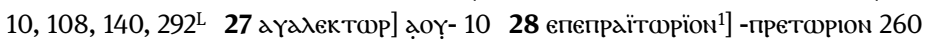




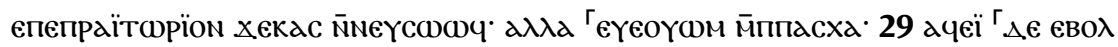

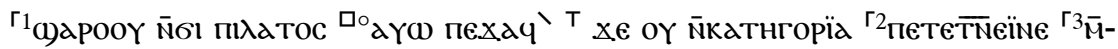

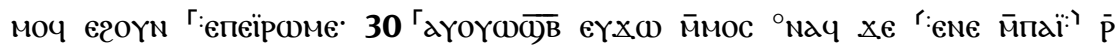

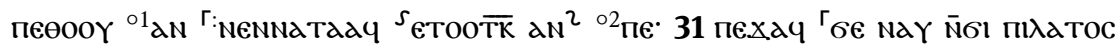

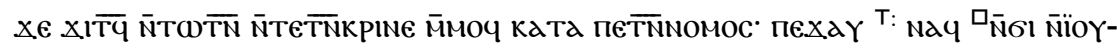

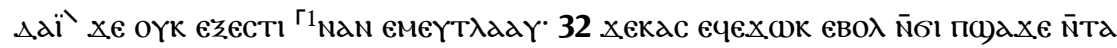

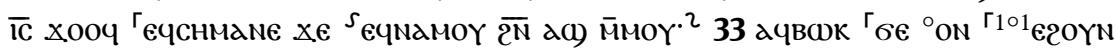

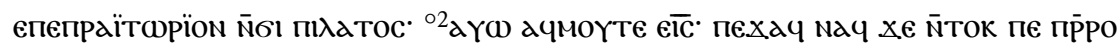

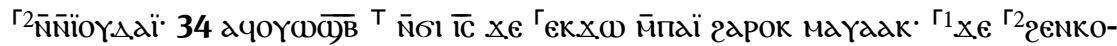

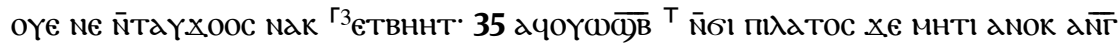

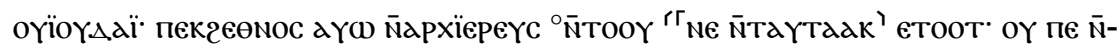

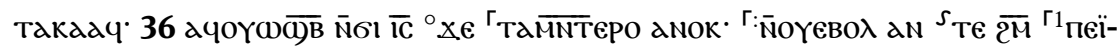

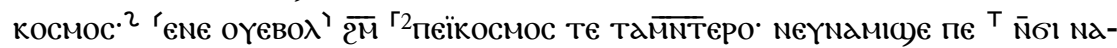

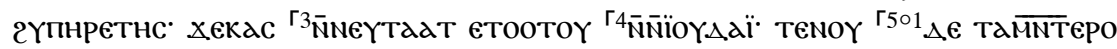

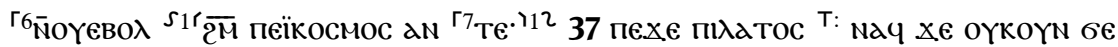

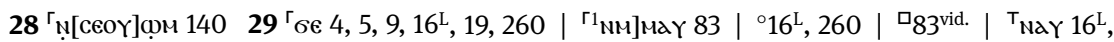

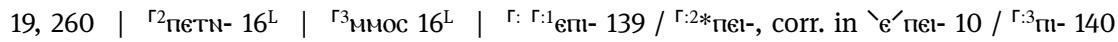

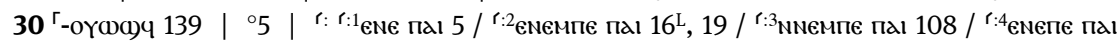

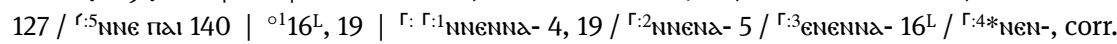

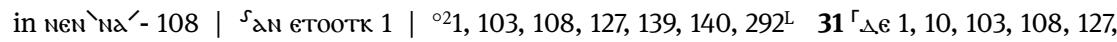

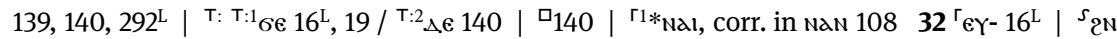

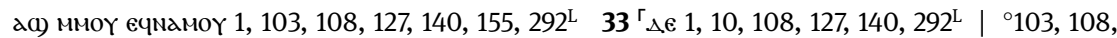

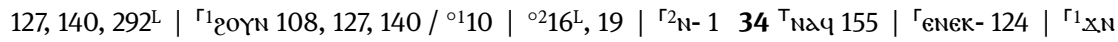

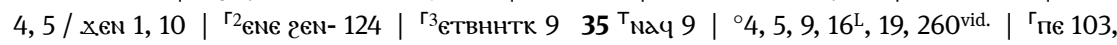

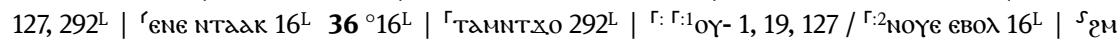

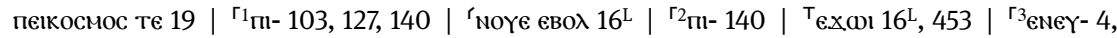

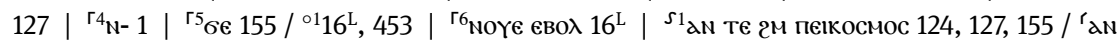

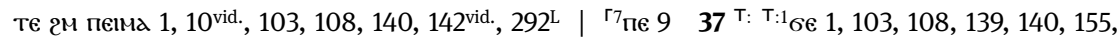
$292^{\mathrm{L}} / \mathrm{T}^{\mathrm{T}: 2} \Delta \in 142$

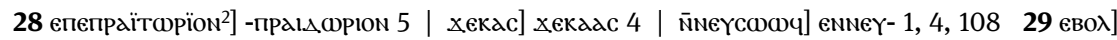

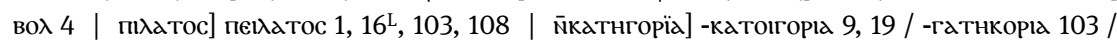

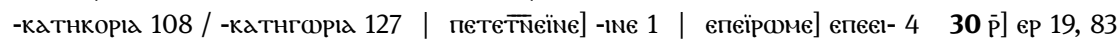

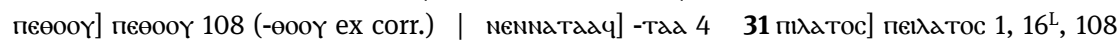

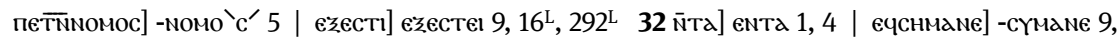

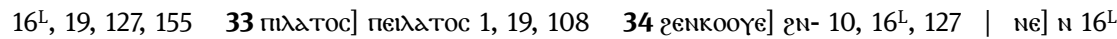

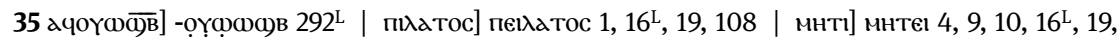

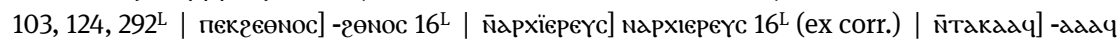

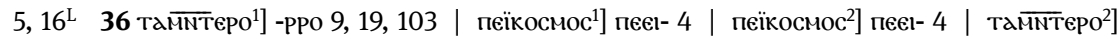

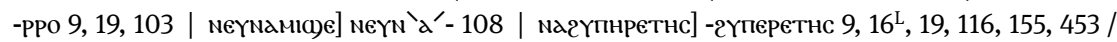

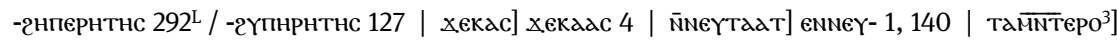

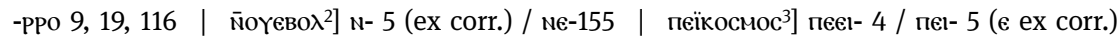
37 пілатос] пєілатос $1,16^{\mathrm{L}}, 108,140$ 


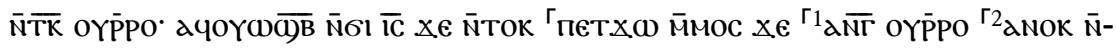

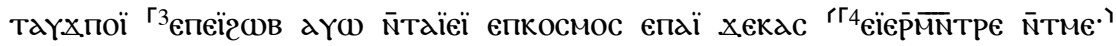

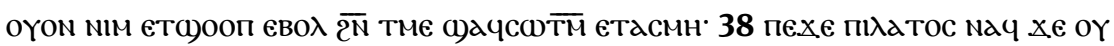

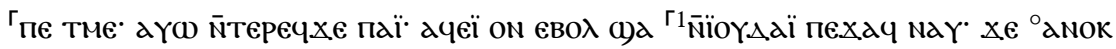

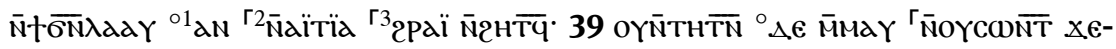

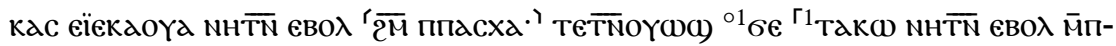

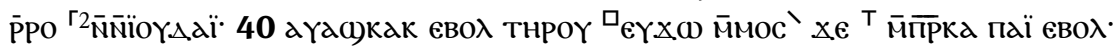

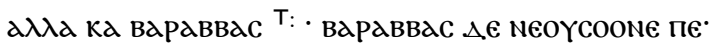

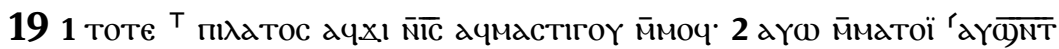

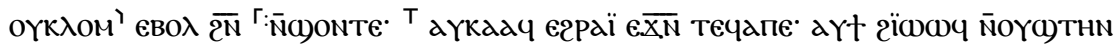

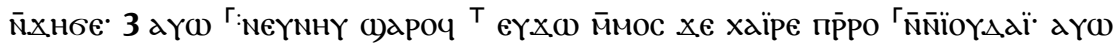

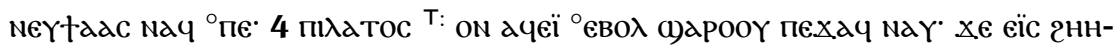

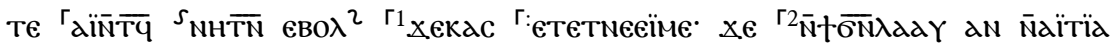
Г:1 2 раї $\overline{\text { N}}$ ${ }^{\circ}$ epe Te()THN $\overline{\mathrm{N}} \mathrm{x}$.

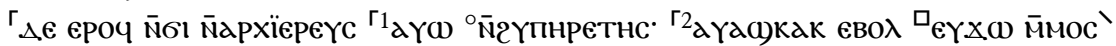

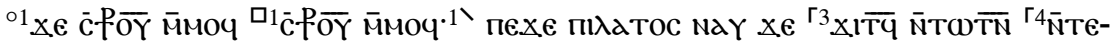

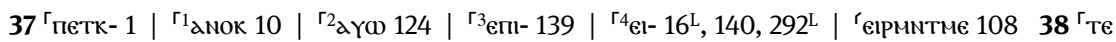

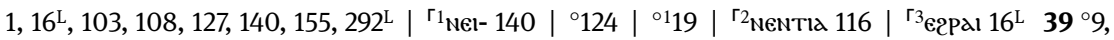

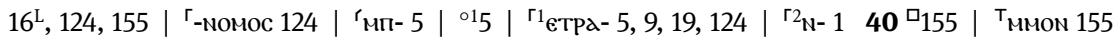

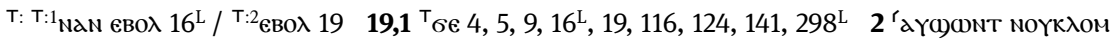

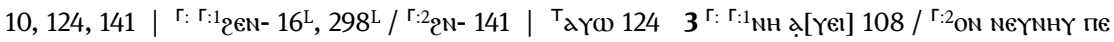
евол $\left.124\right|^{\top}$ пе 1, 103, 108, 127, 139, 140, 142, 155, 292 | ${ }^{\mathrm{r}} \mathrm{N}-1 \mid{ }^{\circ} 9,16^{\mathrm{L}}, 19,116,1424^{\mathrm{T}: \mathrm{T}: 1} \Delta \epsilon$

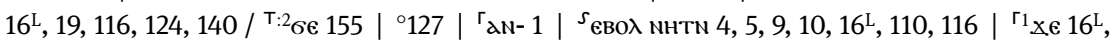
19 | Г: Г:1

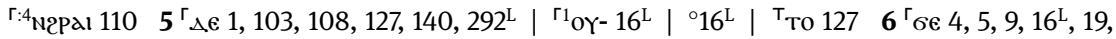

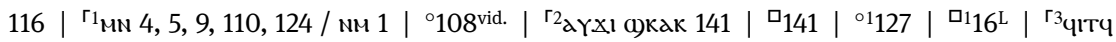
$16^{\mathrm{L}}, 141,\left.292^{\mathrm{L}}\right|^{\Gamma 4 * \overline{\mathrm{C}} \mathrm{P} \overline{\mathrm{OY}}}$, corr. in ' ${ }^{\mathrm{NTETN}}{ }^{\prime} \overline{\mathrm{c}} \mathrm{P} \overline{\mathrm{OY}} 5$

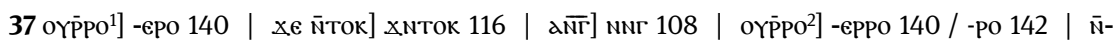
таүхпоі] емтаү- 108 ( $\gamma$ ex corr.), 140, 292L, 330L / -хпоє $1 /$-хпо 108 (ı ех corr.) | епеїгов]

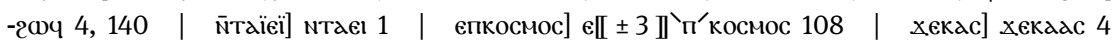

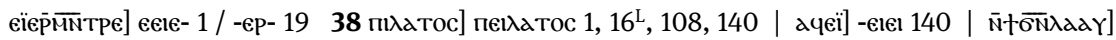

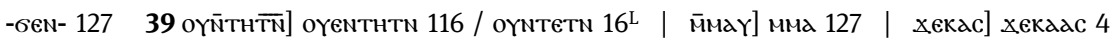

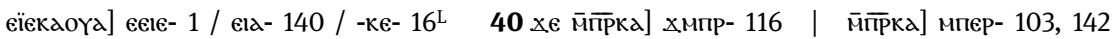

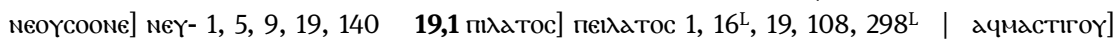

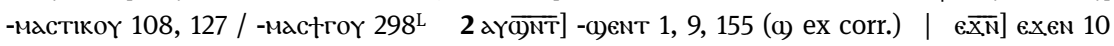

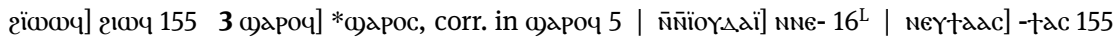

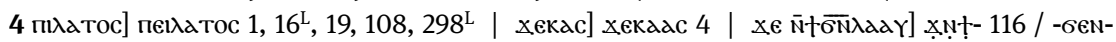

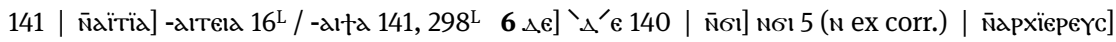
мe- 116 / -дрхіреүс 16L | ї2үпнетнс] -әүперетнс 4, 9, 10, 116, 141 / -әнперетнс 19 / -әүпернтнс

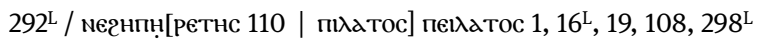




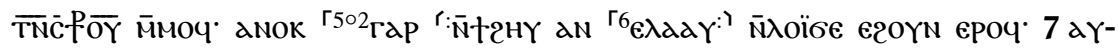

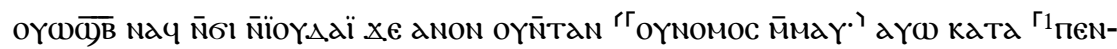

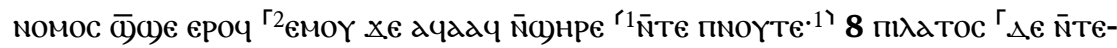

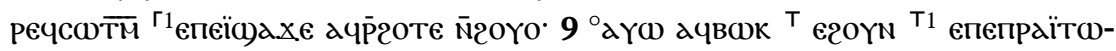

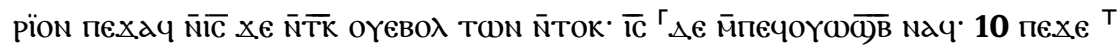

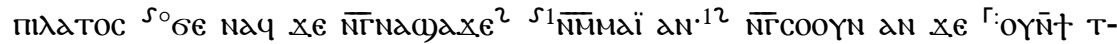

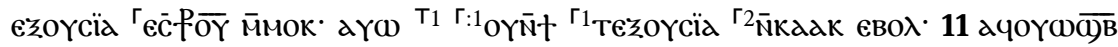

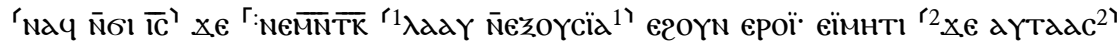

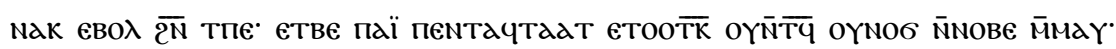

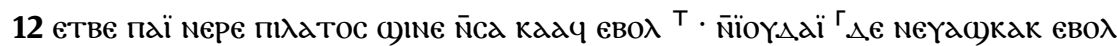

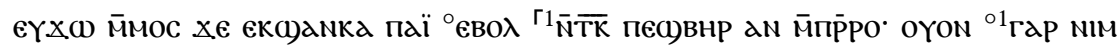

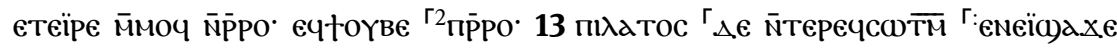

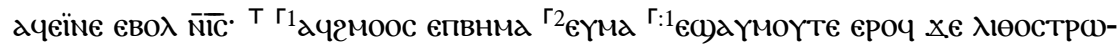

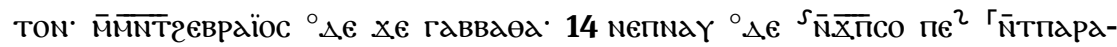

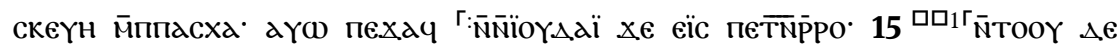

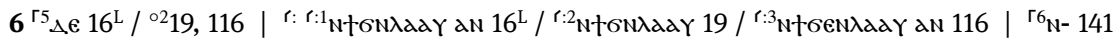

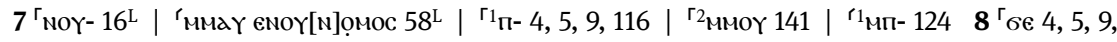
$16^{\mathrm{L}}, 19,116,124,141$ | Г1 ачрспнне аүс $1249^{\circ} 141^{\text {vid. }}$ | ${ }^{\mathrm{T}}$ on 1, 103, 108, 127, 140 | ${ }^{\mathrm{T}} \mathrm{on} 292^{\mathrm{L}}$

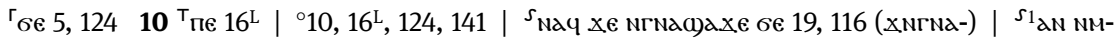

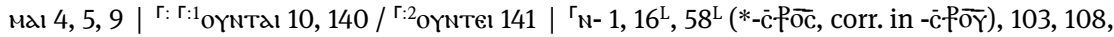

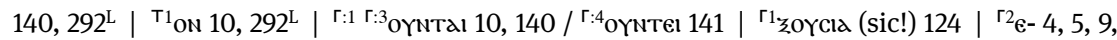

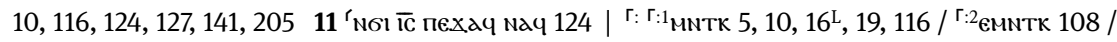

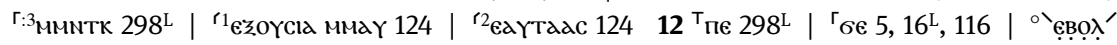

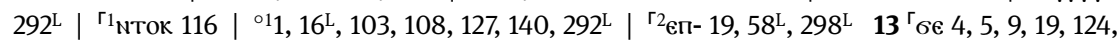

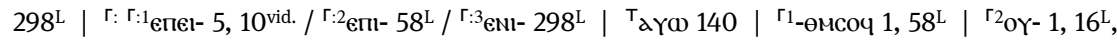

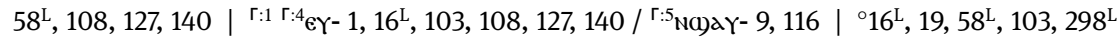

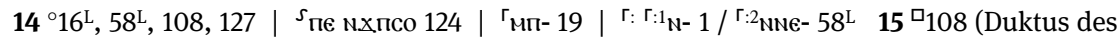
Kopisten bricht in der Kolumne mit 19,14 ab, 19,15 von anderer Hand) $\left.\right|^{\Gamma *}$ NTоч, corr. in NTooY $\left.124\right|^{\square} 1298^{\mathrm{L}}$
}

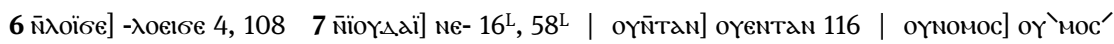

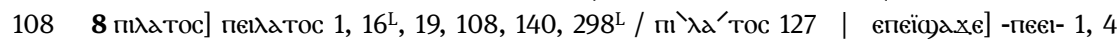

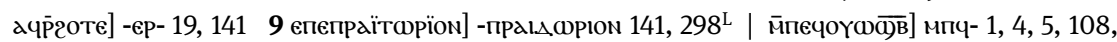

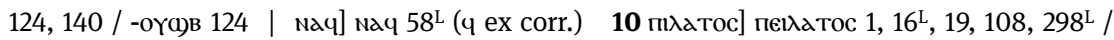

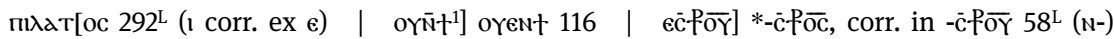

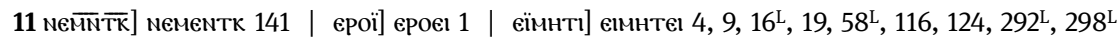

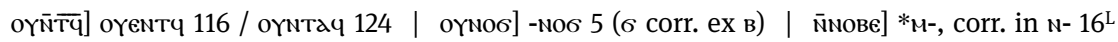

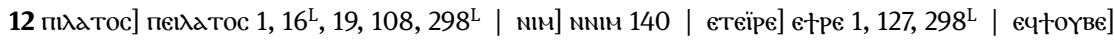

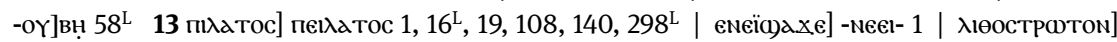

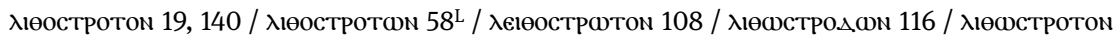

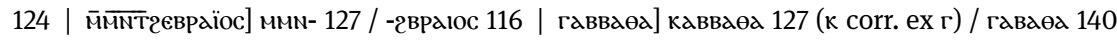
$14 \overline{\mathrm{N}} \overline{\mathrm{x}} \overline{\mathrm{n}} \mathrm{co}]$-соо 1, 4, 103 | і̄тпараскеүн] -параскеєүн 58 / -параскеоүн 124 


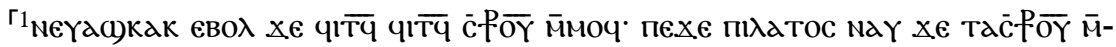

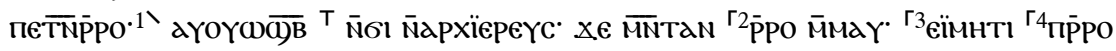

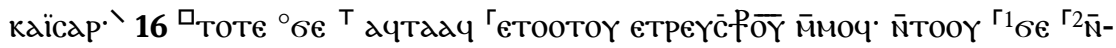

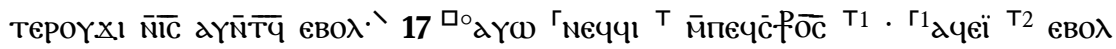

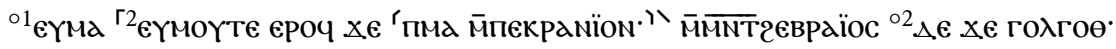

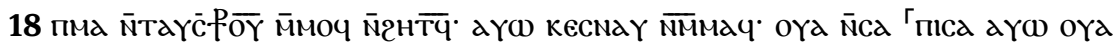

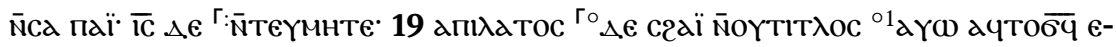

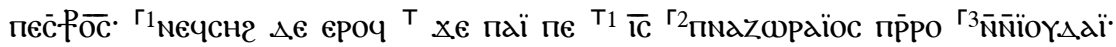

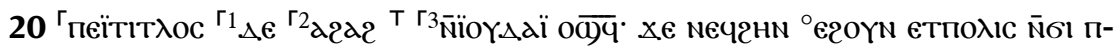

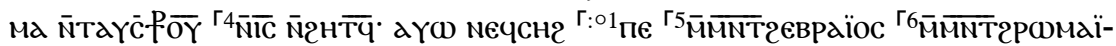

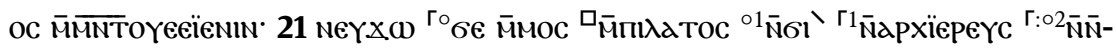

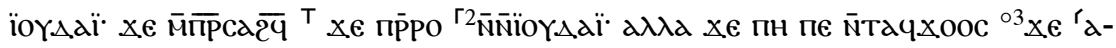

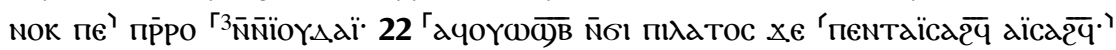

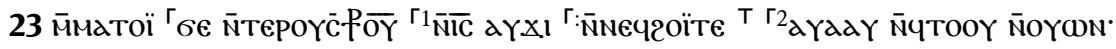

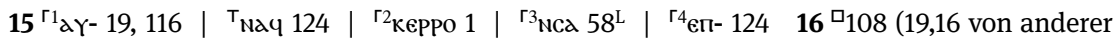

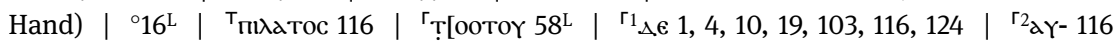
$17^{\circ} 19$ | $\square_{108}$ (19,17 teils andere Hand; mit Seitenwechsel führt der ursprüngliche Schreiber

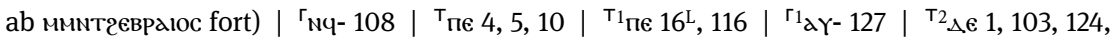

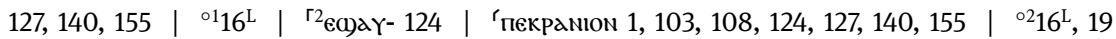

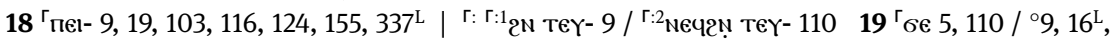

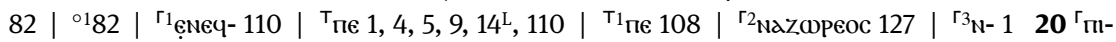

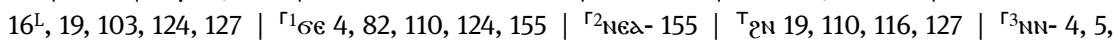

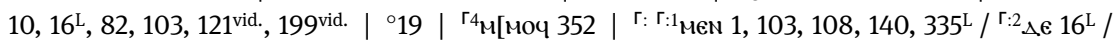

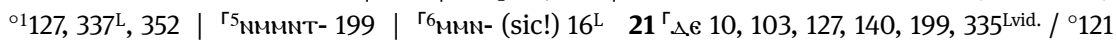

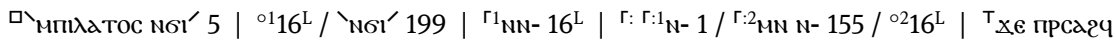

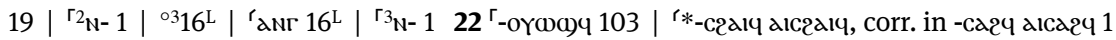
$23^{\Gamma_{\Delta \in}} 1,103,108,124,127,140,199,337^{\mathrm{L}} \quad{ }^{{ }^{1} 1}{ }_{\text {ммоч }} 1,14^{\mathrm{L}}, 103,108,127,140,199,337^{\mathrm{L}} \mid \Gamma_{\text {: }}$

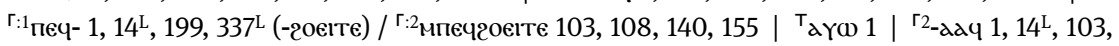
$108,140,155,199,337^{\mathrm{L}}$

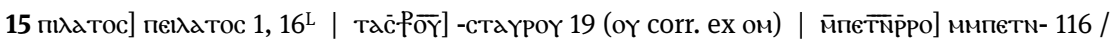

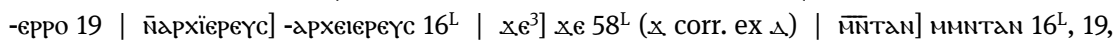

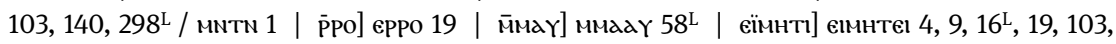

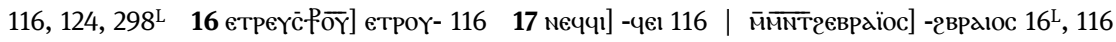

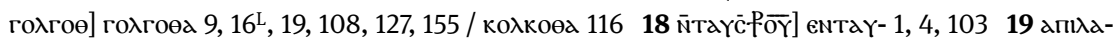

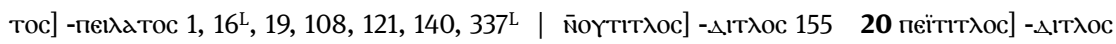

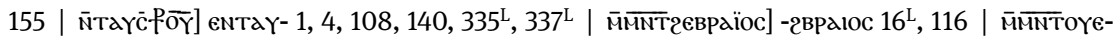

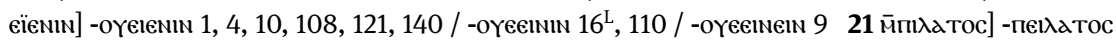

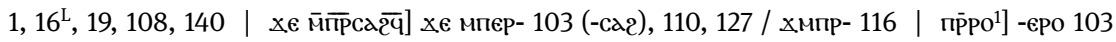

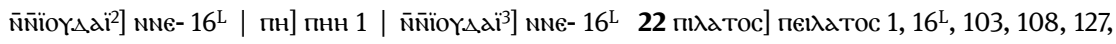
140, 337 23 м̄мечгоїте] мпечгоєাте 103, 108, 140, 155 / печгоєเте 337 


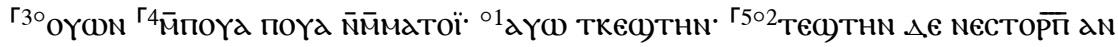

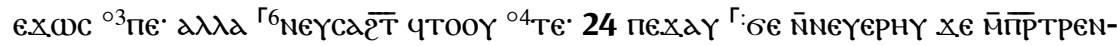

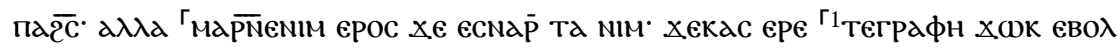

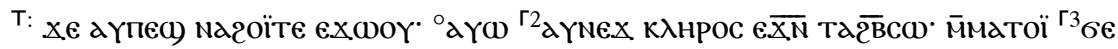

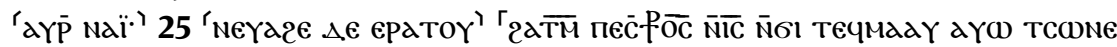

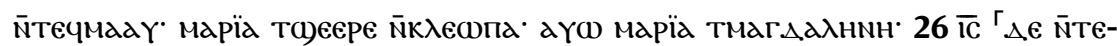

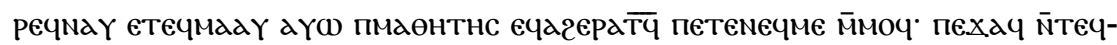

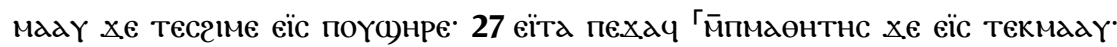

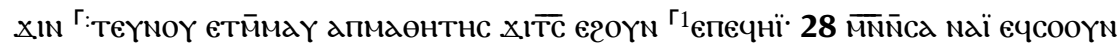

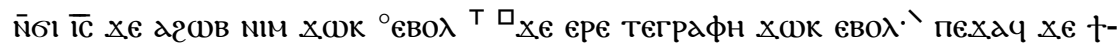

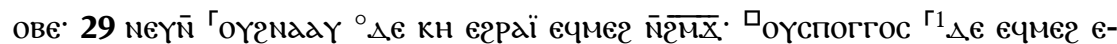

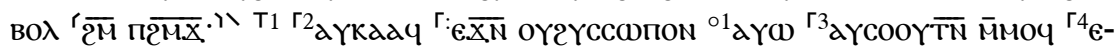

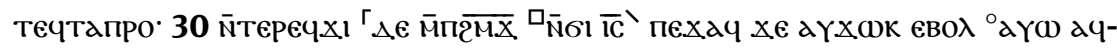

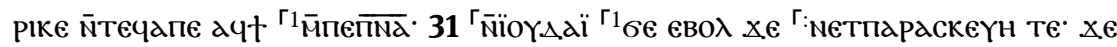

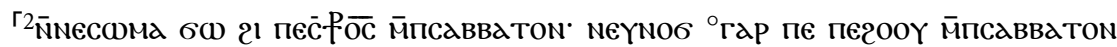

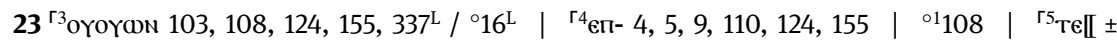

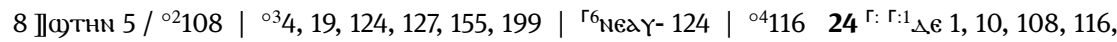

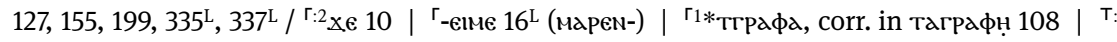

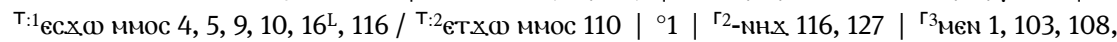

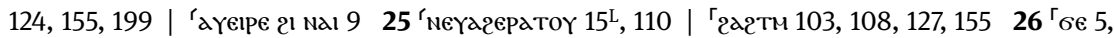

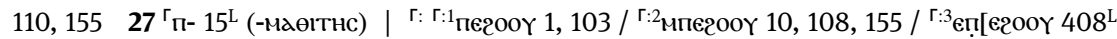

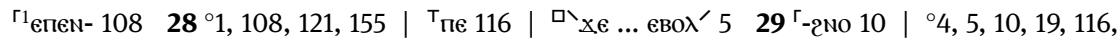

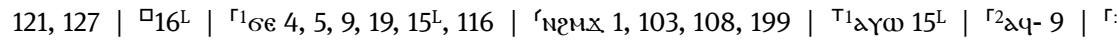

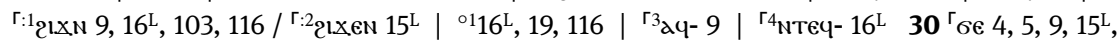

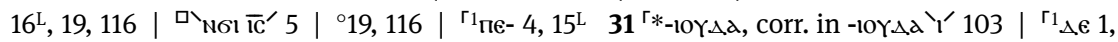

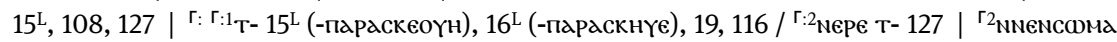
1, 4, 5, 9, 103, 116 (XNNEN-) | ${ }^{\circ} 19,116$

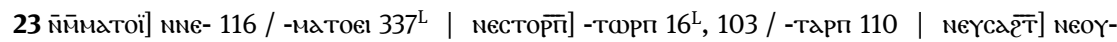

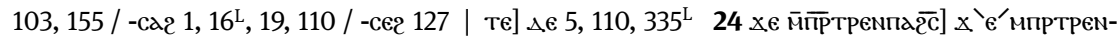

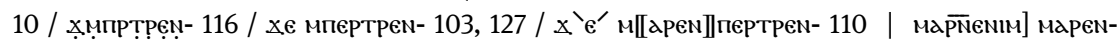

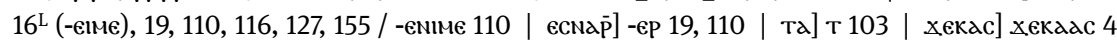

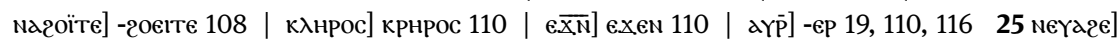

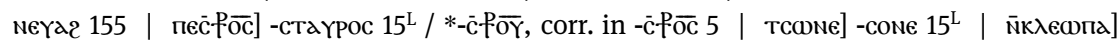

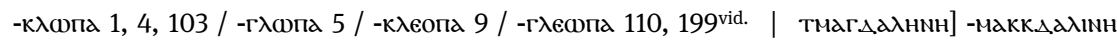

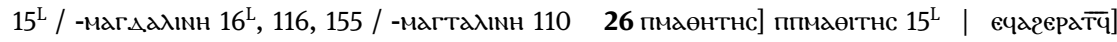

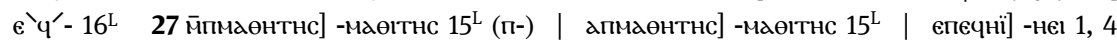

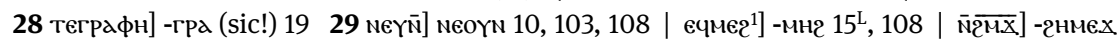

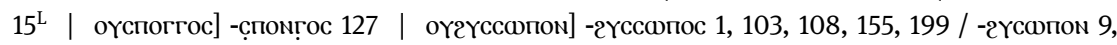

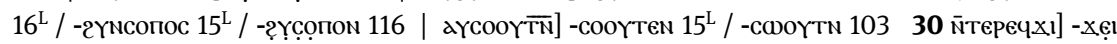

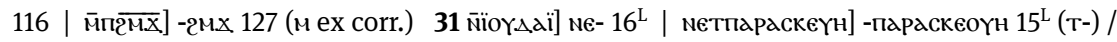

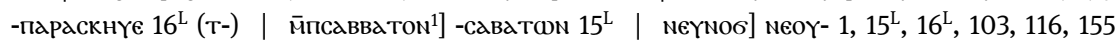
мппсаввдтоN $\left.{ }^{2}\right]$-савдтоN $15^{\mathrm{L}}$ 


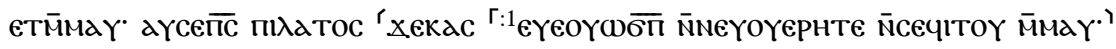

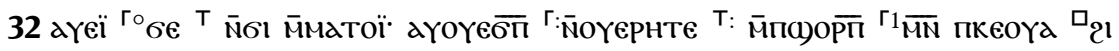

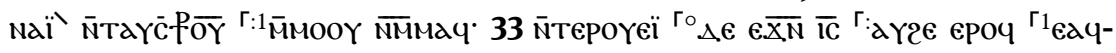

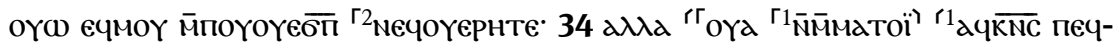

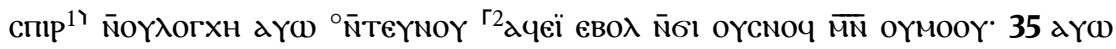

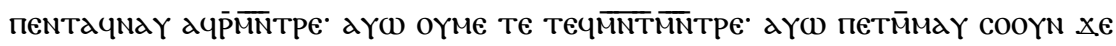

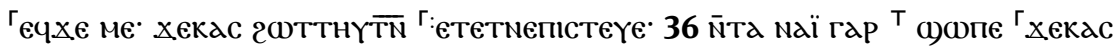

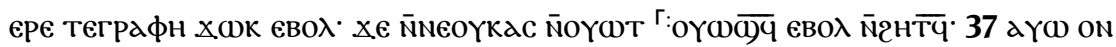

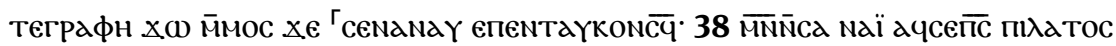

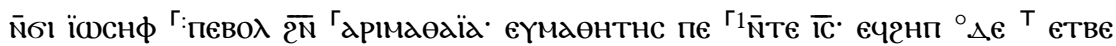

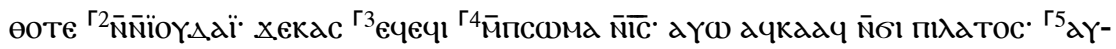

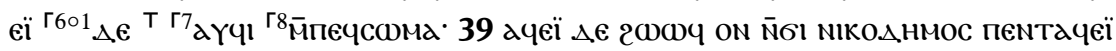

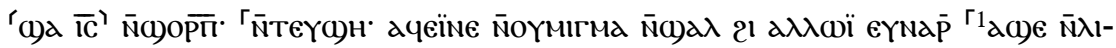

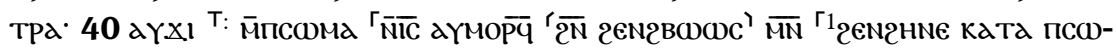

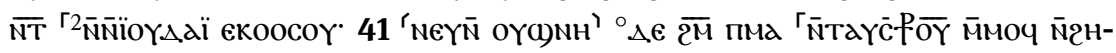

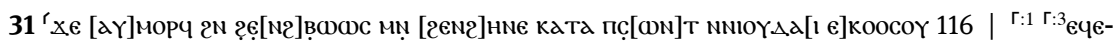

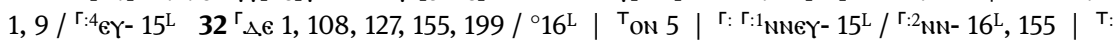

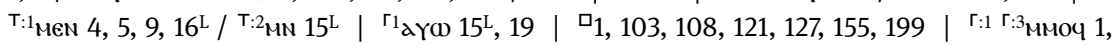

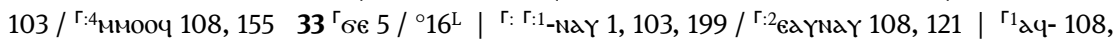

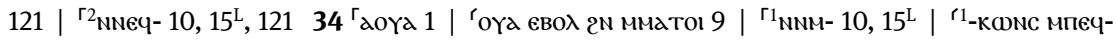

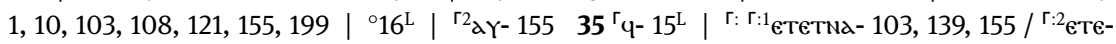

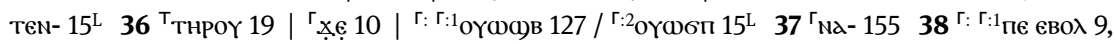

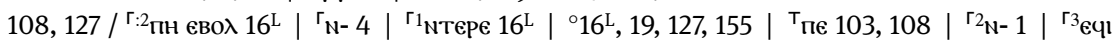

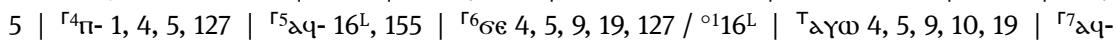

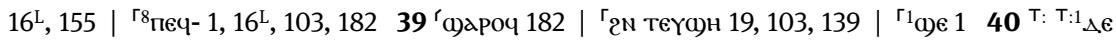

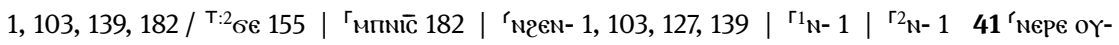

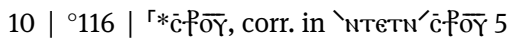

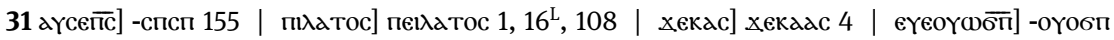

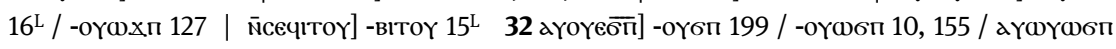

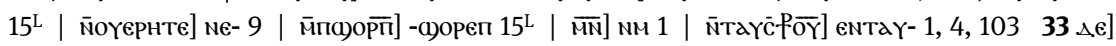

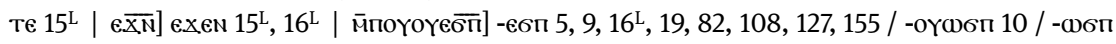

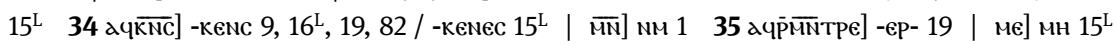

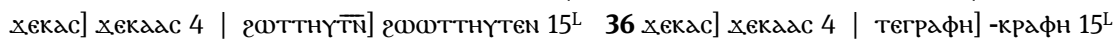

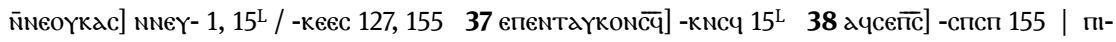

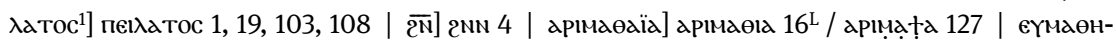

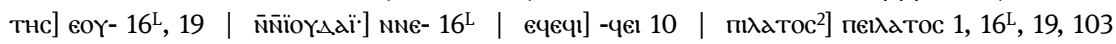

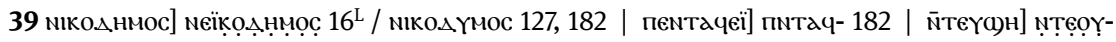

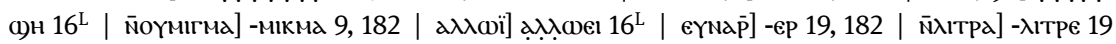

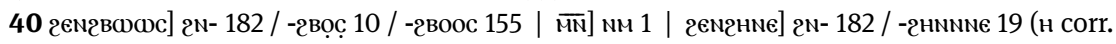

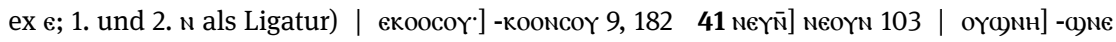
182 | ज̄TaYc̄PoY] enTaY- 1, 4, 217 


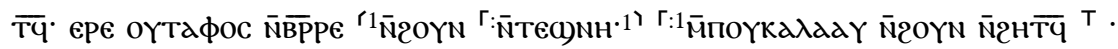

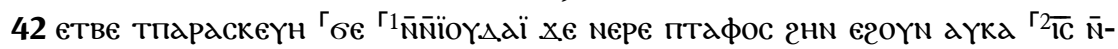
2OYN $\overline{\mathrm{N}} 2 \mathrm{HT} \overline{\mathrm{TM}}$.

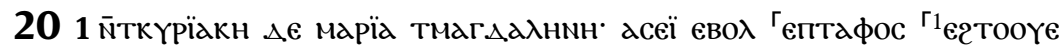

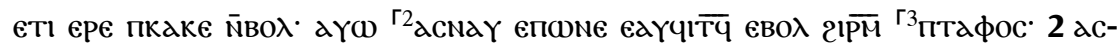

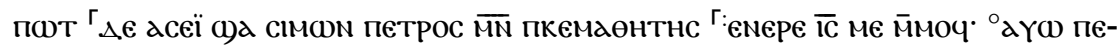

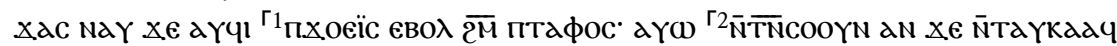

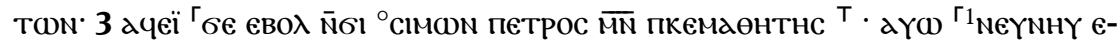

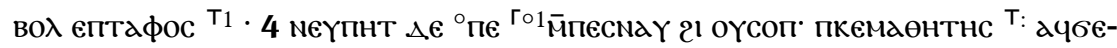

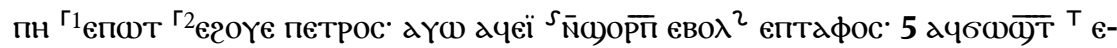

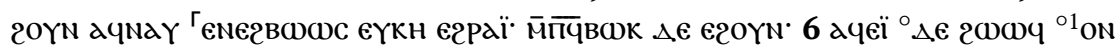

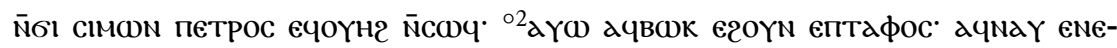

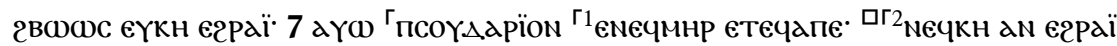

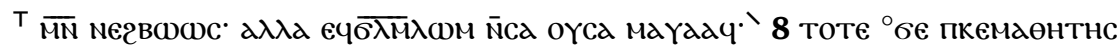

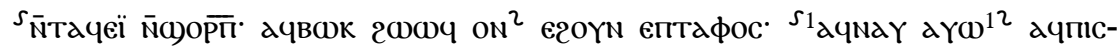

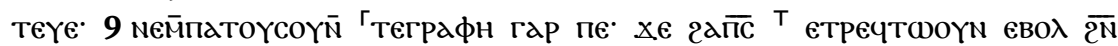

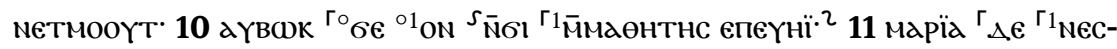

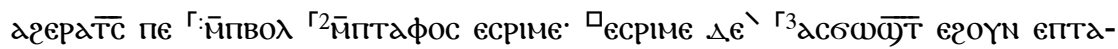

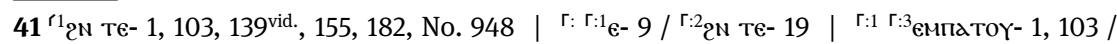

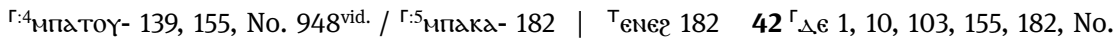

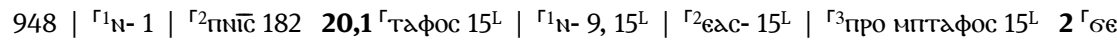

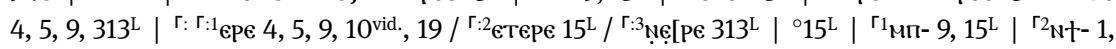

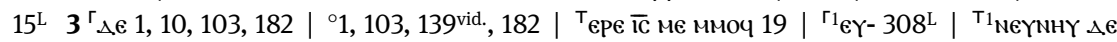

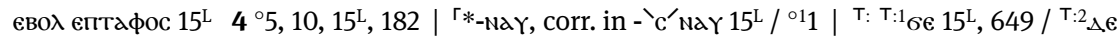

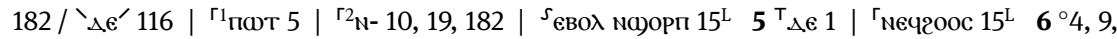

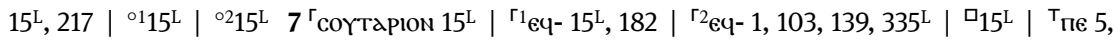

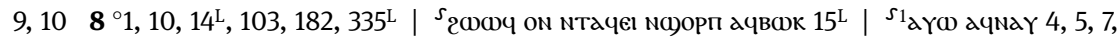

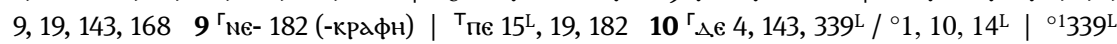

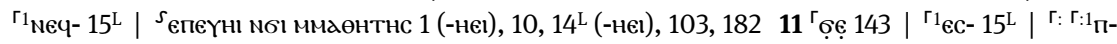

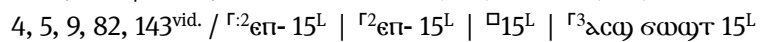

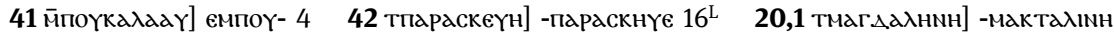

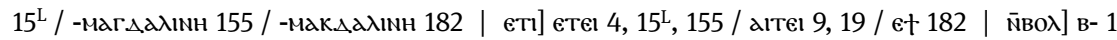

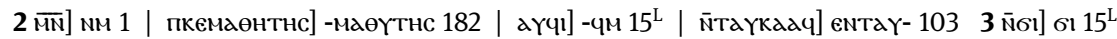
$\overline{\text { MN] }}$ мм 1 | пкемдөнтнс] -мдөүтнс 1824 пкемдөнтнс] -мдөүтнс 182 | ептдфос] -пе- $15^{\mathrm{L}} \mathbf{5} \overline{\mathrm{M}}$ -

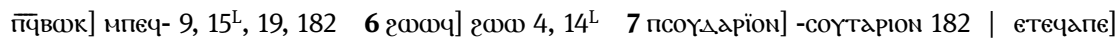

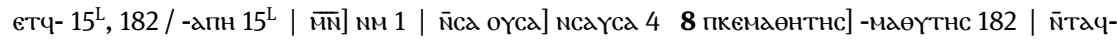
еi] емтач- 4, 14

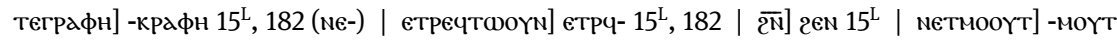

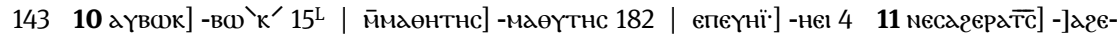
ePaT [c 143 


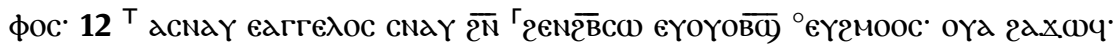

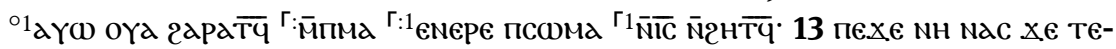

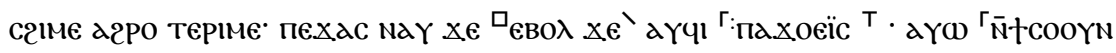

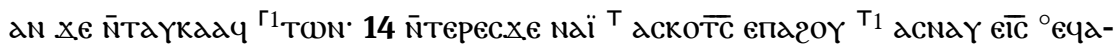

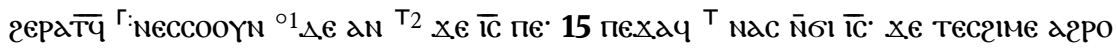

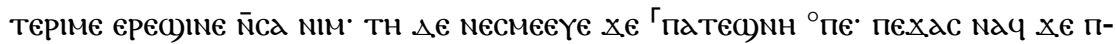

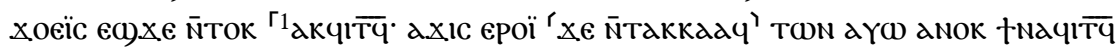

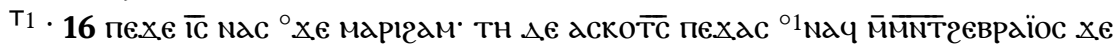

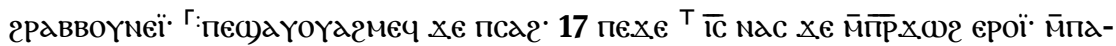

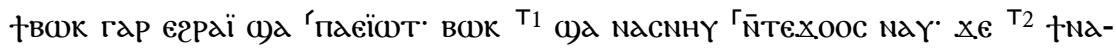

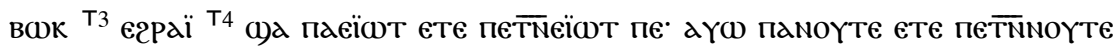

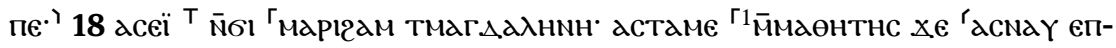

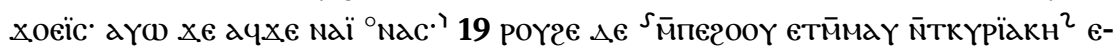

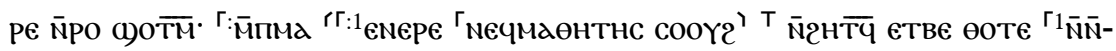

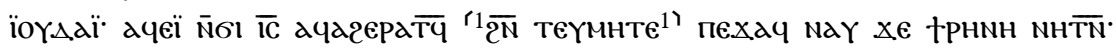

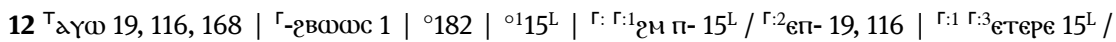

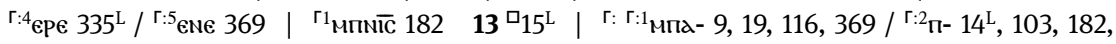
339L / Г:3мпа пос 15 | '

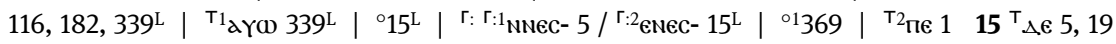

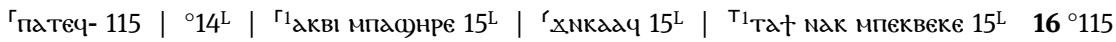

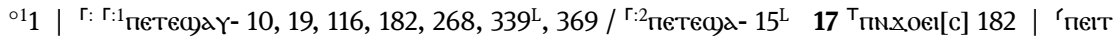

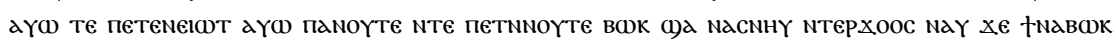

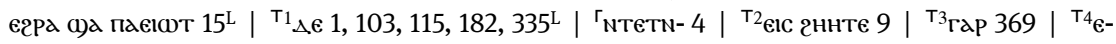

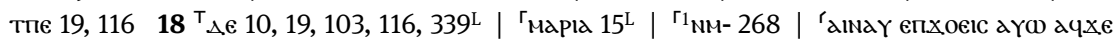

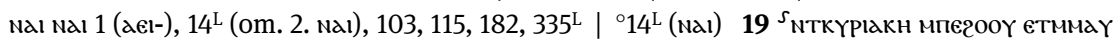

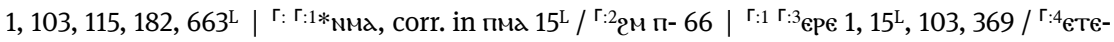

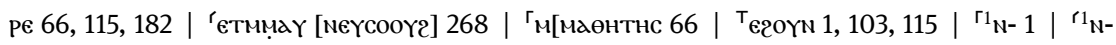
TеҮ[Mнте] 268

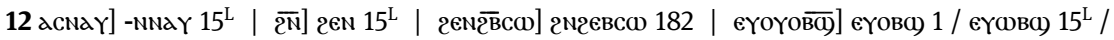

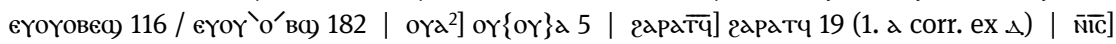

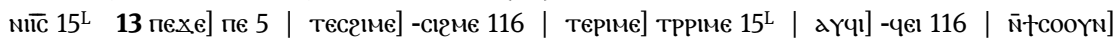

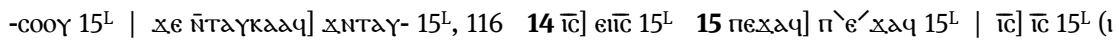

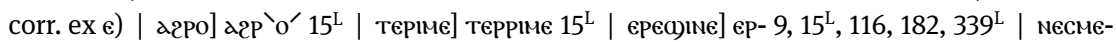

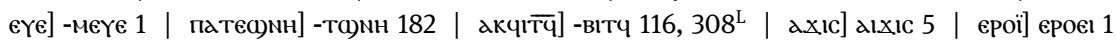

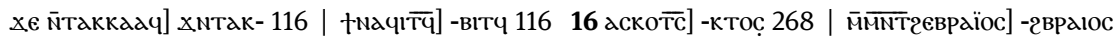

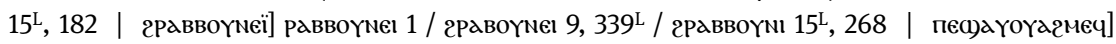

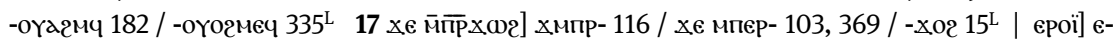

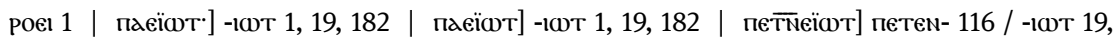

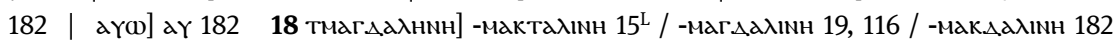
астаме] -тамме 9 / -тмме 15 | м̈мдөнтнс] -мдөІтнс 15 / -мдөүтнс 18219 м̄ткүрїакн] -күрд-

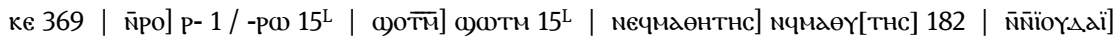

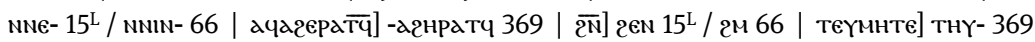




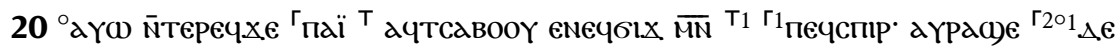

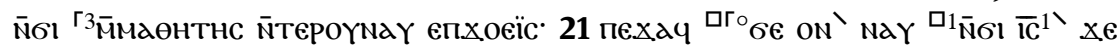

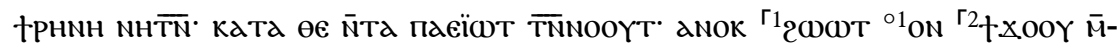

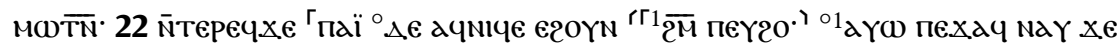

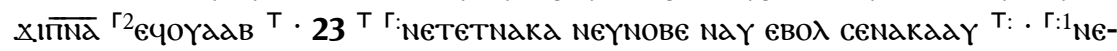

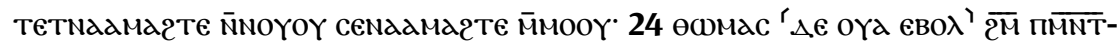

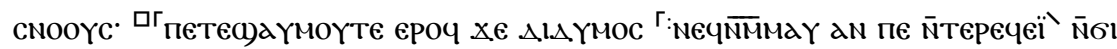

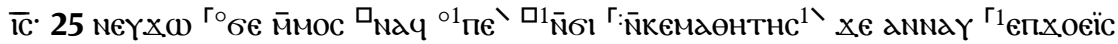

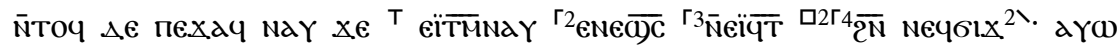

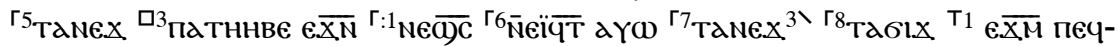

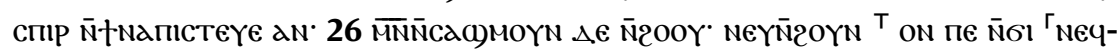

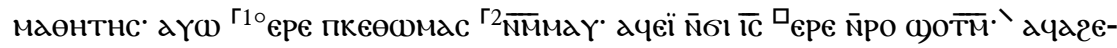

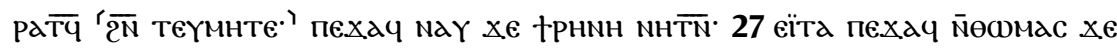

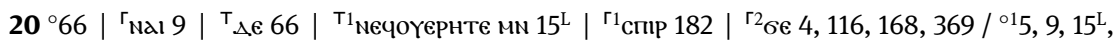

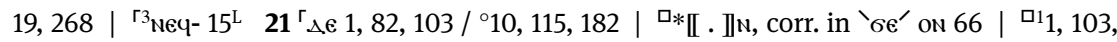

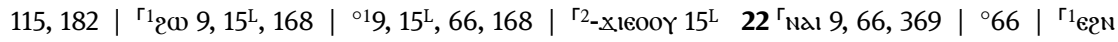

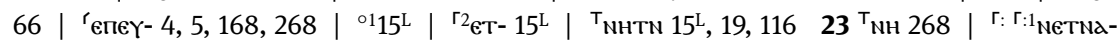

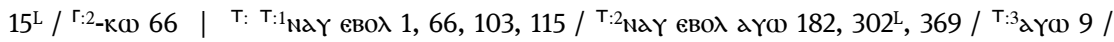

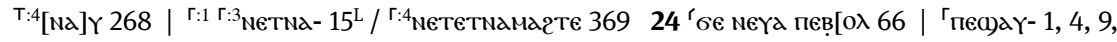

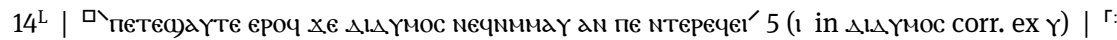

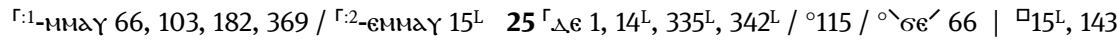

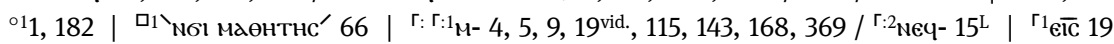

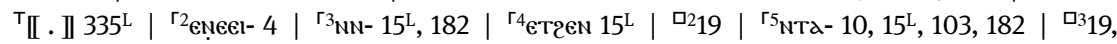

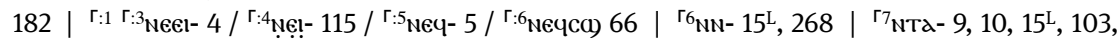

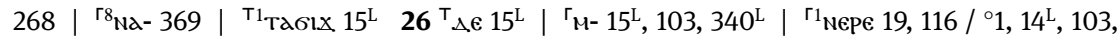

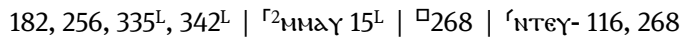

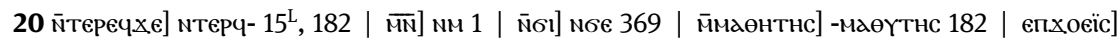

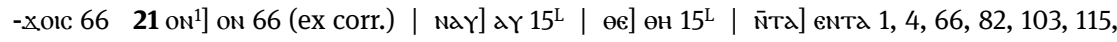

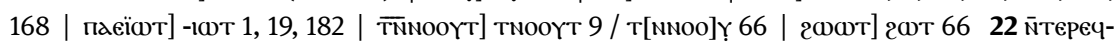
хє] мтерч- 15L, 182 | ачміче] -меiче 9 / -міве 19, 66, 116, 182, 369 | егоүм] егроүм 9 | пехач]

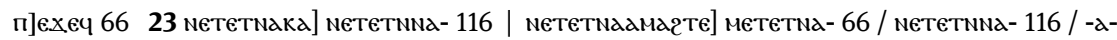

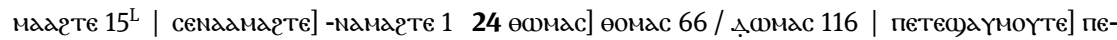

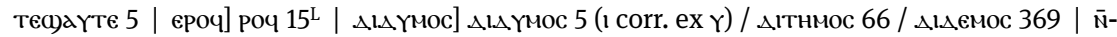

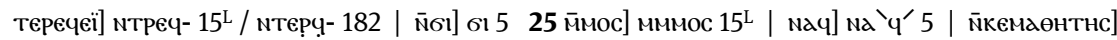

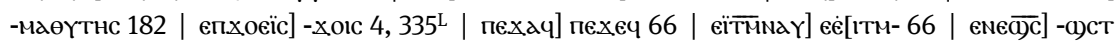

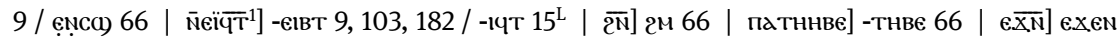

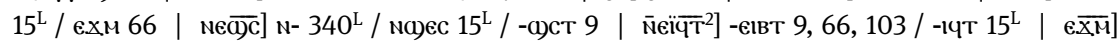

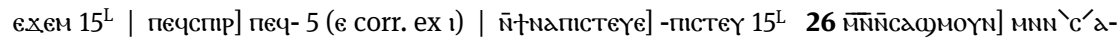

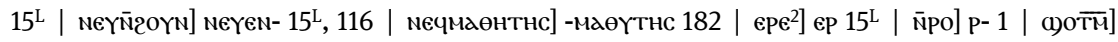

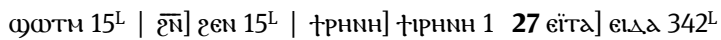




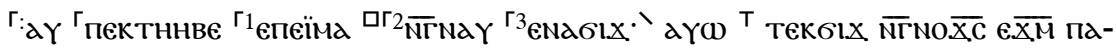

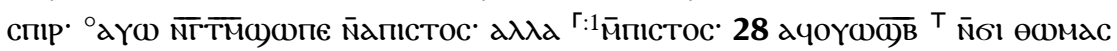

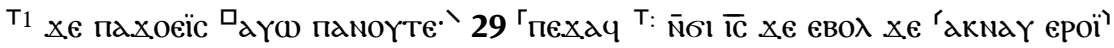

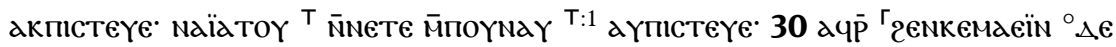

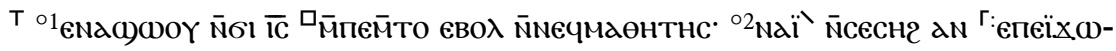

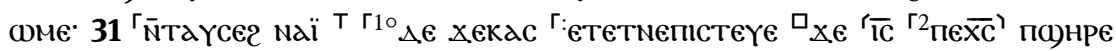

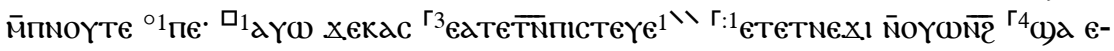

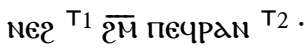

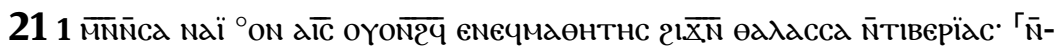

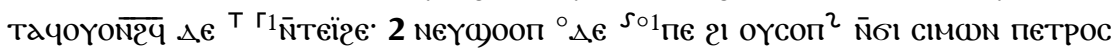

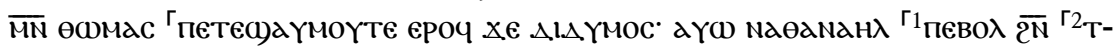

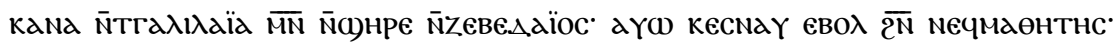

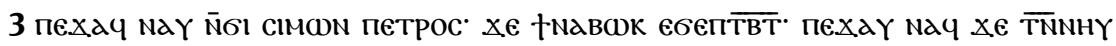

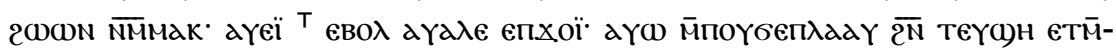

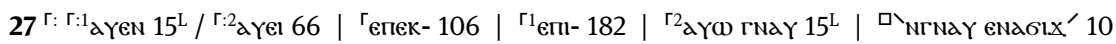

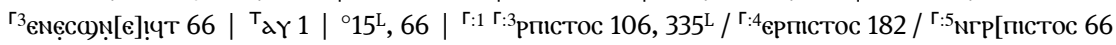

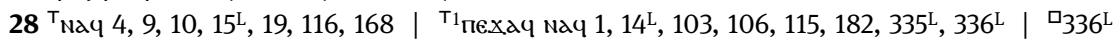

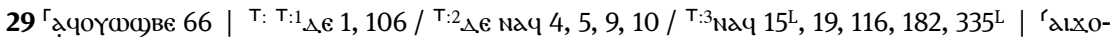

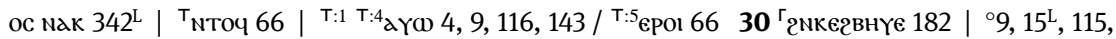

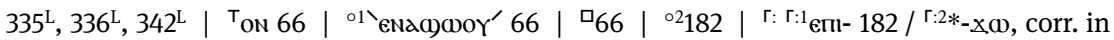

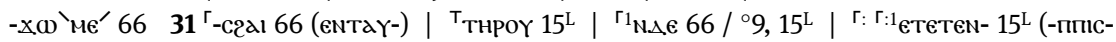

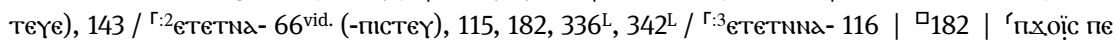

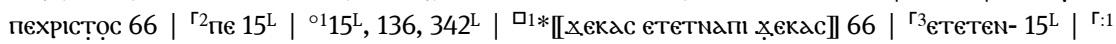

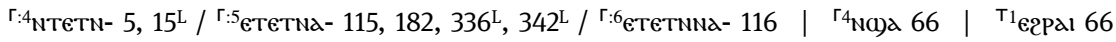

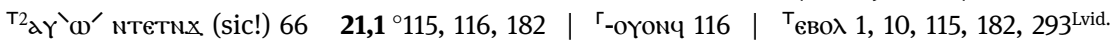

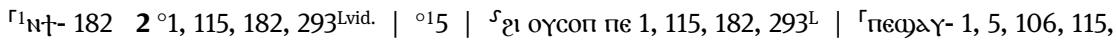

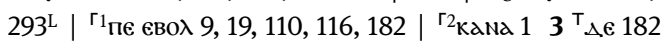

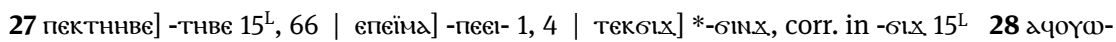

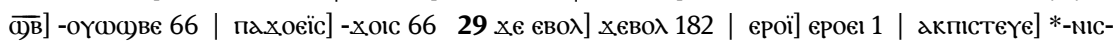

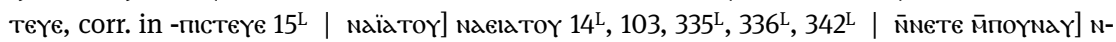

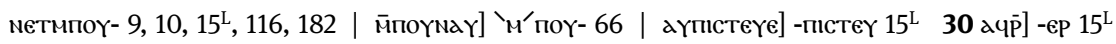

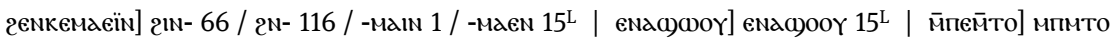

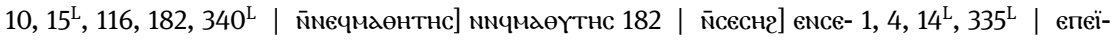

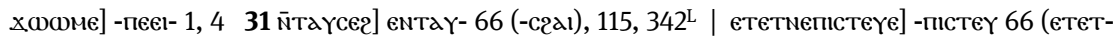

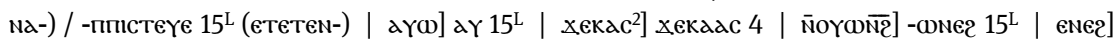

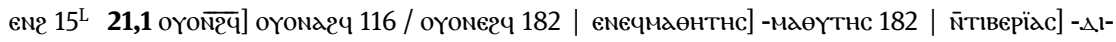

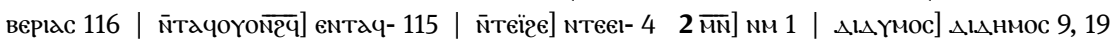

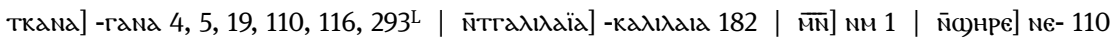

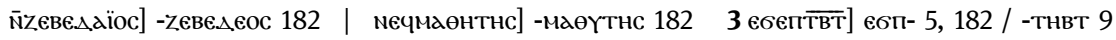

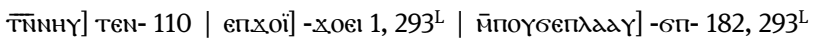




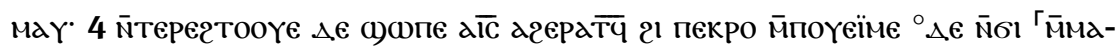

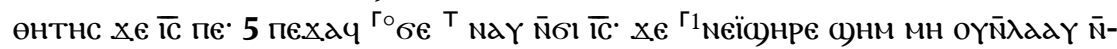

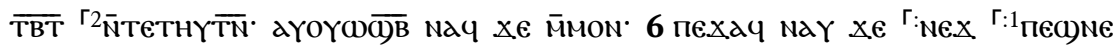

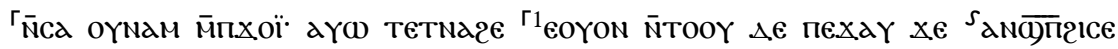

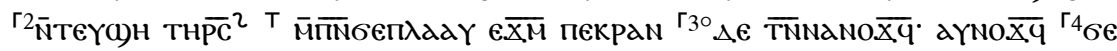

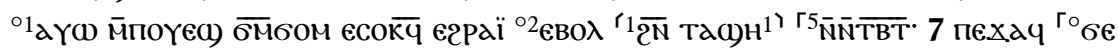

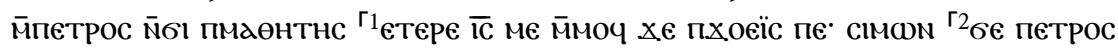

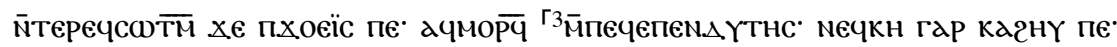

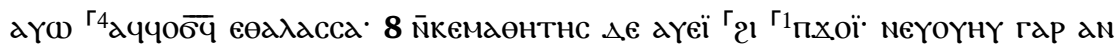

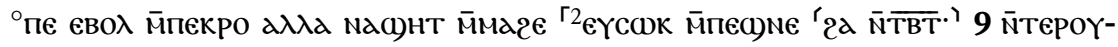

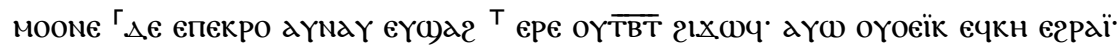

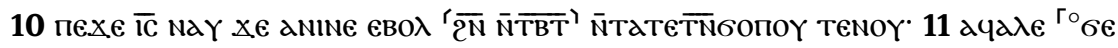

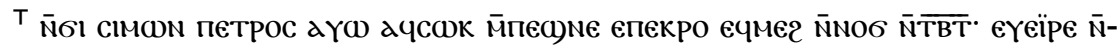

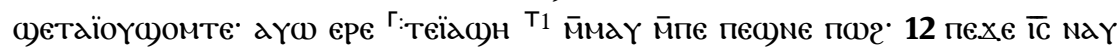

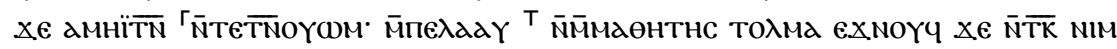

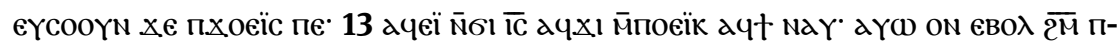

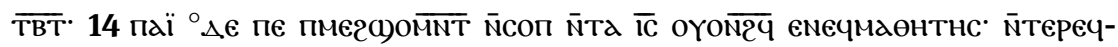

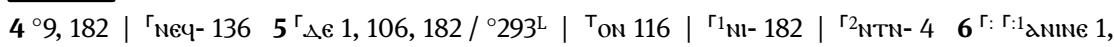

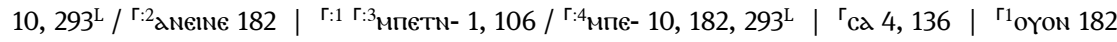

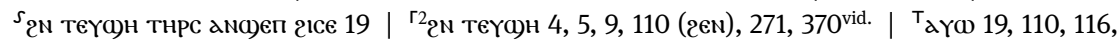

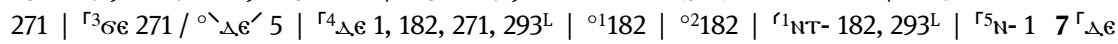

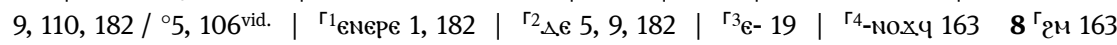

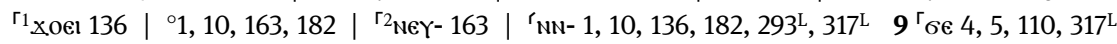

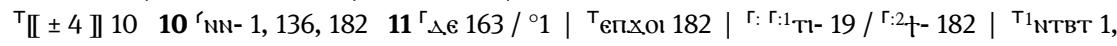
$10,136,182,\left.317^{\mathrm{L}} 12^{\text {гоүсм }} 63^{\mathrm{L}}\right|^{\top}{ }^{\top} \in 1914^{\circ} 19$

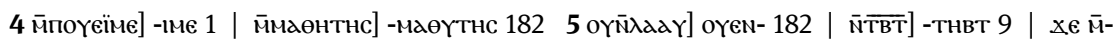

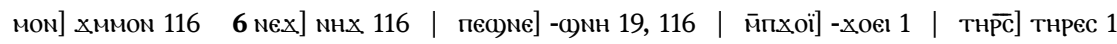

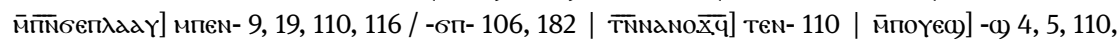

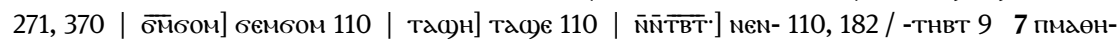

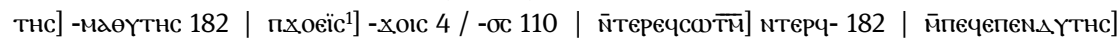

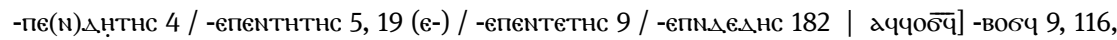

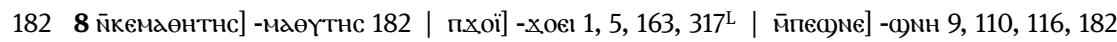

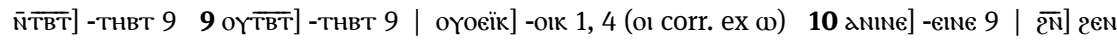

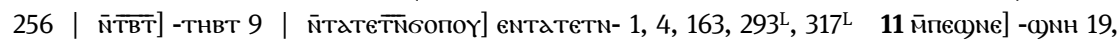

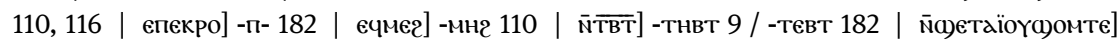

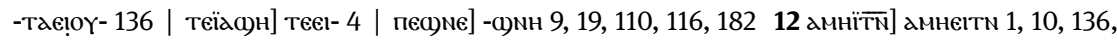

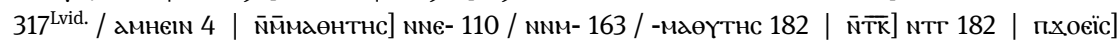

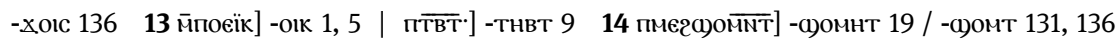

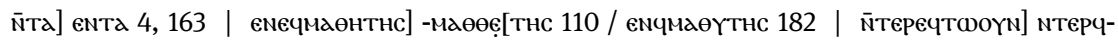
182 / -TWOYN(N) 163 


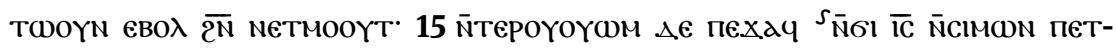

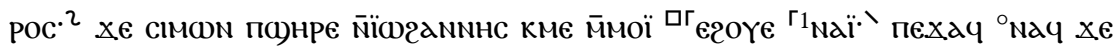

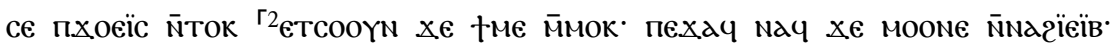

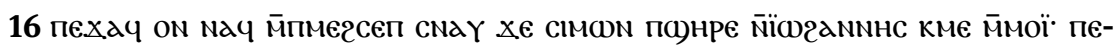

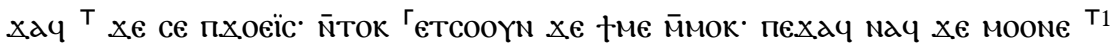

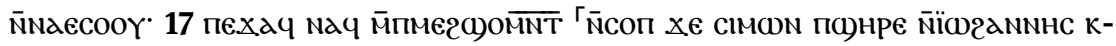

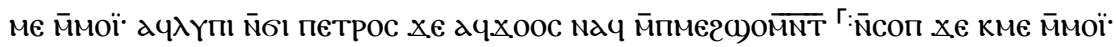

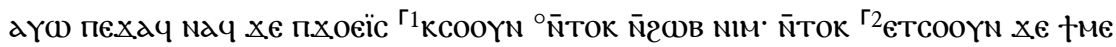

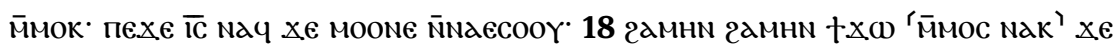

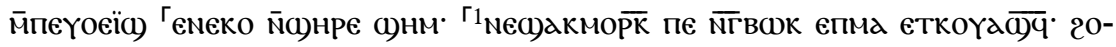

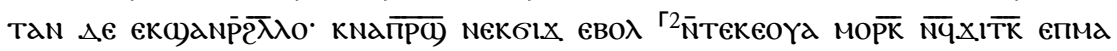
${ }^{\Gamma 3} \in$ teत̄ M̈пnоүте '

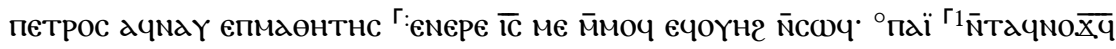

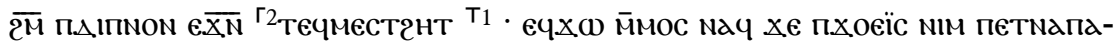

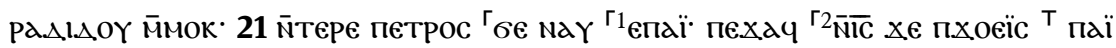

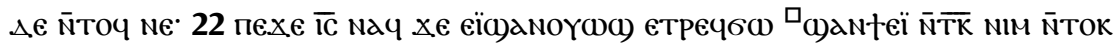

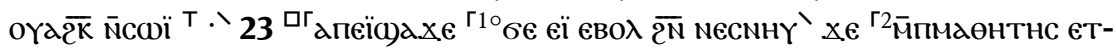

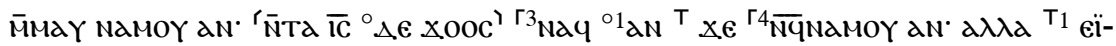

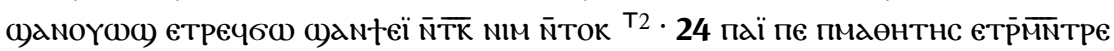

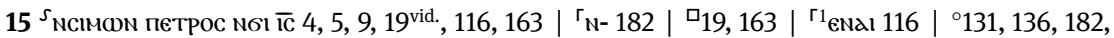

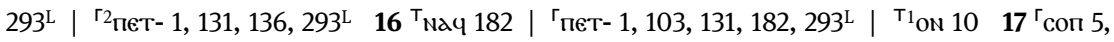
$163 \mid$ г: Г: 1 сөюп 1, 4, 5, 19 / Г:2

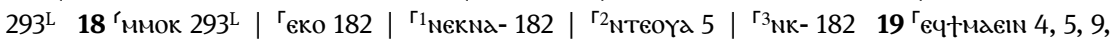

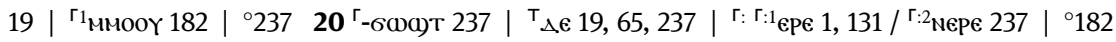

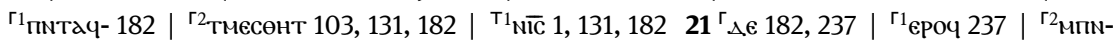

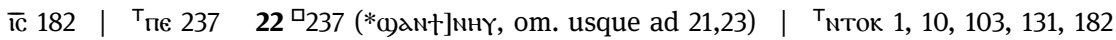

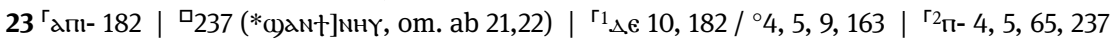

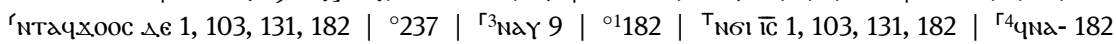
${ }^{T_{1}} \chi \in$ 9, 65, 182, $237 \mid{ }^{T_{2}}$ OYa2K NCO1 5

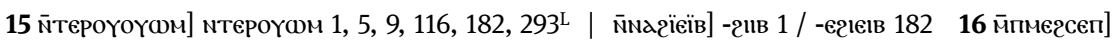

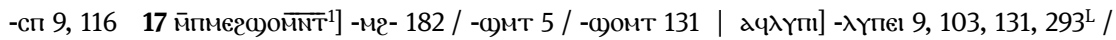

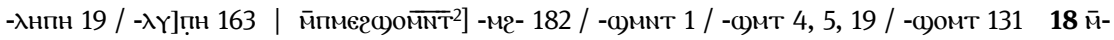

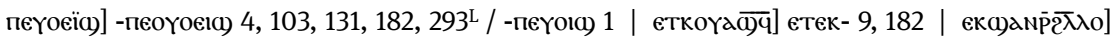

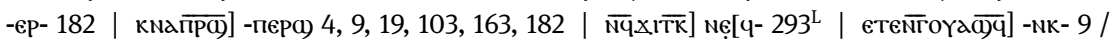

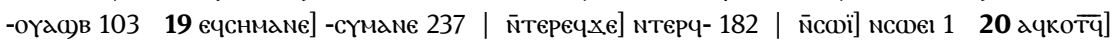

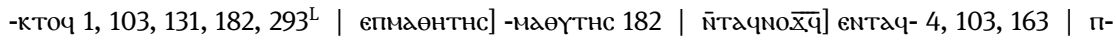
АІпмон] -Аеппмом 1, 131 | течместгнт] -месент 5, 103 (т-), 131 (т-), 182 (т-), 237 | петнапа-

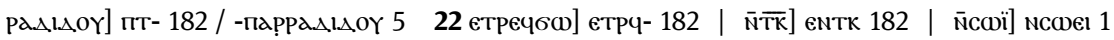

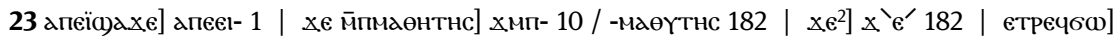
етрч- 182 


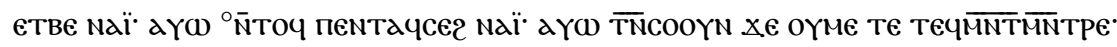

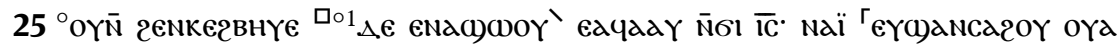

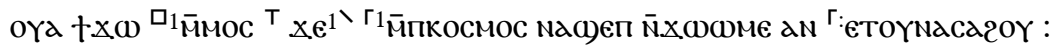

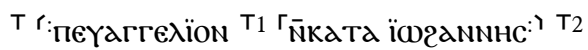

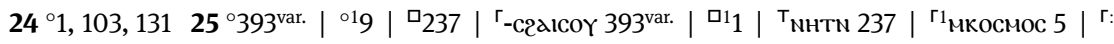

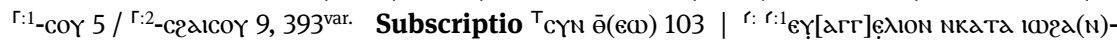

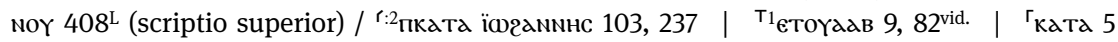
${ }^{\mathrm{T} 2}$ B, 131 (,2300“, Stichoiangabe)

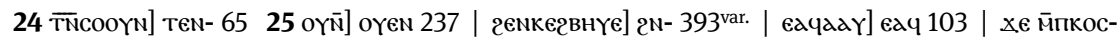
мос] Хмп- 10 | мас)еп] -()п 1, 103, 131 Subscriptio їгамnнс] ıюанмнс 1, 5 